\title{
WestVirginiaUniversity
}

THE RESEARCH REPOSITORY @ WVU

Graduate Theses, Dissertations, and Problem Reports

2003

\section{Locomotive emissions effects due to engine configuration}

Nicholas P. Amandus

West Virginia University

Follow this and additional works at: https://researchrepository.wvu.edu/etd

\section{Recommended Citation}

Amandus, Nicholas P., "Locomotive emissions effects due to engine configuration" (2003). Graduate Theses, Dissertations, and Problem Reports. 1341.

https://researchrepository.wvu.edu/etd/1341

This Thesis is protected by copyright and/or related rights. It has been brought to you by the The Research Repository @WVU with permission from the rights-holder(s). You are free to use this Thesis in any way that is permitted by the copyright and related rights legislation that applies to your use. For other uses you must obtain permission from the rights-holder(s) directly, unless additional rights are indicated by a Creative Commons license in the record and/ or on the work itself. This Thesis has been accepted for inclusion in WVU Graduate Theses, Dissertations, and Problem Reports collection by an authorized administrator of The Research Repository @ WVU. For more information, please contact researchrepository@mail.wvu.edu. 


\title{
Locomotive Emissions Effects Due to Engine Configuration
}

\author{
Nicholas P. Amandus \\ Thesis submitted to \\ the College of Engineering and Mineral Resources \\ at West Virginia University \\ in partial fulfillment of the requirements \\ for the degree of \\ Master of Science \\ in \\ Mechanical Engineering \\ W. Scott Wayne, Ph.D., Chair \\ Nigel Clark, Ph.D. \\ Mridul Gautam, Ph.D.
}

Department of Mechanical and Aerospace Engineering

Morgantown, West Virginia

2003 


\section{Abstract \\ Locomotive Emissions Effects Due to Engine Configuration \\ Nicholas P. Amandus}

There are two studies reported in this document. The first study tested a General Electric C39-8 (Norfolk Southern Engine Number 8678) locomotive and a General Electric D8-40C (Norfolk Southern Engine Number 8692) locomotive, which were equipped with General Electric Model 7FDL16L6 diesel engines with mechanically controlled fuel injection. The objective of this study was to determine if a mechanically fuel injected diesel locomotive engine could be made to meet the EPA Tier 0 emissions limits without a substantial loss in fuel economy by retarding the injection timing and installing a more efficient turbocharger. The first locomotive was equipped with a Turbo and Compressor Maintenance LLC. Inc., or TCM, turbocharger that raised the boost pressure to offset the loss in the fuel economy. The second was equipped with a stock General Electric turbocharger. The fuel injection timing of locomotive 8678 was retarded from the stock timing of $12^{\circ} \mathrm{BTDC}$ to $11^{\circ}, 9^{\circ}$, and $8^{\circ} \mathrm{BTDC}$, and emissions were measured in each configuration. Locomotive 8692 was only tested at $8^{\circ}$ BTDC. The results from this study showed that there can be adjustments to the fuel injection timing without a dramatic change in the fuel economy. However, among the settings that were tested, only the $8^{\circ} \mathrm{BTDC}$ passed all emission requirements.

The objective of the second study was to determine if remanufactured turbochargers and used cylinder liners were able to meet current EPA standards. This study tested an electronically fuel injected General Electric D9-40C locomotive (Norfolk Southern Engine Number 8867) and a mechanically fuel injected General Electric C40-8 locomotive (Norfolk Southern Engine Number 8695). Both were equipped with a General Electric Model 7FDL16L6 diesel engine. This study investigated the use of 
alternative, remanufactured and aftermarket turbochargers and used cylinder sleeves, regardless of vintage on emissions. They were replaced to determine if alternative components could be used without negative impacts on emissions. If there is no need to use new components on the engine at the time the engine is rebuilt, there can be a savings in the cost that is needed in servicing the engines. There were five configurations applied to the locomotives in this study. The first was a baseline run that consisted of a Tier 0 locomotive with a stock GE 1883 turbocharger with new cylinder liners. The second configuration consisted of an aftermarket Hispana Suiza turbocharger and new cylinder liners. The third configuration consisted of new cylinder liners and a Globe 1883 turbocharger, which is a rebuilt GE 1883 turbocharger with Globe components. The forth and fifth configurations both consisted of used cylinder liners, however, the forth configuration consisted of the stock GE 1883 turbocharger and the fifth configuration consisted of the Globe 1883 turbocharger. The results of this study proved that there is no significant change in the emissions through altering the turbochargers and cylinder liners. In conclusion, the companies that pay to have these engines serviced should be able to use rebuilt turbochargers and used cylinder liners, regardless of vintage, while still complying with EPA Tier 0 emissions regulations. 


\section{Acknowledgements}

There have been many people that have made this accomplishment possible. First and foremost I would like to thank God for the abilities He has given me and the people that He has surrounded me with that have given me the support I needed to get through life.

I would like to thank my parents for pushing me to achieve and succeed. If not for you, I would never have gotten as far as I have. And my brother for being a person within whom I can confide and trust when I need someone.

I would especially like to thank my soon to be wife, Beth, for the love and attention that she has given me to help me get through some of the most stressful times in my life. The rest of my life will be a joy and a pleasure with her by my side.

I would also like to thank my committee W. Scott Wayne, Nigel Clark, and Mridul Gautam who have helped give me the knowledge and opportunities that I will need to succeed in the engineering field.

Finally, I would like to thank Norfolk Southern and Turbo and Compressor Maintenance LLC Inc., or TCM, for providing the funding for the research for this project.

On a lighter note, it is known that the US standard railroad gauge (distance between the rails) is 4 feet, 8.5 inches. That's an exceedingly odd number. Why was that gauge used? Because that's the way they built them in England, and English expatriates built the US Railroads. Why did the English build them like that? Because the first rail lines were built by the same people who built the pre-railroad tramways, and that's the gauge they used. Why did "they" use that gauge then? Because the people who built the 
tramways used the same jigs and tools that they used for building wagons, which used that wheel spacing. Okay! Why did the wagons have that particular odd wheel spacing? Well, if they tried to use any other spacing, the wagon wheels would break in some of the old, long distance roads in England, because that's the spacing of the wheel ruts. So who built those old rutted roads? Imperial Rome built the first long distance roads in Europe (and England) for their legions. The roads have been used ever since. As for the ruts in the roads? Roman war chariots formed the initial ruts, which everyone else had to match for fear of destroying their wagon wheels. Since the chariots were made for Imperial Rome, they were all alike in the matter of wheel spacing. The United States standard railroad gauge of 4 feet, 8.5 inches is derived from the original specifications for an Imperial Roman war chariot, and bureaucracies live forever. So the next time you are handed a spec and told we have always done it that way and wonder what horse's rear came up with that, you may be exactly right, because the Imperial Roman war chariots were made just wide enough to accommodate the back ends of two war horses. Now the twist to the story...

When you see a Space Shuttle sitting on its launch pad, there are two big booster rockets attached to the sides of the main fuel tank. These are solid rocket boosters, or SRBs. The SRBs are made by Thiokol at their factory in Utah. The engineers who designed the SRBs would have preferred to make them a bit fatter, but the SRBs had to be shipped by train from the factory to the launch site. The railroad line from the factory happens to run through a tunnel in the mountains. The SRBs had to fit through that tunnel. The tunnel is slightly wider than the railroad track, and the railroad track, as you now know, is about as wide as two horses' behinds. So, a major Space Shuttle design 
feature of what is arguably the world's most advanced transportation system was determined over two thousand years ago by the width of a horse's rear. And you thought being a horse's rear wasn't important?? 


\section{Table of Contents}

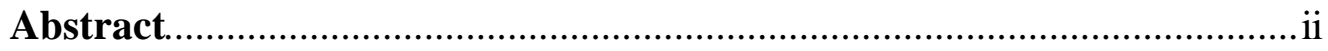

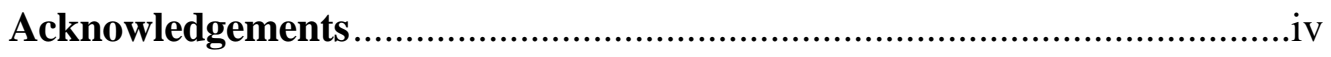

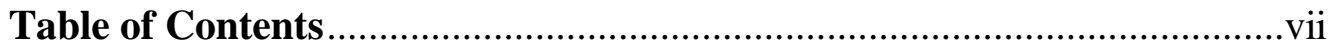

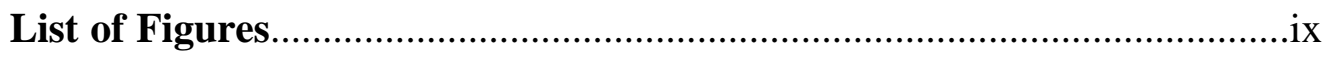

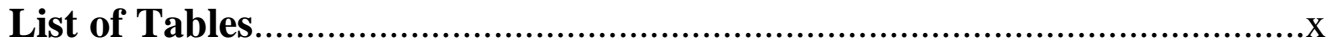

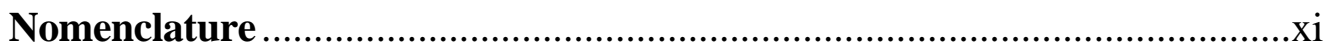

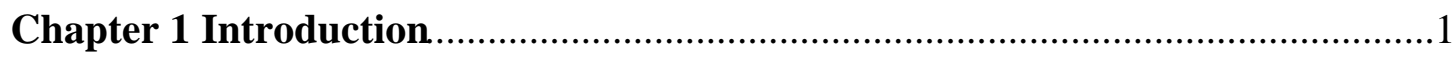

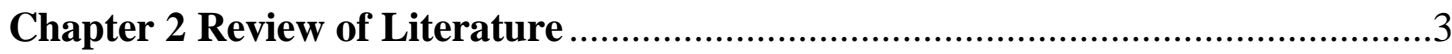

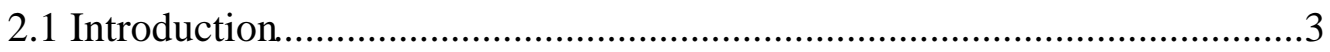

2.2 Environmental Protection Agency Standards...........................................4

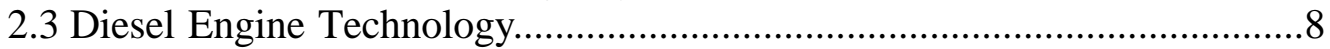

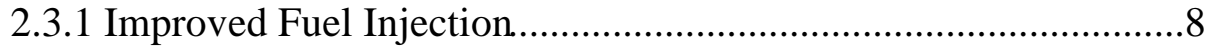

2.3.1.1 Injector Nozzles.....................................................11

2.3.1.2 Effects of Swirl on Combustion.................................12

2.3.1.3 Spray to Wall Impingement........................................13

2.3.1.4 Multiple Injections and Rate Shaping.........................14

2.3.1.5 Alternative Fuels.........................................................14

2.3.2 Combustion Chamber Modifications ........................................16

2.3.2.1 Compression Ratio....................................................16

2.3.3 Turbocharger Improvements..................................................17

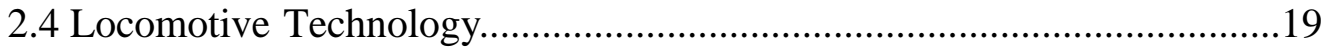

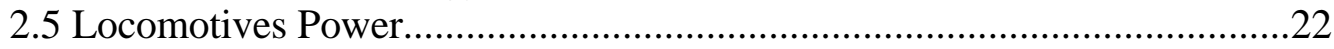

2.6 Train Resistance.............................................................................24

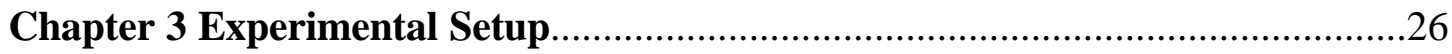

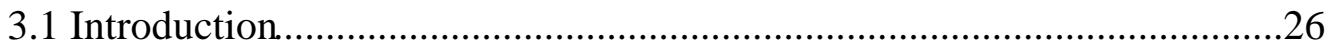

3.2 Fuel Injection Timing Study.............................................................28

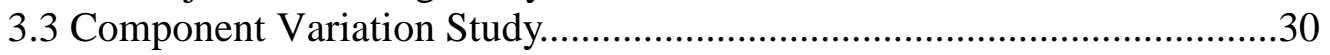

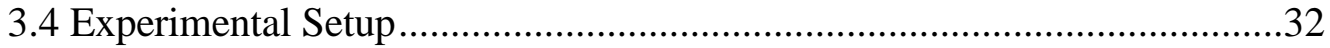

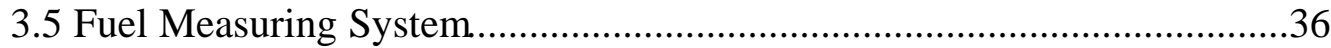

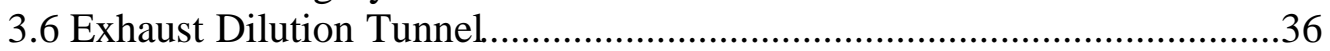

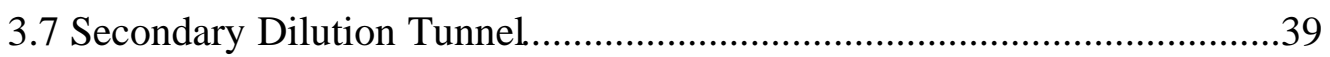

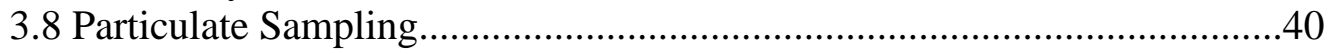

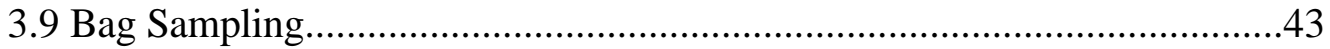

3.10 Gaseous Emissions Sampling System..............................................43 
3.10.1 Oxides of Nitrogen $\left(\mathrm{NO}_{\mathrm{x}}\right)$ Analyzer...................................45

3.10.2 Carbon Monoxide (CO) Analyzer.........................................48

3.10.3 Carbon Dioxide $\left(\mathrm{CO}_{2}\right)$ Analyzer..........................................50

3.10.4 Hydrocarbon (HC) Analyzer............................................50

3.10.5 Sample Gaseous Calculation...........................................51

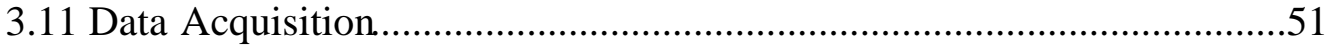

3.12 Smoke Opacity Meter..................................................................52

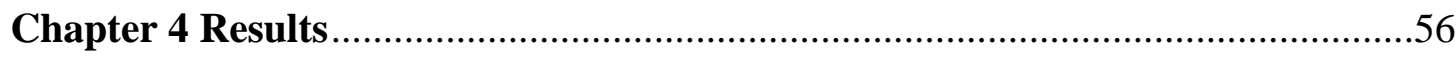

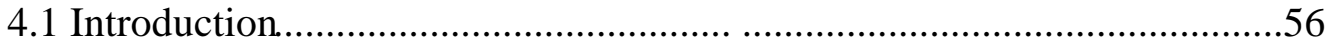

4.2 Emissions and Smoke Opacity Results...............................................56

4.3 Fuel Injection Timing Study Results.................................................59

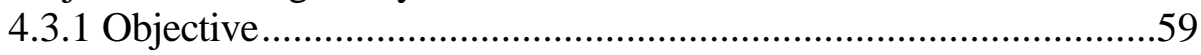

4.3.2 Gaseous and Particulate Emissions Results..............................60

4.3.3 Smoke Opacity Results......................................................65

4.4 Component Variation Study Results.................................................6

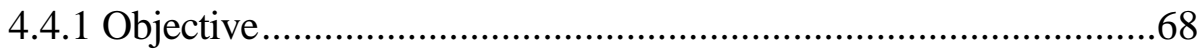

4.4.2 Gaseous and Particulate Matter Emission Results.....................69

4.4.3 Smoke Opacity Results......................................................76

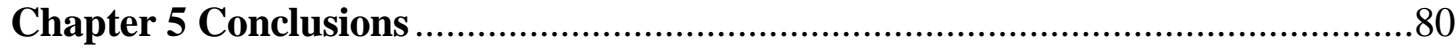

5.1 Fuel Injection Timing Study Conclusions ..........................................8

5.2 Component Variation Study Conclusions..............................................82

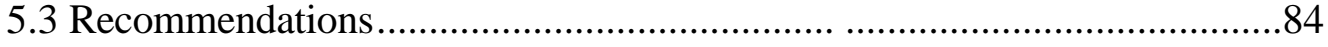

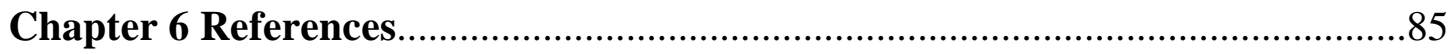

Appendix A

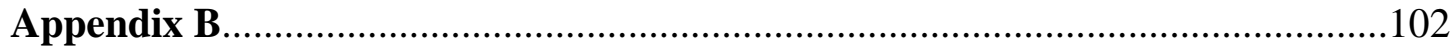

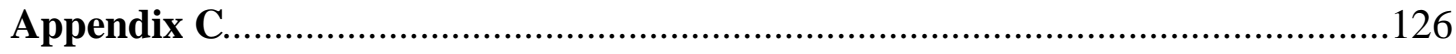

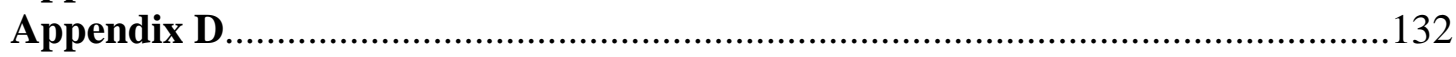




\section{List of Figures}

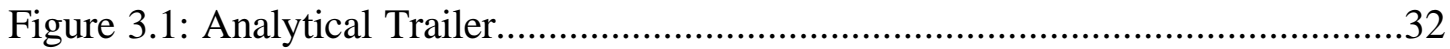

Figure 3.2: Sampling Probe ...................................................................................33

Figure 3.3: Partial Exhaust Sampling System..........................................................34

Figure 3.4: Schematic of Partial Exhaust Sampling System........................................34

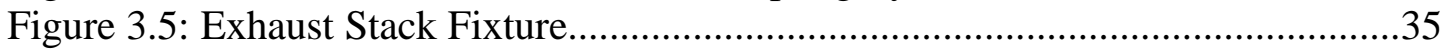

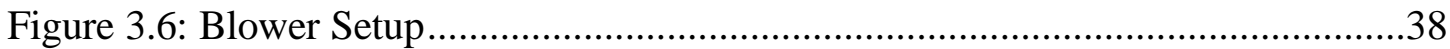

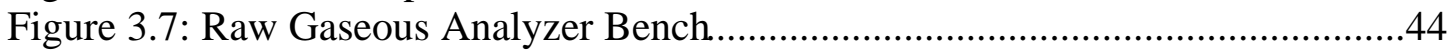

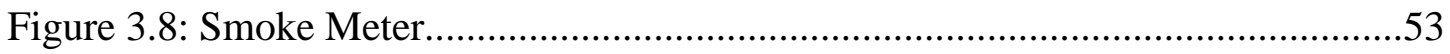

Figure 3.9: Smoke Meter Lens Assembly.................................................................54

Figure 4.1: Brake-Specific Hydrocarbons Emissions for Locomotive 8678.................60

Figure 4.2: Brake-Specific Oxides of Nitrogen Emissions for Locomotive 8678........61

Figure 4.3: Brake-Specific Carbon Monoxide Emissions for Locomotive 8678..........61

Figure 4.4: Brake-Specific Particulate Emissions for Locomotive 8678......................62

Figure 4.5: Fuel Economy Results for Locomotive 8678..........................................62

Figure 4.6: Weighted Emissions for Locomotive 8692................................................63

Figure 4.7: Fuel Economy Results for Locomotive 8692...........................................63

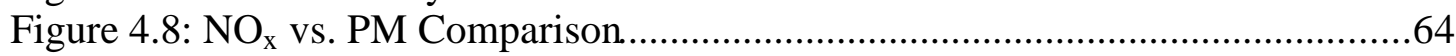

Figure 4.9: Smoke Opacity vs. PM Comparison......................................................64

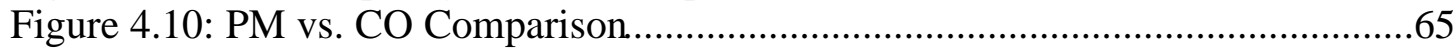

Figure 4.11: 8678 Steady State Smoke Opacity (30\%)..............................................65

Figure 4.12: 867830 Second Peak Smoke Opacity (40\%)..........................................66

Figure 4.13: 86783 Second Peak Smoke Opacity (50\%)............................................66

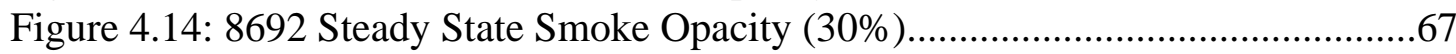

Figure 4.15: 869230 Second Peak Smoke Opacity (40\%).........................................67

Figure 4.16: 86923 Second Peak Smoke Opacity (50\%)............................................68

Figure 4.17: Brake-Specific Hydrocarbon Emissions of Locomotive 8867..................71

Figure 4.18: Brake-Specific Oxides of Nitrogen Emissions of Locomotive 8867.......71

Figure 4.19: Brake-Specific Carbon Monoxide Emissions of Locomotive 8867.........72

Figure 4.20: Brake-Specific Particulate Emissions of Locomotive 8867......................72

Figure 4.21: Fuel Economy Results for Locomotive 8867...........................................73

Figure 4.22: Brake-Specific Hydrocarbon Emissions of Locomotive 8695..................73

Figure 4.23: Brake-Specific Oxides of Nitrogen Emissions of Locomotive 8695.......74

Figure 4.24: Brake-Specific Carbon Monoxide Emissions of Locomotive 8695..........74

Figure 4.25: Brake-Specific Particulate Emissions of Locomotive 8695.......................75

Figure 4.26: Fuel Economy Results for Locomotive 8695.........................................75

Figure 4.27: 8867 Steady State Smoke Opacity (30\%).............................................76

Figure 4.28: 886730 Second Peak Smoke Opacity (40\%)............................................77

Figure 4.29: 88673 Second Peak Smoke Opacity (50\%).............................................77

Figure 4.30: 8695 Steady State Smoke Opacity (30\%)..............................................78

Figure 4.31: 869530 Second Peak Smoke Opacity (40\%)...........................................78

Figure 4.32: 86953 Second Peak Smoke Opacity (50\%).............................................79 


\section{List of Tables}

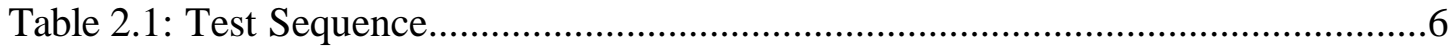

Table 2.2: Deterioration Factors for 7FDL Tier 0 EFI Engine Family........................6

Table 2.3: Exhaust Emission Standards for Locomotives..........................................

Table 2.4: Exhaust Emission Weighting Factors.....................................................

Table 2.5: Smoke Standards for Locomotives (Percent Opacity -Normalized).............8

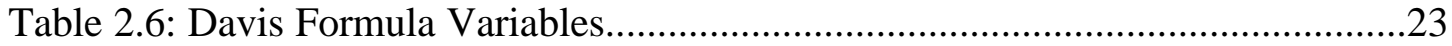

Table 3.1: Mechanical Fuel Injection Tier 0 Modifications....................................27

Table 3.2: Electronic Fuel Injection Tier 0 Modifications........................................27

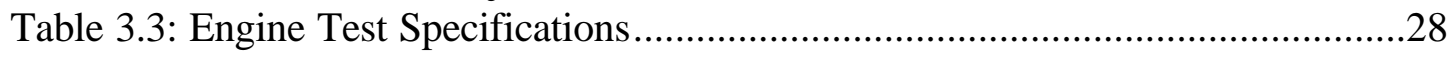

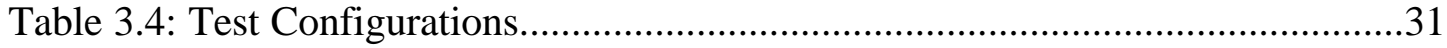

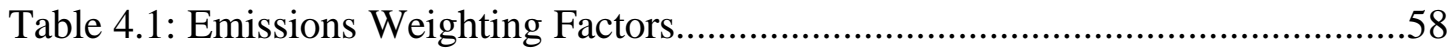

Table 4.2: Deterioration Factors for 7FDL Tier 0 EFI Engine Family........................58

Table 4.3: Low Mileage Standards for 7FDL Tier 0 EFI Engine Family.....................59

Table 4.4: Test Configurations.........................................................................69

Table 5.1: Deterioration Factors for 7FDL Tier 0 EFI Engine Family........................80

Table 5.2: Percent Difference Line Haul Results for Locomotive 8678......................81

Table 5.3: Percent Difference Switch Results for Locomotive 8678..........................81

Table 5.4: Percent Difference Line-Haul Results for Locomotive 8692......................81

Table 5.5: Percent Difference Switch Results for Locomotive 8692..........................82

Table 5.6: Percent Difference Line Haul Results for Locomotive $8867 \ldots \ldots \ldots \ldots \ldots \ldots \ldots . . . . .83$

Table 5.7: Percent Difference Switch Results for Locomotive 8867..........................83

Table 5.8: Percent Difference Line Haul Results for Locomotive 8695.....................83

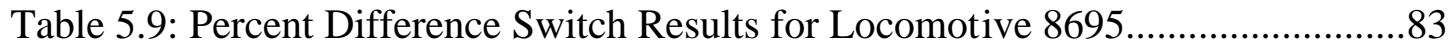




\section{Nomenclature}

\begin{tabular}{|c|c|}
\hline $\mathrm{ADC}$ & Analog Digital Controller \\
\hline $\mathrm{a}$ & Average Particle Projected Area \\
\hline BTDC & Before Top Dead Center \\
\hline b & Wheel Bearing Resistance \\
\hline $\mathrm{C}$ & Celsius \\
\hline CFR & Code of Federal Regulations \\
\hline CFV-CVS & Critical Flow Venturi-Constant Volume Sampler \\
\hline $\mathrm{CMW}_{\mathrm{f}}$ & Molecular Weight of the Fuel per Carbon Atom \\
\hline $\mathrm{CO}$ & Carbon Monoxide \\
\hline $\mathrm{CO}_{2}$ & Carbon Dioxide \\
\hline $\mathrm{CO}_{2 \mathrm{E}}$ & Carbon Dioxide Concentration of the Exhaust \\
\hline $\mathrm{CO}_{2 \mathrm{D}}$ & Carbon Dioxide Concentration of the Dilution Air \\
\hline $\mathrm{D}$ & Drive Wheel Diameter \\
\hline $\mathrm{D}_{\mathrm{c}}$ & Drive Wheel Circumference \\
\hline DF & Dilution Factor \\
\hline $\mathrm{d}$ & Diameter of Cylinder \\
\hline ECU & Electronic Control Unit \\
\hline EFI & Electronic Fuel Injection \\
\hline EMD & Electromotive Division \\
\hline EPA & Environmental Protection Agency \\
\hline $\mathrm{F}$ & Fahrenheit \\
\hline $\mathrm{f}$ & Flange Resistance \\
\hline GE & General Electric \\
\hline $\mathrm{g} / \mathrm{bhp}-\mathrm{hr}$ & Grams per Brake-horsepower Hour \\
\hline $\mathrm{H}$ & Specific Humidity \\
\hline $\mathrm{HC}$ & Hydrocarbons \\
\hline HP & Horsepower \\
\hline HFID & Heated Flame Ionization Detector \\
\hline I & Emitted Light Intensity \\
\hline $\mathrm{I}_{0}$ & Received Light Intensity \\
\hline $\mathrm{I} / \mathrm{I}_{0}$ & Smoke Intensity \\
\hline $\mathrm{K}$ & Smoke Density \\
\hline $\mathrm{K}_{\mathrm{H}}$ & Humidity Correction Factor \\
\hline $\mathrm{K}_{\mathrm{T}}$ & Temperature Correction Factor \\
\hline $\mathrm{L}$ & Stroke Length \\
\hline $\mathrm{L}_{\mathrm{S}}$ & Light Beam Path Length within the Smoke \\
\hline $\mathrm{L}_{\mathrm{d}}$ & $\begin{array}{l}\text { Actual Distance from the Point at which the Light Beam Enters the } \\
\text { Exhaust Plume to the Point at which the Light Beam leaves the } \\
\text { Exhaust Plume }\end{array}$ \\
\hline MFI & Mechanical Fuel Injection \\
\hline $\mathrm{M}_{\mathrm{NOx}}$ & Oxides of Nitrogen Emissions in Grams per Hour \\
\hline $\mathrm{M}_{\mathrm{PM}}$ & Mass of the Particulate Emitted per Test Phase \\
\hline $\mathrm{M}_{\mathrm{PMe}}$ & Measured Mass of Particulate in Exhaust Sample \\
\hline $\mathrm{M}_{\mathrm{PMd}}$ & Measured Mass of Particulate in Dilution Air \\
\hline
\end{tabular}




\begin{tabular}{|c|c|}
\hline $\mathrm{N}$ & Smoke Opacity \\
\hline $\mathrm{N}_{\mathrm{n}}$ & Normalized Percent Opacity \\
\hline $\mathrm{N}_{\mathrm{m}}$ & Average Measured Percent Opacity \\
\hline NDIR & Non Dispersive Infrared \\
\hline NMHC & Non Methane Hydrocarbons \\
\hline $\mathrm{No}_{\text {cars }}$ & Number of Cars \\
\hline NO & Nitric Oxide \\
\hline $\mathrm{NO}_{2}$ & Nitrogen Oxide \\
\hline $\mathrm{NO}_{\mathrm{x}}$ & Oxides of Nitrogen \\
\hline $\mathrm{NO}_{\mathrm{xe}}$ & $\begin{array}{l}\text { Oxides of Nitrogen Concentration in the Dilute Exhaust Bag } \\
\text { Sample }\end{array}$ \\
\hline $\mathrm{NO}_{\mathrm{xd}}$ & Oxides of Nitrogen Concentration in the Dilution Air Sample \\
\hline $\mathrm{n}$ & Number Density of Particles \\
\hline PDP-CVS & Positive Displacement Pump-Constant Volume Sampler \\
\hline PM & Particulate Matter \\
\hline ppm & Parts per Million \\
\hline Q & Average Particle Extinction Coefficient \\
\hline $\mathrm{R}$ & Rolling Resistance \\
\hline lbs & Pounds \\
\hline $\mathrm{PM}_{\text {conc }}$ & Particulate Concentration of the Diluted Exhaust Sample \\
\hline psi & Pounds per Square Inch \\
\hline$\% \mathrm{G}$ & Maximum Ascending Gradient \\
\hline$\rho$ & Mean Effective Pressure \\
\hline$\rho_{\mathrm{NO} 2}$ & Density of Oxides of Nitrogen \\
\hline SCFM & Standard Cubic Feet per Minute \\
\hline $\mathrm{SO}_{\mathrm{x}}$ & Sulfates \\
\hline SOF & Soluble Organic Fractions \\
\hline $\mathrm{T}$ & Tractive Force \\
\hline $\mathrm{T}_{\mathrm{A}}$ & Intake Air Temperature at Ambient Temperatures below $30^{\circ} \mathrm{C}$ \\
\hline $\mathrm{T}_{30}$ & Intake Air Temperature as Tested \\
\hline TCM & Turbo and Compressor Maintenance \\
\hline TDC & Top Dead Center \\
\hline THC & Total Hydrocarbon \\
\hline $\mathrm{V}$ & Velocity \\
\hline$V_{f}$ & Fraction of the Total Raw Exhaust \\
\hline $\mathrm{V}_{\mathrm{m}}$ & Volume of One Mole of Gas at Standard Temperature and Pressure \\
\hline $\mathrm{V}_{\text {mix }}$ & Total Dilute Exhaust Volumetric Flow Rate \\
\hline $\mathrm{V}_{\text {sampe }}$ & $\begin{array}{l}\text { Total Wet Volume of Sample Removed for the Exhaust Particulate } \\
\text { Measurement }\end{array}$ \\
\hline $\mathrm{V}_{\text {sampd }}$ & $\begin{array}{l}\text { Total Wet Volume of Sample Removed for the Dilution Air } \\
\text { Particulate Measurement }\end{array}$ \\
\hline WCO & Percent Wet Concentration of CO in the Exhaust \\
\hline $\mathrm{WCO}_{2}$ & Raw Carbon Dioxide Concentration in the Exhaust \\
\hline WHC & Percent Wet Concentration of $\mathrm{HC}$ in the Exhaust \\
\hline WVOL & Total Exhaust Flow Rate on a Wet Basis \\
\hline $\mathrm{W}_{\mathrm{em}}$ & Work done by Electric Motor \\
\hline
\end{tabular}


$\mathrm{W}_{\mathrm{f}}$

$\mathrm{Wg}$

WVU

$\mu \mathrm{m}$

Mass Flow-Rate of Fuel Used in the Engine

Car Gross Weight

West Virginia University

Micrometer 


\section{Chapter 1 Introduction}

The topic of emission testing on locomotives is a relatively new one. There was no significant testing completed until 1990 when the Clean Air Act was passed which mandated the EPA to set standards for locomotive emissions. The standards account for the gaseous emissions of $\mathrm{CO}, \mathrm{NO}_{\mathrm{x}}, \mathrm{HC}$, and $\mathrm{PM}$, as well as all smoke emissions. It was found that locomotives are a major producer of emissions, primarily $\mathrm{NO}_{\mathrm{x}}$, in the United States. The standards that were set should have a dramatic effect on the emissions produced in the future.

This document reports the effects on emissions due to changes in engine configuration. By changing the engine configuration, a locomotive is able to produce emissions that are lower than the standards set by the EPA. This proves that there should be a decrease in the amount of emissions that locomotives produce in the years to come.

There are two studies reported in this document. The first study records the effects of fuel injection timing and upgraded turbochargers on emissions from a mechanically fuel injected locomotive. The second study records the effects of aftermarket and remanufactured turbochargers and reuse of cylinder liners on emissions. In the first study there were two dieselelectric locomotives tested. Both of the engines incorporated at mechanical fuel injection system. The main difference in the two engines was that the first engine was equipped with a TCM turbocharger to increase the boost pressure to offset the loss in fuel economy as a result of retarding the injection timing to reduce $\mathrm{NO}_{\mathrm{x}}$ emissions. The second was equipped with a stock General Electric 1883 turbocharger. The first locomotive was tested at its stock fuel injection timing of $12^{\circ} \mathrm{BTDC}$ for baseline emissions. The fuel injection timing was then retarded one degree 
after each test to determine if the standards could be met without suffering a loss in fuel economy. The second locomotive was only tested at a fuel injection timing of $8^{\circ}$ BTDC. After the data was analyzed, it was found that retarding the injection timing can be beneficial. The tests proved that the emissions passed the standard and that the locomotives did not suffer a drastic reduction in fuel economy.

In the second study two major engine components, the turbocharger and cylinder liners were exchanged. The objective of the test was to determine if there was a need for the locomotives to be equipped with new components or if the used liners and rebuilt or aftermarket turbochargers could be used without negatively impacting emissions and emissions certification. By using the used components, there can be a dramatic savings in the cost that is associated with servicing locomotive engines. The results that are posted later in this document prove that there is not enough significant change in the gaseous, particulate and smoke emissions to require the need of a new, or specifically specified, turbocharger and new cylinder liners. This means that companies, such as Norfolk Southern, will be able to save a dramatic amount of money in servicing their fleet. 


\section{Chapter 2 Review of Literature}

\subsection{Introduction}

The topic of emission testing on locomotives is relatively a new one. There were no laws that restricted locomotive emissions until the Clean Air Act was passed in 1990. This act mandated the Environmental Protection Agency (EPA) to establish emission standards for unregulated nonroad mobile sources. Previous studies reported from BoozAllen and Hamilton stated that locomotives emitted 90 tons of oxides of nitrogen $\left(\mathrm{NO}_{\mathrm{x}}\right)$, 6.6 tons of sulfates $\left(\mathrm{SO}_{\mathrm{x}}\right)$, two tons of particulate matter $(\mathrm{PM})$, and 3.8 tons of reactive hydrocarbons (HC) per day in California in 1987. These values translate into the production of $3.4 \% \mathrm{NO}_{\mathrm{x}}, 1.6 \% \mathrm{SO}_{\mathrm{x}}, 0.12 \% \mathrm{HC}$, and $0.06 \% \mathrm{PM}$ in California alone. Although the values are relatively small when compared to the total inventory of emissions, the requirements to lower emissions makes the contribution significant [45]. Other studies have reported that locomotives produced $5.5 \%$ of the total $\mathrm{NO}_{\mathrm{x}}$ emissions in the United States 1998. They are in the top ten percent of the total source of $\mathrm{NO}_{\mathrm{x}}$ emissions for nonroad mobile systems [42].

Fuel consumption is another topic that is addressed when locomotive testing is discussed. In 1993 16\% of all freight in the U.S. was transported by train [42]. This was accomplished through the use of multiple locomotives, called a consist, per train. The average train would be made of three locomotives and around seventy cars that could transport 2912 tons of freight. It was not uncommon to see a train with a consist of five locomotives and over 120 cars [42]. With trains of this magnitude burning high amounts of fuel per year, there has been a need to reduce the fuel economy of these engines. 


\subsection{Environmental Protection Agency Standards}

The EPA has set three standards that apply to locomotive engines. The standards are known as Tiers, where each Tier covers a range of model years. Tier 0 applies to all locomotives that were manufactured between 1973 and 2001. This standard also applies to all new production locomotives in the 2001 model year, as well as any freight locomotives remanufactured from 1994 through the 2001 model year. It also applies to all other 1973 through 2001 model year locomotives remanufactured on or after Jan. 1, 2002 [7]. After 2001, Tier 1 covers 2002 through 2004. The Tier 1 standards are expected to reduce the $\mathrm{NO}_{\mathrm{x}}$ emissions from newly manufactured locomotives by fifty percent. The final promulgated set of standards, Tier 2, applies to locomotives and locomotive engines originally manufactured in 2005 and later. The only locomotives that do not have to meet the standards set by the EPA are the electric, historic steam powered, and locomotives originally manufactured before 1973 . They simply do not contribute enough to the current emissions problem to deserve a regulation [7].

Locomotives emissions are tested through a series of steady-state tests. The tests cover all throttle positions to which the engine is subjected. The throttle positions consist of various idle, dynamic brake, and eight power modes which are called notches.

There are typically two idle modes; a low idle and a normal idle. The low idle is used to keep the engine warm. It is common for a locomotive to run for long periods of time when the ambient temperature could cause damage to the engine. The normal idle mode is used for moving the locomotives around the yards where there is no need for a large amount of power. 
There are a series of dynamic brake modes that are used to control the train without any application of the locomotives brakes or the brakes that are on cars of the train. The dynamic brake system is an electrical device that holds the train back through the electric motors and main generator [11]. When the train needs to decrease its speed, the operator changes the dynamic brake lever to a higher mode. When the dynamic brake is engaged, the electric motors that drive the train work in reverse. Instead of applying power to the rails, they act as generators and send the power to a resistor bank where it is dissipated. As the dynamic brake mode increases, more power is sent to the resistor bank which decreases the speed of the train.

The eight power modes, or notches, are used when there is a need for greater amount of power then the idle modes can provide. The notch system is desirable since it makes operations of the locomotive simpler, more reliable, and produces lower emissions through a more steady-state engine cycle [45]. The lower notches are used in the switch yards and the higher notches are used on open rails where higher speeds are desired. The EPA mandated emissions test sequence is given in Table 2.1.

The EPA also subjects locomotives to deterioration factors that are used to reflect locomotive engine family's emissions through its life [12]. CFR 40, Part 92, Subpart C states that the deterioration factors are to be determined using good engineering practice to assure that locomotives or locomotive engines will meet the emission standards in actual use for the useful life of the locomotive or locomotive engine. The factors become a new set of standards that are applied to a locomotive engine family in which the engines must comply throughout their useful lives. This allows locomotive engine manufactures to certify a family of engines to the same standards. Determination of deterioration 
factors is left to the engine manufacturer or emissions certificate holder. The deterioration factors with respect to exhaust emission are given in Table 2.2.

\begin{tabular}{|c|c|c|c|c|}
\hline \multicolumn{5}{|c|}{ Table 2.1: Test Sequence } \\
\hline $\begin{array}{l}\text { Mode } \\
\text { Number }\end{array}$ & Notch Setting & $\begin{array}{c}\text { Time in Notch } \\
\text { (min) }\end{array}$ & $\begin{array}{c}\text { Emission } \\
\text { Measured }\end{array}$ & $\begin{array}{c}\text { Power / Fuel } \\
\text { Consumption } \\
\text { Measured }\end{array}$ \\
\hline Warm-up & Notch 8 & $5 \pm 1$ & None & None \\
\hline Warm-up & Lowest Idle & $15 \max$ & None & None \\
\hline 1a & Low Idle & $6 \mathrm{~min}$ & All & Both \\
\hline 1 & Normal Idle & $6 \min$ & All & Both \\
\hline 2 & Dynamic Brake & $6 \mathrm{~min}$ & All & Both \\
\hline 3 & Notch 1 & $6 \mathrm{~min}$ & All & Both \\
\hline 4 & Notch 2 & $6 \mathrm{~min}$ & All & Both \\
\hline 5 & Notch 3 & $6 \mathrm{~min}$ & All & Both \\
\hline 6 & Notch 4 & $6 \mathrm{~min}$ & All & Both \\
\hline 7 & Notch 5 & $6 \mathrm{~min}$ & All & Both \\
\hline 8 & Notch 6 & $6 \mathrm{~min}$ & All & Both \\
\hline 9 & Notch 7 & $6 \mathrm{~min}$ & All & Both \\
\hline 10 & Notch 8 & $15 \mathrm{~min}$ & All & Both \\
\hline
\end{tabular}

\begin{tabular}{|c|c|c|}
\hline \multicolumn{2}{|c|}{$\begin{array}{c}\text { Table 2.2: Deterioration Factors for 7FDL Tier O EFI } \\
\text { Engine Family as Determined by General Electric }\end{array}$} \\
\hline Emission & Line-Haul & Switch \\
\hline HC & 0.21 & 0.24 \\
\hline CO & 0.7 & 1.3 \\
\hline NO $_{\mathbf{x}}$ & 1.2 & 1.5 \\
\hline PM & 0.26 & 0.28 \\
\hline \hline \multicolumn{3}{|c|}{ Smoke Opacity } \\
\hline Steady-State & $11.7 \%$ \\
\hline \hline 30 Sec. Peak & $19.8 \%$ \\
\hline \hline 3 Sec. Peak & $22.7 \%$ \\
\hline
\end{tabular}

Once the test had been run, the data were weighted through two sets of factors; one set for the line-haul and one set for the switch cycle. The line-haul weighting factors place greater emphasis on the high power notches while the switch test weighting factors 
more heavily weights the low power notches. Locomotives generally are required to meet the standards for both duty-cycles. However, Tier 0 also mandates that switch locomotives rated at 2,300 hp or less are only required to meet the switch duty-cycle standard [7].

Although there is no regulation on the amount of fuel consumed by a locomotive, it is a concern during testing. With $55 \%$ of the rated power being used in notch eight, $58 \%$ of the fuel consumption occurs while in line-haul applications. Due to the large amounts of fuel being consumed by these engines every day, there are on-going studies being performed to reduce the total fuel consumption [34].

The emission standards and current emission levels for hydrocarbon (HC), carbon monoxide $(\mathrm{CO})$, oxides of nitrogen $\left(\mathrm{NO}_{\mathrm{x}}\right)$, and particulate matter $(\mathrm{PM})$ are listed in Table 2.3, the weighting factors that were used to calculate the weighted steady-state emissions are listed in Table 2.4, and the smoke opacity standards are listed in Table 2.5 [12].

\begin{tabular}{|l|c|c|c|c||}
\hline \multicolumn{4}{|c|}{ Table 2.3: Exhaust Emission Standards for Locomotives } \\
\hline \hline \multirow{2}{*}{ Tier and Duty-cycle } & Gaseous and Particulate Emissions & (g/bhp-hr) \\
\cline { 2 - 5 } & HC & CO & NO $_{\mathbf{x}}$ & PM \\
\hline Tier 0 - line-haul & 1.00 & 5.0 & 9.5 & 0.60 \\
\hline Tier 0 - switch & 2.10 & 8.0 & 14.0 & 0.72 \\
\hline Tier 1 - line-haul & 0.55 & 2.2 & 7.4 & 0.45 \\
\hline Tier 1 - switch & 1.20 & 2.5 & 11.0 & 0.54 \\
\hline Tier 2 - line-haul & 0.30 & 1.5 & 5.5 & 0.20 \\
\hline Tier 2 - switch & 0.60 & 2.4 & 8.1 & 0.24 \\
\hline
\end{tabular}

The HC standards are in the form of total hydrocarbon (THC) for diesel, biodiesel, or any combination of fuels with diesel as the primary fuel and non-methane 
hydrocarbon (NMHC) for natural gas, or any combination of fuels where natural gas is the primary fuel.

\begin{tabular}{|c|c|c|}
\hline \multicolumn{2}{|c|}{ Table 2.4: Exhaust Emission Weighting Factors } \\
\hline Engine Operating Point & Line Haul & Switch \\
\hline Low Idle & 0.19 & 0.299 \\
\hline Normal Idle & 0.19 & $\mathbf{0 . 2 9 9}$ \\
\hline Dynamic Brake & $\mathbf{0 . 1 2 5}$ & $\mathbf{0 . 0}$ \\
\hline Notch 1 & $\mathbf{0 . 0 6 5}$ & $\mathbf{0 . 1 2 4}$ \\
\hline Notch 2 & $\mathbf{0 . 0 6 5}$ & $\mathbf{0 . 1 2 3}$ \\
\hline Notch 3 & $\mathbf{0 . 0 5 2}$ & $\mathbf{0 . 0 5 8}$ \\
\hline Notch 4 & $\mathbf{0 . 0 4 4}$ & $\mathbf{0 . 0 3 6}$ \\
\hline Notch 5 & $\mathbf{0 . 0 3 8}$ & $\mathbf{0 . 0 3 6}$ \\
\hline Notch 6 & $\mathbf{0 . 0 3 9}$ & $\mathbf{0 . 0 1 5}$ \\
\hline Notch 7 & $\mathbf{0 . 0 3 0}$ & $\mathbf{0 . 0 0 2}$ \\
\hline Notch 8 & $\mathbf{0 . 1 6 2}$ & $\mathbf{0 . 0 0 8}$ \\
\hline
\end{tabular}

\begin{tabular}{|c|c|c|c|}
\hline \multicolumn{3}{|c|}{ Table 2.5: Smoke Standards for Locomotives } \\
(Percent Opacity -Normalized)
\end{tabular}

\subsection{Diesel Engine Technology}

There have been many advances that improved the emissions for diesel engines.

This section will discuss some of the technology that has improved diesel emissions, primarily fuel injection, combustion chamber, and turbocharger modifications.

\subsubsection{Improved Fuel Injection}

It is known that fuel injection has a major role in the production of emissions and fuel economy. Depending on how and when the fuel enters the combustion chamber, the emissions and fuel economy can vary. There have been studies performed that prove the 
advancements of fuel injection have had an impact on the amount of emissions produced today. One example of emission reduction is through retarding the fuel injection timing to lower the overall $\mathrm{NO}_{\mathrm{x}}$ emissions. The problem that occurs is that when the $\mathrm{NO}_{\mathrm{x}}$ is reduced, the PM is increased. This has been proven to be corrected through an increase in the fuel injection pressure and injection rate shaping [45] which is discussed later. Other advancements consist of injector modification, multiple injections, and swirl modifications. All of these methods help to lower the overall diesel emissions.

There are various studies of fuel injection systems that have been tested which range from the relatively simple mechanical fuel injection system to the highly advanced electronic fuel injection system. One such study, conducted in 1997 [23], tested a spool acceleration type injection system which relies on the concept of using hydraulic spool acceleration to pressurize the injection lines. Within the system, injector pressure increases with fuel quantity and there is little dependence on the engine speed which avoids poor combustion that may be seen at low speeds. It became known to the researchers that through the use of pilot injections and high pressure injections with a reduced initial rate, there is a potential to reduce $\mathrm{PM}, \mathrm{NO}_{\mathrm{x}}$, and engine noise simultaneously through rate shaping that will be defined later in this document. Therefore, the study was conducted to prove the effects of shaped injection rates on engine performance and exhaust emissions. It proved that $\mathrm{NO}_{\mathrm{x}}$ and noise could be reduced at low engine speeds through the use of a spool acceleration type fuel injection system. This occurs since the system allows the initial injection pressure to continually drop as combustion occurs. It was also found that smoke emissions were significantly 
reduced from increasing the average injection rate by having a higher main injection pressure [23].

Another study, performed by Hlousek in 1998 [20, 46], compared an electromechanical pump-line-nozzle system with a common rail system that was completely controlled by an electronic control module. The pump-line-nozzle system consisted of a fuel supply pump, cam driven injector pumps, high pressure lines and injectors, and an electronic control unit (ECU). This system allows the start and end of the injection cycle to be flexibly controlled with respect to crank position. It minimizes the risk of over fueling since only one uncontrolled injection can occur in the case of unwanted energizing impulses or sticking control valves. The ECU manages the sensor data and controls the function of the fuel system while the two stage injector controls the injection rate, which makes this system electro-mechanical.

The common rail system that was tested consisted of a low pressure fuel supply pump, a high pressure fuel pump, high pressure rail, high pressure lines connected to the injector of each cylinder, and an ECU that controlled the entire process. The injectors were equipped with spring loaded nozzles, hydraulically controlled valves and electronically controlled solenoids. As the injection process starts, the solenoid opens the connection to the low pressure supply which delivers the fuel at a constant flow from the tank to the high pressure pump. The high pressure pump then pressurizes the fuel rail which is monitored by the ECU through pressure sensors. The rail acts as an accumulator and a damper that lessens the force from pressure spikes that occur during the injection process. Once the rail is pressurized, the connection between the nozzle and low pressure line is closed and the connection between the rail and the nozzle is opened for injection to 
begin. The process ends when the solenoid is closed which quickly drops the nozzle pressure by opening the low pressure line.

The results of this study showed that both systems had the ability of rate shaping and to control fuel injection timing. The common rail system, however, allowed for a more simplified system and is more suitable for new engine projects. It was proven through the study that through the use of pilot and post injections, there could be a reduction in noise and an increase in $\mathrm{NO}_{\mathrm{x}}$ catalyst efficiency [20, 46].

\subsubsection{Injector Nozzles}

The goal of an injector is to inject a determined amount of fuel at a determined time. The parameters of the injector nozzle are designed to atomize the fuel and spray the fuel into a desired location as it is injected into the combustion chamber. The nozzle must first atomize the fuel to ensure proper air-fuel mixing. The proper air-fuel mixture is important since it is directly related to the emissions that will be produced. If the airfuel mixture is lean, which has more air than fuel, there will be higher amounts of $\mathrm{NO}_{\mathrm{x}}$ produced. If the air-fuel mixture is rich, which has more fuel than air; there will be higher amounts of $\mathrm{HC}$ and PM produced. This can be corrected by minimizing the nozzle volume, which will allow the correct amount of fuel to be injected [45], which allows for adequate mixing to ensure the proper air-fuel ratio.

The injector nozzle parameters that affect the fuel distribution are the area and fuel velocity. The velocity is determined from the pressure in the fuel line, and a higher velocity will result in a more complete fuel atomization. Once the velocity is determined, the nozzle area can then be found. If it is found that there are multiple nozzle holes needed, the number of holes in the nozzle should be matched with the fuel injection 
pressure and combustion chamber parameters to ensure that there is an optimal air-fuel ratio.

The number of holes within a nozzle can have an effect on the emissions produced and the engine response as well. A study was performed by Larsson in 1999 [28] to test the effects of injector nozzle holes. The study examined the emissions with respect to a four-hole nozzle and an eight-hole nozzle. The parameters of the engine that were analyzed were the start of injection, the inlet air temperature and pressure, amount of fuel injected, load effects, spray penetration, flame lift off, and flame length. It was found that the emissions, load effects, inlet temperature and pressure, flame lift off and length followed the same trend. As more fuel was added from the eight-hole nozzle, the emissions, load, and inlet temperature and pressure all increased. When the four-hole nozzle was tested, there was a higher injection velocity with a deeper spray penetration that resulted in a longer ignition delay due to lower surface and residual gas temperature in the combustion chamber [28].

The combustion chamber may be designed to manipulate the mixture even further. The piston may be modified so that it will cause the mixture to "swirl" which will cause further mixing of the fuel and air. For this reason, the injector must be able to inject the fuel into a desired location in the combustion chamber.

\subsubsection{Effects of Swirl on Combustion}

It is known that for an engine to operate smoothly and produce desirable emissions, the proper air-fuel ratio must be obtained. This can be made possible through the idea of swirl. Within an engine, the combustion chamber and injector can be designed in such a way that as the fuel is injected into the cylinder, the geometry will 
cause the fuel to "swirl" which will allow adequate mixing with the air to occur and the proper air fuel ratio to be achieved.

A study conducted in 1993 [34] tested air-fuel mixing, spray trajectories, flame movement at various operating conditions, the influence of swirl on the heat release rate, cylinder pressure rise and its relation to the level of production of $\mathrm{NO}_{\mathrm{x}}$ and $\mathrm{PM}$ on a small high speed diesel engine. The parameters that were varied in the study were engine speed and load, injection timing, and swirl ratio.

The study found that at low swirl and low speed, the sprays were slightly affected, but at high speeds, even with low swirl, the sprays were heavily deflected. The adjacent sprays overlapped very quickly which created fuel rich zones which will create an increase in PM and HC production. At moderate speeds and high swirl a state of over mixing was found to occur. It was found that as engine speed increased, even low swirl results in low combustion. Also the amount of fuel to burn at combustion decreased at speeds above $2000 \mathrm{rpm}$ at high swirl due to over mixing and diffusion combustion of fuel vapors which makes the mixture lean and produces higher $\mathrm{NO}_{\mathrm{x}}$ as a result of an increase in the cylinder temperature and pressure. It was proven that small engines are sensitive to inlet swirl. The results showed that variable inlet swirl with respect to engine speed and load would allow gains in the fuel economy and smoke emissions of nearly $30 \%$ [34].

\subsubsection{Spray to Wall Impingement}

When discussing injection spray characteristics, spray to wall impingement is a topic that should be addressed. It is an important issue due to its perceived role in increased emissions of soot, or PM, and unburned hydrocarbons. There is an increase in the various emissions when spray to wall impingement occurs since the fuel comes in 
contact with the cylinder wall and there is not an adequate air fuel ratio for complete combustion to occur. A studied carried out by Borthwick and Farrell in 2002 [5] examined parameters that could affect fuel injection characteristics, which consisted of combustion chamber density and temperature at top dead center (TDC), engine speed, and fuel injection pressure and duration. The study proved that as the combustion chamber density or temperature at TDC increased, and an increase in the engine speed would cause a decrease in the spray penetration distance and spreading angle and velocity. It also proved that spray to wall impingement occurred at lower combustion chamber densities and engine speeds.

\subsubsection{Multiple Injections and Rate Shaping}

There can be a reduction in emissions depending on when and how the fuel is injected. At a high speed and high load condition, the injection process may have a lower slope at the beginning of injection. This will allow less premix combustion to occur that will result in a lower production of $\mathrm{NO}_{\mathrm{x}}$. If the engine is operating at a low load or idle condition, the injection may be split into two smaller injections [15]. This is beneficial since there will not be a dramatic temperature and pressure increase due to the smaller initial injection. This will produce a lower amount of $\mathrm{NO}_{\mathrm{x}}$ that may be oxidized through the second stage of the combustion.

\subsubsection{Alternative Fuels}

Through the knowledge of how different fuels ignite and combust to produce different emissions, it has been found that alternative fuels in diesel engines have great potential for reducing fuel economy and environmental impact. There are various studies that have been performed to prove the effects of these fuels on emissions. Among the 
fuels tested, Fischer-Tropsch diesel and natural gas have proven to have significant impacts on the reductions of emissions.

Fischer-Tropsch diesel is a fuel that is produced through a process in which iron in a cobalt catalyst is reacted with a mixture of hydrogen and carbon monoxide. Through high amounts of heat, methane, synthetic gasoline and waxes, and alcohols are produced with water and carbon dioxide produced as a byproduct. The process was discovered in 1923 by two German coal researchers named F. Fischer and H. Tropsch [24]. The fuel has many of the same characteristics of natural gas in that they both contain no sulfur and no aromatic compounds that contribute to the formation of PM. Fischer-Tropsch diesel has been found to have a high cetane number, which defines the ignitability of a fuel, with excellent ignition characteristics. This is a desirable fuel for locomotive engines since it needs no engine modifications and will allow a reduction in all emissions without a large reduction in power [42].

There have also been studies that tested the use of a dualprocess in locomotive engines. Within the process, a small amount of diesel is injected with the rest of the injection being natural gas, or another type of clean burning fuel. The diesel is needed to help ignite the secondary fuel where the ratio between fuels is usually around 5\% diesel and 95\% secondary fuel. Tests have proven that locomotives on dual-fuel system, diesel and natural gas for example, are able to produce $\mathrm{NO}_{\mathrm{x}}$ emissions less than $1.5 \mathrm{~g} / \mathrm{bhp}-\mathrm{hr}$ compared to 9 to $15 \mathrm{~g} / \mathrm{bhp}-\mathrm{hr}$ on diesel. Although there were similar amounts of energy used in the comparison, when tested in modes under notch three, the engine ran on diesel alone due to high a $\mathrm{CO}$ and $\mathrm{HC}$ production and efficiency loss at light loads while in dual-fuel mode [42]. 


\subsubsection{Combustion Chamber Modifications}

There have been many changes in the combustion chamber designs of a diesel engine. They range from flat top pistons to the "Mexican Hat" style piston design that is thought to induce the air-fuel mixture into a swirl which will ensure a more complete mixing. There have also been advancements in the valve and piston ring assemblies that have eliminated some of the engine oil from traveling into the cylinder which may dramatically increase the PM emissions of an engine.

Through the use of better computer models, engine designers are assisted in the design process that involves extensive testing, modeling, validation, predictions, and further testing. Through this process, the engines can be modified to the parameters that mostly affect the engine components. Modifying the compression ratio is a significant method of combustion chamber modification.

\subsubsection{Compression Ratio}

There can be a reduction in emissions through increasing the compression ratio of an engine. The ignition delay period decreases when the compression ratio is increased. This allows the $\mathrm{NO}_{\mathrm{x}}$ emissions to be controlled since the fuel injection timing can be retarded. The retardation of the fuel injection timing is made possible since the amount of fuel burned in the premixed region is reduced. High compression ratios offer the most emissions reductions at high speed, light load conditions when ignition delay is the longest, and under cold operating conditions [6].

The temperature in the cylinder is also affected through the increase of the compression ratio. When the compression ratio is increased, the in-cylinder temperature 
increases. This allows the cold start PM emissions and white smoke emissions to be reduced.

\subsubsection{Turbocharger Improvements}

Turbocharger design has been fairly constant over the years. There have not been

many changes to the overall system. Although there have been modifications to the basic components such as the turbines and impellers, the system as a whole has not seen any drastic modifications. There have also been modifications to the seals and bearings within the turbochargers. There were various problems that were faced in the early stages of turbocharger advancement with respect to heavy duty trucks. Among the problems that needed to be addressed was that of the low load creep strength and low cycle fatigue strength which were too inadequate for the amount of work that was applied to the system. The problem became more severe through advancements in compressor impellers. Another problem that occurred was in the oxidation and cracking of turbine housing due to high exhaust gas temperatures and increased heat load fluctuations. This was a significant problem, especially in the center wall of the turbochargers. These problems, as well as new ones, were addressed as the technology improved and the demand for more efficient and reliable systems arose [26].

The main purpose of a turbocharger is to provide the engine with more air which results in an increase in power. This is accomplished through the parameters of the turbocharger. The main components of the turbocharger that affect the intake charge are the nozzle and throat. There have been advancements made that allow the nozzle and throat dimensions to be varied during operation. These variable geometry turbochargers provide a leaner air-fuel ratio under full load conditions, which results in an improved 
engine response at lower loads and speeds and a reduction in emissions. Through the use of variable geometry turbochargers, sufficient boost pressure can be achieved in low flow regions, and a wide operating range that extends to high flow rates and high speed ranges can be obtained $[2,33]$. This technology can also lead to the reduction of PM at a constant $\mathrm{NO}_{\mathrm{x}}$ production by refining the match between the turbocharger and engine. Also, by taking measures to reduce the temperature of the air charge coming into the combustion chamber, there may be a reduction in the amount $\mathrm{PM}$ and $\mathrm{NO}_{\mathrm{x}}$ produced [45].

Turbocharger efficiency improvement is another method in which emissions can be reduced through the use of a turbocharger. A relatively simple way to improve the efficiency of a turbocharger is to make the clearance between the housing and the blades of the turbine and compressor impeller as small as possible. A study in 1999 [39] was completed following that idea. The researchers coated the housing of a turbocharger and tested it in comparison with the same turbocharger without the internal coating. It was found that there was no difference in the production of gaseous emissions, but the coated turbocharger had an improved compressor and turbine efficiency, engine torque, throttle response, and fuel economy. It also lowered the PM emissions by $0.01 \mathrm{~g} / \mathrm{bhp}-\mathrm{hr}$.

A turbocharger may also be chosen depending on the type of use to which a vehicle is to be subjected. If the vehicle is to be used primarily for long distance hauling, in which the engine may run at high speeds, a turbocharger that will produce the maximum efficiency and power at high engine speed should obviously be chosen. Similarly, if a vehicle is to be used around a stock yard or switch yard type environment, a turbocharger that works well under low speeds and high loads should be chosen. One 
such turbocharger was proven to work well in that type of environment in a study conducted in 2002 [32]. In the study, two turbochargers were tested; one standard and one waste-gate turbocharger. After both were tested on the same engine at three speeds within the entire load range, it was found that the waste-gate produced reduced amounts of PM and smoke emissions at high loads with a low to moderate speed range.

\subsection{Locomotive Technology}

There have been great changes over the years in locomotive design. The design has change from a primitive steam engine to a highly advanced diesel-electric hybrid system. In the steam engine design, the engine was simply a piston that was connected directly to the drive wheels of the locomotive, so when the steam was injected, the drive wheels would turn and the train would move. The modern system is much more complex. The diesel engine is connected to a generator that produces power that is transferred to the wheel motors in the trucks of the locomotive.

The trucks are the units under the train that contain the wheels. There are typically four to six wheels per truck depending on the intended usage of the locomotive. If the locomotive is to be used on a rail system that contains tight turns the four wheel truck locomotive is used, and if the locomotive is to be used on a rail system that is relatively straight, a six wheel truck is used. However, there have been recent advancements in truck design that will allow six wheel trucks to travel on rail systems that would normally be for four wheel trucks [42]. This is advantageous since having more drive wheels means more weight can be transported. Within the truck is where the wheel motors, which are directly connected to the axle shafts, transfer the power to the 
drive wheels. The dieserelectric system is desirable since it allows maximum torque to be applied to the rails at zero speed which is essential for initial train motion [45].

The locomotives of today are an excellent example of technology and machinery working hand in hand. Once the microprocessor was built into locomotives, their control systems were simplified and became more reliable. The need for a more advanced system quickly became evident as the need for higher horsepower engines became desirable and their control requirements had to be addressed. An advancement the microprocessor brought with it is the display system that is seen in modern locomotives. Through the use of the display system, the operator is able to monitor the functions of the locomotive which allows any problems that may occur to be corrected quickly before they render the locomotive inoperable [3].

There are two locomotive manufacturers in the U.S. today. They are the Electromotive Division of General Motors (EMD) which produces two-stroke locomotive engines and the General Electric Transportation Systems (GE) which produces fourstroke locomotive engines. The engines used in modern locomotives can produce anywhere from 3000 horsepower to 6000 horsepower depending on the function of the engine [45]. The engines produce high amounts of horsepower but operate only at a maximum speed of nearly $1100 \mathrm{rpm}$. This may seem slow but the size of the engine must be considered. The displacement of a locomotive engine that produces 3200 horsepower is 11.6 liters or 710 cubic inches per cylinder. These specifications belong to a General Motors EMD 710 series engine. The EMD 710 is a V-12 engine which means it has an overall displacement of 139.2 liters or 8520 cubic inches. With that much displacement the pistons must move fairly slowly to prevent any engine component failure from 
occurring. It has been reported that through the technological improvements of heavy truck emissions, locomotive emissions have been reduced and their engines have become more efficient. Their efficiency has been improved through higher peak pressure, improved thermal management, reduced friction, improved combustion, and exhaustenergy utilization [42].

There have been advances in locomotive fuel injection systems that allow modern locomotive engines to be equipped with an electronic fuel injection system that allows a desired amount of fuel to be injected at any desired time during the engine cycle regardless of engine speed. This means that there can be a difference in the injection timing between the lower level power modes and the notch modes. This may benefit locomotive emissions depending on the type and function of the locomotive. With this method, adjustments can easily be made to change the fuel injection timing, which can be very useful since it is known that certain emissions are more likely to occur depending on when fuel is injected. For example, if the fuel is injected early in the cycle, there will be more $\mathrm{NO}_{\mathrm{x}}$ and less PM produced in the exhaust stream. This is an important piece of knowledge since locomotives produce high amounts of $\mathrm{NO}_{\mathrm{x}}$ and PM [42].

There are also modern locomotives that are equipped with a mechanical fuel injection system that can have the same results. The main difference is that a mechanical system has the same injection timing regardless of engine speed. Also, changing the fuel injection timing on the mechanical system is more labor intensive than that of the electronic system. Instead of simply changing the fuel injection mapping through the computer, a few hours must be spent disassembling the engine and manually adjusting the fuel system components for a change in fuel injection timing. 


\subsection{Locomotives Power}

A typical engine's power is measured in horsepower. However, this is not the case for a locomotive. A locomotive's power is measured by the tractive force, or effort, that the drive wheels, or drivers, apply to the rails. There are a few ways to calculate the tractive force. When locomotives were steam powered it was actually quite simple to solve. The equation is expressed as:

\section{Equation 1: $\quad T=\left(d^{2} L \rho\right) / D$}

where $T$ is the tractive force, $d$ is the diameter of the cylinder, $L$ is the stroke length, $\rho$ is the effective mean steam pressure on the piston, and $\mathrm{D}$ is the diameter of the driving wheels [27].

A method used today is through the work the electric motor exerts. More specifically, the tractive force is found by determining the amount of work that the electric motor exerts during each revolution of the drivers. Once the work is found, the value is divided by the circumference of drivers. The result is the force exerted through each foot the motor moves the drivers.

\section{Equation 2: $\quad \mathrm{T}=\mathrm{W}_{\mathrm{em}} / \mathrm{D}_{\mathrm{c}}$}

Where $\mathrm{T}$ is the tractive force, $\mathrm{W}_{\mathrm{em}}$ is the work exerted from the electric motor, and $\mathrm{D}_{\mathrm{c}}$ is the circumference of the drivers [29].

Another method is through the use of the Davis Formula which calculates the trains rolling resistance based on the mechanical and air resistance [42]. The formula is expressed in Equation 3 and the variables are given in Table 2.6.

Equation 3: $R=F W+b n+f W V+C A V^{2}$ 


\begin{tabular}{|c|c|c|c||c|c|c|}
\hline \multicolumn{9}{|c|}{ Table 2.6: Davis Formula Variables } \\
\hline \hline & \multicolumn{2}{|c|}{ Wheel Bearing Resistance } & $\begin{array}{c}\text { Flange } \\
\text { Resistance }\end{array}$ & \multicolumn{2}{c|}{ Air Resistance } \\
\hline \hline Unit & $\mathrm{F}$ & $\mathrm{b}$ & $\mathrm{n}$ & $\mathrm{f}$ & $\mathrm{C}$ & $\mathrm{A}$ \\
\hline \hline Locomotive & 1.3 & 29 & 4 & 0.03 & 0.0024 & 140 \\
\hline \hline Railcar & 1.3 & 29 & 4 & 0.045 & 0.0024 & 90 \\
\hline
\end{tabular}

Since the wheels should not slip, the tractive force must be at least four times less than that of the weight resting on the drivers. However, if the rails are wet, the resting weight on the drivers will be nearly ten times the force that is exerted on the drivers [44]. With wheetrail adhesion being the limiting factor of the tractive force at speeds lower than $25 \mathrm{mph}$, more weight can be added if there is any wheel slippage. If it is possible to use a six-wheel truck which is able to handle more weight than a four wheel truck, the tractive force can be increase by approximately 50\% [45].

The tractive force can be related to the brake horsepower, or usable horsepower, of the engine through a relatively simple relation. From start of motion to a speed of ten miles per hour, the tractive force is determined through Equation 4 and at speeds of ten miles per hour and greater, the tractive force is determined through Equation 5 [44].

Equation 4: $\quad T=30 \times H P$

Equation 5: $\quad T=\frac{300 \times H P}{V}$

where $\mathrm{T}$ is the tractive force in pounds, HP is the engines brake-horsepower at a given speed, and $\mathrm{V}$ is the traveling speed in miles per hour.

The tractive force is desirable since it is directly related to the number of cars, or weight, that a locomotive can pull. This weight is known as the tonnage rating of a locomotive. The main factors that affect the tonnage rating are the tractive force and the 
gradient which the train must travel over. The tonnage rating is expressed through Equation 6.

$$
\text { Equation 6: } \quad N o_{\text {cars }}=\frac{T}{[3+(20 * \% G)] W_{g}}
$$

where $\mathrm{No}_{\text {cars }}$ is the number of cars the locomotive can pull in pounds, $\mathrm{T}$ is the tractive force, $\% \mathrm{G}$ is the maximum ascending gradient that is long enough to contain the whole train, and $\mathrm{Wg}$ is gross weight of the cars in tons [44].

\subsection{Train Resistance}

There are many causes of resistance that are applied to a locomotive. Wheel friction, gradient change, curves in the track, and atmospheric or wind pressure top the list. Although these seem to be fairly obvious forms of resistance, there are no trustworthy formulas for calculating the resistance.

A large amount of the resistance that a train sees is simply through the weight of the railcars. Since many trips made by a freight train consist of empty railcars, it was found that an empty car without a container, or a flat bed railcar, weighs between 45 and $55 \%$ of a full car, and a railcar with the container weighs 60 to $65 \%$ of a full car. This shows that even an unloaded train is able to put enormous loads on the locomotives.

Much of the resistance that a locomotive experiences is from the atmosphere. Under a speed of twenty miles per hour the affects are slight, but once the train is moving at a fairly high rate of speed, the resistance starts to multiply. It is difficult to calculate an exact number since there are so many differences in the body of the train. If there are passenger cars in the line, their raised roofs give the wind many places to cause additional resistance. If the train is a freight train, the resistance is difficult to calculate because if 
any of the doors are left open, the freight car may act like a parachute to catch the wind. Then there are flat cars that give the train little resistance, until they are coupled to a freight car. This exposes the freight car to the full force of the wind to hold the train back.

The wind that is pushing on the front of the train is not the only place where it can cause a great amount of resistance. The cross winds that a train sees can apply just as much friction between the wheels and the track. When a train encounters sees a cross wind the wheelflanges rub on the rail causing a great amount of resistance.

The curves that a train travels over may offer a fair amount of resistance as well. The resis tance the train sees is in direct proportion to the curvature of the track. This is an important piece of information since it has been stated that each degree of track curvature applies enough resistance to increase the fuel consumption by nearly eight percent when compared to a straight track [42]. 


\section{Chapter 3 Experimental Setup and Procedures}

\subsection{Introduction}

There were two studies conducted which are recorded in this document. The studies consisted of four locomotives, two in the first and two in the second. All tests were performed at Norfolk Southern Locomotive Shops in Roanoke, Virginia. Before testing began, Norfolk Southern installed General Electric's Tier 0 emissions kit on locomotives 8867 and 8695 for the second study. However, the locomotives in the first study, 8678 and 8692, were not equipped with a GE Tier 0 kit. The engine rebuild kits must allow each engine to meet the EPA Tier 0 standard. The components that were changed on the mechanically fuel injected locomotive 8695 are listed in Table 3.1 and the components changed on locomotive 8867 are listed in Table 3.2.

The GE Tier 0 kit changes the injector pumps and nozzles and increases the fuel pump pressure from 65 psi to 95 psi. Also new cams and liners are applied to the power assemblies. The biggest change is the electronic fuel injection software that sets the timing strategy for emissions compliance. 


\begin{tabular}{|c|}
\hline $\begin{array}{c}\text { Table 3.1: Mechanical Fuel Injection } \\
\text { Tier 0 Modifications. }\end{array}$ \\
\hline Component Description \\
\hline Camshaft \\
\hline \hline Right Camshaft End Section \\
\hline Left Camshaft End Section \\
\hline Right Camshaft Mid Section \\
\hline Left Camshaft Mid Section \\
\hline Power Assembly \\
\hline Full Power Assembly \\
\hline Long Power Assembly \\
\hline Short Power Assembly \\
\hline Head Liner Assembly \\
\hline Piston Crown \\
\hline Turbocharger \\
\hline Turbocharger \\
\hline \hline Rotor (Compressor, Turbine Disk, and \\
\hline Shaft) \\
\hline \hline Turbine Disk Assembly \\
\hline Turbine Nozzle Ring \\
\hline \hline Buckets \\
\hline \hline Engine Air System \\
\hline \hline Engine Air (baggy) Filters \\
\hline \hline Fuel System \\
\hline \hline Injector \\
\hline \hline High Pressure Pump \\
\hline Sensors \\
\hline \hline Intercoolers \\
\hline \hline Right Intercooler Assembly \\
\hline Cooling System \\
\hline Assembly \\
\hline \hline
\end{tabular}

\begin{tabular}{|c|}
\hline $\begin{array}{c}\text { Table 3.2: Electronic Fuel Injection } \\
\text { Tier O Modifications. }\end{array}$ \\
\hline Component Description \\
\hline Camshaft \\
\hline Right Camshaft End Section \\
\hline Left Camshaft End Section \\
\hline Right Camshaft Mid Section \\
\hline Left Camshaft Mid Section \\
\hline Power Assembly \\
\hline Full Power Assembly \\
\hline Long Power Assembly \\
\hline Short Power Assembly \\
\hline Head Liner Assembly \\
\hline Piston Crown \\
\hline Turbocharger \\
\hline Turbocharger \\
\hline Rotor (Compressor, Turbine Disk, and \\
Shaft) \\
\hline \hline Turbine Disk Assembly \\
\hline Turbine Nozzle Ring \\
\hline Buckets \\
\hline \hline Engine Air System \\
\hline \hline Engine Air (baggy) Filters \\
\hline Fuel System \\
\hline \hline Injector \\
\hline \hline High Pressure Pump \\
\hline Sensors \\
\hline Larometric Pressure Sensor \\
\hline Engine Harness \\
\hline Intercoolers \\
\hline Right Intercooler Assembly \\
\hline Cooling System \\
\hline \hline
\end{tabular}


The testing procedures and data acquisition were identical for all tests in both studies. Gaseous emissions $\left(\mathrm{CO}_{2}, \mathrm{CO}, \mathrm{NO}_{\mathrm{x}}\right.$, and $\left.\mathrm{THC}\right)$, particulate matter emissions (PM), and exhaust opacity data were collected through procedures mandated in CFR 40, Part 92, Subpart B [10]. All engine specifications are listed below in Table 3.3.

\begin{tabular}{|c|c|c|c|c|}
\hline \multicolumn{5}{|c|}{ Table 3.3: Engine Test Specifications } \\
\hline Vehicle & $\begin{array}{c}\text { GE C39-8 } \\
\text { Locomotive }\end{array}$ & $\begin{array}{l}\text { GE D8-40C } \\
\text { Locomotive }\end{array}$ & $\begin{array}{l}\text { GE D9-40C } \\
\text { Locomotive }\end{array}$ & $\begin{array}{c}\text { GE C40-8 } \\
\text { Locomotive }\end{array}$ \\
\hline $\begin{array}{l}\text { Vehicle } \\
\text { Number }\end{array}$ & 8678 & 8692 & 8867 & 8695 \\
\hline $\begin{array}{c}\text { Engine } \\
\text { Manufacture }\end{array}$ & $\begin{array}{l}\text { General } \\
\text { Electric }\end{array}$ & $\begin{array}{l}\text { General } \\
\text { Electric }\end{array}$ & $\begin{array}{l}\text { General } \\
\text { Electric }\end{array}$ & $\begin{array}{l}\text { General } \\
\text { Electric }\end{array}$ \\
\hline Engine Model & 7FDL16L6 & 7FDL16L6 & 7FDL16L6 & 7FDL16L6 \\
\hline $\begin{array}{c}\text { Power Rating } \\
\text { (hp) }\end{array}$ & 3900 & 4000 & 4000 & 4000 \\
\hline Configuration & V-16 & V-16 & V-16 & V-16 \\
\hline Induction & Turbocharged & Turbocharged & Turbocharged & Turbocharged \\
\hline Injection & Direct & Direct & Direct & Direct \\
\hline $\begin{array}{c}\text { Fuel Injection } \\
\text { Control }\end{array}$ & Mechanical & Mechanical & Electronic & Mechanical \\
\hline
\end{tabular}

\subsection{Fuel Injection Timing Study}

This study examined the emission and fuel consumption effects of fuel injection timing of a General Electric C39-8 (Norfolk Southern Locomotive Number 8678) locomotive and a General Electric D8-40C (Norfolk Southern Locomotive Number 8692) locomotive. Both were equipped with a General Electric Model 7FDL16L6 diesel engine. The purpose of these tests was to determine if retarding the fuel injection timing could enable a mechanically fuel injected locomotive to meet EPA standards and still operate with a satisfactory fuel economy. The reason for retarding the fuel injection 
timing is to lower the $\mathrm{NO}_{\mathrm{x}}$ emissions. The problem that results from this is that the fuel economy is reduced and the PM emissions are potentially increased. These problems occur since there is not a complete burn in the cylinder. When all the fuel is not combusted, there is typically an increase in the amount of PM and a decrease in the amount of power that the engine produces. The reduction in fuel economy is directly related to the reduction in power. When an engine's fuel injection timing is retarded and an incomplete burn occurs, it takes more fuel to produce the same amount of power as if the fuel injection timing was not retarded, which leads to a reduction in fuel economy. All gaseous emission $\left(\mathrm{CO}, \mathrm{CO}_{2}, \mathrm{THC}, \mathrm{NO}_{\mathrm{x}}\right)$, particulate matter $(\mathrm{PM})$, and smoke opacity were recorded during each test in accordance to the guidelines in CFR 40, Part 92, Subpart B [10].

The first engine tested was locomotive number 8678 and was equipped with an aftermarket TCM turbocharger. The purpose of the aftermarket turbocharger was to increase the boost pressure to offset any loss in power and fuel economy resulting from retarding the fuel injection timing. Once the baseline run was completed at the stock fuel injection timing of $12^{\circ} \mathrm{BTDC}$, the injection timing was retarded to 11,9 , and $8^{\circ} \mathrm{BTDC}$. After each run, the data was recorded and the injection timing was retarded one degree.

The second engine tested in this study, locomotive number 8692, was equipped with the stock General Electric 1883 turbocharger. The stock fuel injection timing of the locomotive was $12^{\circ} \mathrm{BTDC}$. The tests were completed with a fuel injection timing retarded to $8^{\circ} \mathrm{BTDC}$. 


\subsection{Component Variation Study}

The set of testing in this study measured the exhaust and smoke emissions from two locomotives. The first was a General Electric D9-40C locomotive (Norfolk Southern Locomotive Number 8867) that was equipped with a General Electric Model 7FDL16L6 electronically fuel injected diesel engine. The engine was equipped with a GE 1883 turbocharger for the baseline emissions in this study. All together there were five different configurations of turbochargers and cylinder liners tested on the engine. After each test the engine was taken to the service shop and setup with a different component configuration for the next test. The configurations are listed in Table 3.4.

The second locomotive tested in this study was a General Electric C40-8 locomotive (Norfolk Southern Locomotive Number 8695) that was also equipped with a General Electric Model 7FDL16L6 mechanically fuel injected diesel engine. This engine was equipped with a GE 1869 turbocharger for the baseline emissions. After each test the engine was taken to the service shop and setup with a different turbocharger and retested. There were three test configurations for locomotive 8695, which are listed in Table 3.4.

There were two goals in this study. The first was, of course, to determine if the engines would meet the Tier 0 EPA regulations and the second was to determine how much the emissions might be affected by exchanging the selected components. If it is found that rebuilt turbochargers and used cylinder liners do not negatively impact the emissions or violate the emissions standards, there can be a significant savings in servicing and rebuilding locomotive engines. 


\begin{tabular}{|c|c|c|}
\hline \multicolumn{3}{|c|}{ Table 3.4: Test Configurations } \\
\hline \multirow{2}{*}{ Vehicle Number } & \multicolumn{2}{|c|}{ Configuration } \\
\hline & Turbochargers & Cylinder Liners \\
\hline \multirow{5}{*}{8867} & GE 1883 & New \\
\hline & Hispana Suiza & New \\
\hline & Globe 1883 & New \\
\hline & GE 1883 & Used \\
\hline & Globe 1883 & Used \\
\hline \multirow{3}{*}{8695} & GE 1869 & No Change \\
\hline & Globe 1869 & No Change \\
\hline & Globe 1883 & No Change \\
\hline
\end{tabular}

It should be noted that all Globe turbochargers were General Electric 1883

turbochargers that were rebuilt using Globe components. The only turbocharger components that were changed were the blades, or buckets, in the turbine disks. The turbine disks had four possible combinations of parts. There were two turbine disks, a 64 blade and a 70 blade, in which there were a standard and a high efficiency (EB) type of each. To form the Globe 1883, the GE 1883 turbocharger was fitted with a high efficiency 70 blade turbine disk for the electronic fuel injected locomotive 8867. To form the Globe 1869, the GE 1869 turbocharger was fitted with a standard 60 blade turbine disk for the mechanical fuel injected locomotive 8695. Also, the terms new and used in the table above refers to the design of the cylinder liners. A new design was being tested with respect to an old, or used, design. 


\subsection{Experimental Setup}

In both studies the testing was accomplished by using the West Virginia University Transportable Heavy Duty Emission Testing Laboratory. The testing equipment that was used in Roanoke consisted of an analytical trailer and a constant volume sampler (CVS) blower assembly.

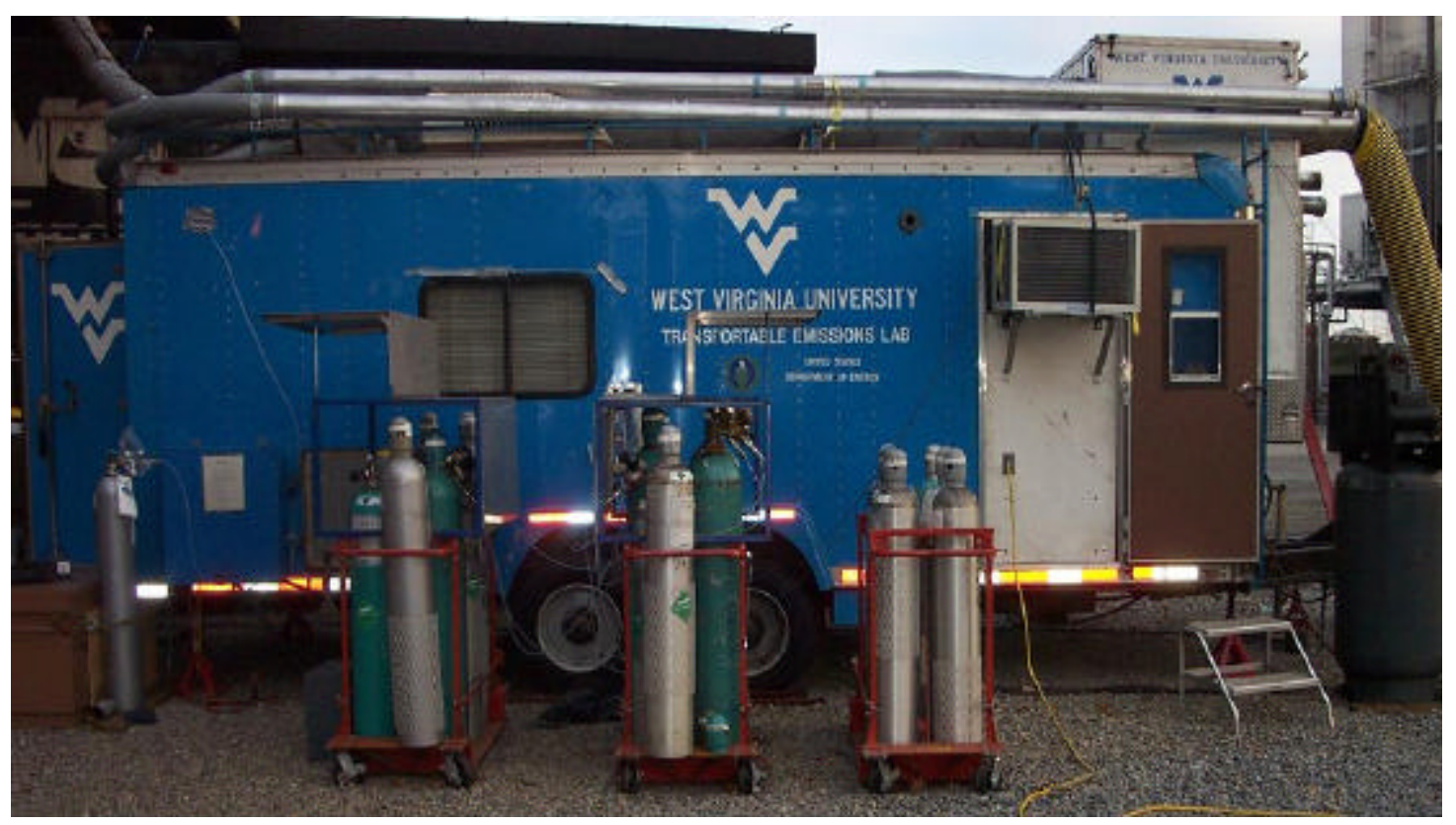

\section{Figure 3.1: Analytical Trailer}

The trailer held all the gaseous emission analyzers and particulate matter sampling system which included a secondary dilution tunnel that will be discussed later in Section 3.7, and an environmental chamber that was used for conditioning the filters before and after they were put into the exhaust stream. The trailer was also fixed with a data acquisition system that was used to control and monitor the test cycles. Gas bottles that were used to calibrate the analyzers were kept just outside the trailer. Mounted to the top of the trailer was an exhaust dilution tunnel that used the ambient air to dilute the raw exhaust coming from the engine. 
Normally when testing over the road truck and buses, all the exhaust that is produced by the vehicle's engine is drawn through the dilution tunnel. Since a locomotive produces such a large quantity of exhaust, only a partial sample was taken. A partial sample can be taken provided that the ratio of raw sample volume to diluted sample volume is determined for systems that determine mass emission rates in grams per hour from measured fuel flow rates. This was accomplished by mounting a fixture to the top of the locomotive stack that had a two inch diameter probe mounted in the exhaust stream. The fixture was also equipped with the smoke opacity meter assembly that will be discussed later.

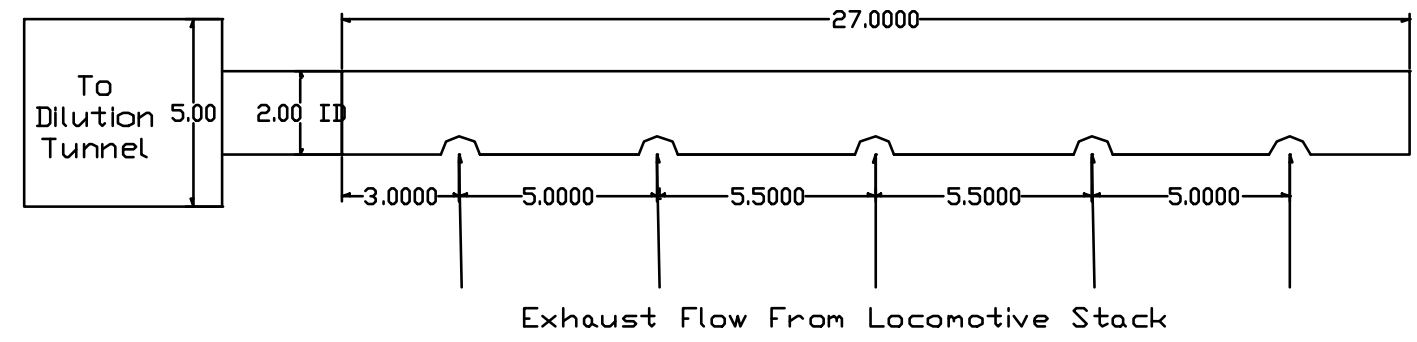

\section{Figure 3.2: $\quad$ Sampling Probe}

The probe was used to draw the proper amount of raw exhaust from the exhaust stream through a series of holes in the probe. All dimensions of the probe met the guidelines set forth in the CFR [10]. The dilution tunnel was fixed with a manifold that sealed the tunnel so that there would be enough suction at the probe to draw enough raw exhaust through the tunnel. The manifold also allowed the amount of dilution air that the tunnel could draw in to be varied until the correct amount was found. The correct 
amount of dilution air was needed so that acceptable analyzer ranges could be obtained.

To find the correct amount of dilution air, the raw exhaust emissions were measured and compared to the diluted exhaust. The measurement procedures are discussed in Section 3.10 of this document. The raw exhaust to diluted exhaust ratio was adjusted by adjusting the amount of dilution air until the correct amount of dilution air was determined. The system that was used is shown in Figure 3.3 and a detailed schematic is given in Figure 3.4 and Figure 3.5.
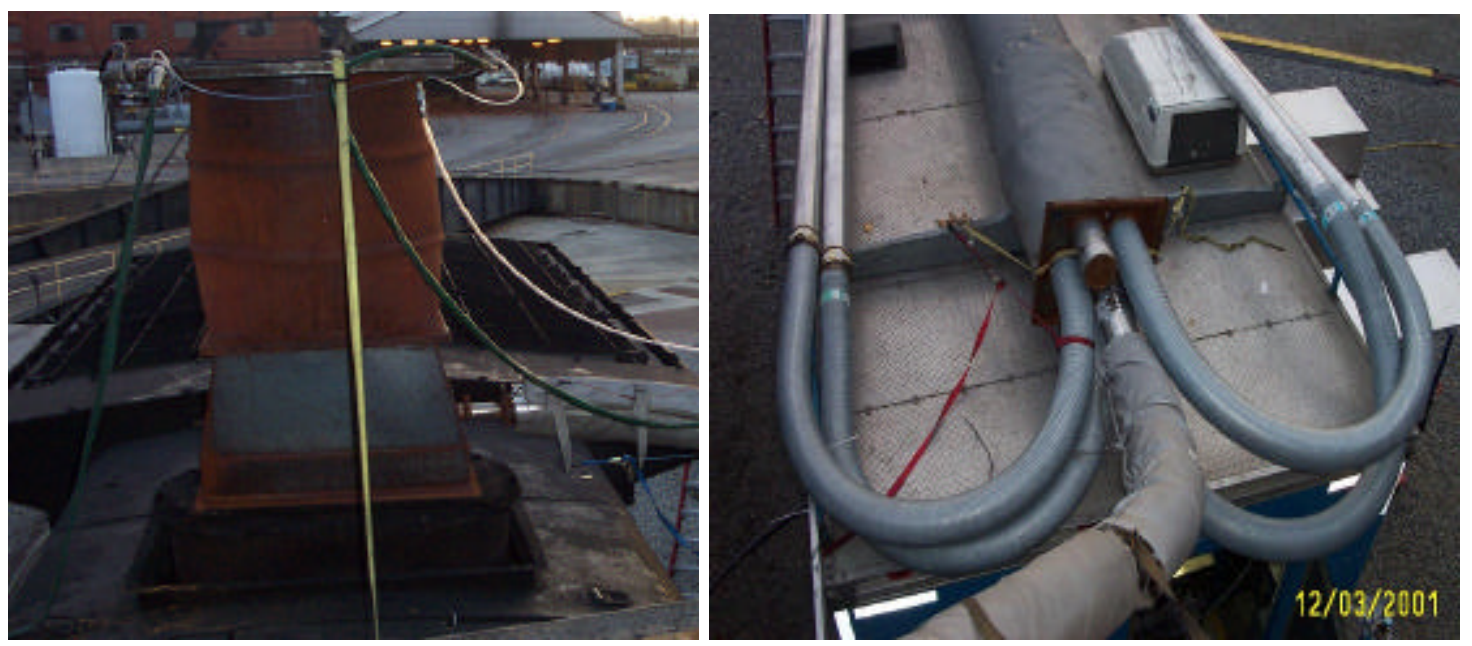

Figure 3.3: Partial Exhaust Sampling System

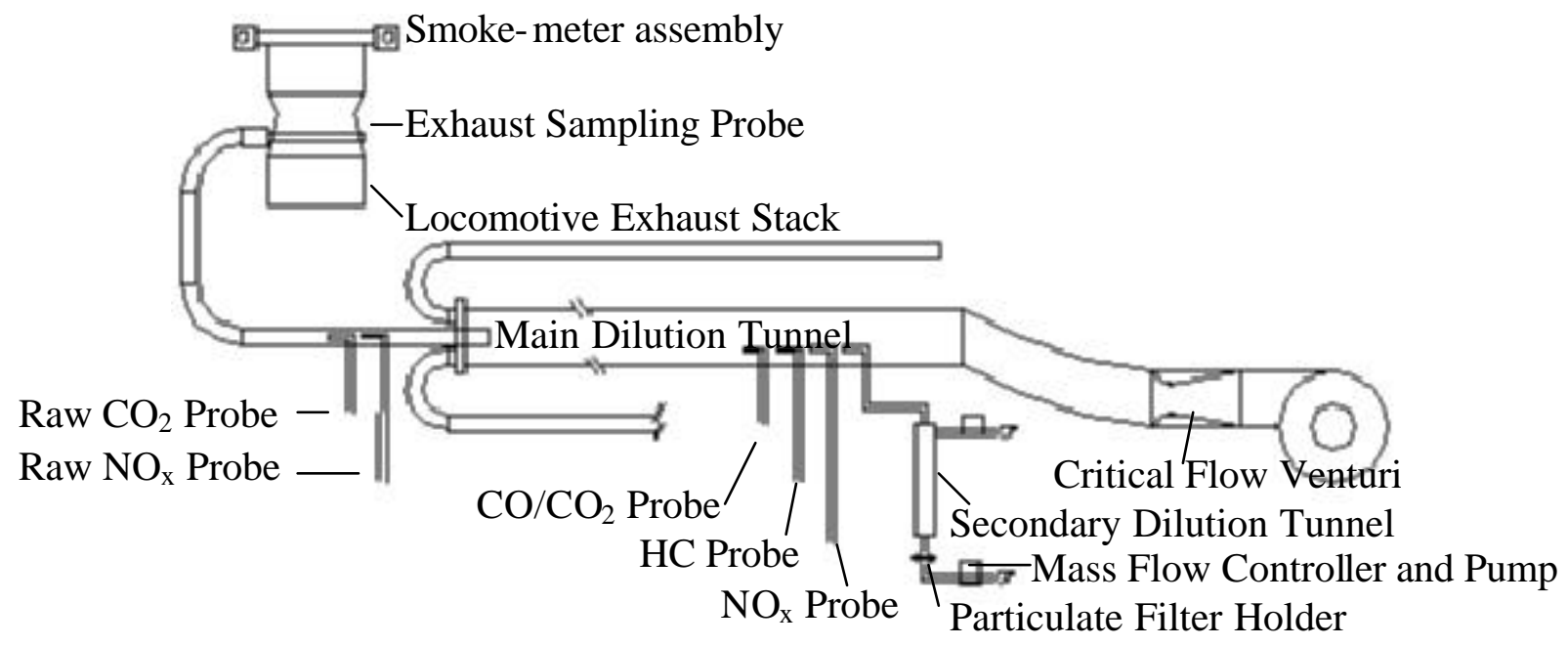

Figure 3.4: Schematic of Partial Exhaust Sampling System 


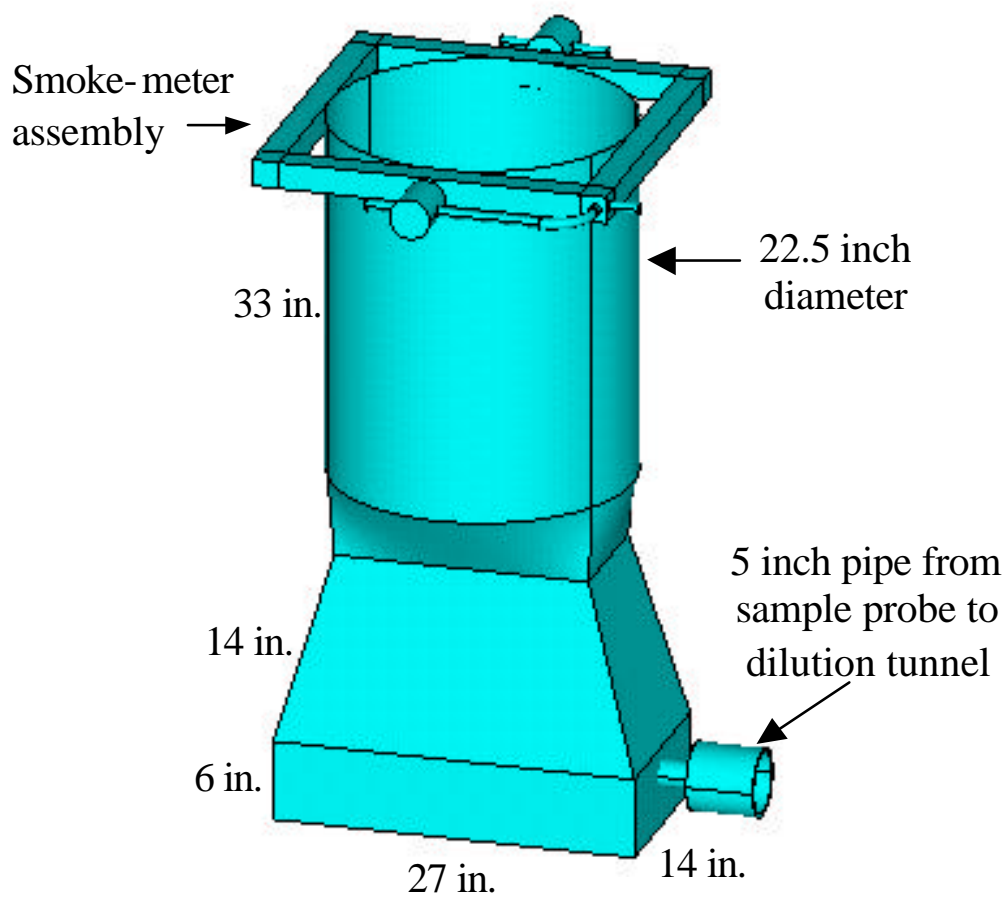

Figure 3.5: $\quad$ Exhaust Stack Fixture

The load was applied to the locomotives by two different methods in these studies. In the first study, both locomotives were loaded through an external bank of resisters that was kept on the test site and operated by Norfolk Southern. In the second study the locomotives were loaded through their own internal resister bank. Since the locomotives in both studies were hybrid-electric, it was relatively simple to load the engines. The resister banks, internal or external, simply absorbed the power that the generator produced. After an interview with the Norfolk Southern locomotive operator, it was determined that a simulated load of a sixty-five mile per hour wind was applied to the locomotive. Since locomotives are constant horsepower machines, there was no need to simulate a load that would be applied by the train that the locomotive was transporting. 


\subsection{Fuel Measuring System}

The CFR mandates that a locomotive's fuel supply must be disconnected and a system that can measure the net rate of fuel supplied to the engine installed when measuring emissions [10]. Therefore a fuel monitoring system was used in both studies. The 4000 gallon fuel tank of the locomotive was filled and was used as a reservoir to fill the monitoring system. The system consisted of tank that held 470lbs of fuel, an eight gallon per minute pump to refill the tank, a Drake Refrigeration, model PAC6052-T4$\mathrm{HA}$, five ton chiller that kept the fuel between 60 and $70^{\circ} \mathrm{F}$ as mandated in the CFR [10]. The fuel temperature was maintained with R22 refrigerant as the cooling agent within the chiller.

In the cab of the locomotive there was a Weigh-Tronix WI.130 monitor that had a continuous digital read-out of the weight of the fuel in the tank. At the end of each notch, the amount of fuel that was used was recorded and the tank was refilled. There was also a Cooper Instruments Corp. model SH66A Electro-therm Mult Probe Temperature Tester that was used to monitor the fuel, engine intake manifold, and ambient temperatures.

\subsection{Exhaust Dilution Tunnel}

The lab was set up so that when the exhaust left the locomotive a partial sample was drawn through an exhaust dilution tunnel where it was diluted with the ambient air. This was to mimic the effects on the exhaust that would normally be seen due to atmospheric conditions. There are multiple reasons to dilute the exhaust. One reason is to allow any in- use exhaust-air interactions to take place. Another reason is to quench post-cylinder combustion reactions and lower the exhaust gas dew point. In lowering the 
dew point, condensation which can harm the analyzers and measurement errors associated with soluble emissions is kept from occurring.

Once the raw emissions were diluted, the sample was analyzed through a system of analyzers. The raw exhaust emissions were also measured through a slightly different system. The measurement systems are discussed later in Section 3.10.

There are two types of dilution tunnels that can be used when measuring heavy duty diesel engine emissions. They are critical flow venturi constant volume sampler (CFV-CVS) or a positive displacement pump constant volume sampler (PDP-CVS) as stated in the CFR $[9,10]$. West Virginia University used the CFV-CVS type dilution system. In this system, a critical flow venturi, that will be discussed later, is used to draw the exhaust through the main dilution tunnel. When the flow through the venturi reaches a choked condition, a constant mass flow rate is maintained in the dilution tunnel.

Choked flow is the maximum mass flow rate that can pass through a given throat [21]. The choked condition occurs when the flow reaches sonic conditions. When this occurs, the flow rate through the venturi becomes a function of the throat diameter and pressure, and the upstream gas temperature.

The stainless steel tunnel measured twenty feet long with a diameter of eighteen inches. The raw exhaust and dilution air were mixed at an eight inch diameter mixing orifice that was three feet downstream of the tunnel opening. The orifice created a turbulent flow in the flow path within the tunnel that promoted thorough mixing. There were three sample probes at the sampling plane. Their tips were six inches into the tunnel where they were oriented with the opening upstream toward the entrance of the tunnel. The sampling plane in the tunnel was ten diameters, which is 180 inches, 
downstream of the mixing orifice to ensure that there was adequate mixing of the exhaust and the dilution air. The mixture was drawn through the tunnel by means of a blower that is shown in Figure 3.6.

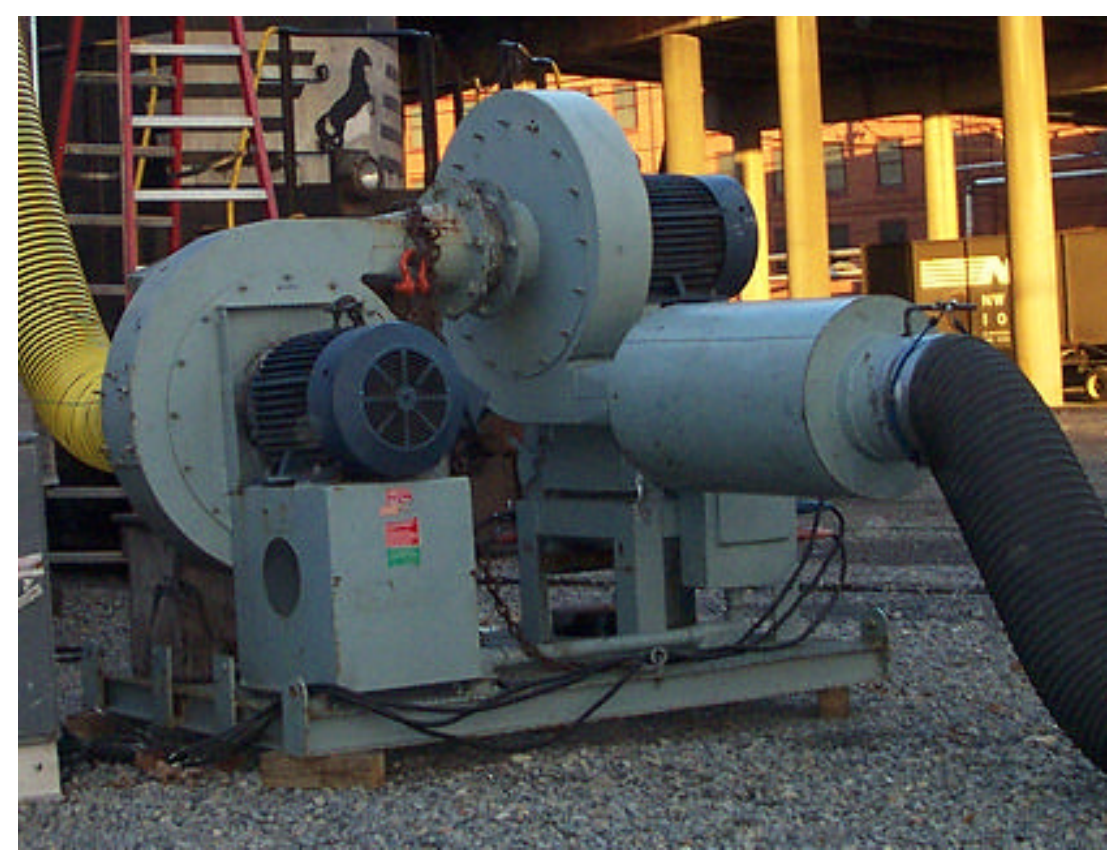

Figure 3.6: Blower Setup

The blower drew the mixture through a critical flow venturi. The venturi could be changed to allow nominal dilution flow rates of 1000, 1500, 2000, 2500, and 3000 SCFM. There are multiple reasons the venturi may be changed to increase or decrease the flow. The first is to keep the exhaust temperature at a minimum of $235^{\circ} \mathrm{F}$ at the sampling plane and another depends on the amount of exhaust the vehicle can produce. Another reason is to help bring an analyzer into range. If the emissions are out of the range of the analyzer, the flow through the tunnel can be changed to dilute or enrich the exhaust so that an accurate reading can be obtained. Also, the exhaust can be managed to maintain the particulate filter face temperature below $125^{\circ} \mathrm{F}$ which is mandated in the CFR $[9,10]$. 
Another reason for changing the venturi is to prevent water from condensing on the inside of the tunnel and the sampling probes that transfer the exhaust to the analyzers. Since there is a temperature range in which water will condensate in the tunnel, the flow through the tunnel can be maintained so that the temperature inside the tunnel does not reach the condensation temperature.

\section{7 $\quad$ Secondary Dilution Tunnel}

There are two systems that are available for measuring particulate matter emissions according to the CFR $[9,10]$ : a single dilution and double dilution system. In both systems the filter face temperature must be maintained below $125^{\circ} \mathrm{F}$, which is mandated in the CFR 40, Part 86, Subpart N and Part 92, Subpart B [9, 10]. In the single dilution system the tunnel must be able to draw enough background (ambient) air to keep the filter temperature less than $125^{\circ} \mathrm{F}$.

West Virginia University used the secondary dilution system, in which there was a secondary dilution tunnel that was mounted in the sampling plane. The primary reason for a secondary tunnel is to add extra dilution air to the mixture to keep the filter face temperature under $125^{\circ} \mathrm{F}$. The secondary dilution tunnel is controlled to prevent condensation and thermophoresis from occurring. Thermophoresis is the tendency of particles which are suspended in a fluid in which there is a thermal gradient, to move down the gradient in the direction of the cooler fluid. Therefore, a temperature is maintained in the tunnel to prevent particles from traveling through the tunnel and being deposited on places that is not the particulate filter. The filter face temperature must be maintained below $125^{\circ} \mathrm{F}$ to prevent any volatile fractions of the particulate matter form being lost in the sampling process. 
The secondary tunnel and the filter holders were made of stainless steel to prevent any reactions from occurring due to the corrosive nature of certain exhaust samples. The tunnel measured three inches in diameter and spanned a length of thirty-six inches. These dimensions gave the exhaust in the tunnel sufficient time for mixing and cooling due to the addition of the extra dilution air. For the locomotive testing, secondary air was not required because sufficient cooling of the sample was accomplished through primary dilution and heat transfer from the secondary tunnel walls.

One of the main advantages in using the secondary dilution method is that the re is more control over the amount of dilution air that is added to the mixture. The dilute air can easily be controlled with a mass flow controller. The ideal case is to have enough dilution air to keep the filter at the correct temperature, but if there is too much dilute air there may not be enough of the exhaust to get an accurate particulate matter reading, and an error will result in the filter weight measurement. If there is too little dilution air, the filter temperature will exceed $125^{\circ} \mathrm{F}$ obviously run to high which may alter the sample deposited on the filter. The PM consists of elemental carbon, sulfates, soluble organic fractions (SOF), engine wear materials, and bound water. If the temperature rises above $125^{\circ} \mathrm{F}$, some of the PM constituents may burn or evaporate which will result in an incorrect PM measurement.

\subsection{Particulate Sampling}

Particulate samples were taken at the end of the secondary dilution tunnel. The filters used to trap the sample were two Pallflex (T6OA2D) seventy millimeter fluorocarbon coated fiberglass filters that were held in a primary / secondary series within the fixture. The filters were held in a stainless steel fixture that was mounted to the 
tunnel with a quick disconnect for easy access between tests. The efficiency rating of the filters is over ninety-nine percent on $0.5 \mu \mathrm{m}$ particles. The flow over the filters was controlled with a set of mass flow controllers. One of the controllers was used to control the dilution air that was being added into the secondary tunnel and the other controller was used to control the flow that was drawn across the filters. The sample flow can by varied between zero and six SCFM. The sample and secondary air flow through the secondary dilution tunnel are adjusted to maintain proportionality to the flow in the main tunnel.

The filters were conditioned through the use of an environmental chamber before they were used in a test. The atmosphere inside the chamber was kept constant. The relative humidity inside the chamber was maintained at fifty percent with a tolerance of plus or minus five percent. The temperature in the chamber was maintained at $70^{\circ} \mathrm{F}$ with a tolerance of $\pm 10^{\circ} \mathrm{F}$. The filters were conditioned for a minimum of eight hours before and after the test were run to ensure that the pre-test and post-test filter conditions were the same. There were two sets of filters that were used throughout a day of testing. One set was obviously for an actual test cycle that the locomotive ran through, and the other was the background set.

The background filters were used to sample the ambient particulate levels. All the filters were weighed using a Cahn C-32 microbalance mounted in a vibration isolation chamber. The balance had a sensitivity of 0.01 micrograms. The balance also had a maximum capacity of three and a half grams with three weight ranges.

There was a background run completed at the beginning and end of each day of testing. Once the runs were completed and the filter weights were recorded, the 
background filter weights were used to correct the test filter weights that were taken during the cycles. The calculations of particulate emissions were specified in CFR 40, Part 92, Subpart B [10]. The equations that were used for calculating the corrected particulate matter is as follows:

$$
\begin{gathered}
\text { Equation 7: } M_{P M}=W V O L^{*} P M_{c o n c}(1+D F)+\left(\frac{V_{\text {mix }} P M_{c o n c}}{V_{f}}\right) \\
\text { Equation 8: } \quad \mathrm{PM}_{\text {conc }}=\frac{\mathrm{M}_{\mathrm{PMe}} * 10^{3}}{\mathrm{~V}_{\text {sampe }}}-\frac{\mathrm{M}_{\mathrm{PMd}} * 10^{3}}{\mathrm{~V}_{\text {sampd }}}(1-(1 / \mathrm{DF}))
\end{gathered}
$$

where $\mathrm{M}_{\mathrm{PM}}$ is the mass of the particulate emitted per test phase, WVOL is the total exhaust flow rate on a wet basis in $\mathrm{ft}^{3} / \mathrm{hr}, \mathrm{V}_{\text {mix }}$ is the total dilute exhaust volumetric flow rate in $\mathrm{ft}^{3} / \mathrm{hr}$ corrected to standard conditions, $\mathrm{V}_{\mathrm{f}}$ is the fraction of the total raw exhaust that is diluted, $\mathrm{PM}_{\mathrm{conc}}$ is the particulate concentration of the diluted exhaust sample corrected for background in $\mathrm{g} / \mathrm{ft}^{3}, \mathrm{M}_{\mathrm{PMe}}$ is the measured mass of particulate for the exhaust sample, in $\mathrm{mg}, \mathrm{M}_{\mathrm{PMd}}$ is the measured mass of particulate for the dilution air sample in $\mathrm{mg}, \mathrm{V}_{\text {sampe }}$ is the total wet volume of sample removed from the dilution tunnel for the exhaust particulate measurement in cubic feet at standard conditions, $\mathrm{V}_{\text {sampd }}$ is the total wet volume of sample removed from the dilution tunnel for the dilution air particulate measurement in cubic feet at standard conditions, DF is the dilution factor, which is the volumetric ratio of the dilution air to the raw exhaust sample. The dilution factor is calculated through Equation 9.

$$
\text { Equation 9: } D F=\frac{W C O_{2}-C O_{2 D}}{C O_{2 E}-C O_{2 D}}-1
$$


where $\mathrm{DF}$ is the dilution factor, $\mathrm{WCO}_{2}$ is the raw carbon dioxide concentration in the exhaust, $\mathrm{CO}_{2 \mathrm{E}}$ is the carbon dioxide concentration of the exhaust, and $\mathrm{CO}_{2 \mathrm{D}}$ is the carbon dioxide concentration of the dilution air.

\subsection{Bag Sampling}

When the test cycles were running the exhaust and dilute sample was pumped into two separate bag samples. The bags were eighty liter Telder bags that were held over the analysis bench. Once the test was complete, the bag samples were run through the analyzers and the data was collected. Once the data was collected, the bags were evacuated for the next run. The background bag data was then used to correct the continuo us data recorded during the test. The dilute bag serves as a check of the continuously measured emissions.

\subsection{Gaseous Emissions Sampling System}

The analyzers were held in gas analysis benches. The benches held the analyzers and their pumps which drew the mixture of exhaust and dilution air through the analyzers. From the sampling plane in the main tunnel, the sample was drawn through heated probes and heated sample lines to the analyzers where concentrations were measured and recorded. There were two benches that stored the analyzers. The first was the main bench where diluted gaseous emissions were measured. The analyzers within the bench were: oxides of nitrogen $\left(\mathrm{NO}_{\mathrm{x}}\right)$, carbon monoxide $(\mathrm{CO})$, carbon dioxide $\left(\mathrm{CO}_{2}\right)$, and there was a separate analyzer that was used to measure the hydrocarbon (HC). It was kept separate from the bench due to the $375^{\circ} \mathrm{F}$ oven that was part of the analyzer. Another bench, shown in Figure 3.7, was used to measure the raw gaseous emissions. 


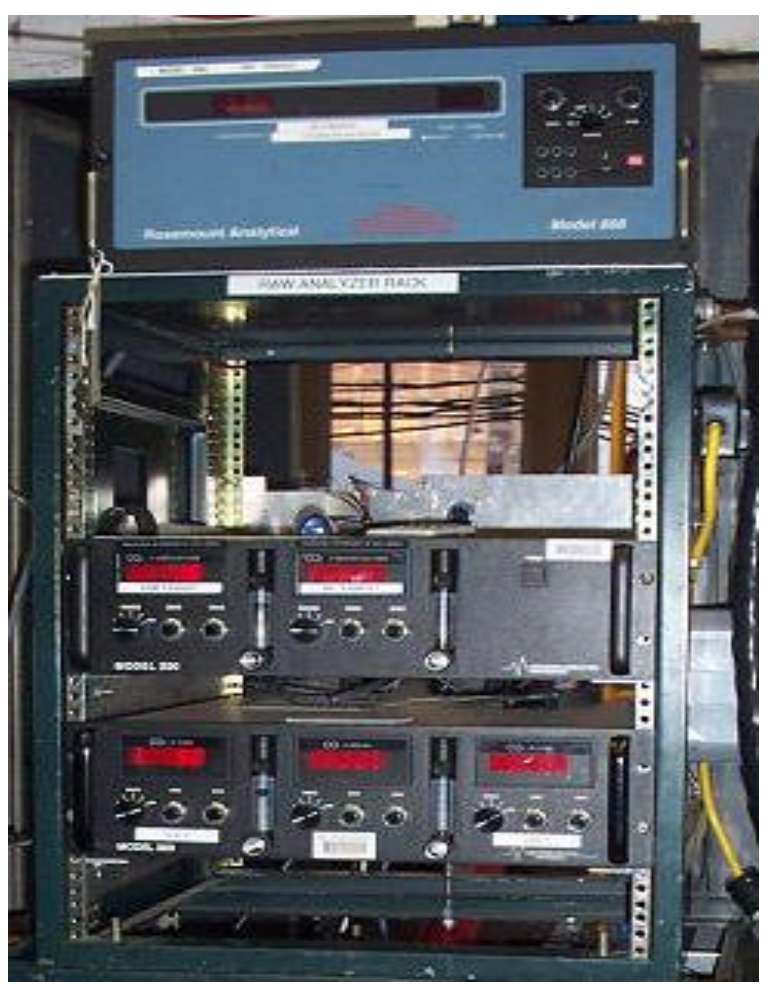

Figure 3.7: Raw Gaseous Analyze r Bench

In the first study, this bench held a raw oxides of nitrogen $\left(\mathrm{NO}_{\mathrm{x}}\right)$, and a raw carbon dioxide $\left(\mathrm{CO}_{2}\right)$ analyzer. In the second study, the bench held two raw carbon dioxide $\left(\mathrm{CO}_{2}\right)$ analyzers. The raw exhaust was transferred through a heated line to a thermoelectric chiller and then to the analyzers. Once the raw and diluted emissions were recorded, they were used to compute the dilution factor. The raw and diluted analyzers were the same types; they simply sampled the exhaust from different locations. All the analyzers had a probe in the exhaust stream. Between the probe and the analyzer was a heated line that was kept at a constant temperature by means of a temperature controller. The HC sample probe and line was kept at a constant $375^{\circ} \mathrm{F}$ to prevent higher molecular weight hydrocarbons for condensing on the surface of the sample lines during the test. The $\mathrm{CO}, \mathrm{CO}_{2}$, and $\mathrm{NO}_{\mathrm{x}}$ lines were heated to $235^{\circ} \mathrm{F}$ to keep any condensation from occurring that could travel into the analyzer and prevent an accurate measurement from 
being taken. There was also an air dryer for an added precaution to keep any condensation out of the $\mathrm{CO}$ and $\mathrm{CO}_{2}$ analyzers.

There are certain emissions that are measured on a dry basis and certain emissions that are measured on a wet basis. They are considered wet or dry depending on if there is any water in the flows when they are measured. The emissions of $\mathrm{NO}_{\mathrm{x}}, \mathrm{HC}$, and $\mathrm{PM}$ are said to be measured on a wet basis since they are not dried before they are measured by their analyzers. The emissions of $\mathrm{CO}$ and $\mathrm{CO}_{2}$ are said to be measured on a dry basis because they pass through a dryer that is used to eliminate any water that may be in the flow which will disrupt the analyzing process. The CFR states that emissions that are measured on a dry basis must be corrected to a wet basis before they can be used in any calculations $[9,10]$. The correction equation is given below in Equation 10.

$$
\text { Equation 10: } W V o l=\frac{V_{m} W_{f}}{C M W_{f}\left(W H C / 10^{6}+W C O / 10^{6}\right) W C O_{2} / 100}
$$

where WVol is the total exhaust flow-rate on a wet basis, $\mathrm{V}_{\mathrm{m}}$ is the volume of one mole of gas at standard temperature and pressure in $\mathrm{ft}^{3} /$ mole, $\mathrm{W}_{\mathrm{f}}$ is the mass flow-rate of fuel used in the engine in grams per hour, $\mathrm{CMW}_{\mathrm{f}}$ is the molecular weight of the fuel per carbon atom, $\mathrm{WCO}$ is the percent wet concentration of $\mathrm{CO}$ in the exhaust, $\mathrm{WCO}_{2}$ is the percent wet concentration of $\mathrm{CO}_{2}$ in the exhaust, and $\mathrm{WHC}$ is the $\mathrm{HC}$ percent wet concentration in the exhaust [10].

\subsubsection{Oxides of Nitrogen $\left(\mathrm{NO}_{\mathbf{x}}\right)$ Analyzer}

The $\mathrm{NO}_{\mathrm{x}}$ analyzer that was used in the analysis bench was a California Analytical model 400-HCLD chemiluminescent analyzer. The mixture was drawn to the analyzer through a $235^{\circ} \mathrm{F}$ heated line by a heated pump equipped with a heated filter to catch any 
particulate matter that may be in the mixture. The line was heated to prevent water from condensing in the line. If any water was allowed to get into the analyzer it could react with the $\mathrm{NO}_{\mathrm{x}}$, since the nitric oxide (NO) component of $\mathrm{NO}_{\mathrm{x}}$ is soluble in water, resulting in a lower reading than what actually occurred. The analyzer had two modes. The first mode was the nitric oxide (NO) mode and the second was a combined mode to form the $\mathrm{NO}_{\mathrm{x}}$ mode. The $\mathrm{NO}_{\mathrm{x}}$ mode is a combined mode because it measures the quantity of $\mathrm{NO}$ plus $\mathrm{NO}_{2}$. The method of chemiluminescent detection is the basis of the analyzer's operation. In the nitric oxide mode the $\mathrm{NO}$ sample is converted into $\mathrm{NO}_{2}$ by gas phase oxidation with molecular ozone produced within the analyzer from air or oxygen supplied by an external source. A characteristic of this reaction is the elevation of approximately ten percent of the $\mathrm{NO}_{2}$ molecules to an electrically excited state which is followed by an immediate reversion to the non-excited state accompanied by an emission of photons. The photons impinge on a photomultiplier detector, generating a low level direct current that is then amplified to drive a front-panel meter and an analog voltage output. When the analyzer is set in the combined mode to measure $\mathrm{NO}_{\mathrm{x}}$, the detection method is the same. The only difference in the modes is that when in the $\mathrm{NO}_{\mathrm{x}}$ mode, the $\mathrm{NO}_{2}$ in the exhaust sample is converted to NO before the mixture enters the reaction chamber within the analyzer. There was also a Beckman Industrial $\mathrm{NO}_{\mathrm{x}}$ efficiency tester that is used to measure the overall efficiency of the internal converter in the $\mathrm{NO}_{\mathrm{x}}$ analyzer, which is maintained at ninety-eight percent or above [37]. In compliance to the CFR, $\mathrm{NO}_{\mathrm{x}}$ emission rates are to be adjusted for the affects of temperature and humidity [10]. The correction factors are expressed in Equation 4 and Equation 7 respectively. However, the correction factor for the temperature was problematic and therefore was not used. The 
correction factor is intended to compensate for the effect of intake air temperatures at or below $30^{\circ} \mathrm{C}$. This is where the problem lies. The ambient temperatures during testing were lower than $30^{\circ} \mathrm{C}$. As a result the temperature correction factor, $\mathrm{K}_{\mathrm{T}}$ was maintained at unity. This resulted in overall $\mathrm{NO}_{\mathrm{x}}$ correction factors that were comparable to the correction factors determined from the guidelines in CFR 40, Part 92, Subpart B [10]. The humidity and temperature correction factors are given in Equations 11 through Equation 14.

$$
\text { Equation 11: } K_{H}=\left[\frac{\mathrm{C} 1+\mathrm{C} 2 * \exp (-0.0143 * 10.714)}{\mathrm{C} 1+\mathrm{C} 2 * \exp (-0.0143 * 1000 \mathrm{H})}\right]
$$

where $\mathrm{K}_{\mathrm{H}}$ is the humidity correction factor, and $\mathrm{H}$ is the specific humidity on a dry basis of the intake air.

$$
\text { Equation 12: } C_{1}=-8.7+164.5 \exp \left(-0.0218(\mathrm{~A} / \mathrm{F})_{\text {wet }}\right)
$$$$
\text { Equation 13: } C_{2}=130.7+3941 \exp \left(-0.0248(\mathrm{~A} / \mathrm{F})_{\text {wet }}\right)
$$

where $C_{1}$ and $C_{2}$ constants based on the air fuel ratio, and $(A / F)_{\text {wet }}$ is the air-fuel ratio on a wet basis.

$$
\text { Equation 14: } K_{T}=\frac{1}{1-0.017\left(\mathrm{~T}_{30}-\mathrm{T}_{\mathrm{A}}\right)}
$$

where $\mathrm{K}_{\mathrm{T}}$ is the temperature correction for tests conducted at ambient temperatures below $30{ }^{\circ} \mathrm{C}\left(\mathrm{K}_{\mathrm{T}}\right.$ is one for tests conducted at ambient temperatures at or above $\left.30{ }^{\circ} \mathrm{C}\right), \mathrm{T}_{30}$ is the measured intake manifold air temperature in the locomotive when operated at $30{ }^{\circ} \mathrm{C}$ (or $100{ }^{\circ} \mathrm{C}$, where intake manifold air temperature is not available), and $\mathrm{T}_{\mathrm{A}}$ is the 
measured intake manifold air temperature in the locomotive as tested (or the ambient temperature $\left({ }^{\circ} \mathrm{C}\right)$, where intake manifold air temperature is not available) [10].

\subsubsection{Carbon Monoxide (CO) Analyzer}

The analysis bench held two CO analyzers; one was for low CO concentrations and the other for high $\mathrm{CO}$ concentrations. The reason for two analyzers is that $\mathrm{CO}$ from diesel engines can vary widely during transient operation. By having two, the range of the emission can essentially be divided into two parts. One analyzer can record the high range and the other analyzer can record the low range of the emission. This allows a more accurate measurement to be made with much less error involved. The CO analyzers had the exhaust gas drawn from the main tunnel at the sampling plane. The gas was drawn from a heated probe through a heated line at $235^{\circ} \mathrm{F}$ to a heated pump and a heated filter to catch any particulate matter. The difference in the $\mathrm{CO}$ and the $\mathrm{NO}_{\mathrm{x}}$ analyzers was that the gas going to the $\mathrm{CO}$ analyzers was not only drawn through a heated line to prevent condensation from the mixture, but was also run through a Hankinson refrigerator/dryer to remove any water. The main problem with water in the $\mathrm{CO}$ analyzers was that it could absorb the infrared light that was used to read the sample, causing an error in measurement. To make sure that the refrigerator/dryer was always working properly, water interference checks were run on a periodic basis, according to procedures outlined in the CFR 40, Part 92 [10].

The high CO analyzer was a Beckman Industrial Non-Dispersive Infrared (NDIR) analyzer model 868 analyzer. The analyzer had a range of 0-5000 ppm. The NDIR detector used the principle of selective absorption. Selective absorption is the process in 
which the infrared energy of a particular wavelength, specific to that gas, would be absorbed by that gas. By this method, certain gases correspond to certain wavelengths in the infrared energy band. For the absorption of $\mathrm{CO}$, the wavelength range is 4.5 to 5 microns. Infrared energy of other wavelengths would pass through the gas just as other gases do not absorb wavelengths in the band absorbed by CO. The analyzer produced two equal energy infrared beams and the two beams passed through two parallel optical cells. One optical cell contained a continuous flowing sample and the other contained a sealed reference gas and was tuned for the wavelength of the CO. The difference between the two readings was the measure of the concentration of $\mathrm{CO}$ in the sample [14].

The low CO analyzer was a Horiba AIA-210LE NDIR analyzer. The range of the analyzer was 0-200 ppm. The concentration of the $\mathrm{CO}$ was able to be measured by the continuous change in the infrared absorption. The infrared light was converted to intermittent light by a chopper which was simply a motor that turned a propeller. The light then traveled though a measurement cell and then into a Luft detector cell. There was a difference of intensity that was produced between the two beams that enter the detector cell when some of the infrared light was absorbed as it passed through the sample cell. The difference of intensity caused a vibration in the detector cell. An electric output was generated by the changes in capacity between the electrodes for the membrane. To detect the $\mathrm{CO}$, the components in the detector cell were sealed under fixed conditions. The specific infrared wavelength for $\mathrm{CO}$ was the only wavelength that was absorbed. This allowed a change in the infrared absorption that the $\mathrm{CO}$ caused and allowed the $\mathrm{CO}$ concentration to be detected [14]. Although both analyzers were used to 
record data, the $\mathrm{CO}$ concentration was well within the range of the low $\mathrm{CO}$ analyzer. Therefore the high $\mathrm{CO}$ data was not used in the calculations.

\subsubsection{Carbon Dioxide $\left(\mathrm{CO}_{2}\right)$ Analyzer}

The $\mathrm{CO}_{2}$ analyzer was a California Analytical Instruments model 300 analyzer. This analyzer used the same method of measurement as the $\mathrm{CO}$ analyzers. It also had a heated line of $235^{\circ} \mathrm{F}$ and an air dryer for the same reason as the $\mathrm{CO}$ analyzer. The primary difference between the analyzers was that the $\mathrm{CO}_{2}$ analyzer had the reference cell tuned from 4 to 4.5 microns instead of 4.5 to 5 microns as for $\mathrm{CO}$ [14].

\subsubsection{Hydrocarbon (HC) Analyzer}

The HC analyzer was a Rosemount Analytical model 402 heated flame ionization detector (HFID), which had a range was 1-5000 ppm. The diluted gas was directed to the analyzer through a heated line at a constant temperature of $375^{\circ} \mathrm{F}$. The heated line was there for the purpose of preventing the loss of heavy hydrocarbons due to condensation. The method in which the analysis was completed was extremely sensitive. It was based on the flame ionization of the hydrocarbon components that were contained in the diluted exhaust gases. Regulated amounts of fuel and hydrocarbon free air were used to sustain a flame that the sample gas passed through when it was analyzed. The fuel used by the analyzer was a mixture of forty percent hydrogen and sixty percent helium. While the sample gas passed through the flame, the hydrocarbon components underwent an ionization process that produced positive ions and electrons. The ions were then collected by polarized electrodes causing current flow through a measuring circuitry that was located within the electronic unit. The current that was caused by the ionization was 
proportional to the rate at which the carbon atoms entered the flame. This allowed a measurement of hydrocarbons in the original sample to be acquired [35].

\subsubsection{Sample Gaseous Calculation}

The CFR defines how to reduce the gaseous data and calculate the mass emissions form the engine. All the gases follow basically the same equation for calculating the mass. For example, the calculation for the mass of $\mathrm{NO}_{\mathrm{x}}$ is as follows:

$$
\text { Equation 15: } M_{N O_{x}}=V_{m i x} \rho_{N O_{2}}\left[\frac{N O_{x e}-N O_{x d}}{V_{f} * 10^{6}}\right](1-1 / D F)
$$

where $\mathrm{M}_{\mathrm{NOx}}$ is the oxides of nitrogen emissions in grams per hour by mode, $\mathrm{V}_{\text {mix }}$ is the total dilute volume corrected to standard conditions, $\rho_{\mathrm{NO} 2}$ is the density of oxides of nitrogen assuming they are in the form of nitrogen dioxides at standard conditions, $\mathrm{NO}_{\mathrm{xe}}$ is the concentration of the oxides of nitrogen in the dilute exhaust bag sample in ppm, $\mathrm{NO}_{\mathrm{xd}}$ is the concentration of the oxides of nitrogen in the dilution air sample in ppm, $\mathrm{V}_{\mathrm{f}}$ is the fraction of the total raw exhaust that is diluted, and DF is the dilution factor which was calculated in Equation 2.

The only change in the calculation is for $\mathrm{CO}$ and $\mathrm{CO}_{2}$. These concentrations are corrected to a wet basis before their mass emissions are calculated.

\subsection{Data Acquisition}

The WVU Transportable Laboratory data acquisition system consisted of a main computer, vehicle driver monitor, control and data acquisition hardware, signal conditioning modules, and a data reduction computer. The main computer was used to control all parts of the test. This includes the analyzer and instrument calibration, test execution and data acquisition. 
Once the test cycle was loaded and the program was executed, a real time trace of the cycle and all continuous emissions were displayed on a monitor where the field engineer could monitor the progress of the test. Although it is not required in locomotive testing, the signal was sent to a driver monitor that was mounted in the locomotive. It was used to allow the engineer to monitor the test cycle to allow any problem to be determined from within the locomotive cab as well.

As the test was running, and the data was being collected, the control and data acquisition hardware was controlling and recording all the necessary information. The system was made up of two signal processing boards, and numerous signal conditioning modules. RTI-815 signal processing boards and Analog Devices 3B signal conditioning modules carried all signals from the analyzers and transducers. The RTI- 815 boards converted all the signals into ADC codes and recorded them on the main computer. Once they were on the main computer, they were sent to the reduction computer.

The reduction computer was used to perform all the post-test analysis. This involved integration of the results and a graphical analysis of the test results. The conversion from ADC codes to engineering units was also completed with the reduction computer [14].

\subsection{Smoke Opacity Meter}

The smoke opacity was measured with a Celesco Berkeley Model 107 In-Line smoke meter at a collection frequency of ten hertz. 


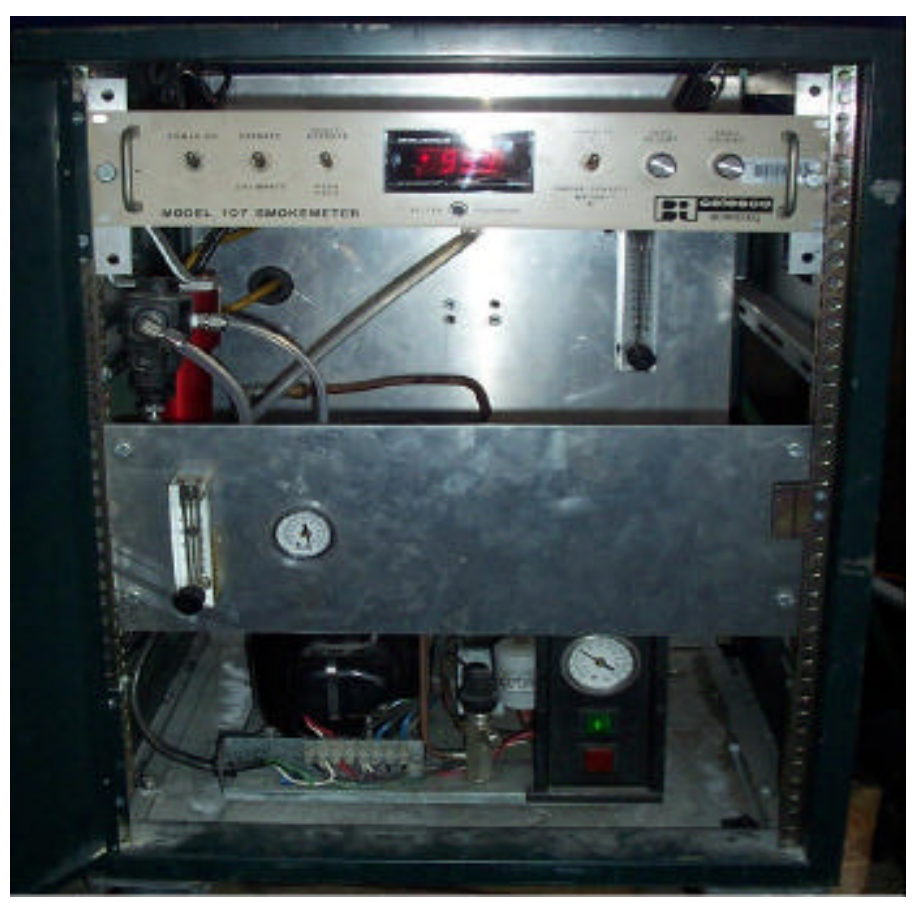

Figure 3.8: Smoke Meter

The smoke meter produced an infrared light which traveled through the exhaust stream where was deflected. The lenses were held in an assembly that was mounted to the top of the exhaust stack fixture. The lens assemblies were equipped with an air and water line. The air was used to keep any PM from being deposited on the lens and the water was used to keep the lens assemblies from over heating. The water jacket around the stack was fabricated from two inch square steel tubing. The lens assembly is shown in Figure 3.9. 


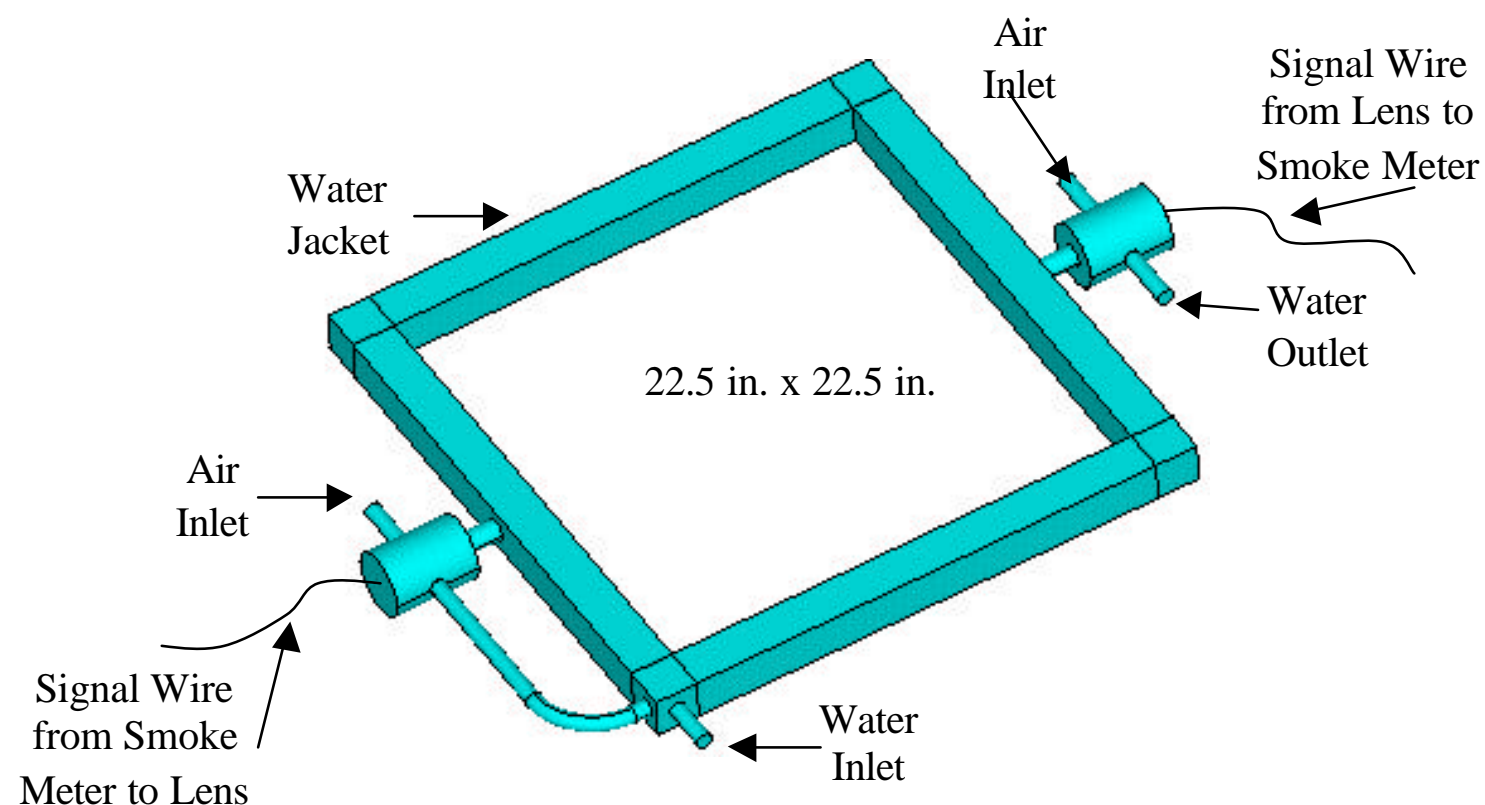

Figure 3.9: Smoke Meter Lens Assembly

The amount of light that was deflected in the exhaust stream resulted in a drop in light transmittance. Once the drop had been measured, it was converted to an opacity value by the control unit. The unit used Lambert's equation to convert the measurement of light intensity to a smoke density. The equation is stated:

$$
\text { Equation 16: } I / I_{0}=e^{-n a Q L}
$$

where $\mathrm{I}$ is the emitted light intensity, $\mathrm{I}_{0}$ is the received light intensity, $\mathrm{n}$ is the number density of particles, a is the average particle projected area, Q is the average particle extinction coefficient, and $\mathrm{L}$ is the light beam path length within the smoke.

Once the intensity was calculated, it was used to find the opacity. The opacity equation is defined as:

$$
\text { Equation 17: } N=\left(1-I / I_{0}\right) * 100
$$

where $\mathrm{N}$ is the smoke opacity and $\mathrm{I} / \mathrm{I}_{0}$ is the intensity. 
The smoke density could then be determined from the equation:

Equation 18: $K=(-1 / L) * \operatorname{Ln}(1-N / 100)$

where $\mathrm{K}$ is the smoke density, $\mathrm{L}$ is the light beam path length within the smoke, and $\mathrm{N}$ is the opacity.

The unit was calibrated to measure opacity within a four inch diameter pipe. This means that the opacity needed to be normalized. The normalized opacity was calculated from the equation:

$$
\text { Equation 19: } N_{n}=100 *\left[1-\left[1-N_{m} / 100\right]^{1 / L}\right]
$$

where $\mathrm{N}_{\mathrm{n}}$ is the normalized percent opacity, $\mathrm{N}_{\mathrm{m}}$ is the average measured percent opacity, and $\mathrm{L}$ is the actual distance in meters from the point at which the light beam enters the exhaust plume to the point at which the light beam leaves the exhaust plume.

The opacity scale had a range of zero to 100 percent. Zero being the equivalent of no visible opacity and 100 being the equivalent of total blackness. In addition to the instrumentation, there also was a water and air line attached that was used to keep any extreme temperatures from damaging the instrumentation [9]. 


\section{Chapter 4 Results}

\subsection{Introduction}

The results from the two studies are given in this section. The studies consisted of four locomotives, two in the first and two in the second. The testing procedures and data acquisition were identical for all tests in both studies. Gaseous emissions $\left(\mathrm{CO}_{2}, \mathrm{CO}\right.$, $\mathrm{NO}_{\mathrm{x}}$, and THC), particulate matter emissions (PM), and exhaust opacity data were collected through procedures mandated in CFR 40, Part 92, Subpart B [10].

\subsection{Emissions and Smoke Opacity Results}

The emissions were measured and calculated following the guidelines stated in CFR 40, Part 92, Subpart B [10]. The weighted values given in the figures are those of the line haul and switch modes that were calculated by summing the notch emissions multiplied by their weighting factor. The weighting factors are listed in Table 4. 1. Once the values were computed, they were compared with the standards mandated in the CFR. The emission values are given in brake specific units of grams per brake-horsepower hour.

The EPA also subjects locomotives to deterioration factors that are used to reflect locomotive engine family's emissions through its life [12]. CFR 40, Part 92, Subpart C states that the deterioration factors are to be determined using good engineering practice to assure that locomotives or locomotive engines will meet the emission standards in actual use for the useful life of the locomotive or locomotive engine. The factors become a new set of standards that are applied to a locomotive engine family in which the engines must comply throughout their useful lives. This allows locomotive engine manufactures to certify a family of engines to the same standards. Determination of deterioration 
factors is left to the engine manufacturer or emissions certificate holder. Therefore, GE has determined a set deterioration factors for the 7FDL Tier 0 EFI engine family. There is also a set of deterioration factors that were formed for the 7FDL Tier 0 MFI engine family that was not obtained by WVU. GE also has chosen to certify the 7FDL Tier 0 EFI engine family to lower $\mathrm{NO}_{\mathrm{x}}$ emission standards. The alternative $\mathrm{NO}_{\mathrm{x}}$ Family Emission Limit is $9.0 \mathrm{~g} / \mathrm{bhp}$ - $\mathrm{hr}$ for the line-haul cycle and $11.9 \mathrm{~g} / \mathrm{bhp}$-hr for the switch cycle. The EPA standard for the line-haul and switch cycle is 9.5 and $14.0 \mathrm{~g} / \mathrm{bhp}-\mathrm{hr}$, respectively. The deterioration factors with respect to exhaust emission are given in Table 4.2, and the low mileage standards that are calculated from the deterioration factors are given in Table 4.3.

The smoke opacity measurements were measured and normalized following the guidelines stated in CFR 40, Part 92, Subpart B [10]. The opacity must be normalized to compensate for the difference in the path length of the smoke meter light beam. The smoke meter that was used was designed to measure the opacity of exhaust flowing through a four inch diameter pipe. This normalization must be applied due to the fact that a twenty-two and a quarter inch diameter exhaust pipe was needed to mount to the stack of the locomotive. 


\begin{tabular}{|c|c|c|}
\hline \multicolumn{2}{|c|}{ Table 4.1: Emissions Weighting Factors } \\
\hline Notch & Line Haul & Switch \\
\hline \hline low idle & 0.19 & 0.299 \\
\hline normal idle & 0.19 & 0.299 \\
\hline Dynamic Brake & 0.125 & 0 \\
\hline Notch 1 & 0.065 & 0.124 \\
\hline Notch 2 & 0.065 & 0.123 \\
\hline Notch 3 & 0.052 & 0.058 \\
\hline Notch 4 & 0.044 & 0.036 \\
\hline Notch 5 & 0.038 & 0.036 \\
\hline Notch 6 & 0.039 & 0.015 \\
\hline Notch 7 & 0.03 & 0.002 \\
\hline \hline Notch 8/7 & 0 & 0 \\
\hline Notch 8 & 0.162 & 0.008 \\
\hline
\end{tabular}

\begin{tabular}{|c|c|c|}
\hline \multicolumn{2}{|c|}{$\begin{array}{c}\text { Table 4.2: Deterioration Factors for 7FDL Tier O EFI } \\
\text { Engine Family as Determined by General Electric }\end{array}$} \\
\hline Emission & Line-Haul & Switch \\
\hline HC & 0.21 & 0.24 \\
\hline \hline CO & 0.7 & 1.3 \\
\hline \hline NO & 1.2 & 1.5 \\
\hline PM & 0.26 & 0.28 \\
\hline \hline \multicolumn{3}{|c|}{ Smoke Opacity } \\
\hline Steady-State & $11.7 \%$ \\
\hline 30 Sec. Peak & $19.8 \%$ \\
\hline \hline 3 Sec. Peak & $22.7 \%$ \\
\hline
\end{tabular}




\begin{tabular}{|c|c|c|}
\hline \begin{tabular}{|} 
Table 4.3: Low Mileage Standards for 7FDL Tier 0 EFI \\
Engine Family as Determined by General Electric
\end{tabular} \\
\hline Emission & Line-Haul & Switch \\
\hline HC & 0.79 & 1.86 \\
\hline CO & 4.3 & 6.7 \\
\hline NO x $_{\mathbf{x}}$ & 7.8 & 10.4 \\
\hline \hline PM & 0.34 & 0.44 \\
\hline Smoke Opacity \\
\hline Steady-State & $18.3 \%$ \\
\hline 30 Sec. Peak & $20.2 \%$ \\
\hline 3 Sec. Peak & $27.3 \%$ \\
\hline
\end{tabular}

\section{3 Fuel Injection Timing Study Results}

\subsubsection{Objective}

The locomotives tested in this study were a four-stroke mechanically fuel injected General Electric C39-8 locomotive (Norfolk Southern Engine Number 8678) and a fourstroke mechanically fuel injected General Electric D8-40C locomotive (Norfolk Southern Engine Number 8692) respectively. Both were equipped with a General Electric Model 7FDL16L6 diesel engine that was equipped with a turbocharger. The emission effects of fuel injection timing on emissions were investigated. The purpose of these tests was to determine if the mechanically injected locomotives could meet EPA standards and still operate with a satisfactory fuel economy when the fuel injection timing was retarded. The main differences in the two locomotives was that locomotive 8678 was equipped with an aftermarket TCM turbocharger and locomotive 8692 was equipped with a stock GE 1883 turbocharger.

The first locomotive tested, 8678, was equipped with a TCM turbocharger to increase the boost pressure to help offset any losses resulting from retarding the fuel 
injection timing. With a baseline test run at the stock fuel injection timing of $12^{\circ} \mathrm{BTDC}$, the injection timing was retarded to 11,9 , and $8^{\circ} \mathrm{BTDC}$ and tested respectively.

The second locomotive tested in this study, 8692, was equipped with the stock General Electric 1883 turbocharger. The fuel injection timing was retarded to 8 degrees BTDC and the tests were completed.

\subsubsection{Gaseous and Particulate Emissions Results}

The emissions per notch mode for locomotive 8678 are shown in Figure 4.1 through Figure 4.4, and the weighted emissions locomotive 8692 are shown in Figure 4.6. The fuel economy for locomotive 8678 and locomotive 8692 is shown in Figure 4.5 and Figure 4.7, respectively. As seen in Figure 4.5, there was little or no effect on fuel consumption. A detailed listing of all gaseous emissions is given in Appendix A.

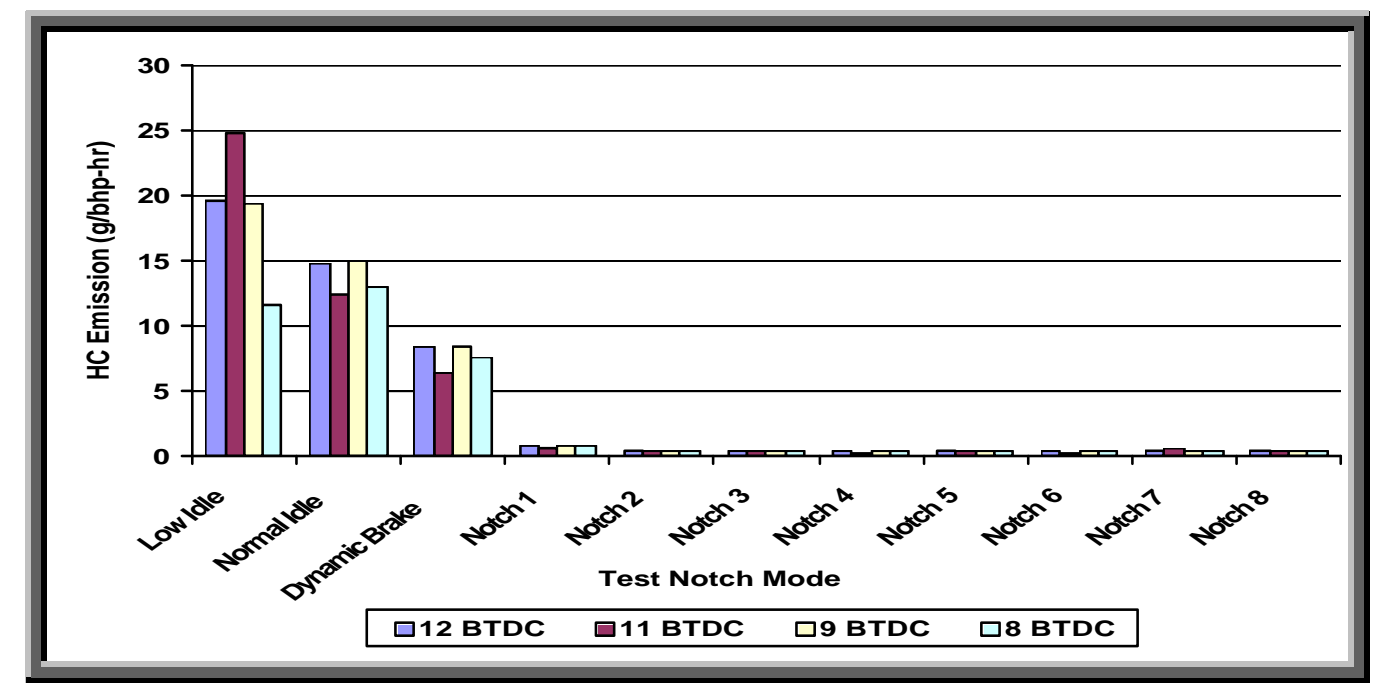

Figure 4.1: Brake-Specific Hydrocarbons Emissions for Locomotive 8678

It is seen in Figure 4.1 that there was no significant difference in the $\mathrm{HC}$ emissions in the notch modes. There was a difference in the lower modes of operation. The $\mathrm{HC}$ emission in low idle increased when the fuel injection timing was set to $11^{\circ} \mathrm{BTDC}$. The only setting to lower the $\mathrm{HC}$ emissions in every test was $8^{\circ} \mathrm{BTDC}$. 


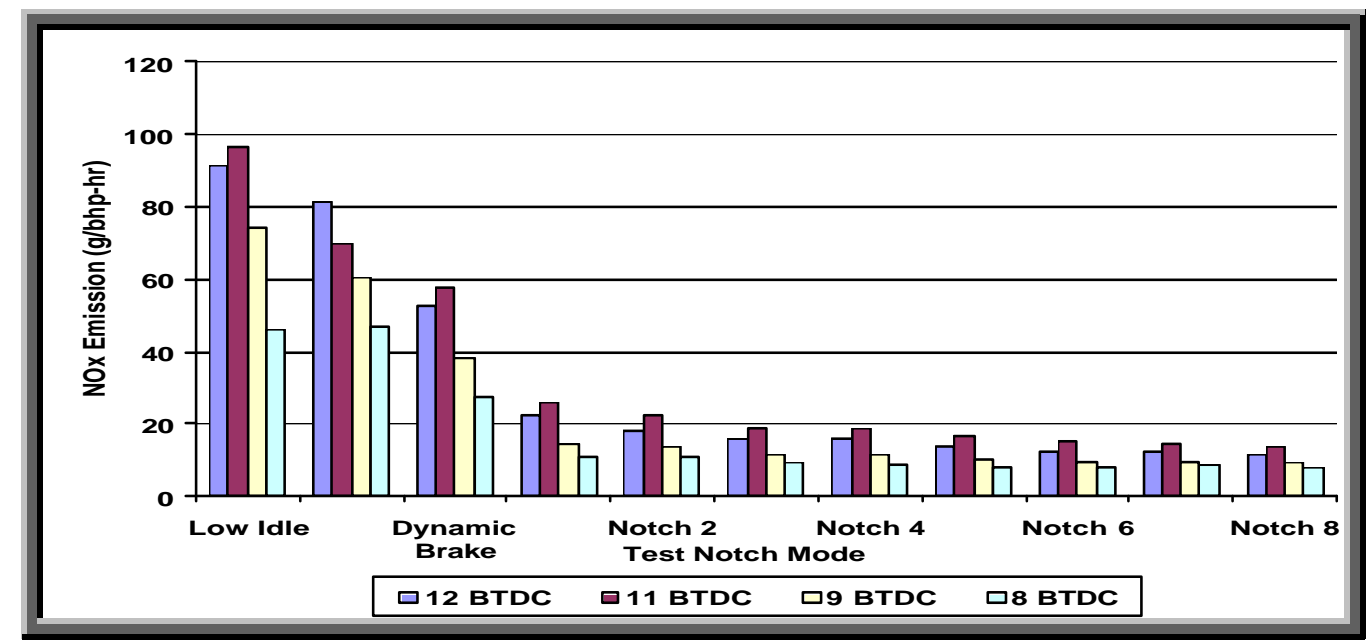

Figure 4.2: Brake-Specific Oxides of Nitrogen Emissions for Locomotive 8678

Figure 4.2 shows a trend in $\mathrm{NO}_{\mathrm{x}}$ production. With the exception of the normal idle mode, the emission follows the same trend throughout the modes of operation with $11^{\circ} \mathrm{BTDC}$ being the highest and $8^{\circ} \mathrm{BTDC}$ is the lowest.

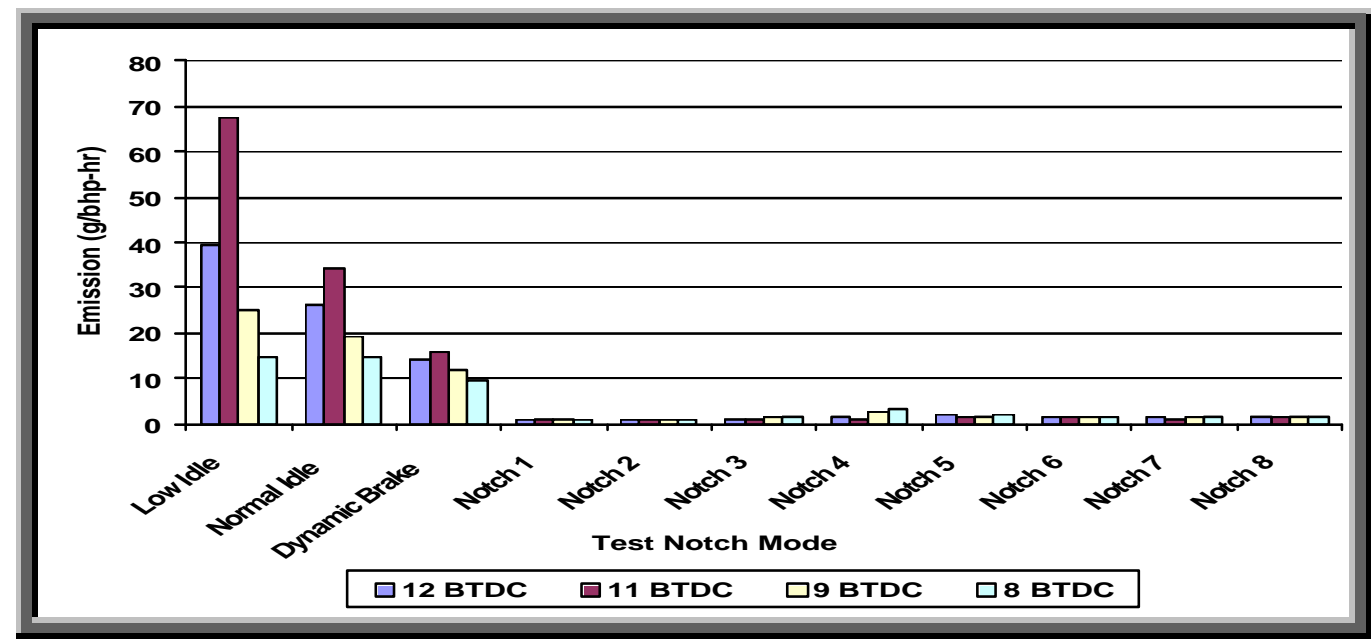

Figure 4.3: Brake-Specific Carbon Monoxide Emissions for Locomotive 8678

As seen in Figure 4.3, the effects of retarding the fuel injection timing are not beneficial in the notch modes. However, there is a significant decrease in $\mathrm{CO}$ with respect to baseline emissions in the lower modes of operation. 


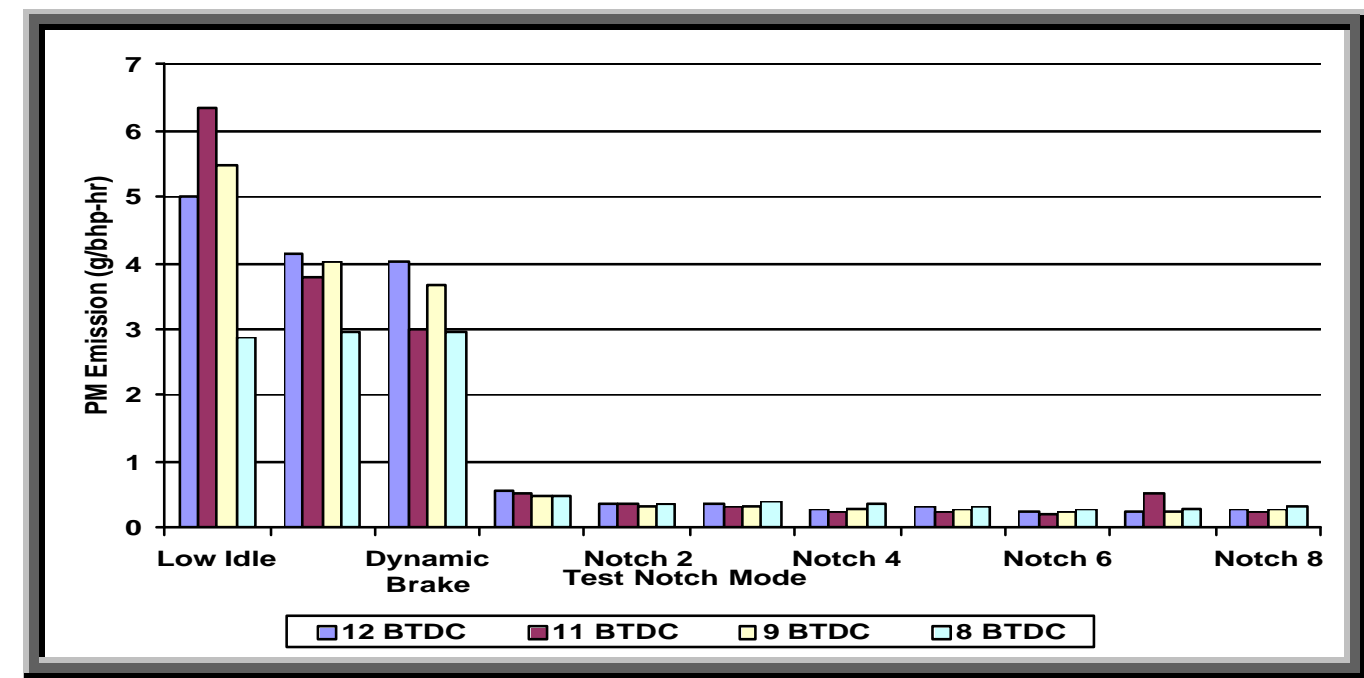

Figure 4.4: Brake-Specific Particulate Emissions for Locomotive 8678

Figure 4.4 shows that there may be a significant difference in PM emissions in the lower modes of operation, but there is no benefit in emissions in the notch modes due to retarded fuel injection timing. The trend seen in the figure is unexpected since PM typically increases when the fuel injection timing is retarded.

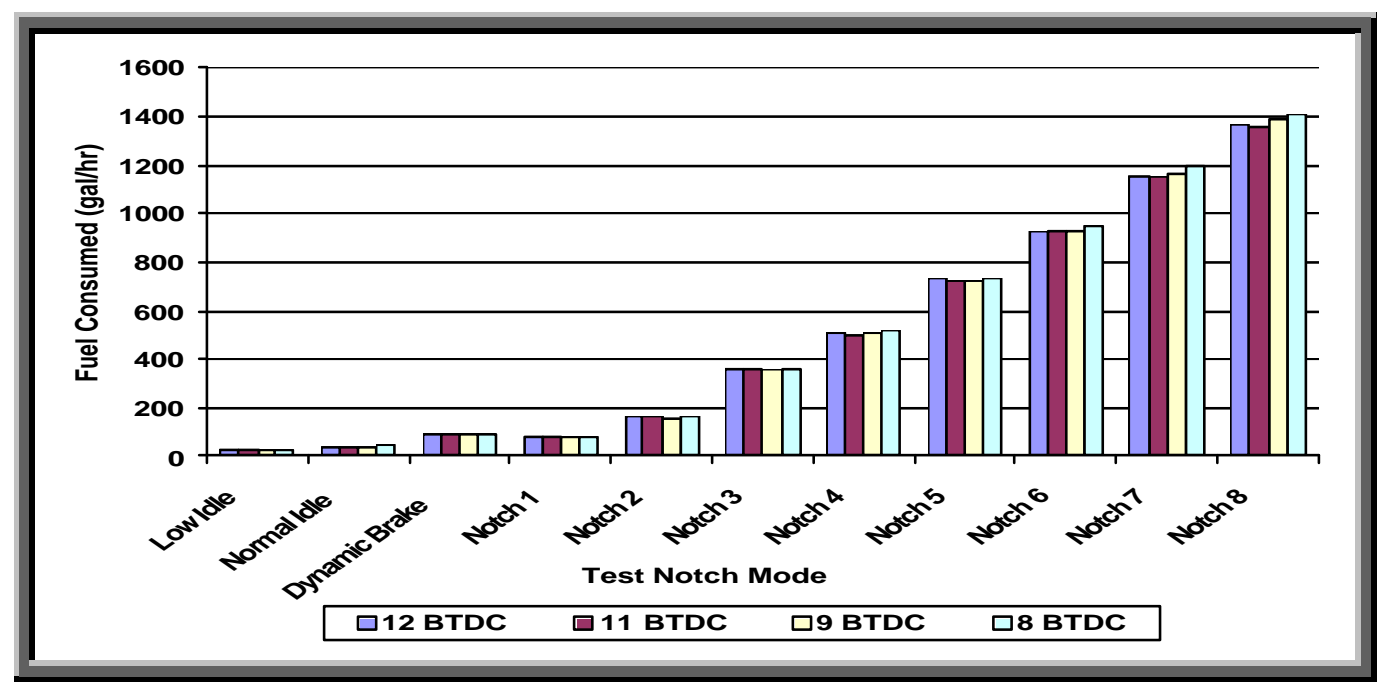

Figure 4.5: Fuel Economy Results for Locomotive 8678

The fuel economy results that are shown in Figure 4.5 show that there is no significant loss in fuel economy due to retarded fuel injection timing. 
Figure 4.6 shows the weighted emissions of locomotive 8692. The locomotive was only tested to determine if it was possible for the engine to produce emissions that were lower than that of the standards set forth by the EPA. The figure shows that the locomotive passed all standards listed in CFR 40. It should be noted that deterioration factors have not been taken into account for the mechanically fuel injected locomotive.

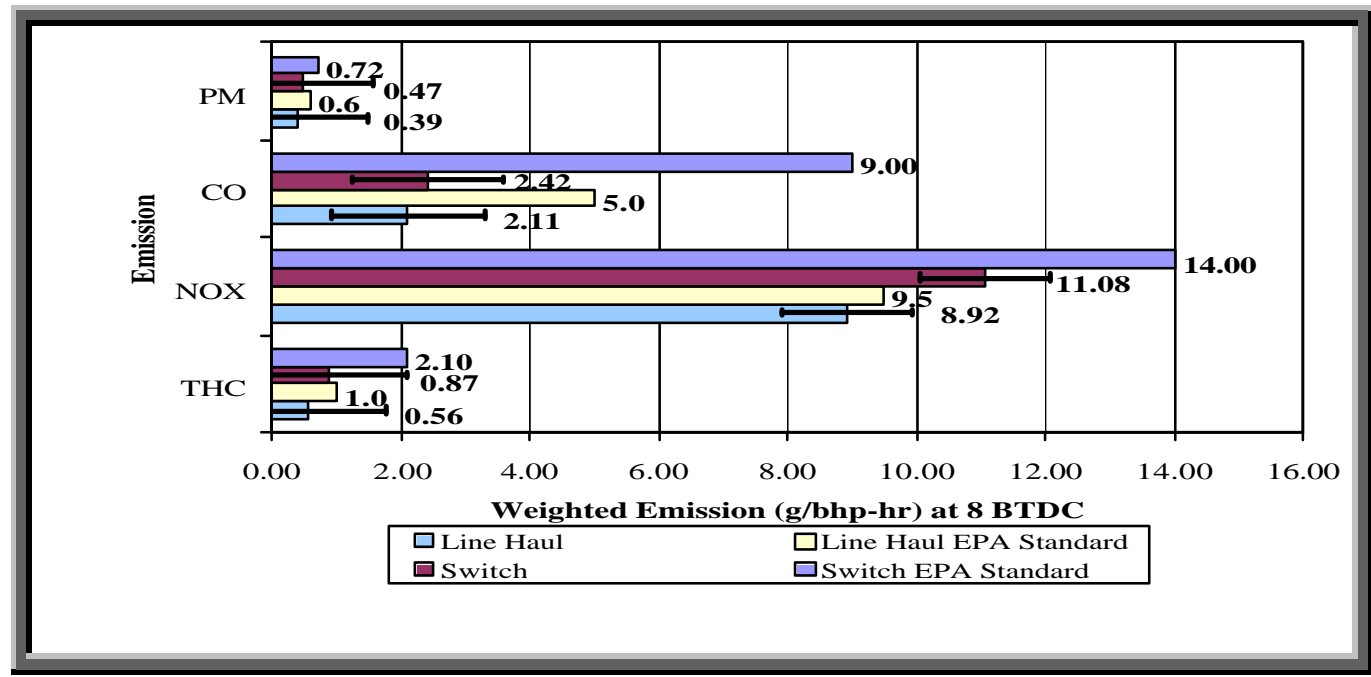

Figure 4.6: Weighted Emissions for Locomotive 8692

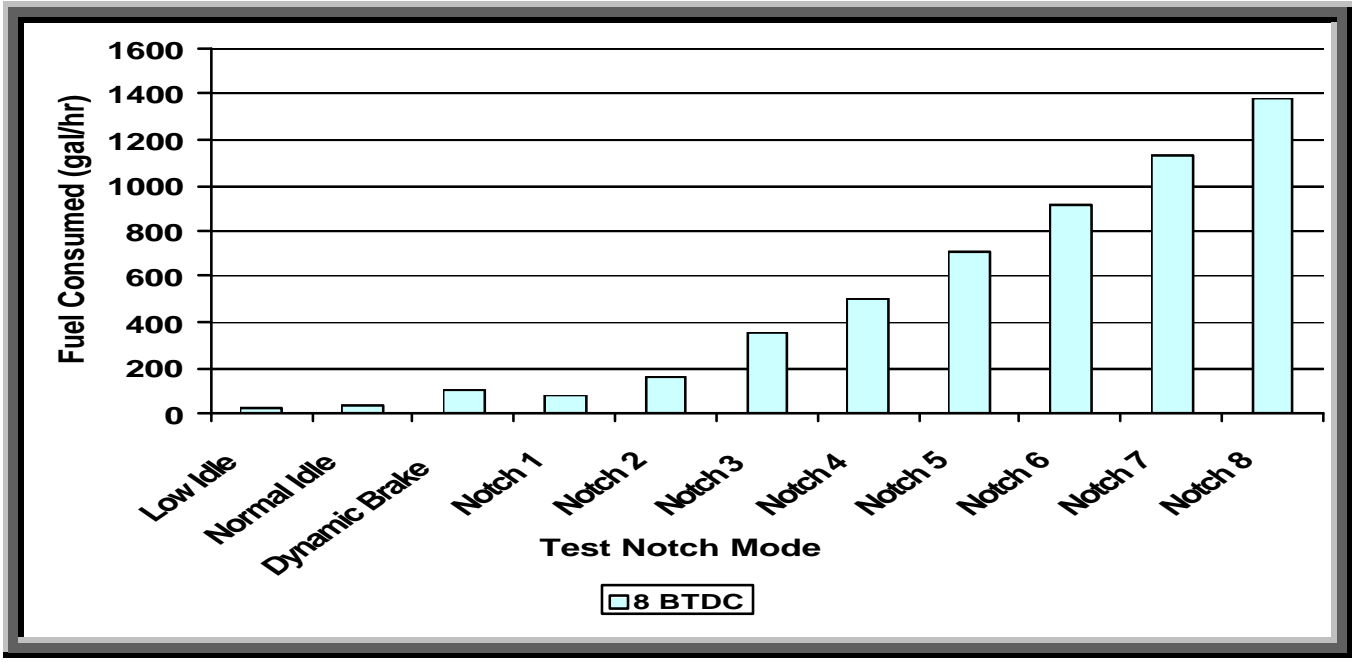

Figure 4.7: Fuel Economy Results for Locomotive 8692

Locomotive 8692 proved to have reasonable fuel economy results after the retarding of the fuel injection timing. 
Figures 4.8 through 4.10 show the trends that were found between $\mathrm{NO}_{\mathrm{x}}$ and $\mathrm{PM}$, smoke opacity and PM, and PM and CO, respectively. The graphs show that PM, smoke opacity and $\mathrm{CO}$ follow the same trends as expected. Figure 4.8 shows that NOx and PM also followed the same trend. This is unusual since PM and NOx typically display opposing trends as the fuel injection is retarded.

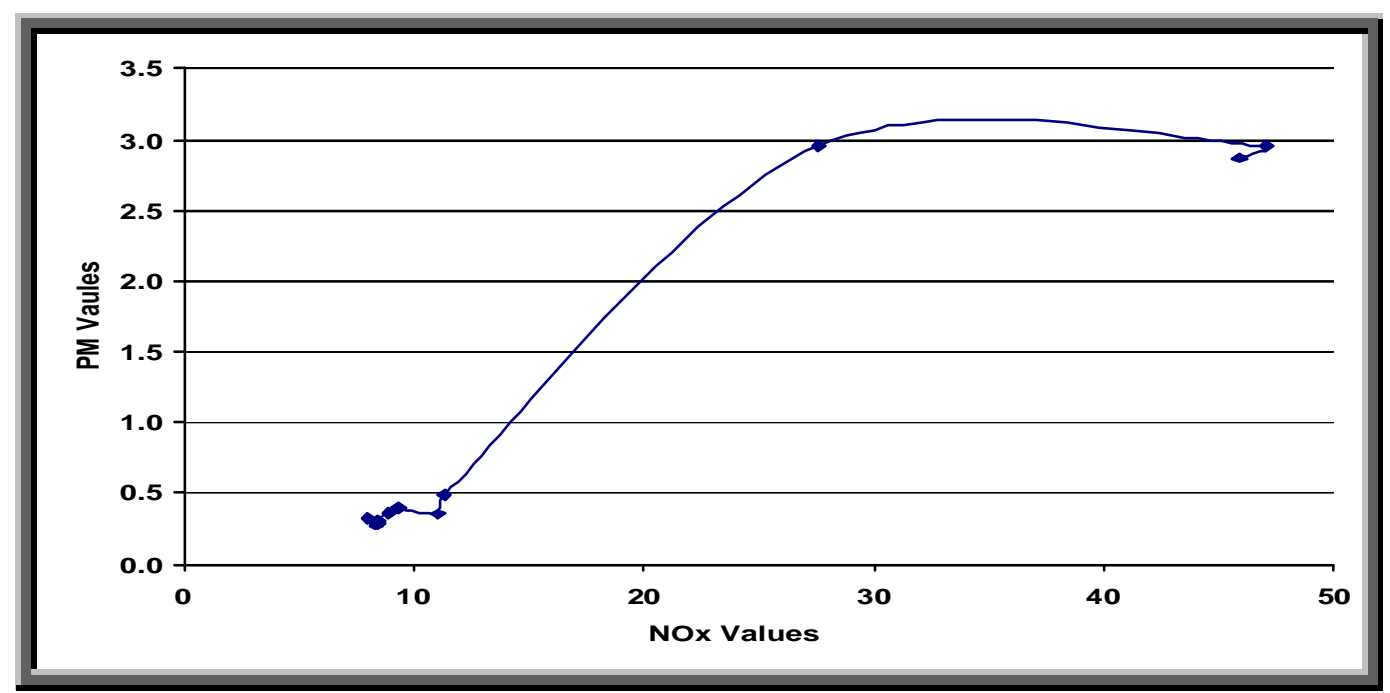

Figure 4.8: $\mathrm{NO}_{\mathrm{x}}$ vs. PM Comparison

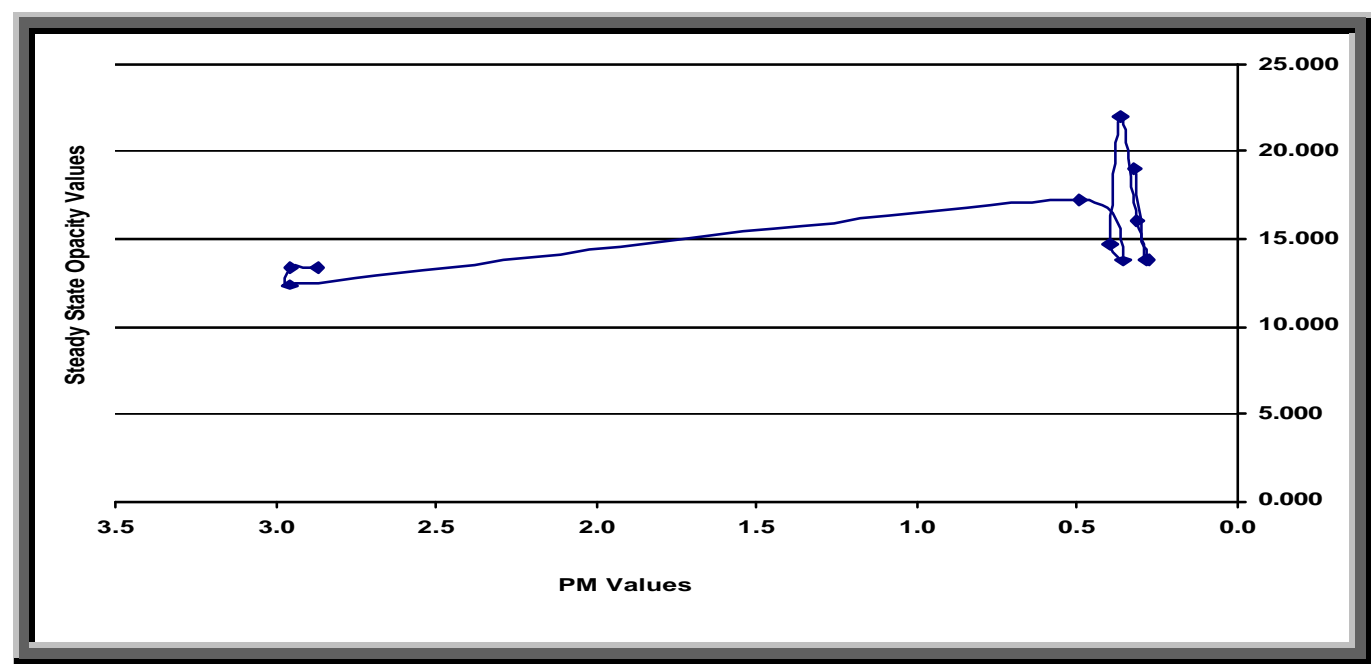

Figure 4.9: Smoke Opacity vs. PM Comparison 


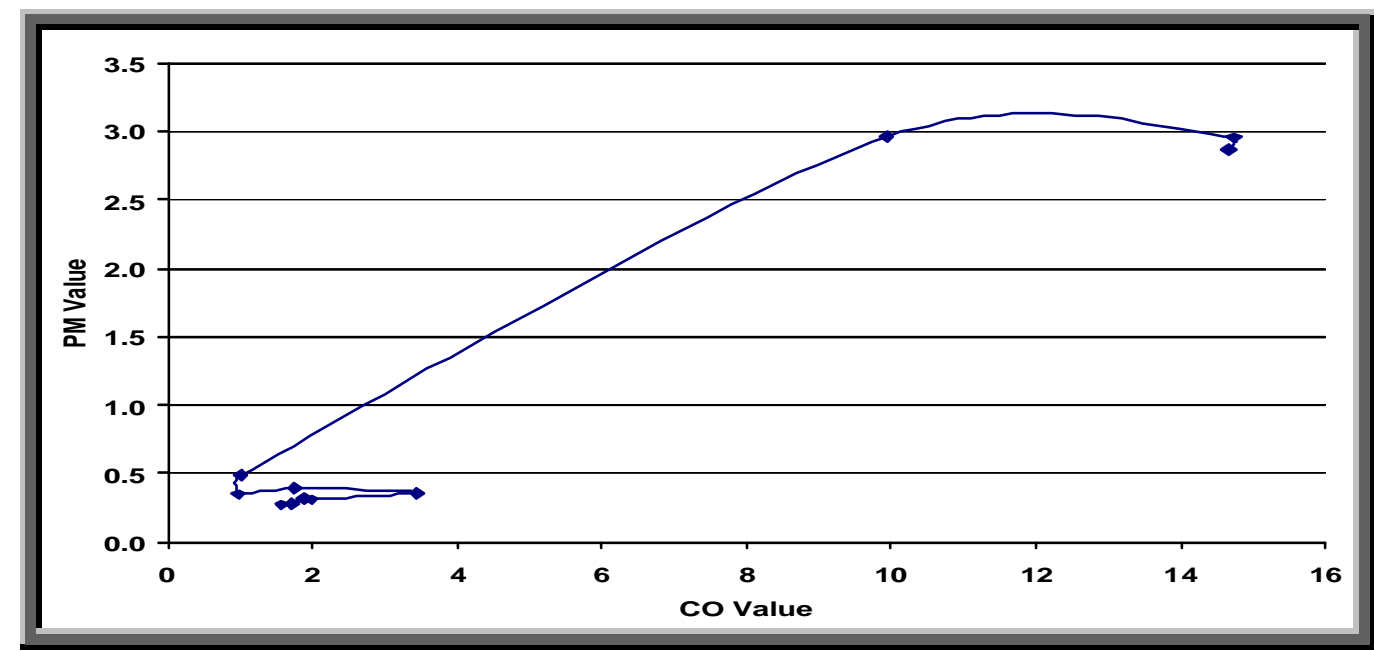

Figure 4.10: PM vs. CO Comparison

\subsubsection{Smoke Opacity Results}

All smoke opacity measurements are given in units of percent opacity. The results for locomotive 8678 and locomotive 8692 are shown in Figures 4.11 through Figure 4.16, respectively. A detailed listing of all smoke opacity measurements is given in Appendix A and the continuous data is given in Appendix C.

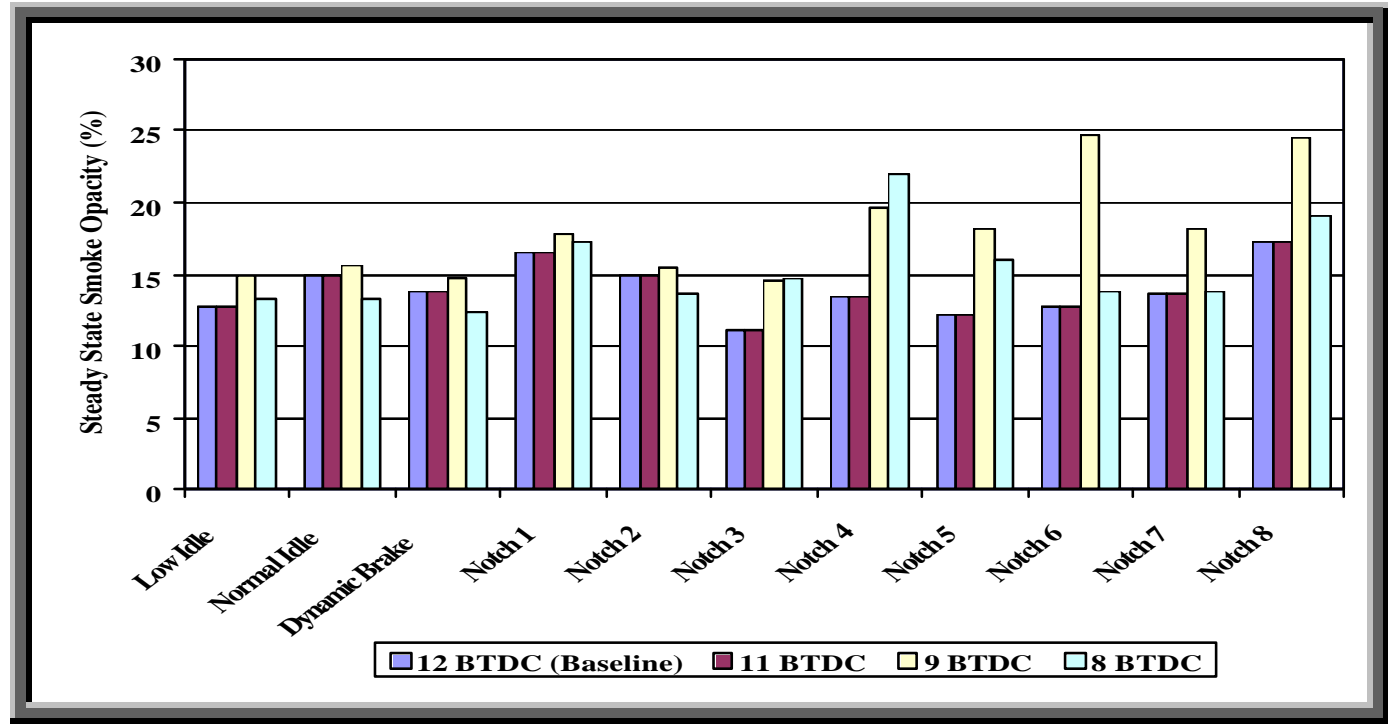

Figure 4.11: 8678 Steady State Smoke Opacity (30\%) 
As seen in the figure above, all test passed the $30 \%$ standard for smoke opacity. However, the there was no benefit in the steady state smoke emissions through retarding the fuel injection timing.

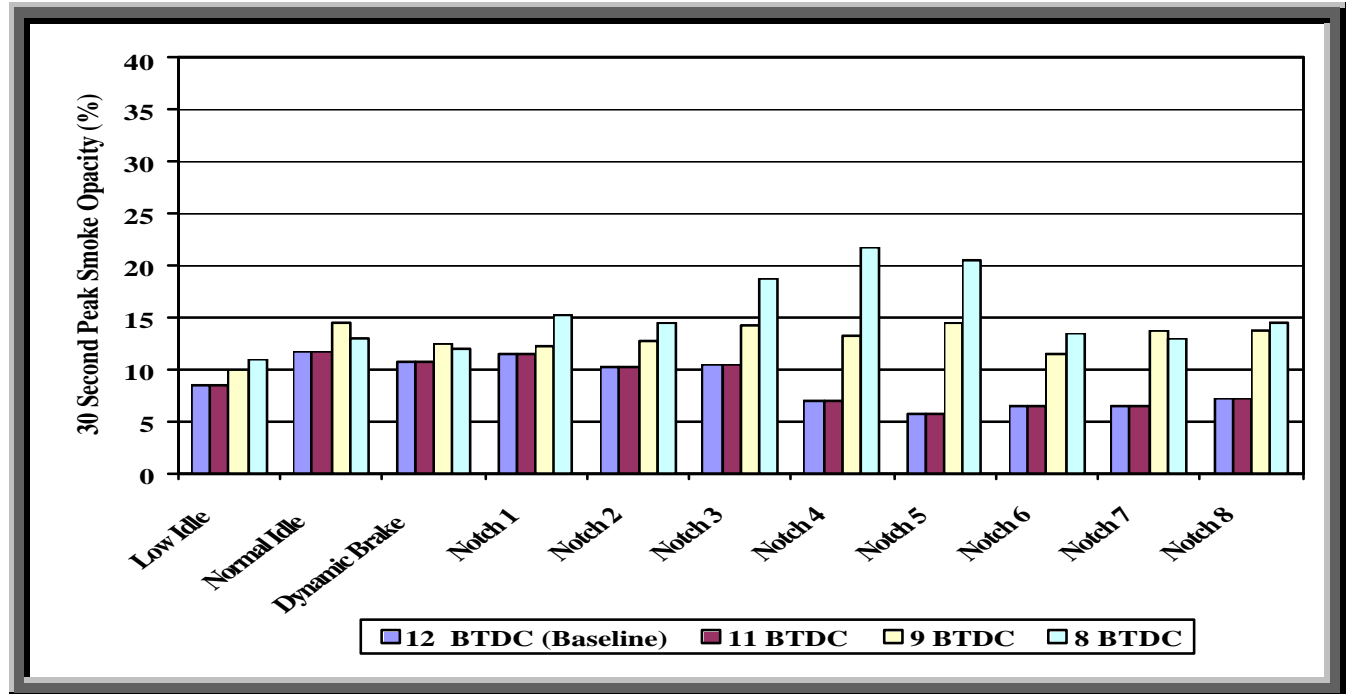

Figure 4.12: 867830 Second Peak Smoke Opacity (40\%)

The 30 second peak smoke emissions produced from locomotive 8678 where significantly higher than the $12^{\circ} \mathrm{BTDC}$ baseline emissions. This is expected since it is known that there is an increase in the amount of smoke emissions when fuel injection timing is retarded.

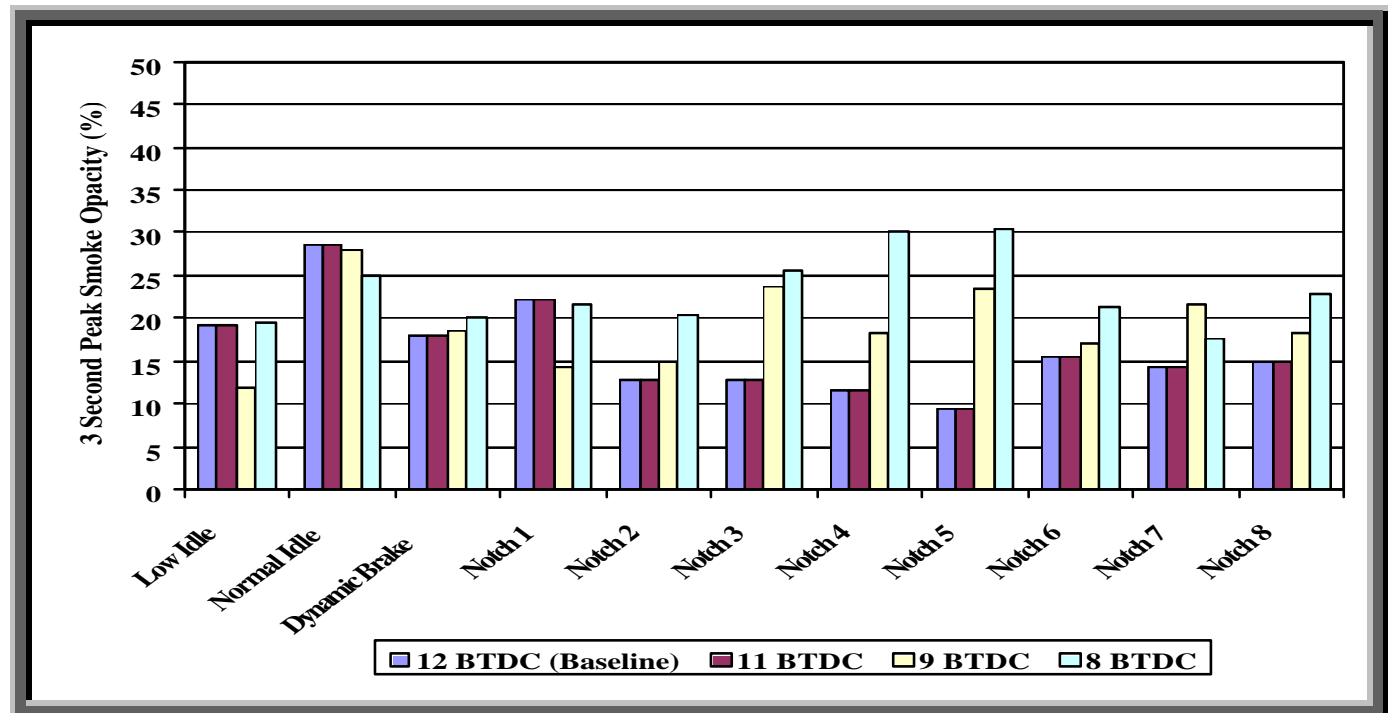

Figure 4.13: 86783 Second Peak Smoke Opacity (50\%) 
There was a slight benefit in the lower modes of operation. As expected, the figure shows that there was no benefit in the 30 second peak smoke emissions through retarding the fuel injection timing in the notch modes of locomotive 8678 .

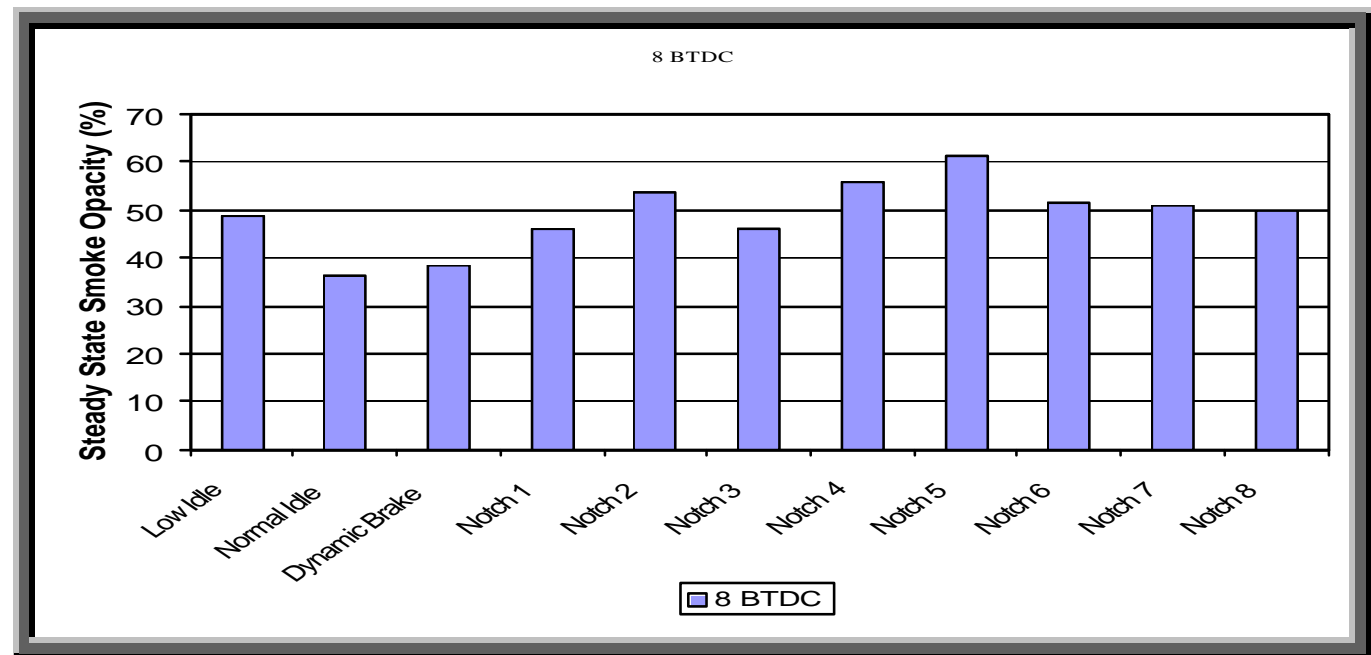

Figure 4.14: 8692 Steady State Smoke Opacity (30\%)

As seen in Figure 4.14, locomotive 8692 failed to meet the steady state smoke opacity standard of $30 \%$ in every test.

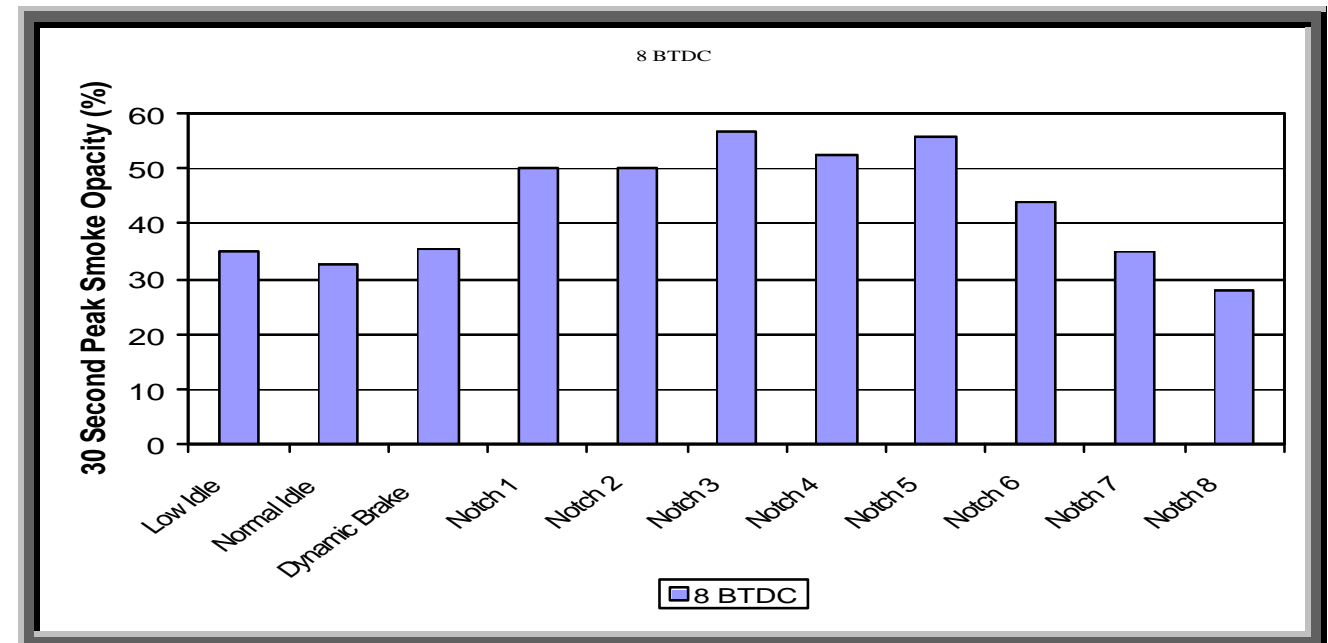

Figure 4.15: 869230 Second Peak Smoke Opacity (40\%)

As seen in Figure 4.15, locomotive 8692 failed to meet the 30 second peak smoke opacity standard of $40 \%$ in six of the eight notch mode tests. 


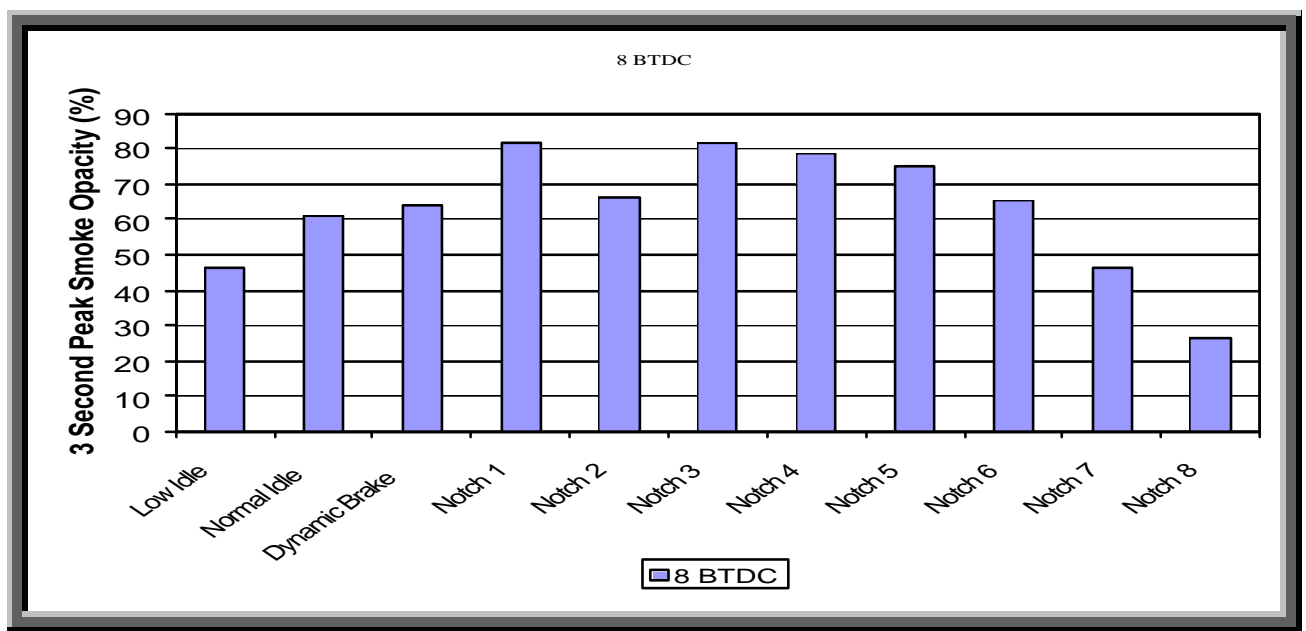

Figure 4.16: 86923 Second Peak Smoke Opacity (50\%)

As seen in Figure 4.16, locomotive 8692 failed to meet the 3 second peak smoke opacity standard of $50 \%$ in all but three tests.

\subsection{Component Variation Study Results}

\subsubsection{Objective}

There were two locomotives tested in this study. The first was a General Electric D9-40C locomotive (Norfolk Southern Engine Number 8867) that was equipped with a four-stroke General Electric Model 7FDL16L6 diesel engine, which operated with an electronic fuel injection system. The engine was equipped with GE 1883 turbocharger for baseline emissions. There were five different configurations of turbochargers and cylinder liners tested on the engine, which are given in Table 4.4. However is should be stated that the Globe turbochargers were the stock GE turbochargers rebuilt with Globe components.

The only turbocharger components that were changed were the blades, or buckets, in the turbine disks. The turbine disks had four possible combinations of parts. There were two turbine disks, a 64 blade and a 70 blade, in which the re were a standard and a high efficiency (EB) type of each. To form the Globe 1883, the GE 1883 turbocharger 
was fitted with a high efficiency 70 blade turbine disk for the electronic fuel injected engine 8867. To form the Globe 1869, the GE 1869 turbocharger was fitted with a standard 60 blade turbine disk for the mechanical fuel injected engine 8695 .

The second locomotive tested in this study was a General Electric C40-8 locomotive (Norfolk Southern Engine Number 8695) that was equipped with a fourstroke General Electric Model 7FDL16L6 diesel engine which operated with a mechanical fuel injection system. The engine was equipped with GE 1869 turbocharger for the baseline emissions. There were three test configurations, which are listed in Table 4.4.1. There were two goals in this study. The first was, of course, to determine if the engines would meet the most recent EPA regulations and the second was to determine how much the emissions would be affected through the different configurations.

\begin{tabular}{|c|c|c|}
\hline \multicolumn{3}{|c|}{ Table 4.4: Test Configurations } \\
\hline \multirow{2}{*}{ Vehicle Number } & \multicolumn{2}{|c|}{ Configuration } \\
\cline { 2 - 3 } & Turbochargers & Cylinder Liners \\
\hline \multirow{4}{*}{8867} & GE 1883 & New \\
\cline { 2 - 3 } & Hispana Suiza & New \\
\cline { 2 - 3 } & Globe 1883 & New \\
\hline \multirow{3}{*}{8695} & GE 1883 & Used \\
\hline & Globe 1883 & Used \\
\hline & GE 1869 & No Change \\
\hline & Globe 1869 & No Change \\
\hline
\end{tabular}

\subsubsection{Gaseous and Particulate Matter Emission Results}

The emission of the electronically fuel injected locomotive 8867 are listed in Figure 4.17 through Figure 4.20 and those of mechanically fuel injected locomotive 8695 
are given in Figure 4.22 and Figure 4.25. The fuel economy for locomotives 8867 and 8695 are shown in Figures 4.21 and 4.26, respectively. A detailed listing of all gaseous emissions is given in Appendix B. 


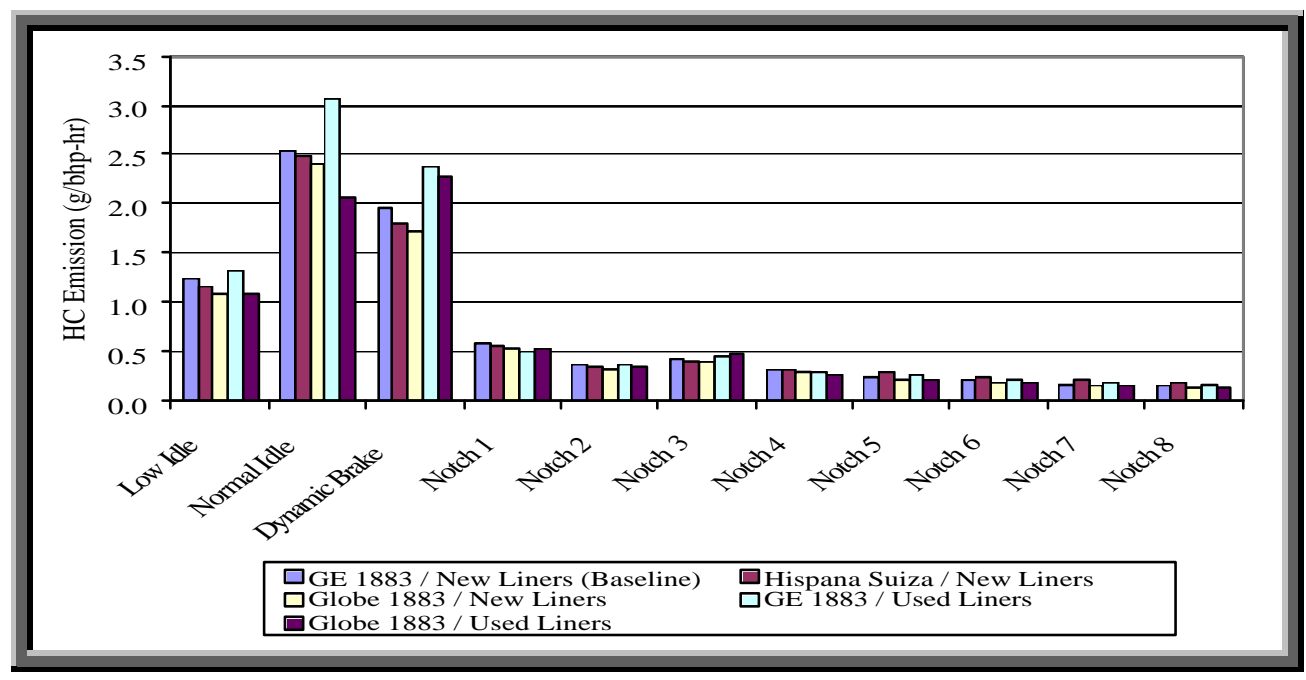

Figure 4.17: Brake-Specific Hydrocarbon Emissions of Locomotive 8867

Figure 4.17 shows that the configuration that benefits $\mathrm{HC}$ emissions is that of the Globe 1883 turbocharger with new cylinder liners. All other configurations exceed the baseline emissions.

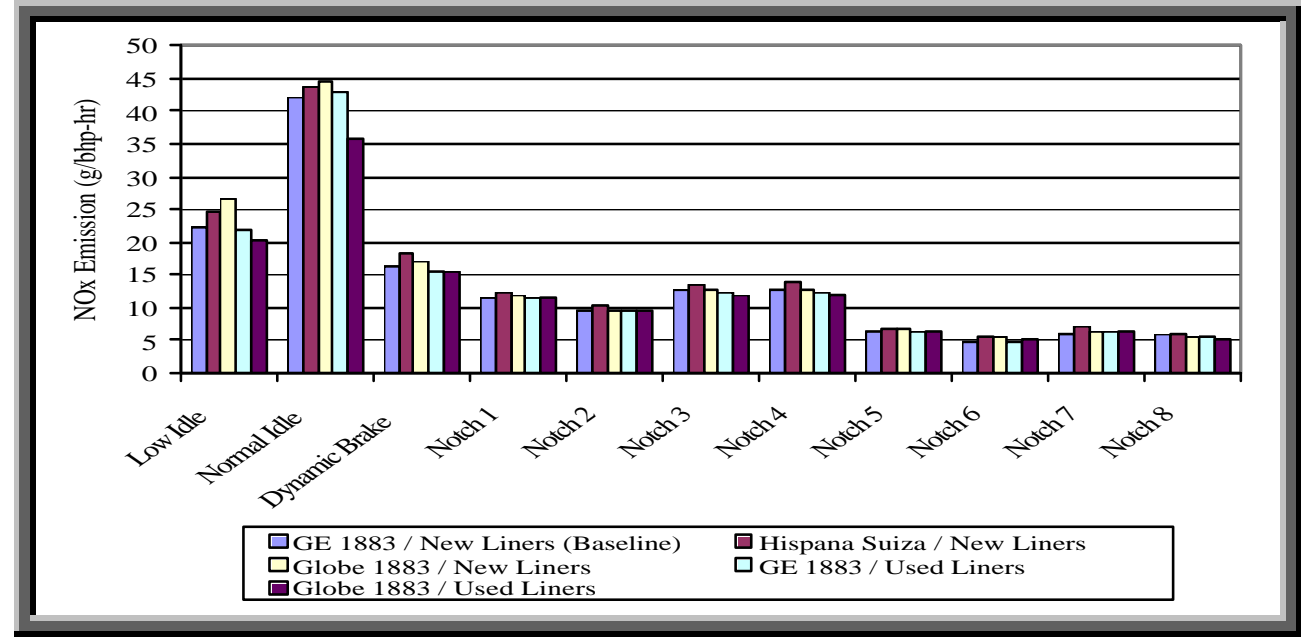

Figure 4.18: Brake-Specific Oxides of Nitrogen Emissions of Locomotive 8867

With the NOx emissions shown in Figure 4.18, it is seen that the only significant reduction occurs in the low idle and normal idle modes through the Globe 1883 turbocharger and used cylinder liner configuration. 


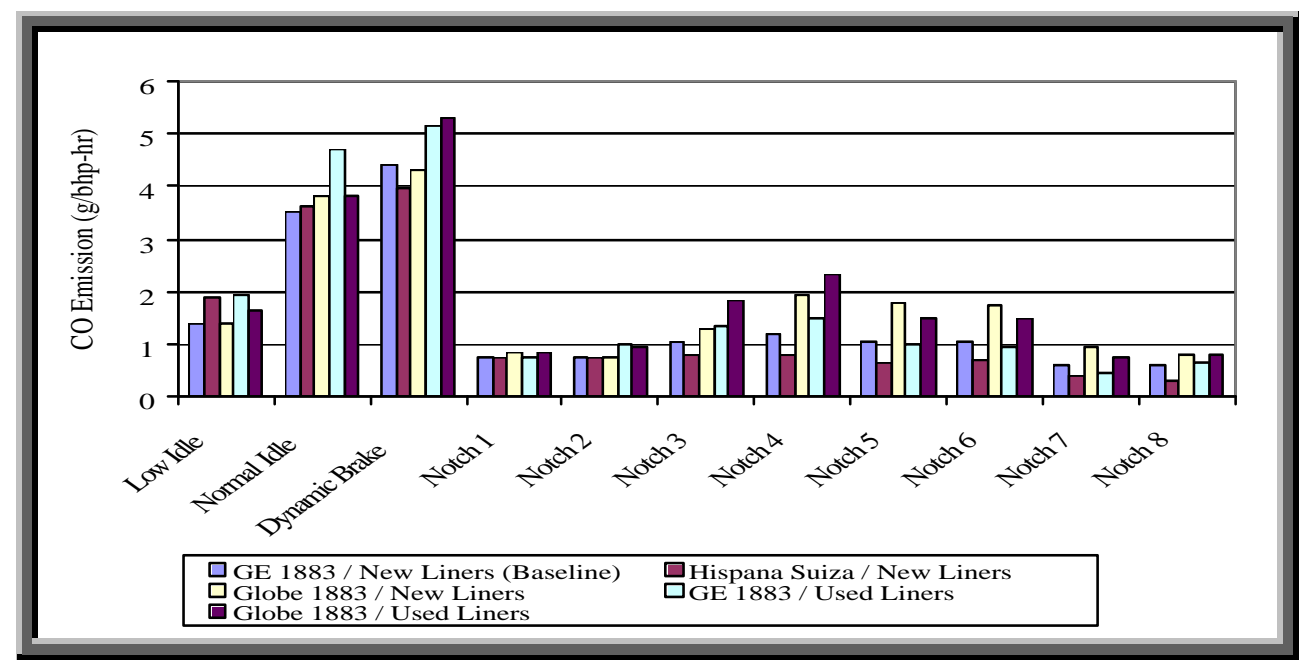

Figure 4.19: Brake-Specific Carbon Monoxide Emissions of Locomotive 8867

The only configuration that proved beneficial throughout the notch tests is shown to be the Hispana Suiza with new cylinder liners. However, the only configuration to be beneficial in $\mathrm{CO}$ emissions in the lower modes of operation was that of the Hispana Suiza with new cylinder liners in the dynamic brake mode.

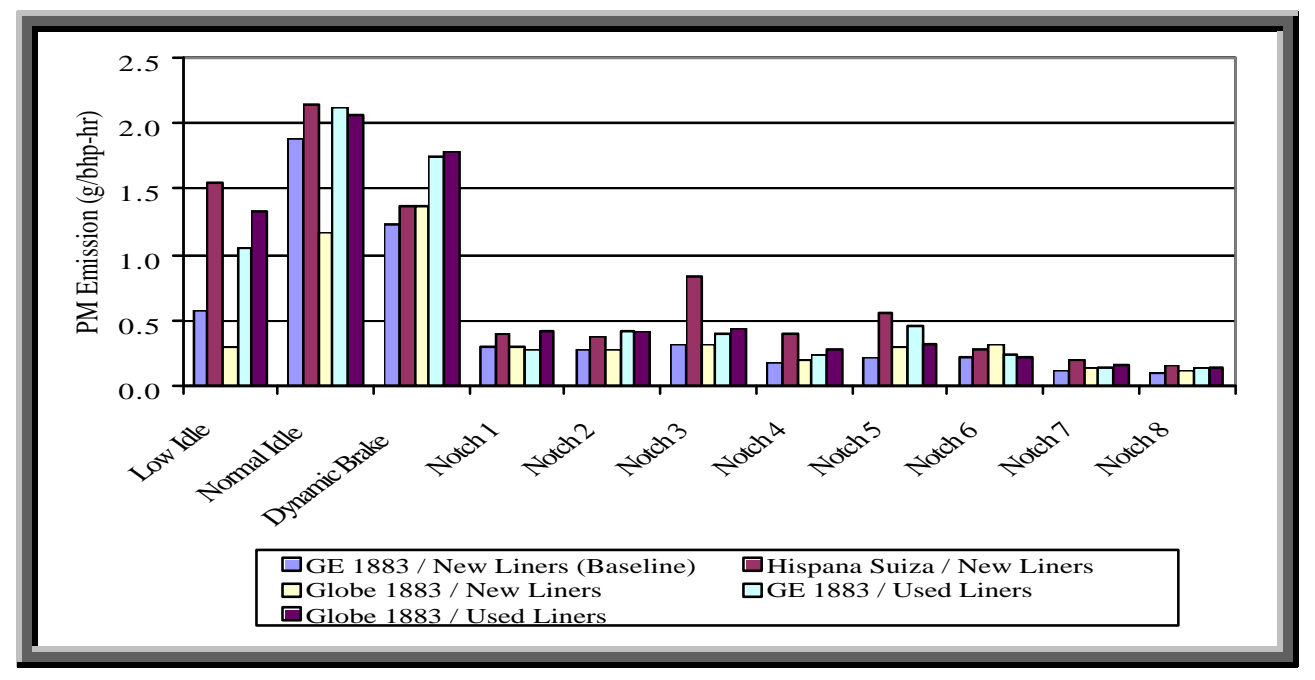

\section{Figure 4.20: Brake-Specific Particulate Emissions of Locomotive 8867}

The figure above shows that the only tests to produce lower PM emissions were the low and normal idle mode tests. All other tests produced higher emissions than that of the baseline configuration. 


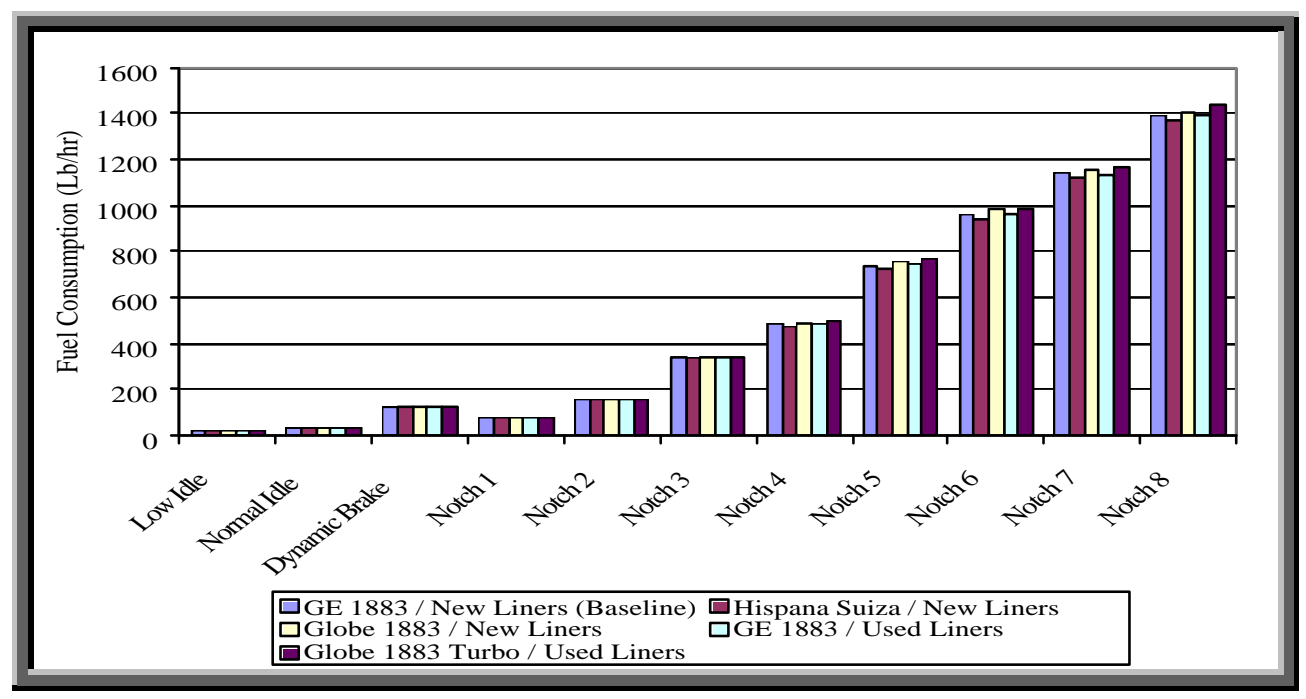

Figure 4.21: Fuel Economy Results for Locomotive 8867

The fuel economy results that are shown in Figure 4.21 show that there was no significant loss in fuel economy due to turbocharger and cylinder liner configuration.

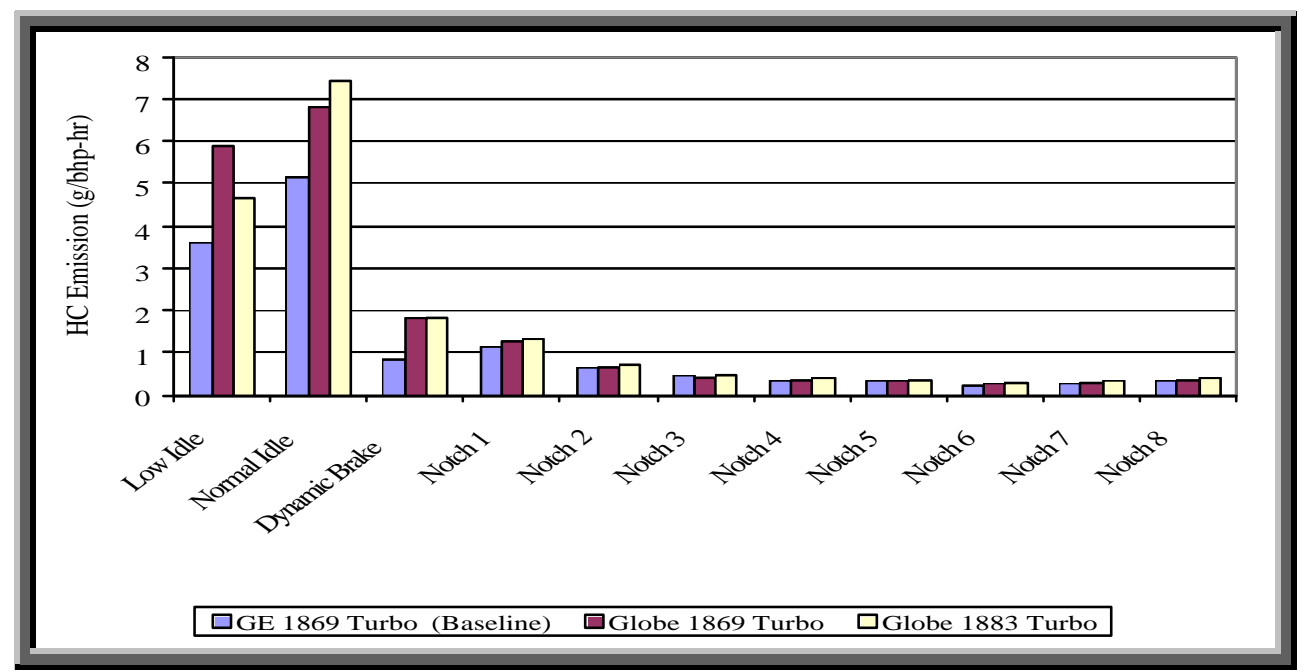

Figure 4.22: Brake-Specific Hydrocarbon Emissions of Locomotive 8695

Figure 4.22 shows that there is no benefit in $\mathrm{HC}$ emission through altering the baseline configuration. Every test failed to meet the baseline $\mathrm{HC}$ emissions. 


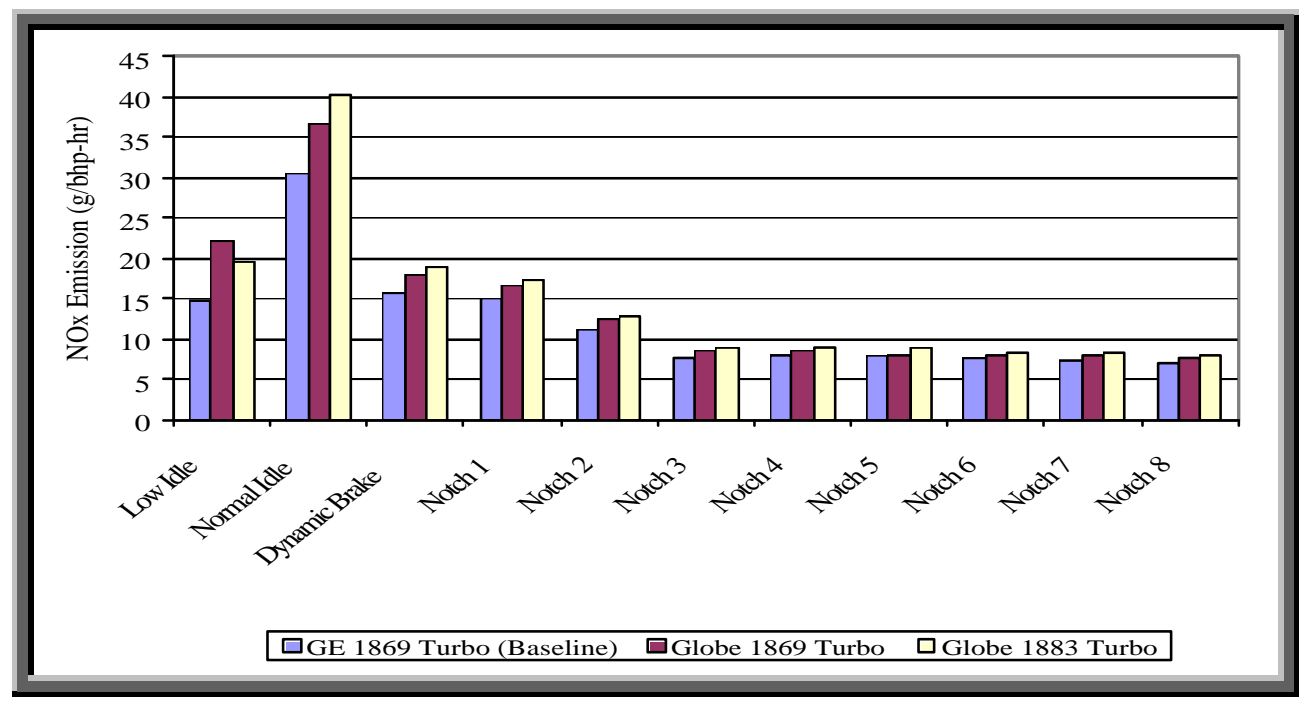

Figure 4.23: Brake-Specific Oxides of Nitrogen Emissions of Locomotive 8695

As seen in Figure 4.23, there was no benefit in $\mathrm{NO}_{\mathrm{x}}$ emission through altering the baseline configuration. Although the emissions passed the EPA standard, every test failed to meet the baseline $\mathrm{NO}_{\mathrm{x}}$ emissions.

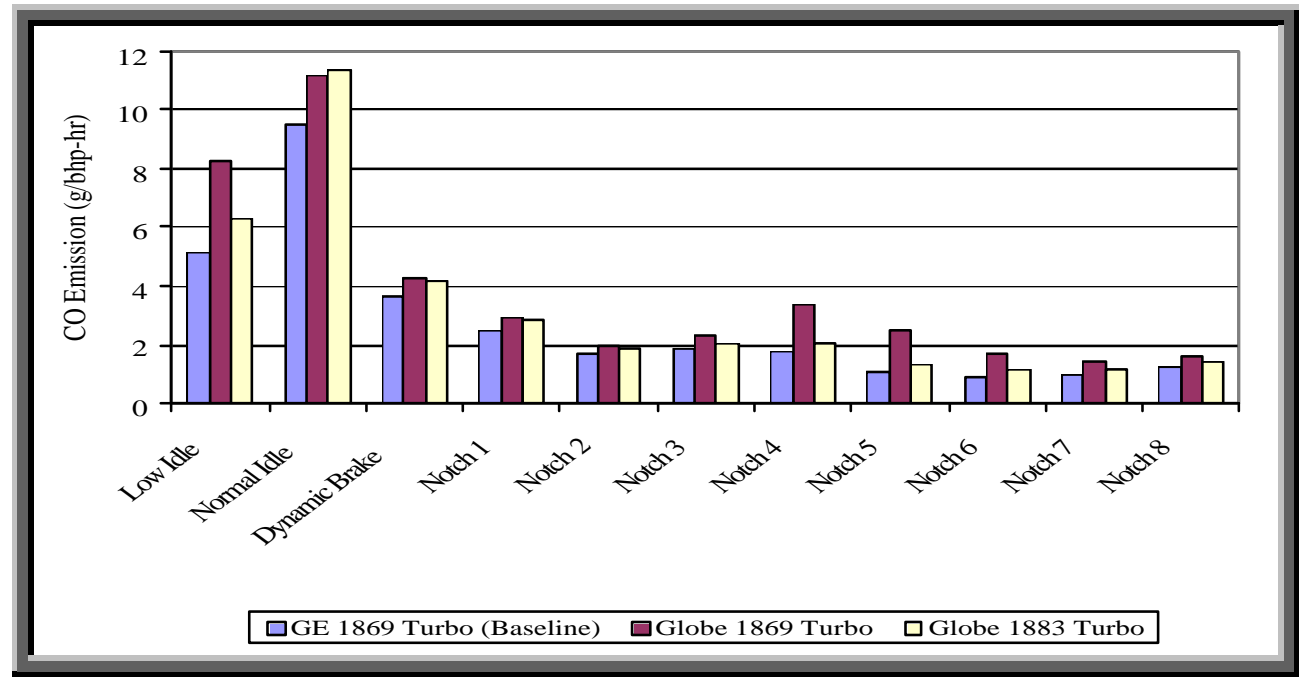

Figure 4.24: Brake-Specific Carbon Monoxide Emissions of Locomotive 8695

Figure 4.24 shows that there is no benefit in $\mathrm{CO}$ emission through altering the baseline configuration. Every test failed to meet the baseline $\mathrm{CO}$ emissions. 


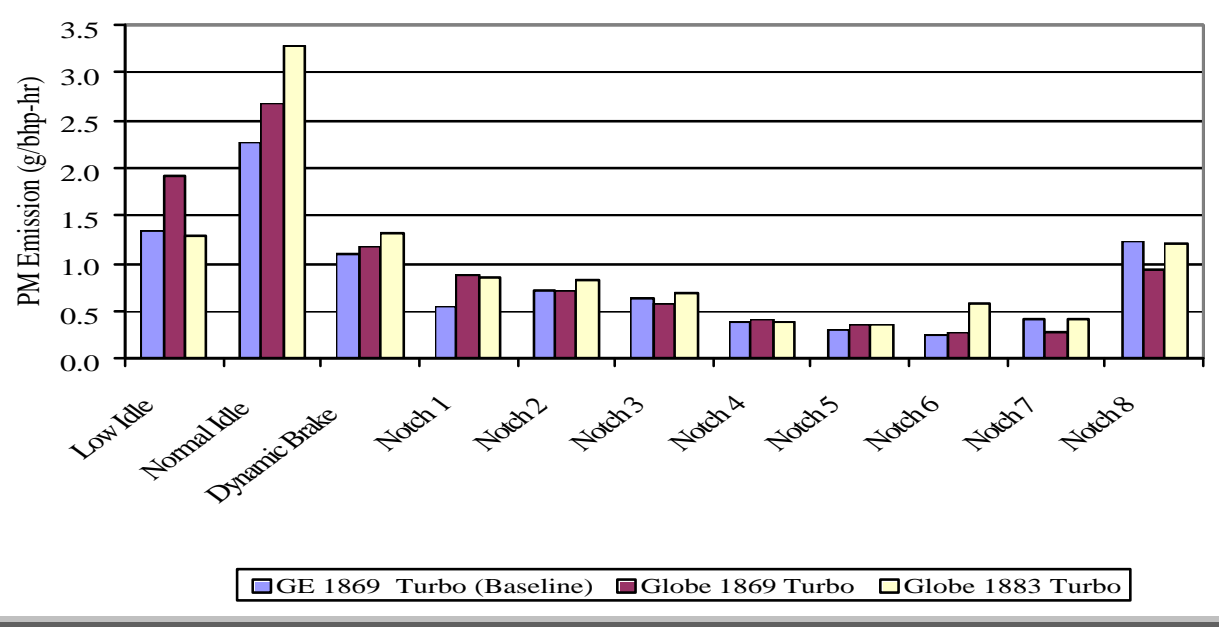

\section{Figure 4.25: Brake-Specific Particulate Emissions of Locomotive 8695}

Figure 4.25 shows that the only tests to benefit in PM emissions through altering the baseline configuration were Notches two, three, and seven through the Globe 1869 turbocharger. The only other test that produced a lower baseline PM emission was the low idle with the Globe 1883 turbocharger.

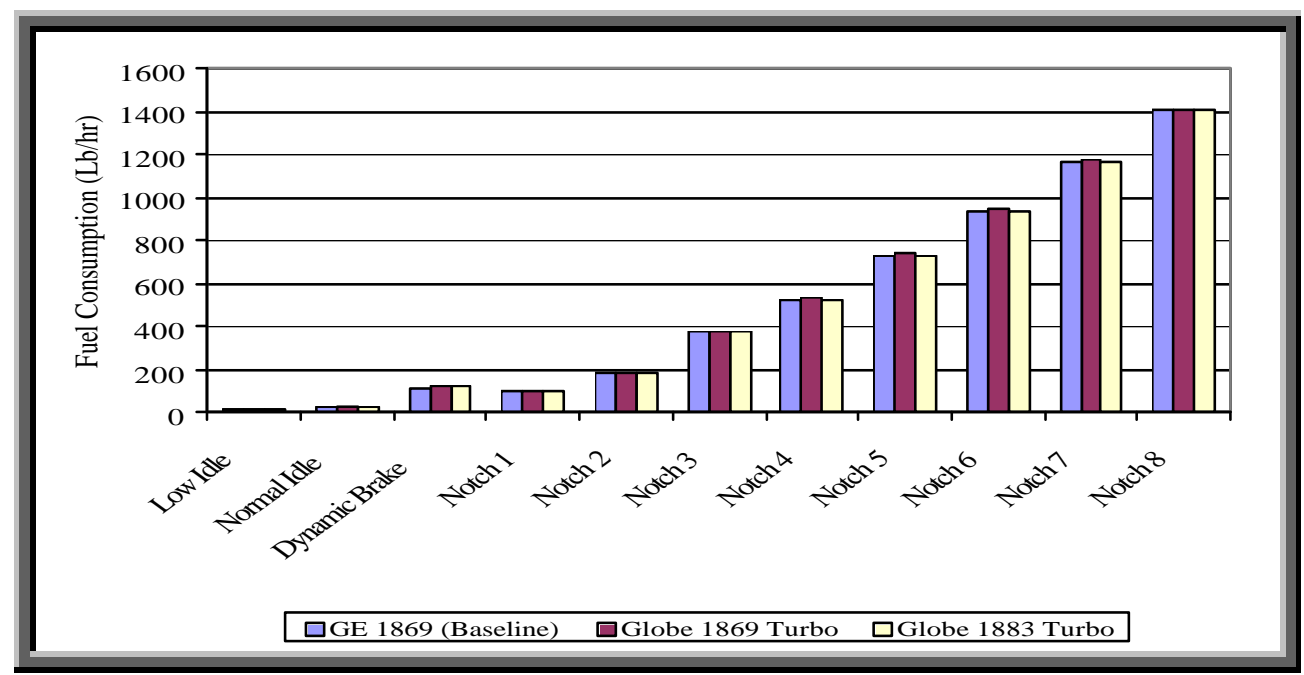

Figure 4.26: Fuel Economy Results for Locomotive 8695

The fuel economy results that are shown in Figure 4.26 show that there is no significant loss in fuel economy due to turbocharger and cylinder liner configuration. 


\subsubsection{Smoke Opacity Results}

The smoke opacity results for the locomotive 8867 are shown in Figure 4.27 through Figure 4.29. The effects of locomotive 8695 are shown in Figure 4.30 through Figure 4.32. The figures show that there was only one test that failed to meet the standard. The test of locomotive 8867 equipped with a Globe 1883 and used cylinder liners failed to meet the steady state standard of thirty percent normalized opacity in notch six. A detailed listing of all smoke opacity measurements for all tests in this study is given in Appendix B and the continuous smoke data is given in Appendix D.

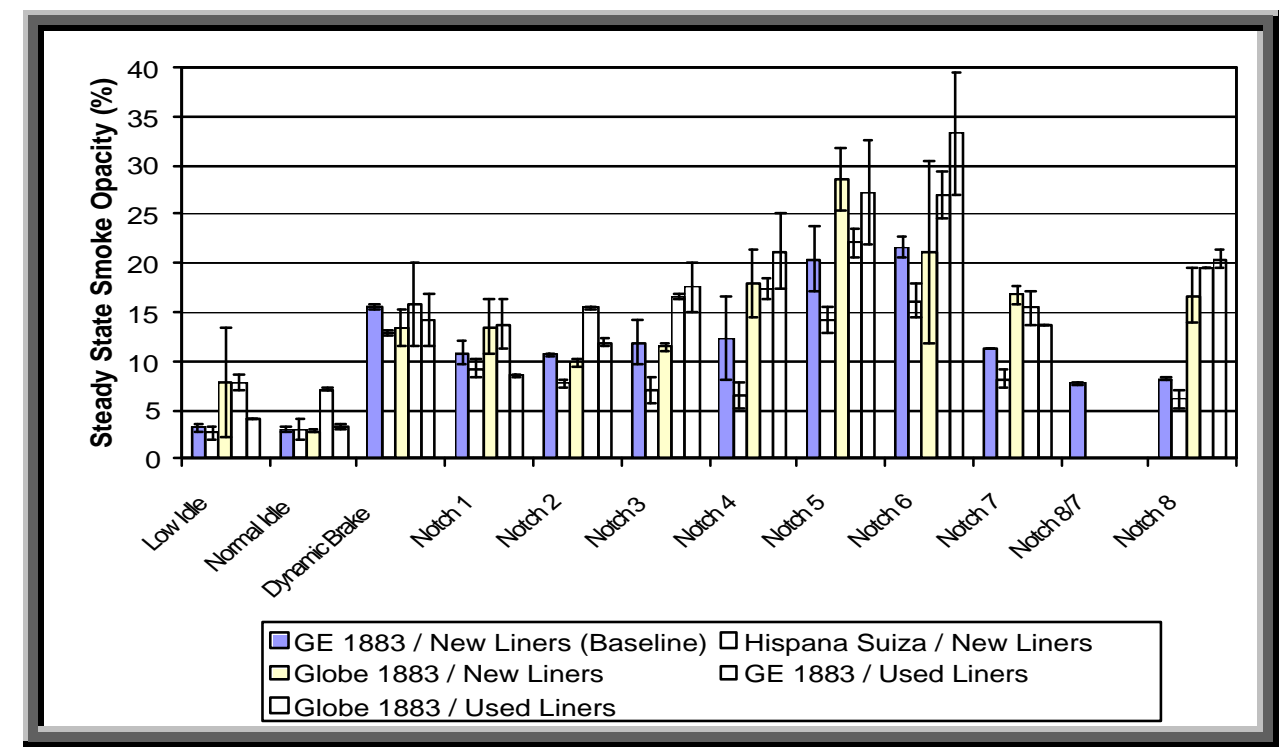

Figure 4.27: 8867 Steady State Smoke Opacity (30\%)

The figure above shows that the only configuration to benefit the smoke emissions when compared to the baseline is the Hispana Suiza turbocharger with new cylinder liners. All other configurations produced unsatisfactory steady state smoke emissions. 


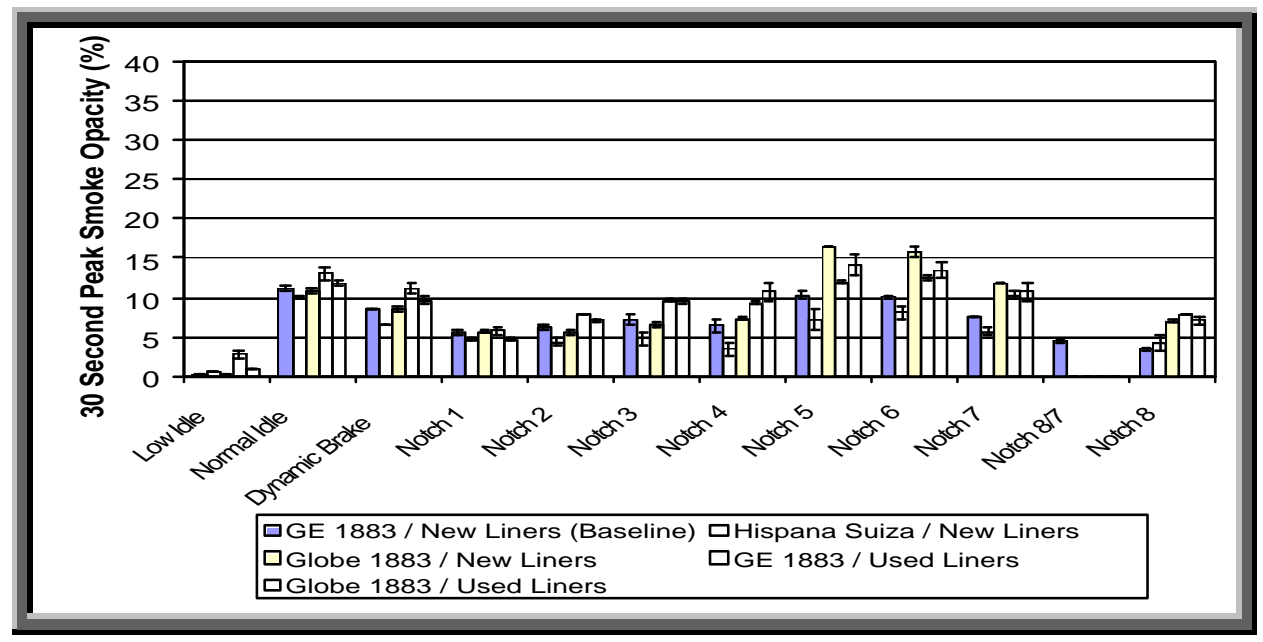

Figure 4.28: 886730 Second Peak Smoke Opacity (40\%)

Similarly to the steady state emissions, the Hispana Suiza produced the best overall thirty second peak smoke emissions. All other configurations produced unsatisfactory steady state smoke emissions when compared to the baseline emissions. All configurations produced emissions that were well under the EPA standard of $40 \%$ throughout all modes of operation.

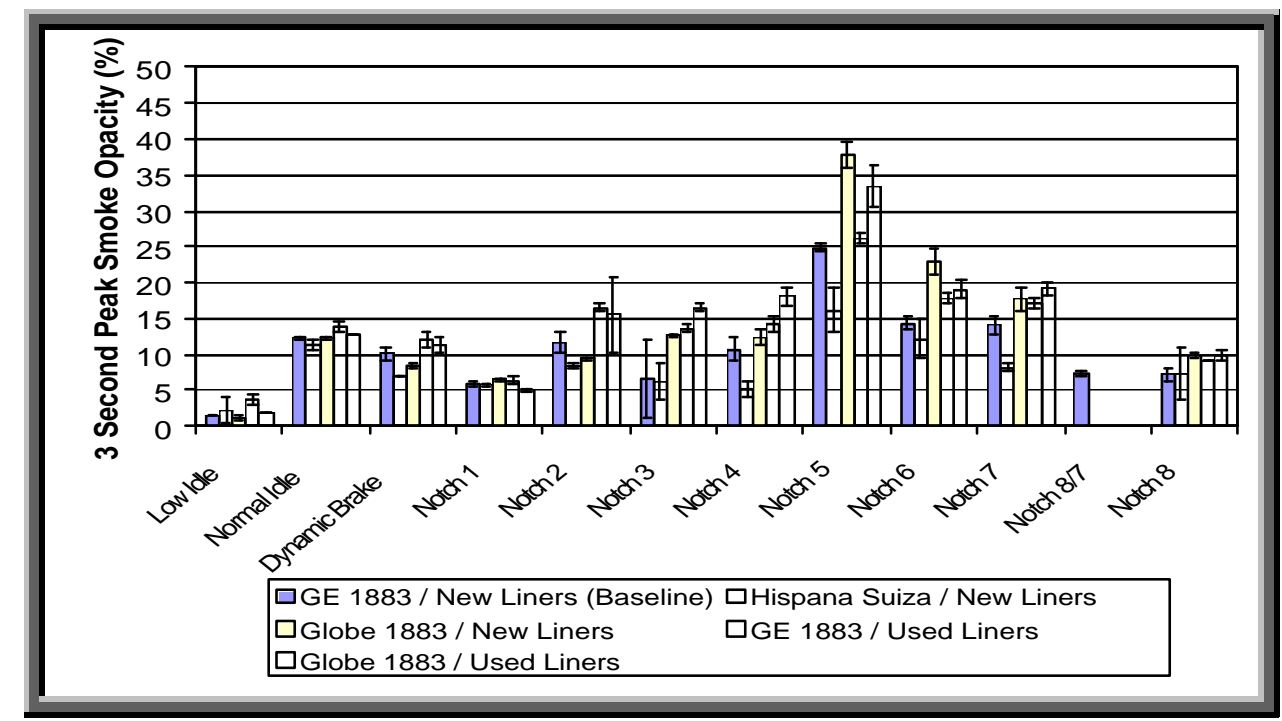

\section{Figure 4.29: 88673 Second Peak Smoke Opacity (50\%)}

Figure 4.29 shows that the Hispana Suiza with new cylinder liners was the only configuration to benefit the three second peak smoke emissions of locomotive 8867 . 


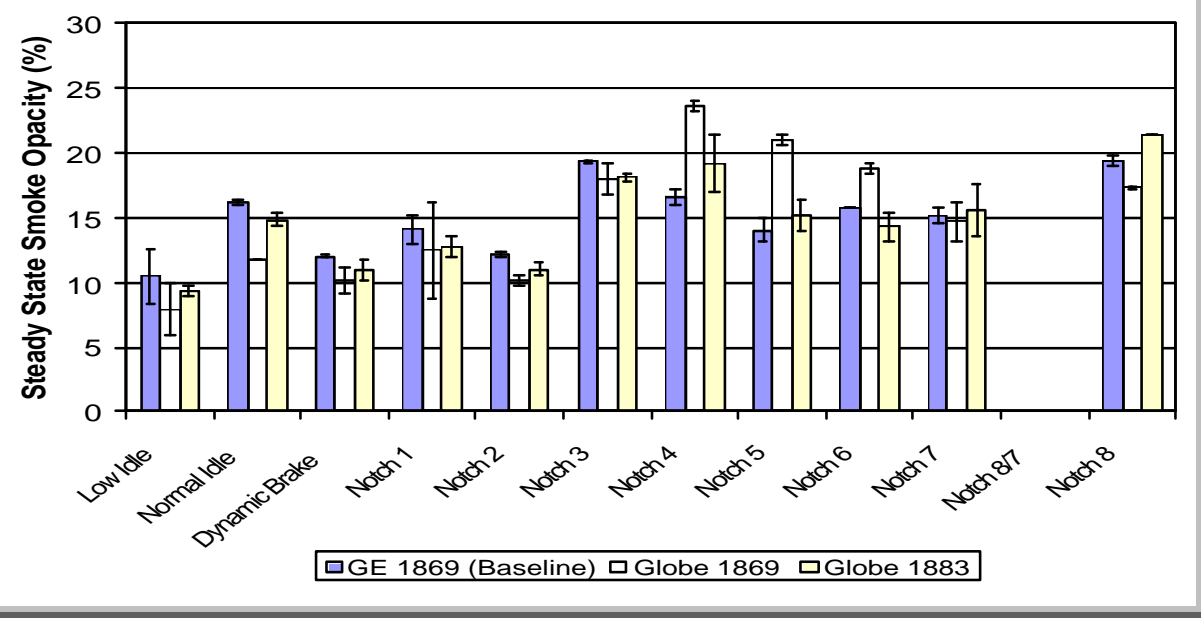

Figure 4.30: 8695 Steady State Smoke Opacity (30\%)

As seen in the figure above, all tests passed the mandated regulation of $30 \%$

Opacity. However, none of the turbochargers proved beneficial over the baseline General Electric model 1869 turbocharger.

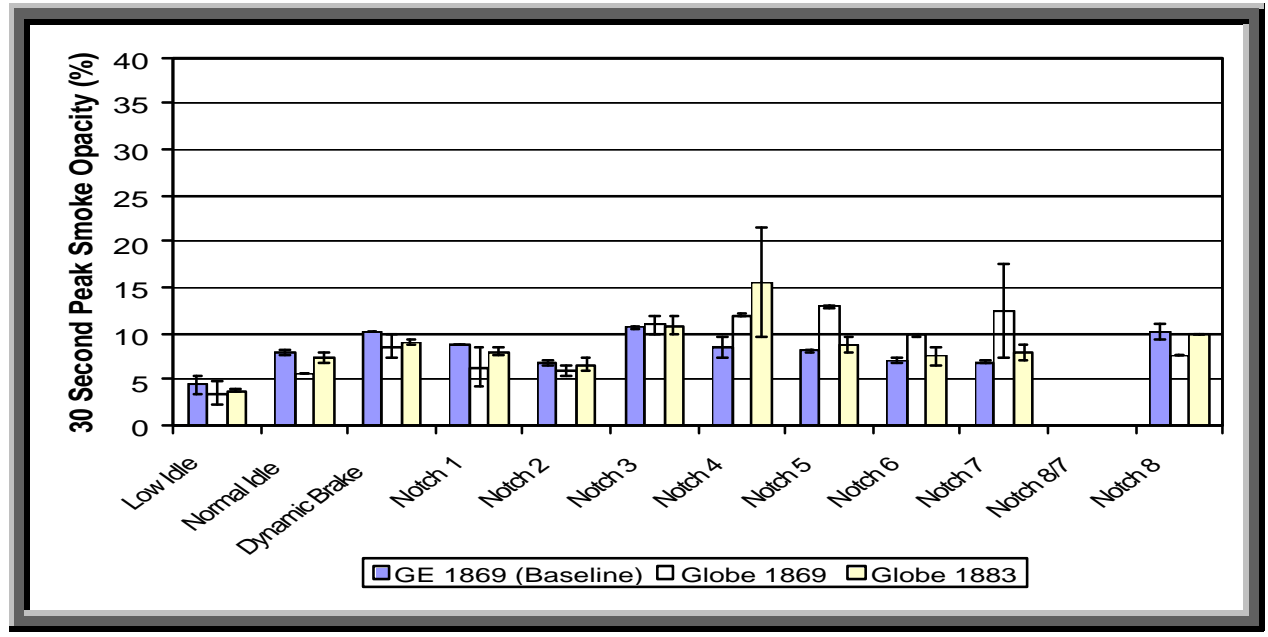

Figure 4.31: 869530 Second Peak Smoke Opacity (40\%)

The figure above shows that both the Globe 1869 and 1883 turbochargers improved the 30 second smoke emissions over the GE 1869 turbocharger in the low level of operation tests. They didn't, however, improve the emissions in the notch modes of operation. 


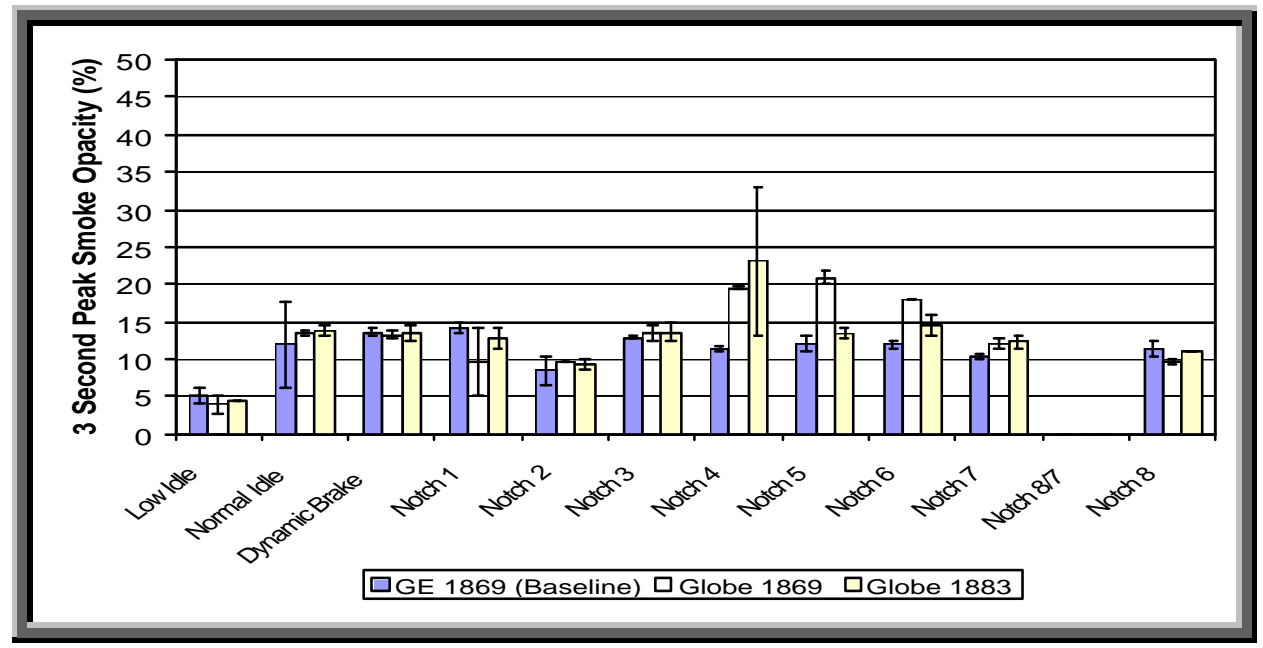

Figure 4.32: 86953 Second Peak Smoke Opacity (50\%)

Locomotive 8695 produced 3 second peak smoke emissions that exceeded the baseline emissions in nearly every test when equipped with the refurbished Globe turbochargers. 


\section{Chapter 5 Conclusions}

The purposes of both studies recorded in this document were to determine what the emission effects of engine component configuration were on a locomotive. The tests reflect the emissions produced with the engines in a newly remanufactured state. Once deterioration factors were obtained from GE, they were applied to the 7FDL Tier 0 EFI engine that was tested in this document. The values for the low mileage test point standards are given in Table 5.1. The deterioration factors for the mechanically fuel injected engines were not obtained from General Electric.

\begin{tabular}{|c|c|c|}
\hline \begin{tabular}{|}
$|c|$ \\
Table 5.1: Deterioration Factors for 7FDL Tier O EFI \\
Engine Family as Determined by General Electric
\end{tabular} \\
\hline Emission & Line-Haul & Switch \\
\hline HC & 0.21 & 0.24 \\
\hline CO & 0.7 & 1.3 \\
\hline NO $_{\mathbf{x}}$ & 1.2 & 1.5 \\
\hline PM & 0.26 & 0.28 \\
\hline \multicolumn{3}{|c|}{ Smoke Opacity } \\
\hline Steady-State & $11.7 \%$ \\
\hline 30 Sec. Peak & $19.8 \%$ \\
\hline 3 Sec. Peak & $22.7 \%$ \\
\hline
\end{tabular}

\subsection{Fuel Injection Timing Study Conclusions}

This study proved to have emissions that passed the standards mandated by the EPA. The Tables 5.2 and 5.4 below show the percent difference between the measured line-haul and switch emissions and the baseline line-haul and switch emissions for locomotive 8678 and 8692 . Any emission that measured higher than the baseline emission is a negative value and is highlighted in the table. The tables show that the fuel injection adjustments that were applied to the locomotives had a positive effect on 
emissions overall, with the exception of $\mathrm{CO}$ and PM in the $8^{\circ} \mathrm{BTDC}$ fuel injection timing setting. There was little or no effect on fuel consumption.

The tables show that line-haul locomotives, which are typically in the higher power notches, and switch locomotives could benefit from having their fuel injection retarded to the timing of $8^{\circ} \mathrm{BTDC}$. Although there were changes in the emissions, the fuel economy was relatively independent of fuel injection timing.

The smoke data previously reported shows that locomotive 8692 failed to meet the standards in many of the notch tests. All smoke data with respect to engine mode for locomotive 8678 and locomotive 8692 is given in Appendix A and all continuous smoke data is given in Appendix $\mathrm{C}$.

\section{Table 5.2: Percent Difference Line Haul Results for Locomotive 8678}

\begin{tabular}{|l|c|c|c|c|}
\hline \multicolumn{1}{|c|}{ Weighted Emission (g/bhp-hr) } & THC & NOx & CO & PM \\
\hline \hline $\mathbf{1 2}^{\circ}$ BTDC & - & - & - & - \\
\hline \hline $\mathbf{1 1}^{\circ}$ BTDC & 8.06 & 7.23 & 8.47 & 8.82 \\
\hline $\mathbf{9}^{\circ}$ BTDC & 9.68 & 39.32 & 2.12 & 5.88 \\
\hline \hline $\mathbf{8}^{\circ}$ BTDC & 16.13 & 48.89 & -7.94 & -7.94 \\
\hline
\end{tabular}

\begin{tabular}{|l|c|c|c|c|}
\hline \multicolumn{4}{|c|}{ Table 5.3: Percent Difference Switch Results for Locomotive 8678} \\
\hline \multicolumn{1}{|c|}{ Weighted Emission (g/bhp-hr) } & THC & NOx & CO & PM \\
\hline \hline $\mathbf{1 2}^{\circ}$ BTDC & - & - & - & - \\
\hline \hline $\mathbf{1 1}^{\circ}$ BTDC & 10.98 & 7.40 & -4.93 & 9.35 \\
\hline \hline $\mathbf{9}^{\circ}$ BTDC & 8.02 & 41.27 & 12.82 & 7.24 \\
\hline \hline $\mathbf{8}^{\circ}$ BTDC & 18.90 & 52.57 & 8.88 & 7.24 \\
\hline
\end{tabular}

\begin{tabular}{|l|c|c|c|c|}
\hline \multicolumn{3}{|c|}{ Table 5.4: Percent Difference Line-Haul Results for Locomotive 8692} \\
\hline \hline Weighted Emission (g/bhp-hr) & THC & NOx $_{\mathbf{x}}$ & CO & PM \\
\hline EPA Standards & 1.0 & 9.5 & 5.0 & 0.6 \\
\hline \hline $\mathbf{8}^{\circ}$ BTDC & 20.97 & 47.84 & 51.32 & -32.35 \\
\hline
\end{tabular}




\begin{tabular}{|l|c|c|c|c|}
\hline \multicolumn{4}{|c|}{ Table 5.5: Percent Difference Switch Results for Locomotive 8692} \\
\hline \hline Weighted Emission (g/bhp-hr) & THC & NOx & CO & PM \\
\hline \hline EPA Standards & 1.0 & 9.5 & 5.0 & 0.6 \\
\hline 8 $^{\circ}$ BTDC & 27.80 & 51.62 & 29.39 & -5.41 \\
\hline
\end{tabular}

\subsection{Component Variation Study Conclusions}

This study also proved to have passing emissions. Although the emissions passed the EPA standards, Tables 5.6 through 5.92 .4 below show the percent difference between the measured and baseline line-haul and switch emissions for locomotives 8867 and 8695 respectively. Any emission that measured higher than the baseline emission is a negative value and is highlighted in the table. The tables show that the component variations that were applied to the locomotives had little or no positive effect, and a negative effect on the PM and $\mathrm{CO}$ emissions.

The tables show that for line-haul locomotives, which are typically in the higher power notches, there is no need to change the engine components. There is also no need to change the configurations of the switch locomotives. Although there were changes in the emissions, the fuel economy was relatively independent of turbocharger and cylinder liner configurations.

The tables show that there was only one test that failed to meet the smoke opacity standard. The test of locomotive 8867 equipped with a Globe 1883 and used cylinder liners failed to meet the steady state standard of thirty percent normalized opacity in notch 6. All smoke data with respect to engine mode for locomotive 8867 and locomotive 8695 is given in Appendix B and all continuous smoke data is given in Appendix D. 


\begin{tabular}{|l|c|c|c|c|c|}
\hline \multicolumn{3}{|c|}{ Table 5.6: Percent Difference Line Haul Results for Locomotive 8867 } \\
\hline \multicolumn{1}{|c|}{ Weighted Emission (g/bhp-hr) } & THC & NOx & CO & PM \\
\hline GE 1883 turbo with new liners (Baseline) & - & - & - & - \\
\hline Hispana Suiza with new liners & -9.61 & -7.92 & 34.53 & -67.85 \\
\hline \hline Globe 1883 with new liners & 7.99 & -0.28 & -36.60 & -16.64 \\
\hline \hline Std. EFI with used liners & -9.20 & 1.07 & -6.85 & -38.50 \\
\hline Rebuilt Globe 1883 with used liners & 4.26 & 4.65 & -37.86 & -40.41 \\
\hline
\end{tabular}

\begin{tabular}{|l|c|c|c|c|}
\hline \multicolumn{3}{|c|}{ Table 5.7: Percent Difference Switch Results for Locomotive 8867} \\
\hline \multicolumn{1}{|c|}{ Weighted Emission (g/bhp-hr) } & THC & NOx & CO & PM \\
\hline \hline GE 1883 turbo with new liners (Baseline) & - & - & - & - \\
\hline \hline Hispana Suiza turbo with new liners & -3.25 & -7.74 & 24.84 & -92.59 \\
\hline Globe 1883 turbo with new liners & 6.87 & -3.31 & -41.21 & -6.26 \\
\hline Std. EFI with used liners & -3.25 & 2.25 & -14.35 & -42.69 \\
\hline $\begin{array}{l}\text { Rebuilt Globe 1883 turbo with used } \\
\text { liners }\end{array}$ & 6.13 & 3.33 & -50.07 & -42.69 \\
\hline
\end{tabular}

\begin{tabular}{|l|c|c|c|c|}
\hline \multicolumn{3}{|c|}{ Table 5.8: Percent Difference Line Haul Results for Locomotive 8695} \\
\hline \multicolumn{1}{|c|}{ Weighted Emission (g/bhp-hr) } & THC & NOx & CO & PM \\
\hline \hline GE 1869 turbo (Baseline) & - & - & - & - \\
\hline \hline Globe 1883 turbo & -22.59 & -13.20 & -15.79 & -5.49 \\
\hline Globe 1869 turbo & -14.63 & -8.75 & -44.79 & 18.33 \\
\hline
\end{tabular}

\begin{tabular}{|l||c|c|c|c||}
\hline \multicolumn{3}{|c|}{ Table 5.9: Percent Difference Switch Results for Locomotive 8695} \\
\hline \multicolumn{1}{|c|}{ Weighted Emission (g/bhp-hr) } & THC & NOx & CO & PM \\
\hline \hline GE 1869 turbo (Baseline) & - & - & - & - \\
\hline \hline Globe 1883 turbo & -19.72 & -14.73 & -14.80 & -18.56 \\
\hline \hline Globe 1869 turbo & -15.78 & -9.60 & -51.17 & -2.05 \\
\hline
\end{tabular}




\subsection{Recommendations}

Through the results of the studies recorded in this document, it is recommended that the fuel injection timing be retarded and the standard turbochargers and used cylinder liners be used in the operations of locomotives and locomotive engines. The increase in the PM emissions needs to be addressed. This may be done either through further examination of the fuel injection and combustion chamber parameters, or through an after treatment system. 


\section{Chapter 6: References}

1. Ahmadi, M. R., Kittelson, D.B., and Brehob, D.D., 1990, "Combustion of Minimally Processed Coal Liquids in a Diesel Engine" SAE 900399.

2. Anada, S., 1997, "Development of SJ (Swirl Jet) Turbocharger for Diesel Engine Vehicles," SAE 970341.

3. Becker, Dean A., 1986, "An Application of Microprocessor Technology to DieselElectric Locomotives" SAE 860754.

4. Benavides, Efren M., Perez. Juan, Herrero, Ramon, and Aroyo, Emilio, 2000, "Numerical Simulation of the Injection Process in a Two-Stroke Diesel Engine" SAE 2000-01-0291.

5. Borthwick, R. Paul and Farrell, Patrick V., 2002, "Fuel Injection Spray and Combustion Chamber Wall Impingement in Large-Bore Diesel Engines" SAE 200201-0496.

6. Borwning, L.H., 1997,'’Technologies and Costs for On-Road Heavy Duty Engines Meeting 2004 Emissions Standards," SAE 973256.

7. Bureau of Transportation. (3/5/03). Emission Regulations for Locomotives. <http://www.bts.gov/publications/nts/html/table 04 35.html >

8. Chernich, Donald J., Chernich, Donald J., Jacobs, Paul E., Kowalski, John D., 1991, "A comparison of Heavy-Duty Diesel Truck Engine Smoke Opacities at high altitudes and at sea level." SAE 911671.

9. Code of Federal Regulation, Title 40, Part 86, Subpart N-Emission Regulations for New Otto-Cycle and Diesel Heavy-Duty Engines; Gaseous and Particulate Exhaust Test Procedures, 1998.

10. Code of Federal Regulation, Title 40, Part 92, Subpart B-Control of Air Pollution from Locomotives and Locomotive Engines; Gaseous and Particulate Exhaust Test Procedures, 2000.

11. Dynamic Brake. (4/5/03). Operations of the Dyna mic Brake System. <http://gelwood.railfan.net/manual/ft-sec1.html>

12. Environmental Protection Agency. (5/5/02). Diesel Emission Regulations. $<$ http://www.epa.org.html>

13. Espey, Christoph and Dec, John E., 1993, "Diesel Engine Combustion Studies in a Newly Designed Optical-Access Engine Using High-Speed Visualization and 2-D Laser Imaging" SAE 930971.

14. Evans, J.C., "Influence of Sulfur Content on Emissions from Diesel Engines Equipped with Oxidation Catalysts," M.S. Thesis, Department of Mechanical and Aerospace Engineering, West Virginia University, Morgantown, WV, 2001.

15. Ghaffarpour, M. and Baranescu, R., 1996, " $\mathrm{NO}_{\mathrm{x}}$ Reduction using Injection Rate Shaping and Intercooling in Diesel Engines," SAE 960845.

16. Hawley, J.G., Wallace, F.J., Cox, A., Horrocks, R.W., and Bird, G.L., 1999, "Reduction of Steady-State NoDx Levels from an Automotive Diesel Engine Using Optimized Vgt/Egr Schedules" SAE 1999-01-0835.

17. Hayashi, Makoto, Ogawa, Hiroshi, and Yahiro, Masahiko 1992, "Development of a Turbocharger System with Variable Area Turbine Nozzle for Heavy-Duty Trucks" SAE 920045. 
18. Heitland, Herbert, Rinne, Gerhart, Vanhalest, Robin, Willmann, Micheal, and Wislocki, Krzysztof, 2001, 'IC Engines for 100 Miles/Gallon Cars" SAE 2001-010258.

19. Hirata, Yutaka, Akita, Takashi, Arnold, Steven, and Ohkita, Akihiro, 1992, 'New Rh..3 Series Turbocharger for Diesel Engine with 400-2000kw per Turbo Rating" SAE 921701.

20. Hlousek, J., 1998, "Electronically Controlled Fuel Injection Systems for MediumSpeed Diesel Engines" SAE 981928.

21. Hodge, B.K. and Koenig, Keith, 1995, Compressible Fluid Dynamics, Prentice-Hall, Inc., Englewood Cliffs, New Jersey 07632.

22. Horbia Instruments Model AIA-210 NDIR Analyzer Instruction Manual 091215, Horbia Instruments Inc., Irvine, California

23. Ikegami, Makoto, Nakatani, Koic hiro, and Tanaka, Shotaro, 1997, 'Fuel Injection Rate Shaping and Its Effect on Exhaust Emissions in a Direct-Injection Diesel Engine Using a Spool Acceleration Type Injection System" SAE 970347.

24. Infoplease. (5/5/03). The Formation of Fischer-Tropsh Diesel Fuel. $<$ http://www.infoplease.com/ce6/sci/A0818760.html>

25. Kobayashi, Shinji, Sakai, Takayuki, Nakahira, Toshino, Komori, Masanori, and Tsujimura, Kinji, 1992, "Measurement of Flame Temperature Distribution in D.I. Diesel Engine with High Pressure Fuel Injection” SAE 920692.

26. Koike, Takaaki, Kobayashi, Takashi, Matsuoka, Kideaki, and Nakamura, Fusayoshi, 1988, "Improvement of Turbocharger Life for Diesel and Gasoline Engines" SAE 880563.

27. Kubota, Yuzuru, Hayashi, Sigenobu, Sawa, Norihiro, and Kajitani, Shuichi, 1991, "Step Response of Engine Torque and Speed in Small Two-Stroke Diesel Engines" SAE 911851.

28. Larsson, Anders, 1999, "Optical Studies in a DI Diesel Engine” SAE 1999-01-3650.

29. Locomotive Engine Running and Management. (3/8/03). Power of Locomotives. <http://www.railroadextra.com/chapt26.html>

30. Mayer, Ronald F. and Wolfe, Albert L., 1981, 'In-Vehicle History Recording of Diesel Engine Performance Parameters SAE 810982.

31. Muller, Martin, Hendricks, Elbert, and Sorenson, Spencer C., 1998, "Mean Valve Modeling of Turbocharged Spark Ignition Engines" SAE 980784.

32. Niemi, Seppo A., Lauren, Mika J., and Murtonen, Timo T., 2002, "Effect of WasteGate Turbocharging on the Exhaust Particulate Matter of An Off-Road Diesel Engine" SAE 2002-01-2159.

33. Ogura, Masaru, Umezaki, Eisaku, and Tomita, Tsuneo, 1989, "Study of Variable Scroll Type Turbocharger (Performance Test in Diesel Engine)" SAE 891873.

34. Roa, K. K., Winterbone, D.E., and Clough, E., 1993, 'Influence of Swirl on High Pressure Injection in Hydra Diesel Engine" SAE 930978.

35. Rosemount Analytical Model 402 Hydrocarbon Analyzer Instruction Manual 01582132, Rosemount Analytical Inc., LaHabra, California.

36. Rosemount Analytical Model 868 NDIR Analyzer Instruction Manual 015-748003, Rosemount Analytical Inc., LaHabra, California.

37. Rosemount Analytical Model 955 NO/NOx Analyzer Instruction Manual 015555479, Rosemount Analytical Inc., LaHabra, California. 
38. Senda, Jiro, Ogawa, Takayuki, Fujimoto, Hajime, Kimura, Norio, and Kubota, Hirofumi, 1992, 'Characteristics of Combustion in An IDI Diesel Engine with a Swirl Chamber Made of Ceramics SAE 920696.

39. Sharp, Christopher A., Khair, Magdi K., Gorel, Alex, 1999, "The Effect of a Turbocharger Clearance Control Coating on the Performance and Emissions of a 2Stroke Diesel Engine" SAE 1999-01-3665.

40. Soteriou, Celia, Andrews, Richard, and Smith, Mark, 1999, 'Further Studies of Cavitation and Atomization in Diesel Injection" SAE 1999-01-1486.

41. Stein, H. Juergen and Herdan, Thorsten, 1998, "Worldwide Harmonization of Exhaust Emission Test Procedures for Nonroad Engines Based on the International Standard Iso 8178" SAE 982043.

42. Stodolsky, Frank, Gaines, Linda, and Cuenca, Rolando M., 1998, 'Lifecycle Analysis for Freight Transport" SAE 982206.

43. Wilson, Brian K., 1993, 'The Analysis of Diesel Engine Turbocharger Vibration Using Time Synchronous Averaging” SAE 932500.

44. U.S. Army Corps of Engineers. (3/2/03). Tractive Force Calculations. <http://www.usace.army.mil/inet/usace-docs/armytm/tm5-850-2/entire.pdf $>$

45. Weaver, Christopher S. and McGregor, Douglas B., 1994, "Emissions Control Technology for Locomotive Engines" SAE 940453.

46. Yang, Minggao and Sorenson, S.C., 1992, 'Modeling of the Dynamic Processes in an Electronic Diesel Fuel Injection” System SAE 920240. 
Appendix A: Test Results for Locomotive 8678

\begin{tabular}{|c|c|c|c|c|c|c|c|c|c|c|c|c|}
\hline \multicolumn{13}{|c|}{ Table A1: Test 3688 -Locomotive 8678 with injection timing set at $11^{\circ} B T D C$} \\
\hline Notch Emissions & $\begin{array}{l}\text { Low } \\
\text { Idle }\end{array}$ & $\begin{array}{l}\text { Normal } \\
\text { Idle }\end{array}$ & $\begin{array}{c}\text { Dynamic } \\
\text { Brake }\end{array}$ & $\begin{array}{c}\text { Notch } \\
1\end{array}$ & $\begin{array}{l}\text { Notch } \\
2\end{array}$ & $\begin{array}{l}\text { Notch } \\
3\end{array}$ & $\begin{array}{c}\text { Notch } \\
4\end{array}$ & $\begin{array}{l}\text { Notch } \\
5\end{array}$ & $\begin{array}{l}\text { Notch } \\
6\end{array}$ & $\begin{array}{c}\text { Notch } \\
7\end{array}$ & $\begin{array}{c}\text { Notch } \\
8 / 7\end{array}$ & $\begin{array}{c}\text { Notch } \\
8\end{array}$ \\
\hline THC (g/bhp-hr) & 24.87 & 12.48 & 6.365 & 0.677 & 0.382 & 0.363 & 0.312 & 0.367 & 0.278 & 0.599 & & 0.426 \\
\hline NOx $\quad$ (g/bhp-hr) & 96.6 & 69.8 & 57.8 & 25.8 & 22.5 & 19.2 & 18.8 & 17 & 15.5 & 14.6 & & 13.7 \\
\hline CO (g/bhp-hr) & 67.4 & 34.45 & 15.86 & 1.28 & 0.87 & 1.08 & 1.3 & 1.54 & 1.35 & 1.25 & & 1.36 \\
\hline PM $\quad$ (g/bhp-hr) & 6.341 & 3.787 & 3.009 & 0.535 & 0.373 & 0.314 & 0.226 & 0.223 & 0.206 & 0.533 & & 0.227 \\
\hline $\mathrm{CO}_{2} \quad$ (g/bhp-hr) & 2815 & 2356 & 1860 & 627 & 561 & 549 & 515 & 502 & 488 & 478 & & 488 \\
\hline Power (hp) & 13 & 23 & 69 & 190 & 423 & 953 & 1405 & 2054 & 2735 & 3439 & & 3992 \\
\hline Speed $\quad(r p m)$ & 439 & 577 & 891 & 439 & 574 & 891 & 888 & 995 & 995 & 992 & & 1047 \\
\hline Fuel Rate $(\mathrm{lb} / \mathrm{hr})$ & 27 & 39 & 91 & 83 & 165 & 364 & 504 & 719 & 930 & 1148 & & 13.58 \\
\hline \multicolumn{13}{|c|}{ Smoke Results } \\
\hline $\begin{array}{c}\text { Steady State } \\
30 \%\end{array}$ & 12.8 & 15.0 & 13.8 & 16.5 & 15 & 11.2 & 13.4 & 12.2 & 12.8 & 13.7 & & 17.2 \\
\hline $\begin{array}{c}30 \text { Sec. Peak } \\
40 \%\end{array}$ & 8.5 & 11.6 & 10.7 & 11.5 & 10.3 & 10.4 & 7.0 & 5.8 & 6.4 & 6.4 & & 7.1 \\
\hline \multirow[t]{3}{*}{$\begin{array}{c}3 \text { Sec. Peak } \\
50 \%\end{array}$} & 19.3 & 28.5 & 18.1 & 22.2 & 12.8 & 12.9 & 11.7 & 9.3 & 15.5 & 14.3 & & 14.8 \\
\hline & \multicolumn{6}{|c|}{ Line Haul } & \multicolumn{6}{|c|}{ Switch } \\
\hline & \multicolumn{3}{|c|}{ Official Test Results } & \multicolumn{3}{|c|}{ Certification Level } & \multicolumn{3}{|c|}{ Official Test Results } & \multicolumn{3}{|c|}{ Certification Level } \\
\hline THC (g/bhp-hr) & \multicolumn{3}{|c|}{0.57} & \multicolumn{3}{|c|}{1.0} & \multicolumn{3}{|c|}{0.90} & \multicolumn{3}{|c|}{2.10} \\
\hline NO $_{x} \quad$ (g/bhp-hr) & \multicolumn{3}{|c|}{15.90} & \multicolumn{3}{|c|}{9.5} & \multicolumn{3}{|c|}{20.48} & \multicolumn{3}{|c|}{14.00} \\
\hline CO (g/bhp-hr) & \multicolumn{3}{|c|}{1.73} & \multicolumn{3}{|c|}{5.0} & \multicolumn{3}{|c|}{2.66} & \multicolumn{3}{|c|}{9.00} \\
\hline PM $\quad$ (g/bhp-hr) & \multicolumn{3}{|c|}{0.31} & \multicolumn{3}{|c|}{0.6} & \multicolumn{3}{|c|}{0.43} & \multicolumn{3}{|c|}{0.72} \\
\hline $\mathrm{CO}_{2} \quad$ (g/bhp-hr) & \multicolumn{3}{|c|}{519} & \multicolumn{3}{|c|}{-} & \multicolumn{3}{|c|}{588} & \multicolumn{3}{|c|}{-} \\
\hline
\end{tabular}




\begin{tabular}{|c|c|c|c|c|c|c|c|c|c|c|c|c|}
\hline \multicolumn{13}{|c|}{ Table A2: Test $3689-$ Locomotive 8678 with injection timing set at $9^{\circ}$ BTDC } \\
\hline Notch Emissions & $\begin{array}{l}\text { Low } \\
\text { Idle }\end{array}$ & $\begin{array}{l}\text { Normal } \\
\text { Idle }\end{array}$ & $\begin{array}{c}\text { Dynamic } \\
\text { Brake }\end{array}$ & $\begin{array}{c}\text { Notch } \\
1\end{array}$ & $\begin{array}{c}\text { Notch } \\
2\end{array}$ & $\begin{array}{c}\text { Notch } \\
3\end{array}$ & $\begin{array}{c}\text { Notch } \\
4\end{array}$ & $\begin{array}{l}\text { Notch } \\
\quad 5\end{array}$ & $\begin{array}{l}\text { Notch } \\
6\end{array}$ & $\begin{array}{c}\text { Notch } \\
7\end{array}$ & $\begin{array}{c}\text { Notch } \\
8 / 7\end{array}$ & $\begin{array}{c}\text { Notch } \\
8\end{array}$ \\
\hline THC $\quad$ (g/bhp-hr) & 19.426 & 15.005 & 8.454 & 0.814 & 0.41 & 0.392 & 0.341 & 0.402 & 0.323 & 0.371 & & 0.405 \\
\hline NO $_{x} \quad(g / b h p-h r)$ & 74.43 & 60.53 & 38.11 & 14.46 & 13.55 & 11.57 & 11.41 & 10.33 & 9.79 & 9.66 & & 9.32 \\
\hline CO (g/bhp-hr) & 25.3 & 19.16 & 12.23 & 1.05 & 0.93 & 1.37 & 2.65 & 1.74 & 1.34 & 1.36 & & 1.68 \\
\hline PM $\quad$ (g/bhp-hr) & 5.484 & 4.014 & 3.676 & 0.487 & 0.336 & 0.338 & 0.286 & 0.273 & 0.223 & 0.243 & & 0.264 \\
\hline $\mathrm{CO}_{2} \quad$ (g/bhp-hr) & 2778 & 2330 & 1866 & 572 & 544 & 539 & 517 & 502 & 487 & 487 & & 500 \\
\hline Power (hp) & 13 & 24 & 71 & 188 & 423 & 954 & 1405 & 2051 & 2734 & 3446 & & 3993 \\
\hline Speed $\quad$ (rpm) & 442 & 574 & 891 & 439 & 574 & 888 & 888 & 995 & 995 & 992 & & 1047 \\
\hline Fuel Rate $\quad$ (lb/hr) & 26 & 40 & 94 & 75 & 160 & 358 & 508 & 719 & 927 & 1169 & & 1392 \\
\hline \multicolumn{13}{|c|}{ Smoke Results } \\
\hline $\begin{array}{c}\text { Steady State } \\
30 \%\end{array}$ & 14.9 & 15.6 & 14.8 & 17.8 & 15.5 & 14.6 & 19.7 & 18.1 & 24.7 & 18.1 & & 24.5 \\
\hline $\begin{array}{c}30 \text { Second Peak } \\
40 \%\end{array}$ & 9.9 & 14.5 & 12.4 & 12.3 & 12.8 & 14.3 & 13.3 & 14.4 & 11.5 & 13.6 & & 13.8 \\
\hline \multirow[t]{3}{*}{$\begin{array}{c}3 \text { Second Peak } \\
50 \%\end{array}$} & 11.9 & 27.9 & 18.5 & 14.3 & 14.8 & 23.7 & 18.3 & 23.6 & 17.2 & 21.7 & & 18.3 \\
\hline & \multicolumn{6}{|c|}{ Line Haul } & \multicolumn{6}{|c|}{ Switch } \\
\hline & \multicolumn{3}{|c|}{ Official Test Results } & \multicolumn{3}{|c|}{ Certification Level } & \multicolumn{3}{|c|}{ Official Test Results } & \multicolumn{3}{|c|}{ Certification Level } \\
\hline THC (g/bhp-hr) & \multicolumn{3}{|c|}{0.56} & \multicolumn{3}{|c|}{1.0} & \multicolumn{3}{|c|}{0.93} & \multicolumn{3}{|c|}{2.10} \\
\hline $\mathrm{NO}_{\mathrm{x}} \quad(\mathrm{g} / \mathrm{bhp}-\mathrm{hr})$ & \multicolumn{3}{|c|}{10.40} & \multicolumn{3}{|c|}{9.5} & \multicolumn{3}{|c|}{12.99} & \multicolumn{3}{|c|}{14.00} \\
\hline CO (g/bhp-hr) & \multicolumn{3}{|c|}{1.85} & \multicolumn{3}{|c|}{5.0} & \multicolumn{3}{|c|}{2.21} & \multicolumn{3}{|c|}{9.00} \\
\hline PM $\quad$ (g/bhp-hr) & \multicolumn{3}{|c|}{0.32} & \multicolumn{3}{|c|}{0.6} & \multicolumn{3}{|c|}{0.44} & \multicolumn{3}{|c|}{0.72} \\
\hline $\mathrm{CO}_{2} \quad$ (g/bhp-hr) & \multicolumn{3}{|c|}{526} & \multicolumn{3}{|c|}{-} & \multicolumn{3}{|c|}{582} & \multicolumn{3}{|c|}{-} \\
\hline
\end{tabular}




\begin{tabular}{|c|c|c|c|c|c|c|c|c|c|c|c|c|}
\hline Notch Emissions & $\begin{array}{l}\text { Low } \\
\text { Idle }\end{array}$ & $\begin{array}{l}\text { Normal } \\
\text { Idle }\end{array}$ & $\begin{array}{l}\text { Dynamic } \\
\text { Brake }\end{array}$ & $\begin{array}{c}\text { Notch } \\
1\end{array}$ & $\begin{array}{c}\text { Notch } \\
2\end{array}$ & $\begin{array}{c}\text { Notch } \\
3\end{array}$ & $\begin{array}{c}\text { Notch } \\
4\end{array}$ & $\begin{array}{c}\text { Notch } \\
5\end{array}$ & $\begin{array}{c}\text { Notch } \\
6\end{array}$ & $\begin{array}{c}\text { Notch } \\
7\end{array}$ & $\begin{array}{l}\text { Notch } \\
8 / 7\end{array}$ & $\begin{array}{l}\text { Notch } \\
8\end{array}$ \\
\hline THC $\quad$ (g/bhp-hr) & 12.2 & 12.52 & 8.065 & 0.83 & 0.405 & 0.323 & 0.382 & 0.415 & 0.35 & 0.412 & & 0.407 \\
\hline $\mathrm{NO}_{\mathrm{x}} \quad$ (g/bhp-hr) & 49.61 & 48.43 & 31.79 & 12.33 & 11.98 & 9.68 & 9.36 & 8.69 & 8.59 & 8.57 & & 7.94 \\
\hline CO $\quad$ (g/bhp-hr) & 16.15 & 15.42 & 11.41 & 1.19 & 1.04 & 1.8 & 3.44 & 1.99 & 1.58 & 1.75 & & 1.93 \\
\hline PM $\quad$ (g/bhp-hr) & 3.151 & 3.144 & 3.352 & 0.554 & 0.398 & 0.416 & 0.359 & 0.322 & 0.292 & 0.295 & & 0.325 \\
\hline $\mathrm{CO}_{2} \quad$ (g/bhp-hr) & 2062 & 2214 & 1869 & 592 & 553 & 545 & 529 & 514 & 497 & 499 & & 506 \\
\hline Power (hp) & 13 & 26 & 71 & 189 & 418 & 955 & 1406 & 2049 & 2732 & 3443 & & 3998 \\
\hline Speed $\quad($ rpm $)$ & 439 & 577 & 891 & 439 & 574 & 891 & 891 & 895 & 995 & 995 & & 1047 \\
\hline Fuel Rate $\quad$ (lb/hr) & 25 & 41 & 94 & 78 & 161 & 363 & 521 & 735 & 946 & 1199 & & 1412 \\
\hline \multicolumn{13}{|c|}{ Smoke Results } \\
\hline $\begin{array}{c}\text { Steady State } \\
30 \%\end{array}$ & 13.4 & 14.3 & 11.5 & 16.2 & 12.3 & 13.5 & 21.4 & 14.9 & 12.8 & 13.1 & & 19.4 \\
\hline $\begin{array}{c}30 \text { Second Peak } \\
40 \%\end{array}$ & 10.9 & 12.6 & 11.9 & 14.3 & 13.1 & 17.5 & 21.4 & 18.3 & 12.6 & 12.5 & & 13.9 \\
\hline \multirow[t]{3}{*}{$\begin{array}{c}3 \text { Second Peak } \\
50 \%\end{array}$} & 20.2 & 26.1 & 18.8 & 18.4 & 19.3 & 25.9 & 33.1 & 27.9 & 21.9 & 13.2 & & 21.60 \\
\hline & \multicolumn{6}{|c|}{ Line Haul } & \multicolumn{6}{|c|}{ Switch } \\
\hline & \multicolumn{3}{|c|}{ Official Test Results } & \multicolumn{3}{|c|}{ Certification Level } & \multicolumn{3}{|c|}{ Official Test Results } & \multicolumn{3}{|c|}{ Certification Level } \\
\hline THC $\quad$ (g/bhp-hr) & \multicolumn{3}{|c|}{0.56} & \multicolumn{3}{|c|}{1.0} & \multicolumn{3}{|c|}{0.87} & \multicolumn{3}{|c|}{2.10} \\
\hline NO $_{x} \quad(g / b h p-h r)$ & \multicolumn{3}{|c|}{8.92} & \multicolumn{3}{|c|}{9.5} & \multicolumn{3}{|c|}{11.08} & \multicolumn{3}{|c|}{14.00} \\
\hline CO (g/bhp-hr) & \multicolumn{3}{|c|}{2.11} & \multicolumn{3}{|c|}{5.0} & \multicolumn{3}{|c|}{2.42} & \multicolumn{3}{|c|}{9.00} \\
\hline PM $\quad$ (g/bhp-hr) & \multicolumn{3}{|c|}{0.39} & \multicolumn{3}{|c|}{0.6} & \multicolumn{3}{|c|}{0.47} & \multicolumn{3}{|c|}{0.72} \\
\hline $\mathrm{CO}_{2} \quad$ (g/bhp-hr) & \multicolumn{3}{|c|}{533} & \multicolumn{3}{|c|}{-} & \multicolumn{3}{|c|}{590} & \multicolumn{3}{|c|}{-} \\
\hline
\end{tabular}




\begin{tabular}{|c|c|c|c|c|c|c|c|c|c|c|c|c|}
\hline \multicolumn{13}{|c|}{ Table A4: Test $3691-$ Locomotive 8678 with injection timing set at $8^{\circ}$ BTDC } \\
\hline Notch Emissions & $\begin{array}{l}\text { Low } \\
\text { Idle }\end{array}$ & $\begin{array}{l}\text { Normal } \\
\text { Idle }\end{array}$ & $\begin{array}{c}\text { Dynamic } \\
\text { Brake }\end{array}$ & $\begin{array}{c}\text { Notch } \\
1\end{array}$ & $\begin{array}{l}\text { Notch } \\
2\end{array}$ & $\begin{array}{c}\text { Notch } \\
3\end{array}$ & $\begin{array}{c}\text { Notch } \\
4\end{array}$ & $\begin{array}{l}\text { Notch } \\
5\end{array}$ & $\begin{array}{c}\text { Notch } \\
6\end{array}$ & $\begin{array}{l}\text { Notch } \\
7\end{array}$ & $\begin{array}{l}\text { Notch } \\
8 / 7\end{array}$ & $\begin{array}{l}\text { Notch } \\
8\end{array}$ \\
\hline THC $\quad(\mathrm{g} / \mathrm{bhp}-\mathrm{hr})$ & 15.64 & 15.84 & 9.09 & 0.8512 & 0.395 & 0.383 & 0.394 & 0.399 & 0.335 & 0.373 & & 0.394 \\
\hline $\begin{array}{ll}\mathrm{NO}_{\mathrm{x}} & (\mathrm{g} / \mathrm{bhp}-\mathrm{hr})\end{array}$ & 58.44 & 56.82 & 31.87 & 12.6 & 12.17 & 10.05 & 9.36 & 9.06 & 8.67 & 8.81 & & 8.34 \\
\hline $\begin{array}{ll}\text { CO } & \text { (g/bhp-hr) }\end{array}$ & 20.86 & 18.34 & 11.67 & 1.15 & 1.08 & 1.86 & 3.56 & 2.1 & 1.68 & 1.82 & & 1.98 \\
\hline $\begin{array}{ll}\text { PM } & \text { (g/bhp-hr) }\end{array}$ & 3.77 & 3.46 & 3.76 & 0.556 & 0.385 & 0.422 & 0.38 & 0.33 & 0.29 & 0.3 & & 0.34 \\
\hline $\mathrm{CO}_{2} \quad$ (g/bhp-hr) & 2362 & 2496 & 1900 & 584 & 552 & 548 & 525 & 514 & 502 & 501 & & 504 \\
\hline $\begin{array}{ll}\text { Power } & \text { (hp) }\end{array}$ & 13 & 24 & 69 & 189 & 422 & 953 & 1404 & 2049 & 2732 & 3441 & & 3997 \\
\hline Speed (rpm) & 442 & 580 & 894 & 442 & 574 & 891 & 891 & 995 & 995 & 995 & & 1050 \\
\hline Fuel Rate $\quad(\mathrm{lb} / \mathrm{hr})$ & 22 & 41 & 93 & 77 & 162 & 364 & 517 & 735 & 957 & 1202 & & 1406 \\
\hline \multicolumn{13}{|c|}{ Smoke Results } \\
\hline $\begin{array}{c}\text { Steady State } \\
30 \%\end{array}$ & 14.6 & 13.9 & 14.3 & 17.9 & 14.9 & 15.3 & 21.5 & 17.3 & 14.9 & 15.0 & & 19.4 \\
\hline $\begin{array}{c}30 \text { Second Peak } \\
40 \%\end{array}$ & 12.2 & 15.3 & 13.3 & 15.4 & 15.2 & 19.7 & 20.9 & 20.9 & 14.1 & 13.8 & & 16.0 \\
\hline \multirow[t]{3}{*}{$\begin{array}{c}3 \text { Second Peak } \\
50 \%\end{array}$} & 21.4 & 26.9 & 22.4 & 23.5 & 21.7 & 24.1 & 24.5 & 29.3 & 21.9 & 19.1 & & 23.5 \\
\hline & \multicolumn{6}{|c|}{ Line Haul } & \multicolumn{6}{|c|}{ Switch } \\
\hline & \multicolumn{3}{|c|}{ Official Test Results } & \multicolumn{3}{|c|}{ Certification Level } & \multicolumn{3}{|c|}{ Official Test Results } & \multicolumn{3}{|c|}{ Certification Level } \\
\hline THC $\quad$ (g/bhp-hr) & \multicolumn{3}{|c|}{0.55} & \multicolumn{3}{|c|}{1.0} & \multicolumn{3}{|c|}{0.90} & \multicolumn{3}{|c|}{2.10} \\
\hline $\mathrm{NO}_{\mathrm{x}} \quad(\mathrm{g} / \mathrm{bhp}-\mathrm{hr})$ & \multicolumn{3}{|c|}{9.23} & \multicolumn{3}{|c|}{9.5} & \multicolumn{3}{|c|}{11.36} & \multicolumn{3}{|c|}{14.00} \\
\hline CO (g/bhp-hr) & \multicolumn{3}{|c|}{2.18} & \multicolumn{3}{|c|}{5.0} & \multicolumn{3}{|c|}{2.53} & \multicolumn{3}{|c|}{9.00} \\
\hline PM $\quad$ (g/bhp-hr) & \multicolumn{3}{|c|}{0.39} & \multicolumn{3}{|c|}{0.6} & \multicolumn{3}{|c|}{0.47} & \multicolumn{3}{|c|}{0.72} \\
\hline $\mathrm{CO}_{2} \quad$ (g/bhp-hr) & \multicolumn{3}{|c|}{532} & \multicolumn{3}{|c|}{ 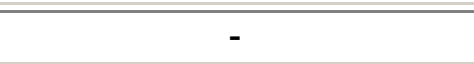 } & \multicolumn{3}{|c|}{565} & \multicolumn{3}{|c|}{-} \\
\hline
\end{tabular}




\begin{tabular}{|c|c|c|c|c|c|c|c|c|c|c|c|c|}
\hline \multicolumn{13}{|c|}{ Table A5: Test 3692 -Locomotive 8678 with injection timing set at $8^{\circ}$ BTDC } \\
\hline Notch Emissions & $\begin{array}{l}\text { Low } \\
\text { Idle }\end{array}$ & $\begin{array}{l}\text { Normal } \\
\text { Idle }\end{array}$ & $\begin{array}{l}\text { Dynamic } \\
\text { Brake }\end{array}$ & $\begin{array}{c}\text { Notch } \\
1\end{array}$ & $\begin{array}{l}\text { Notch } \\
2\end{array}$ & $\begin{array}{c}\text { Notch } \\
3\end{array}$ & $\begin{array}{c}\text { Notch } \\
4\end{array}$ & $\begin{array}{l}\text { Notch } \\
5\end{array}$ & $\begin{array}{l}\text { Notch } \\
6\end{array}$ & $\begin{array}{l}\text { Notch } \\
7\end{array}$ & $\begin{array}{l}\text { Notch } \\
8 / 7\end{array}$ & $\begin{array}{l}\text { Notch } \\
8\end{array}$ \\
\hline THC $\quad$ (g/bhp-hr) & 7.183 & 10.44 & 5.543 & 0.586 & 0.3022 & 0.356 & 0.332 & 0.379 & 0.363 & 0.364 & & 0.381 \\
\hline $\mathrm{NO}_{\mathrm{x}} \quad$ (g/bhp-hr) & 29.67 & 36.01 & 19.16 & 9.02 & 8.99 & 8.28 & 8 & 7.47 & 7.76 & 7.99 & & 7.76 \\
\hline (g/bhp-hr) & 6.98 & 10.45 & 6.74 & 0.71 & 0.8 & 1.63 & 3.32 & 1.85 & 1.44 & 1.56 & & 1.74 \\
\hline $\begin{array}{ll}\text { PM } & \text { (g/bhp-hr) }\end{array}$ & 1.693 & 2.257 & 1.758 & 0.364 & 0.28 & 0.349 & 0.352 & 0.283 & 0.25 & 0.263 & & 0.294 \\
\hline $\mathrm{CO}_{2} \quad(\mathrm{~g} / \mathrm{bhp}-\mathrm{hr})$ & 2133 & 2900 & 1919 & 578 & 554 & 547 & 528 & 508 & 486 & 493 & & 506 \\
\hline Power $\quad$ (hp) & 18 & 24 & 69 & 189 & 421 & 953 & 1405 & 2048 & 2733 & 3445 & & 3996 \\
\hline Speed $\quad(r p m)$ & 442 & 557 & 894 & 442 & 574 & 888 & 888 & 995 & 992 & 992 & & 1047 \\
\hline Fuel Rate $\quad(\mathrm{lb} / \mathrm{hr})$ & 27 & 49 & 93 & 76 & 162 & 363 & 520 & 726 & 926 & 1185 & & 1410 \\
\hline \multicolumn{13}{|c|}{ Smoke Results } \\
\hline $\begin{array}{c}\text { Steady State } \\
30 \%\end{array}$ & 12.1 & 11.9 & 11.3 & 17.7 & 14 & 15.4 & 23 & 15.9 & 13.8 & 13.3 & & 18.4 \\
\hline $\begin{array}{c}30 \text { Second Peak } \\
40 \%\end{array}$ & 9.4 & 11.3 & 10.6 & 15.7 & 14.7 & 18.7 & 22.9 & 22.3 & 13.6 & 12.5 & & 13.9 \\
\hline \multirow[t]{3}{*}{$\begin{array}{c}3 \text { Second Peak } \\
50 \%\end{array}$} & 17.2 & 22.3 & 19.3 & 22.9 & 19.8 & 26.9 & 33.2 & 33.7 & 20.3 & 20.4 & & 23.8 \\
\hline & \multicolumn{6}{|c|}{ Line Haul } & \multicolumn{6}{|c|}{ Switch } \\
\hline & \multicolumn{3}{|c|}{ Official Test Results } & \multicolumn{3}{|c|}{ Certification Level } & \multicolumn{3}{|c|}{ Official Test Results } & \multicolumn{3}{|c|}{ Certification Level } \\
\hline THC $\quad$ (g/bhp-hr) & \multicolumn{3}{|c|}{0.48} & \multicolumn{3}{|c|}{1.0} & \multicolumn{3}{|c|}{0.68} & \multicolumn{3}{|c|}{2.10} \\
\hline $\mathrm{NO}_{\mathrm{x}} \quad$ (g/bhp-hr) & \multicolumn{3}{|c|}{8.12} & \multicolumn{3}{|c|}{9.5} & \multicolumn{3}{|c|}{9.01} & \multicolumn{3}{|c|}{14.00} \\
\hline CO $\quad$ (g/bhp-hr) & \multicolumn{3}{|c|}{1.84} & \multicolumn{3}{|c|}{5.0} & \multicolumn{3}{|c|}{1.99} & \multicolumn{3}{|c|}{9.00} \\
\hline PM $\quad$ (g/bhp-hr) & \multicolumn{3}{|c|}{0.32} & \multicolumn{3}{|c|}{0.6} & \multicolumn{3}{|c|}{0.37} & \multicolumn{3}{|c|}{0.72} \\
\hline $\begin{array}{ll}\mathrm{CO}_{2} & \text { (g/bhp-hr) }\end{array}$ & \multicolumn{3}{|c|}{534} & \multicolumn{3}{|c|}{-} & \multicolumn{3}{|c|}{600} & \multicolumn{3}{|c|}{ 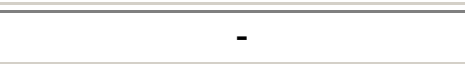 } \\
\hline
\end{tabular}


Notch Emissions for Locomotive 8678

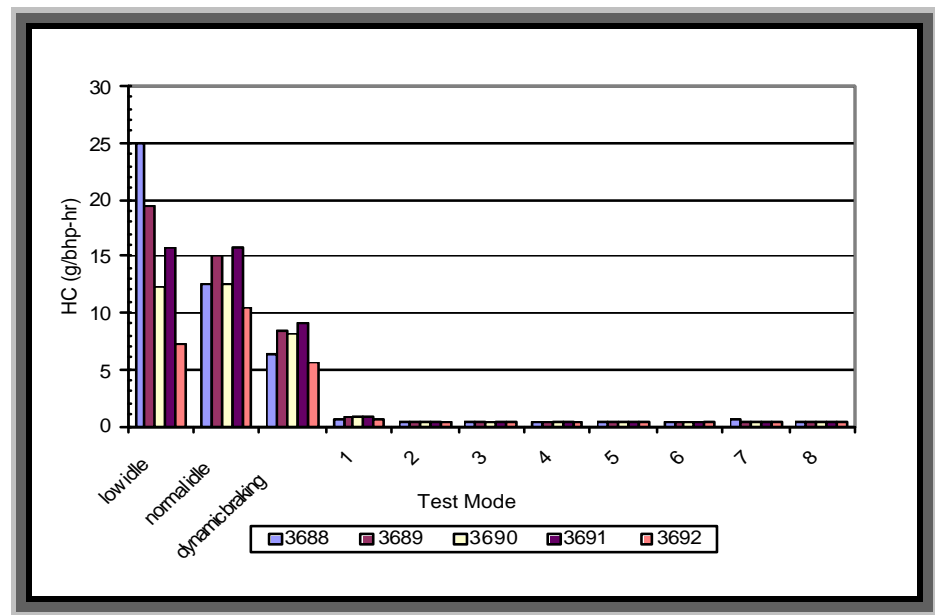

Figure A1: HC Emissions

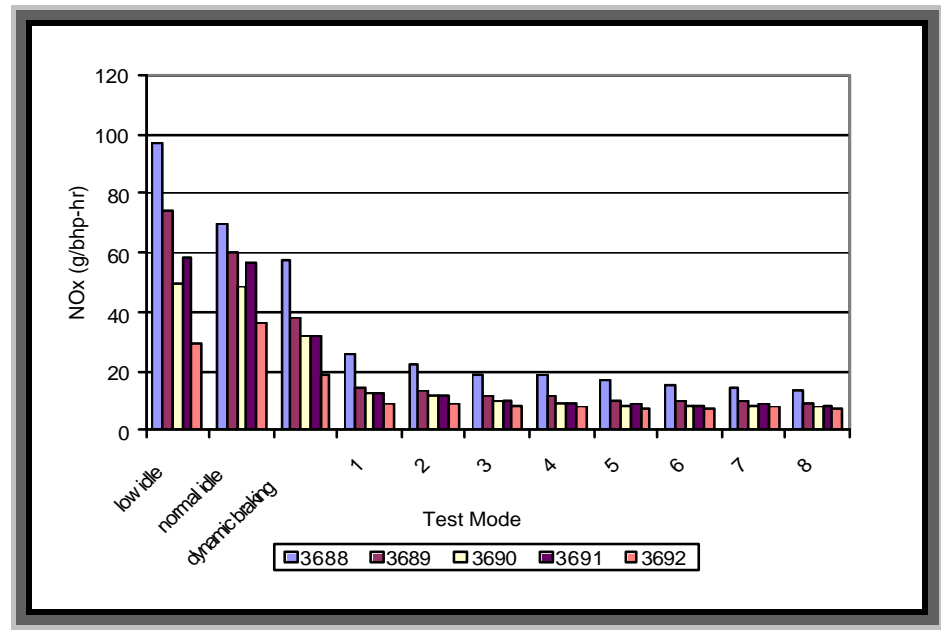

Figure A3: NOx Emissions

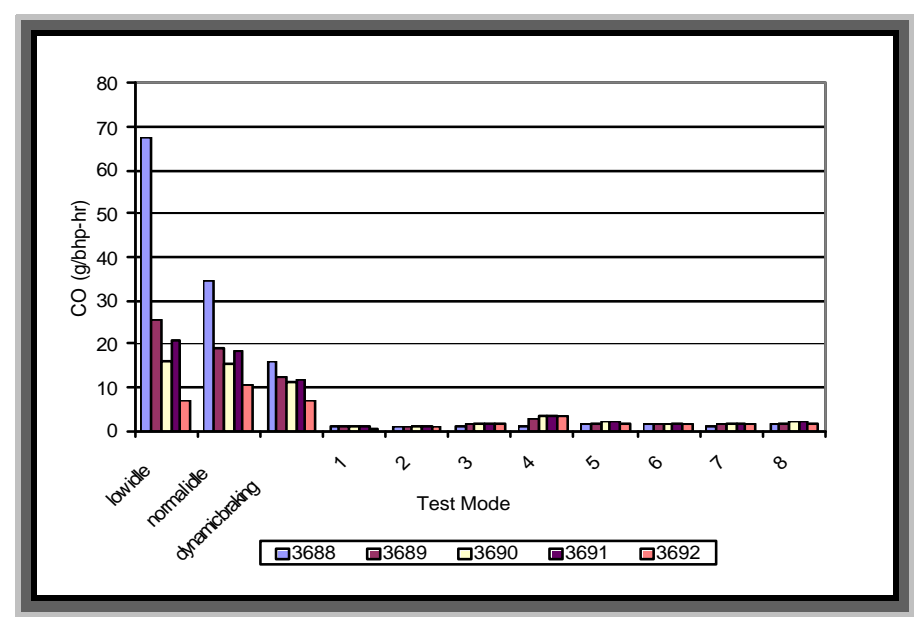

Figure A2: CO Emissions

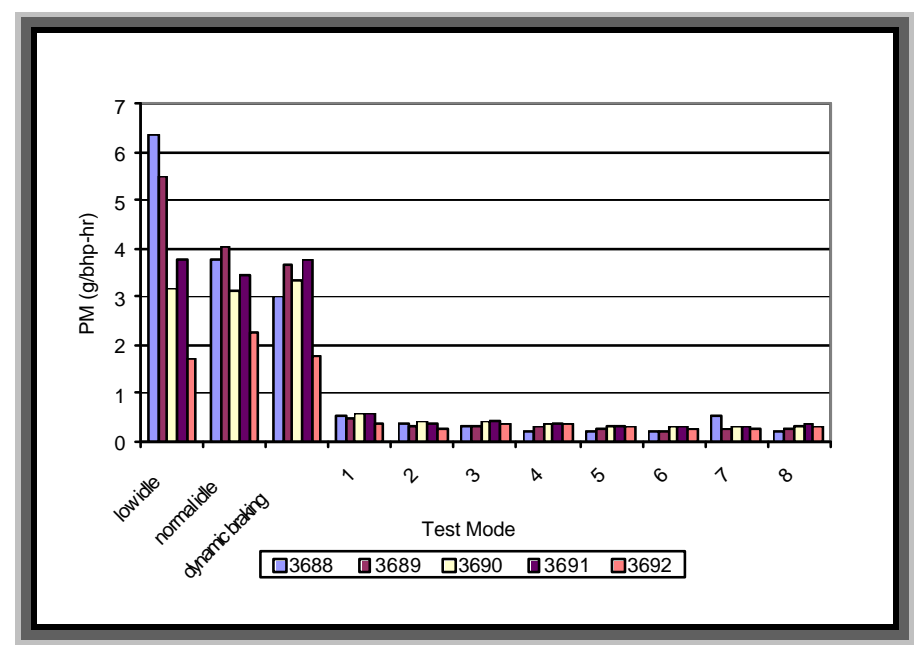

Figure A4: PM Emissions 
Weighted Emissions for Locomotive 8678

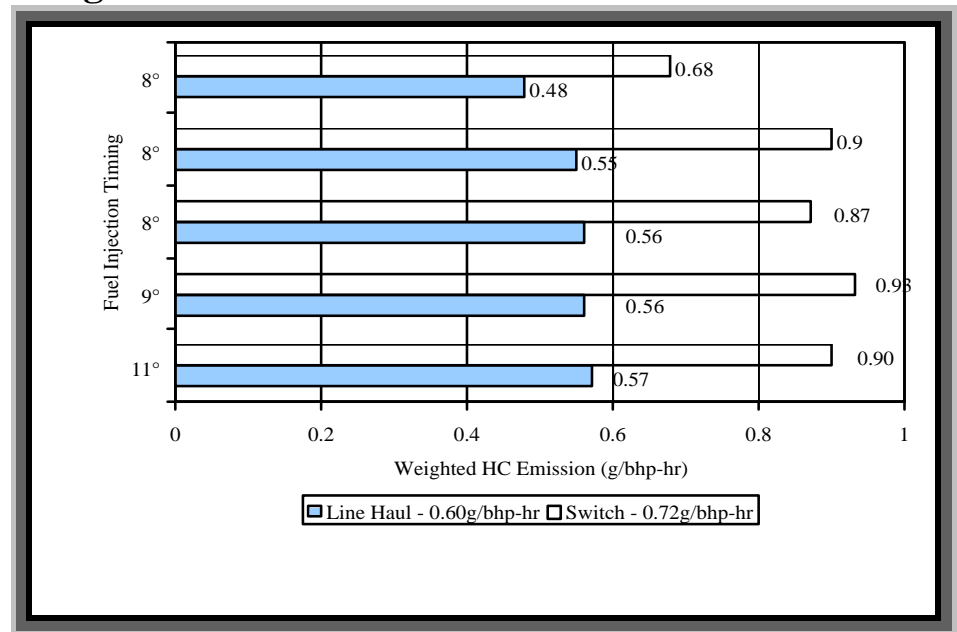

Figure A5: Weighted HC Emissions

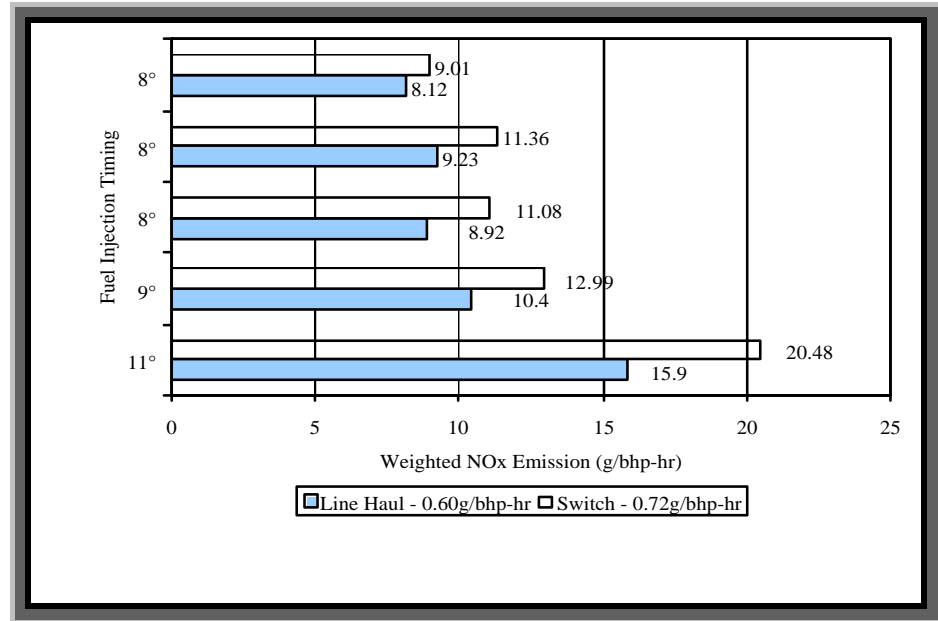

Figure A6: Weighted NOx Emissions

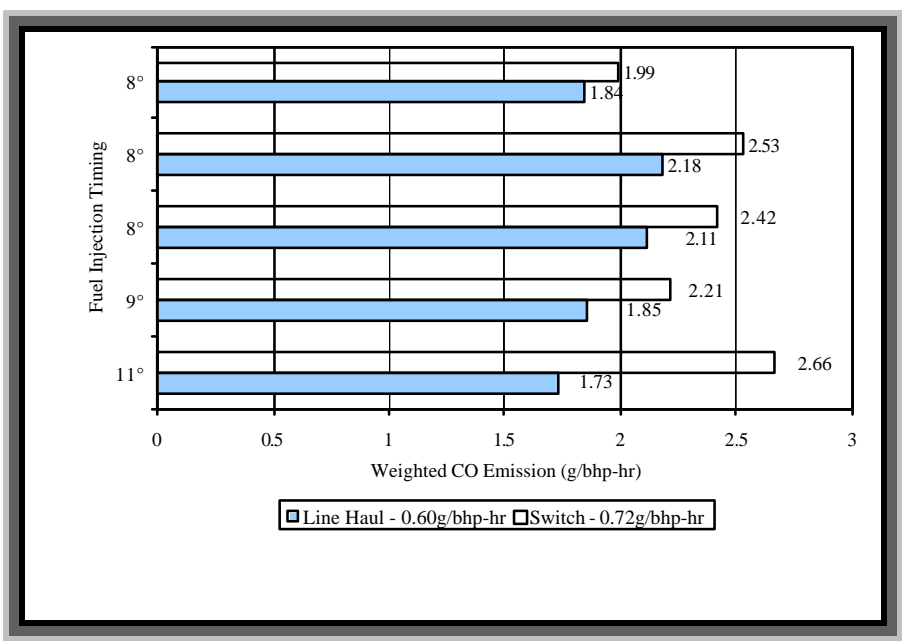

Figure A8: Weighted CO Emissions

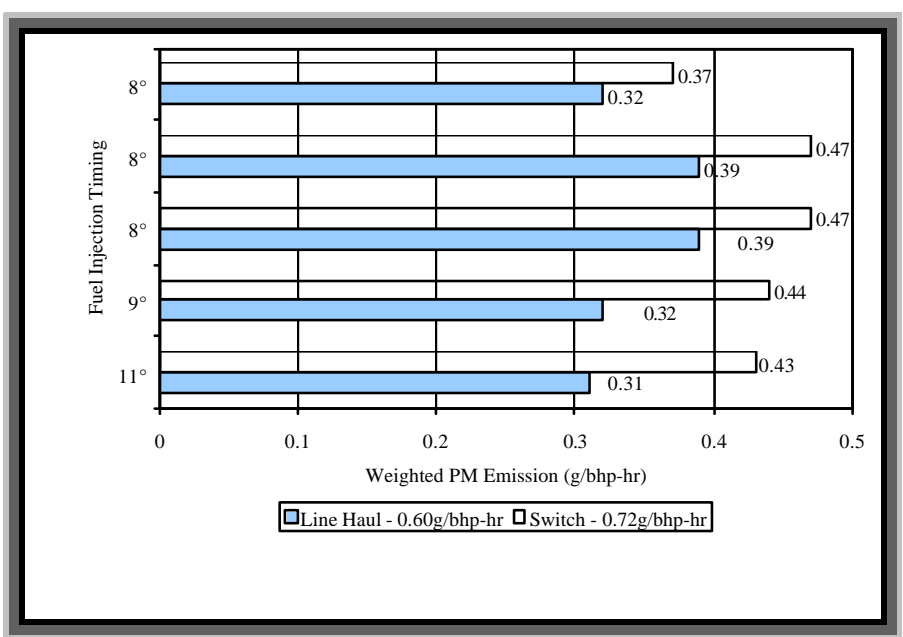

Figure A7: Weighted PM Emission 
Smoke Opacity for Locomotive 8678

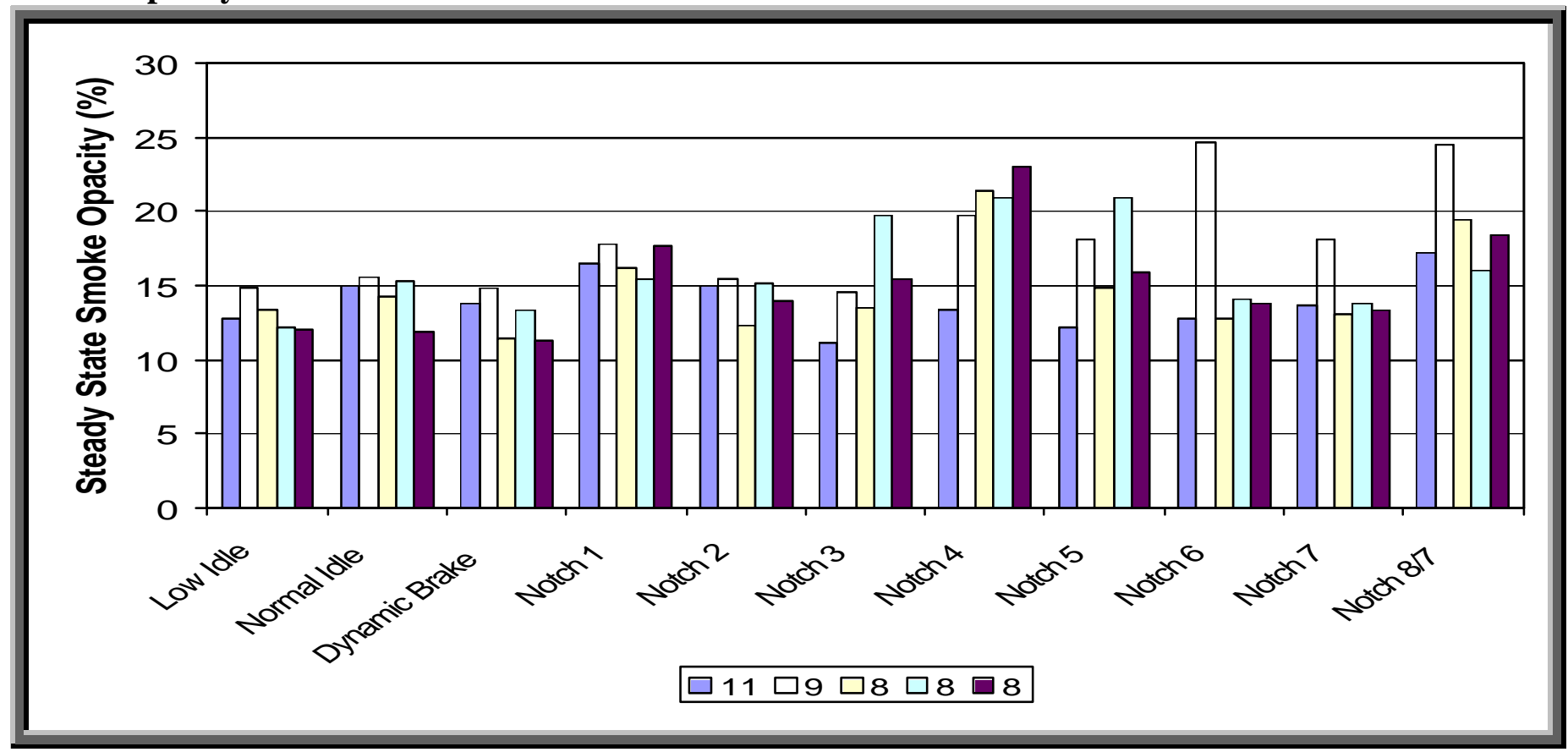

Figure A9: Steady State Smoke Opacity

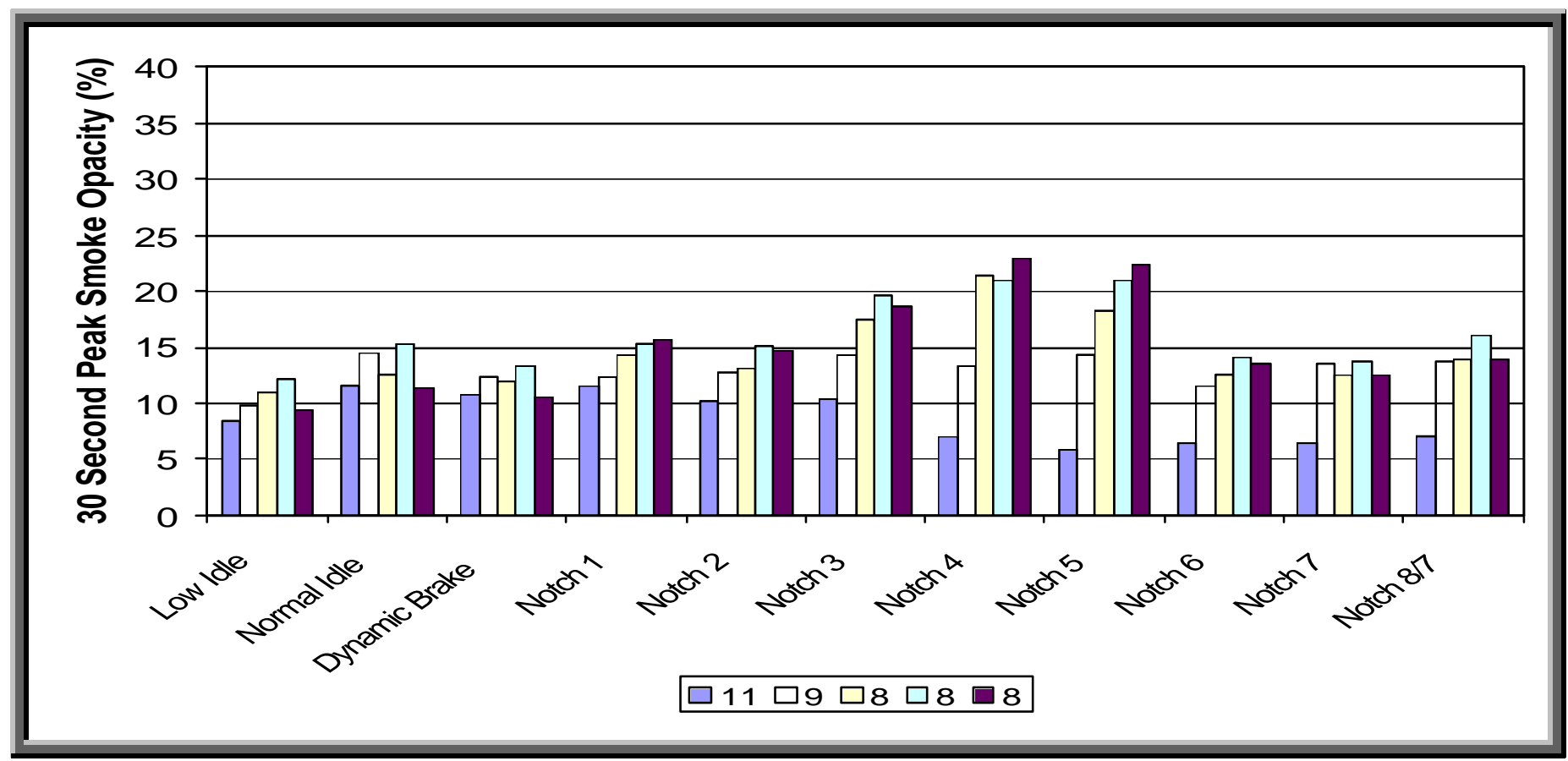

Figure A10: 30 Second Peak Smoke Opacity 


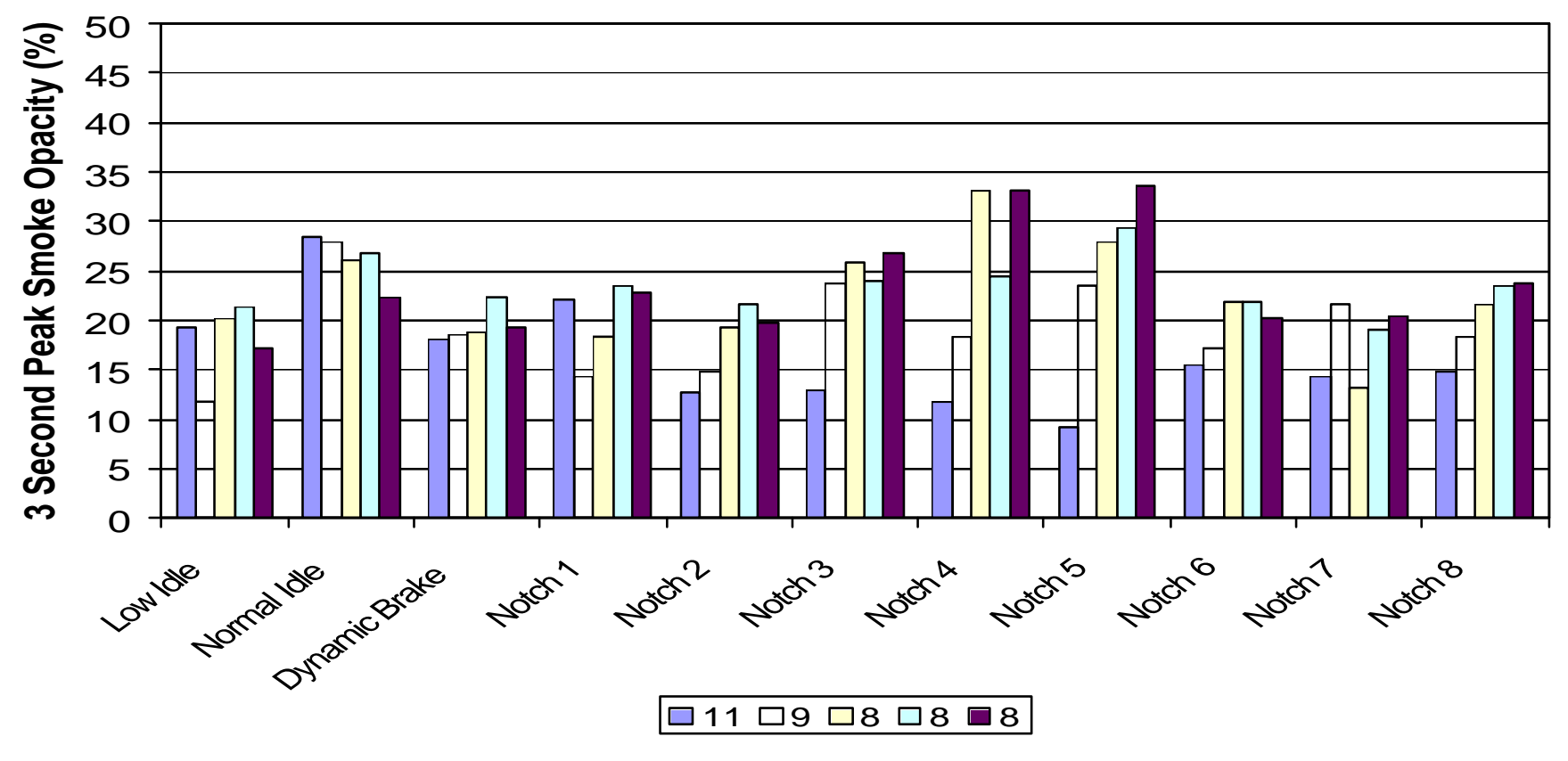

Figure A11: 3 Second Peak Smoke Opacity

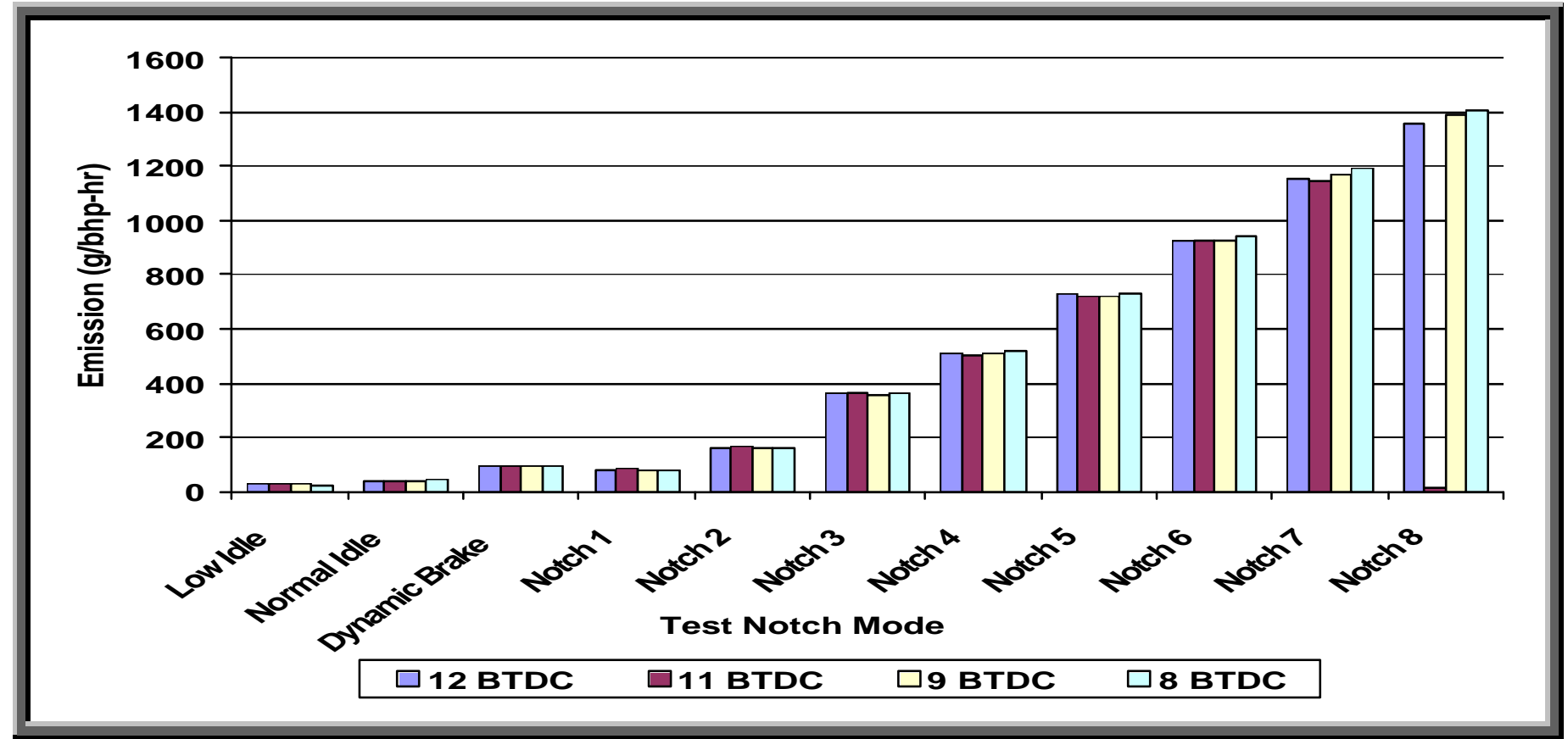

Figure A12: Fuel Consumption 
Test 3693-Locomotive 8692 with injection timing set at $8^{\circ}$ BTDC

\begin{tabular}{|c|c|c|c|c|c|c|c|c|c|c|c|}
\hline \multicolumn{12}{|c|}{ Test 3693 -Locomotive 8692 with injection timing set at $8^{\circ}$ BTDC } \\
\hline Notch Emissions & $\begin{array}{l}\text { Low } \\
\text { Idle }\end{array}$ & $\begin{array}{l}\text { Normal } \\
\text { Idle }\end{array}$ & $\begin{array}{l}\text { Dynamic } \\
\text { Brake }\end{array}$ & $\begin{array}{c}\text { Notch } \\
1\end{array}$ & $\begin{array}{l}\text { Notch } \\
2\end{array}$ & $\begin{array}{c}\text { Notch } \\
3\end{array}$ & $\begin{array}{l}\text { Notch } \\
\quad 4\end{array}$ & $\begin{array}{l}\text { Notch } \\
5\end{array}$ & $\begin{array}{l}\text { Notch } \\
6\end{array}$ & $\begin{array}{l}\text { Notch } \\
7\end{array}$ & Notch 8 \\
\hline (g/bhp-hr) & 15.515 & 12.725 & 9.4 & 0.745 & 0.395 & 0.45 & 0.35 & 0.355 & 0.345 & 0.385 & 0.35 \\
\hline (g/bhp-hr) & 47.35 & 41.185 & 31.12 & 11.425 & 10.32 & 10.095 & 10 & 8.76 & 8.79 & 9.095 & 8.43 \\
\hline (g/bhp-hr) & 17.615 & 13.93 & 15.4 & 1.32 & 1.33 & 1.765 & 2.42 & 1.94 & 1.15 & 0.67 & 0.405 \\
\hline (g/bhp-hr) & 3.87 & 3.52 & 6.79 & 0.8 & 0.67 & 0.515 & 0.35 & 0.265 & 0.25 & 0.275 & 0.35 \\
\hline (g/bhp-hr) & 2667.5 & 2203 & 1980.5 & 569 & 535.5 & 528.5 & 510.5 & 497.5 & 481.5 & 474 & 483.5 \\
\hline Horsepower (hp) & 14.5 & 25.5 & 71 & 189 & 423.5 & 952.5 & 1401 & 2052.5 & 2735 & 3439.5 & 4105 \\
\hline Engine Speed (rpm) & 436 & 584.5 & 886.5 & 436 & 583 & 885 & 886.5 & 995 & 995 & 995 & 1050 \\
\hline Fuel Rate & 27.5 & 40 & 100 & 75 & 158 & 351.5 & 499.5 & 713 & 917.5 & 1135 & 1379 \\
\hline \multicolumn{12}{|c|}{ Smoke Results } \\
\hline Steady State $\quad 30 \%$ & 48.75 & 36.45 & 38.3 & 45.95 & 53.9 & 46.1 & 55.65 & 61.45 & 51.6 & 50.95 & 49.85 \\
\hline 30 Second Peak $\quad 40 \%$ & 35.05 & 32.8 & 35.3 & 50.05 & 50.1 & 56.7 & 52.6 & 55.9 & 43.9 & 34.9 & 28 \\
\hline \multirow[t]{3}{*}{3 Second Peak $\quad 50 \%$} & 46.5 & 60.75 & 64.25 & 81.9 & 66.51 & 81.3 & 78.55 & 75.15 & 65.4 & 46.35 & 26.55 \\
\hline & \multicolumn{6}{|c|}{ Line Haul } & \multicolumn{5}{|c|}{ Switch } \\
\hline & \multicolumn{3}{|c|}{ Official Test Results } & \multicolumn{3}{|c|}{ Certification Level } & \multicolumn{3}{|c|}{ Official Test Results } & \multicolumn{2}{|c|}{ Certification Level } \\
\hline (g/bhp-hr) & \multicolumn{3}{|c|}{0.52} & \multicolumn{3}{|c|}{1.0} & \multicolumn{3}{|c|}{0.82} & \multicolumn{2}{|c|}{2.10} \\
\hline (g/bhp-hr) & \multicolumn{3}{|c|}{9.12} & \multicolumn{3}{|c|}{9.5} & \multicolumn{3}{|c|}{10.73} & \multicolumn{2}{|c|}{14.00} \\
\hline (g/bhp-hr) & \multicolumn{3}{|c|}{0.99} & \multicolumn{3}{|c|}{5.0} & & 1.96 & & & \\
\hline (g/bhp-hr) & & 0.43 & & & 0.6 & & & 0.52 & & & \\
\hline (g/bhp-hr) & & 514.00 & & & - & & & 576.33 & & & \\
\hline
\end{tabular}


Notch Emissions for Locomotive 8692

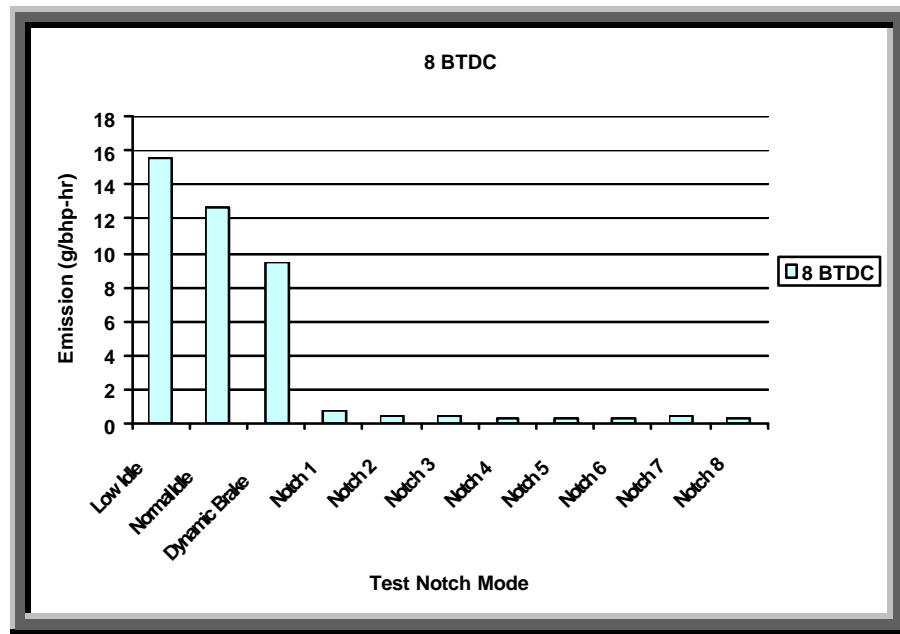

Figure A1: HC Emissions

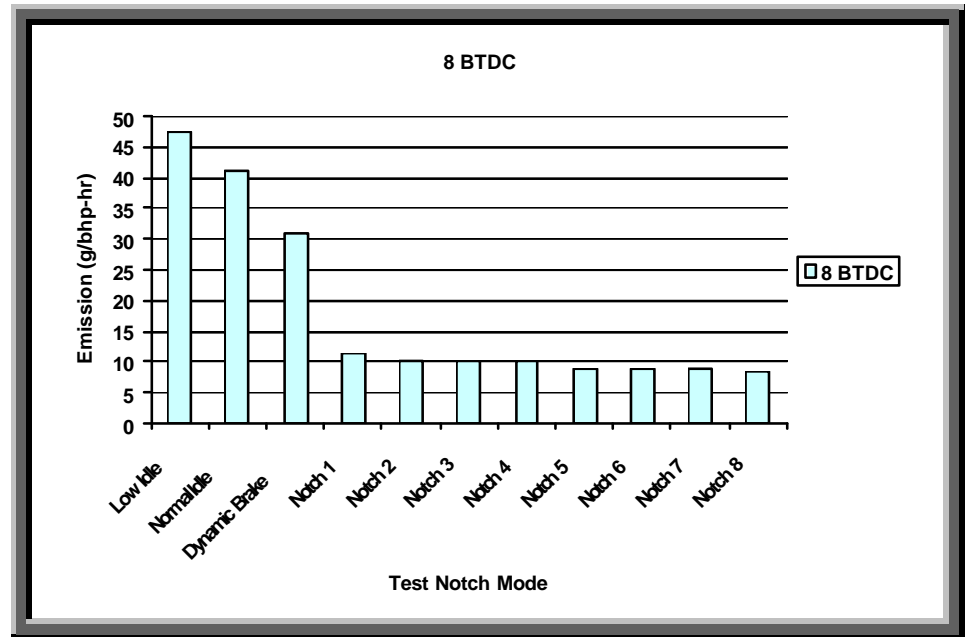

Figure A3: NOx Emissions

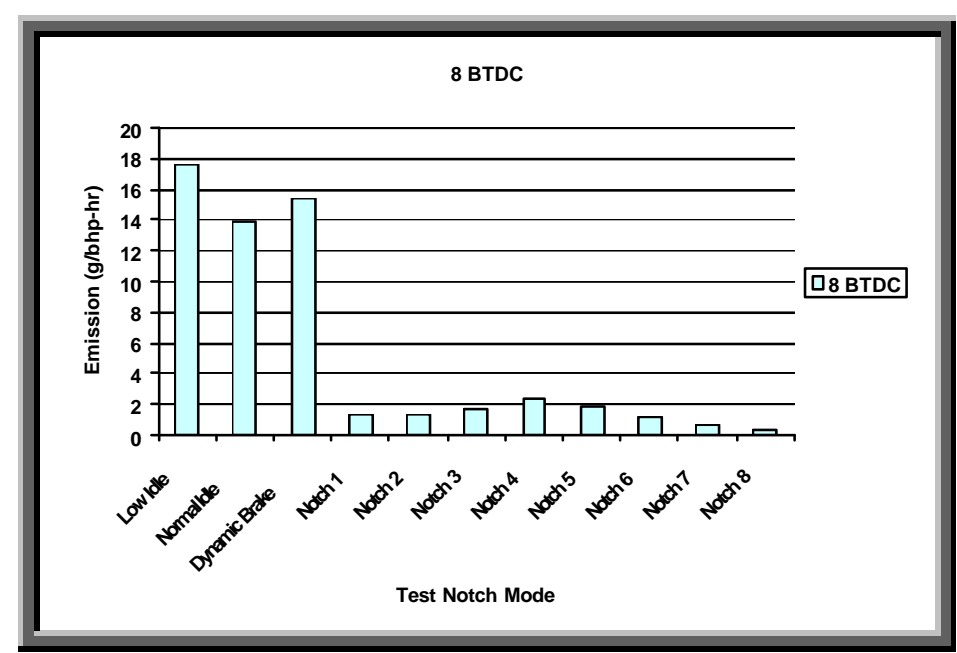

Figure A2: CO Emissions

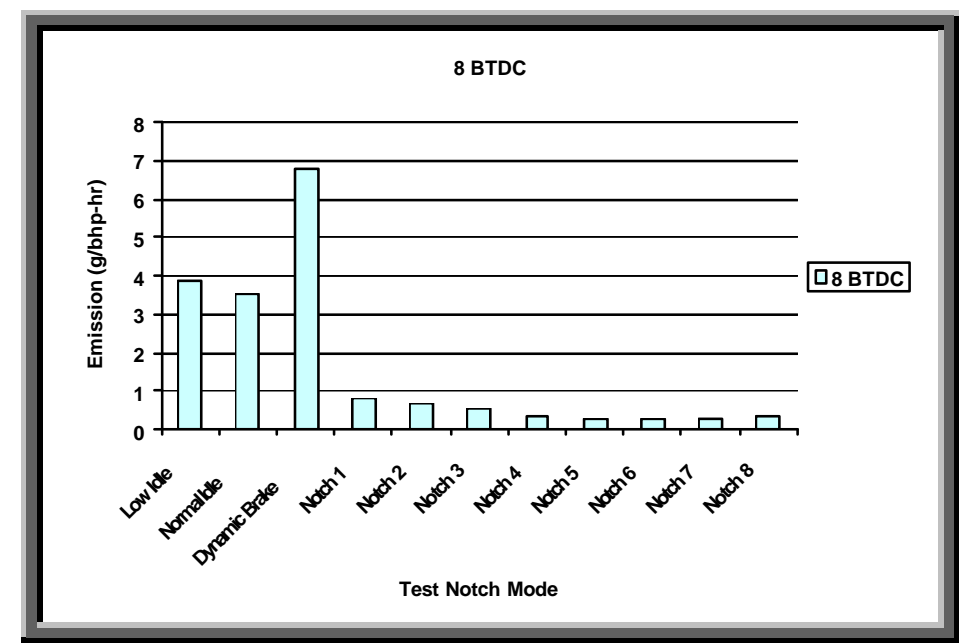

Figure A4: PM Emission 
Weighted Emissions for Locomotive 8692

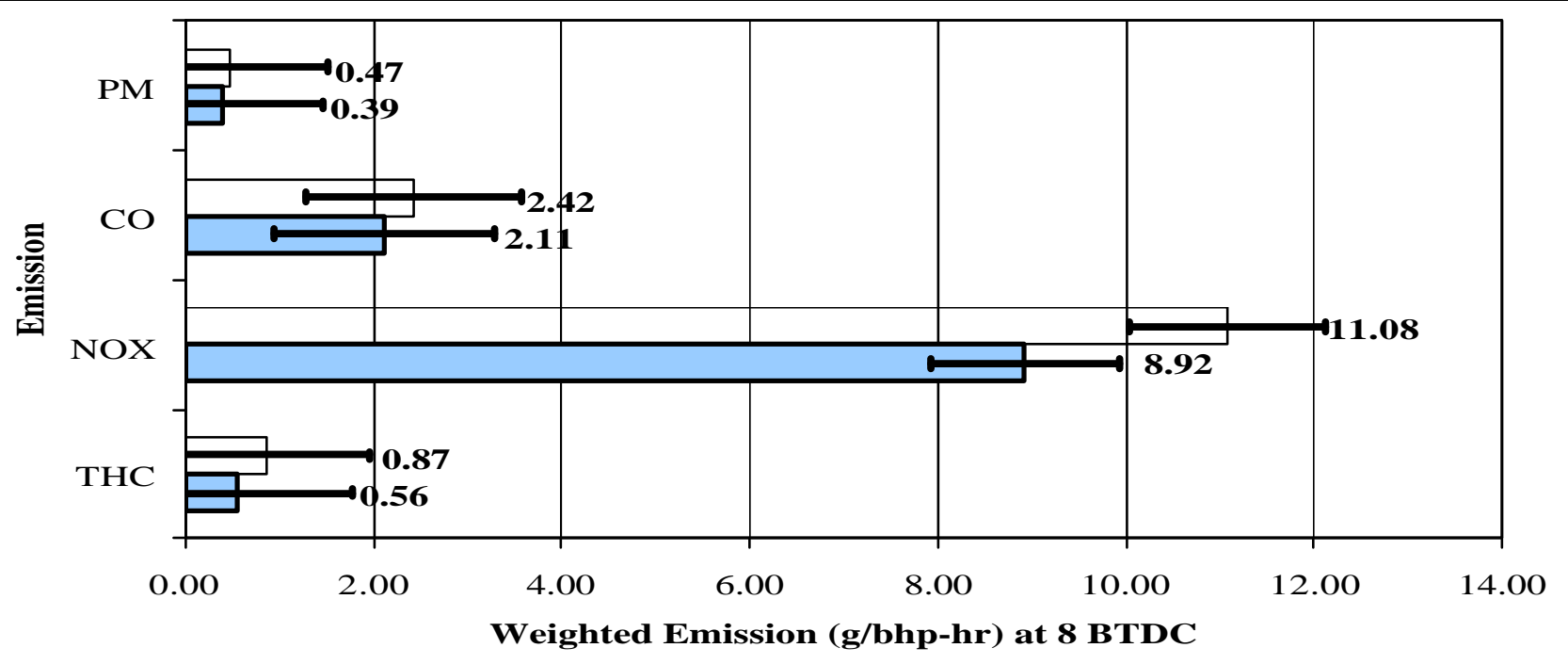

Line Haul - 0.60g/bhp-hr $\square$ Switch - 0.72g/bhp-hr

Figure A5: Weighted Emissions

Smoke Opacity for Locomotive 8678

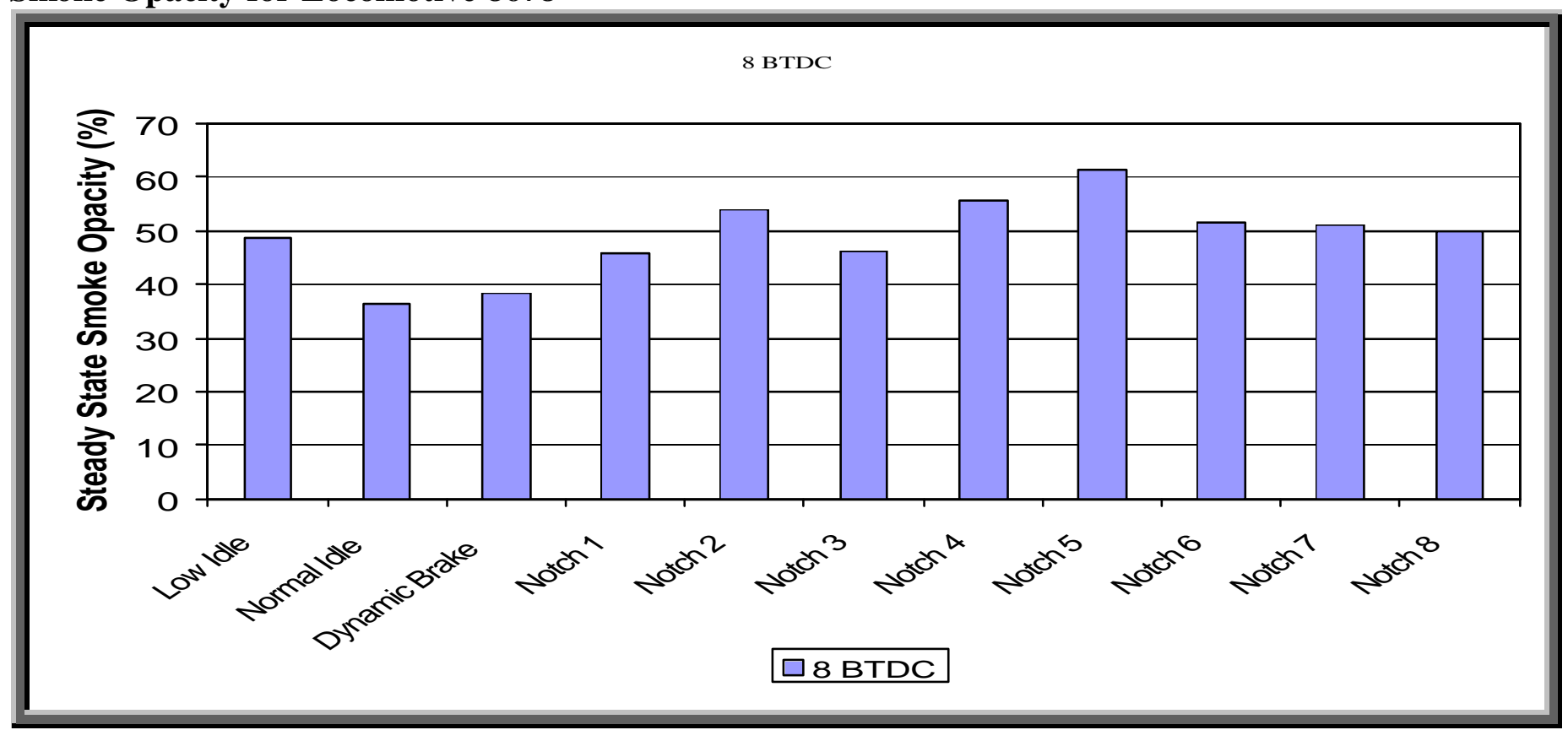

Figure A9: Steady State Smoke Opacity 


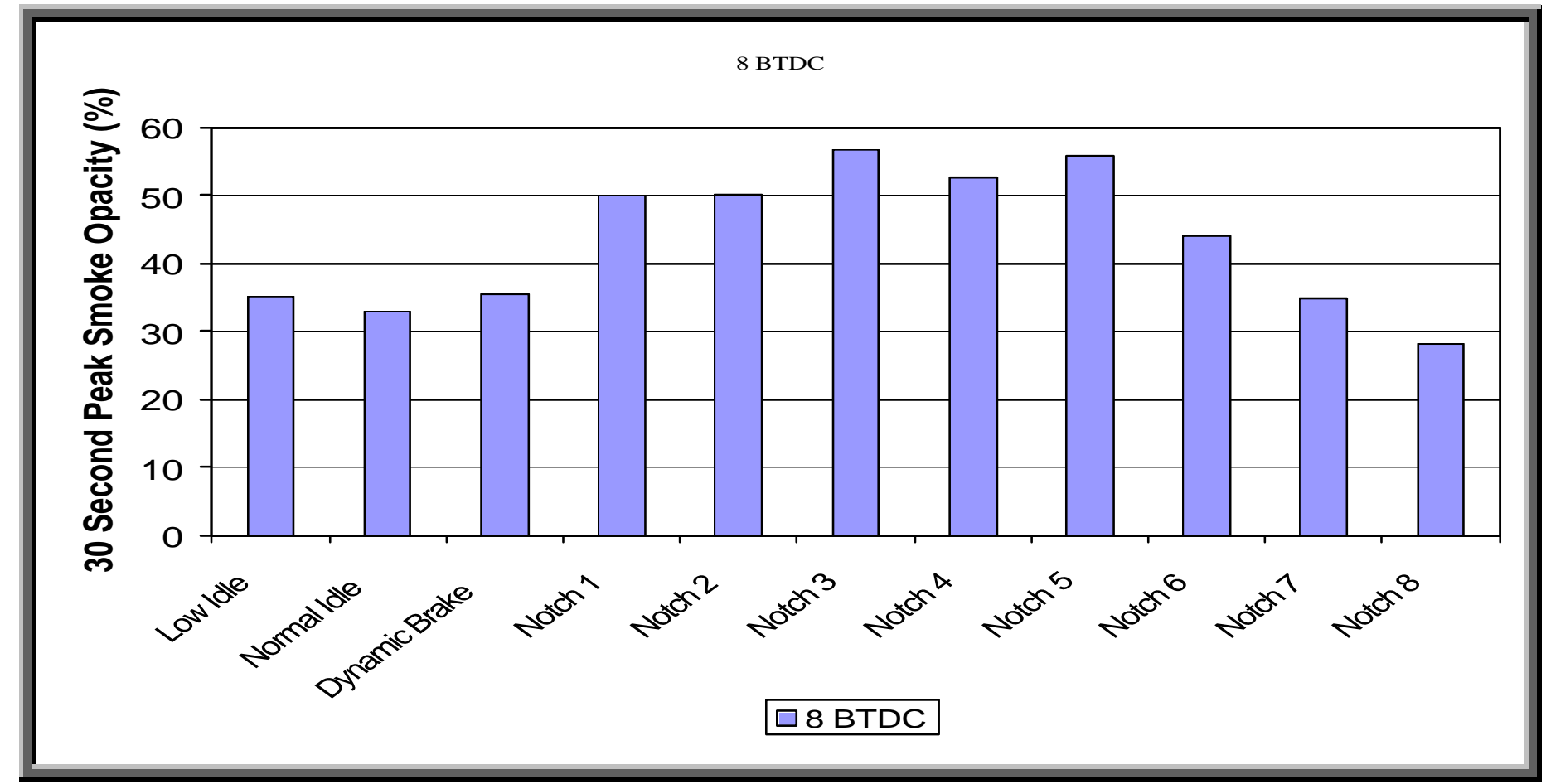

Figure A10: 30 Second Peak Smoke Opacity

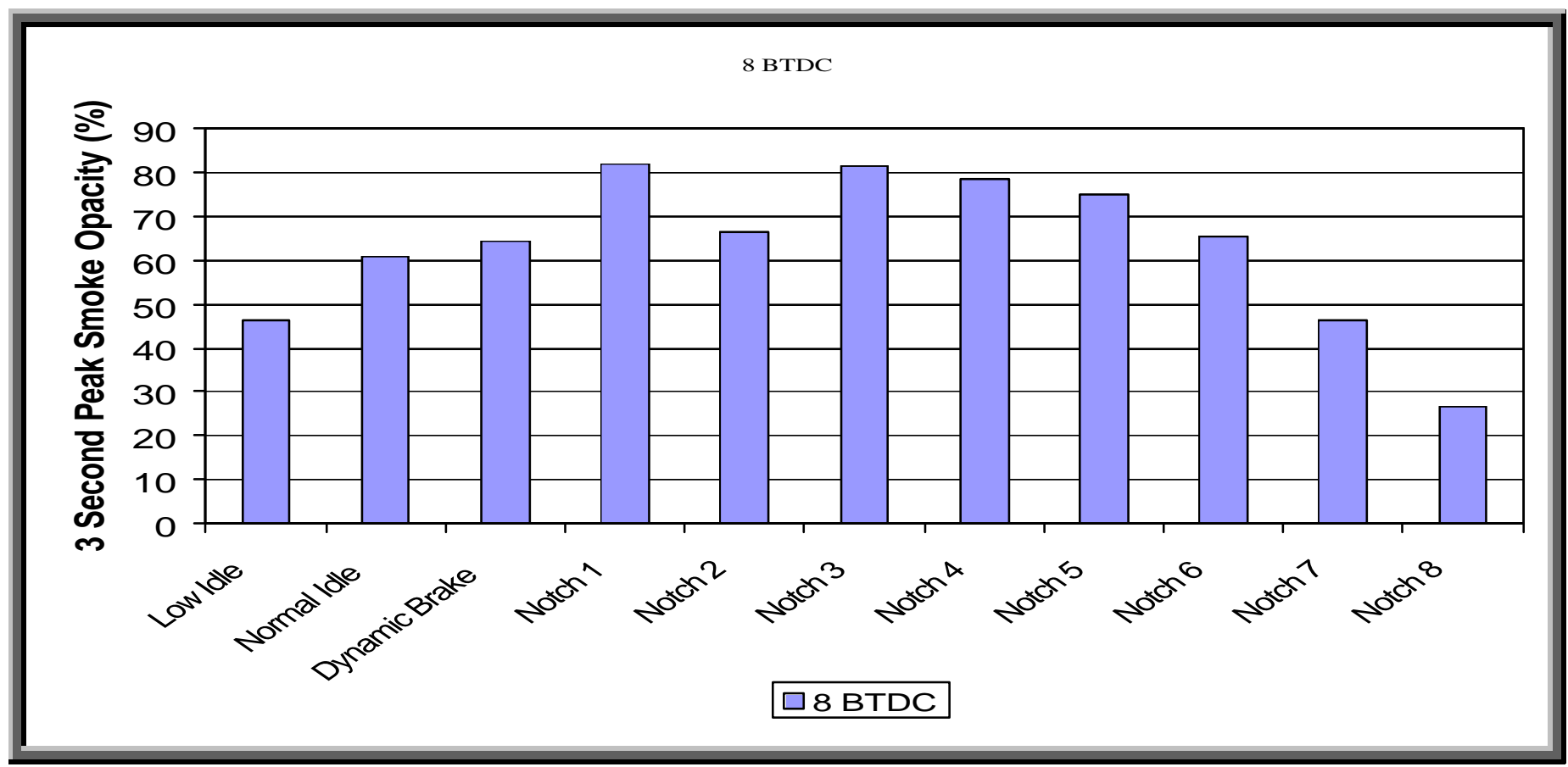

Figure A11: 3 Second Peak Smoke Opacity 
Figure A12: Fuel Consumption for Locomotive 8678

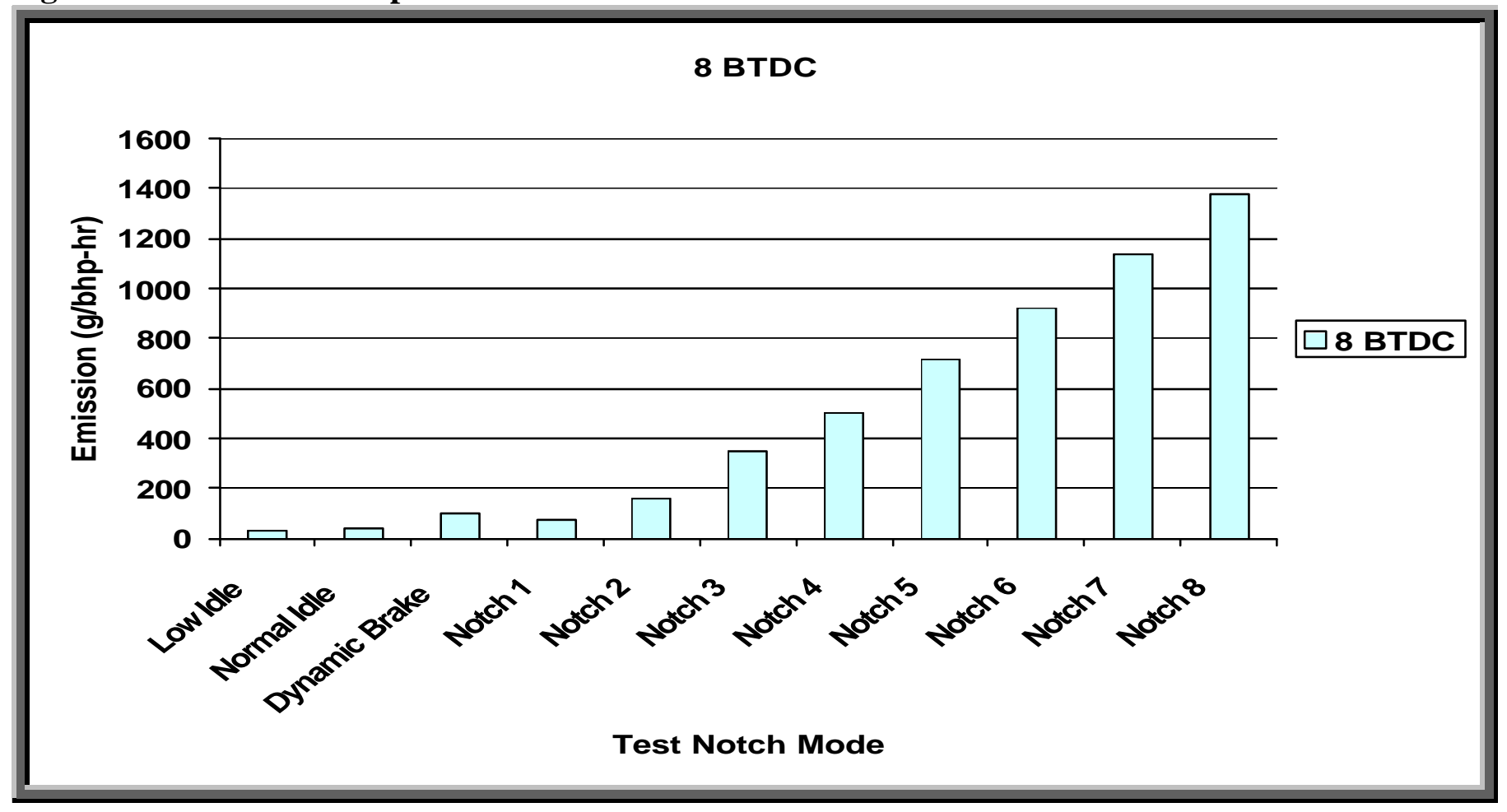


Appendix B: Test Results for Locomotive 8867

\begin{tabular}{|c|c|c|c|c|c|c|c|c|c|c|c|c|}
\hline \multicolumn{13}{|c|}{ Table B1: Test 3961- Locomotive 8867 GE Tier Zero EFI with GE 1883 turbo and new cylinder liners. } \\
\hline Notch Emissions & $\begin{array}{l}\text { Low } \\
\text { Idle }\end{array}$ & $\begin{array}{l}\text { Normal } \\
\text { Idle }\end{array}$ & $\begin{array}{c}\text { Dynamic } \\
\text { Brake }\end{array}$ & $\begin{array}{c}\text { Notch } \\
1\end{array}$ & $\begin{array}{c}\text { Notch } \\
2\end{array}$ & $\begin{array}{c}\text { Notch } \\
3\end{array}$ & $\begin{array}{c}\text { Notch } \\
4\end{array}$ & $\begin{array}{l}\text { Notch } \\
5\end{array}$ & $\begin{array}{c}\text { Notch } \\
6\end{array}$ & $\begin{array}{c}\text { Notch } \\
7\end{array}$ & $\begin{array}{c}\text { Notch } \\
8 / 7^{\star}\end{array}$ & $\begin{array}{c}\text { Notch } \\
8\end{array}$ \\
\hline THC (g/bhp-hr) & 1.24 & 2.65 & 2.14 & 0.60 & 0.37 & 0.42 & 0.31 & 0.25 & 0.19 & 0.16 & 0.14 & 0.15 \\
\hline $\mathrm{NO}_{\mathrm{x}} \quad(\mathrm{g} / \mathrm{bhp}-\mathrm{hr})$ & 22.75 & 43.05 & 16.68 & 11.46 & 9.82 & 12.77 & 12.84 & 6.55 & 4.94 & 6.05 & 6.04 & 5.77 \\
\hline CO (g/bhp-hr) & 1.56 & 3.61 & 4.57 & 0.77 & 0.73 & 1.06 & 1.22 & 1.08 & 1.11 & 0.62 & 0.65 & 0.64 \\
\hline PM $\quad$ (g/bhp-hr) & 0.56 & 1.62 & 1.35 & 0.31 & 0.30 & 0.30 & 0.18 & 0.23 & 0.25 & 0.12 & 0.17 & 0.12 \\
\hline $\mathrm{CO}_{2} \quad$ (g/bhp-hr) & 1241 & 2118 & 884 & 584 & 530 & 514 & 493 & 519 & 505 & 477 & 481 & 488 \\
\hline Power (hp) & 22 & 21 & 201 & 187 & 423 & 948 & 1404 & 2054 & 2734 & 3443 & 4104 & 4099 \\
\hline Speed $\quad$ (rpm) & & & & & & & & & & & & \\
\hline Fuel Rate (lb/hr) & 19 & 31 & 125 & 76 & 156 & 339 & 482 & 741 & 961 & 1141 & 1371 & 1388 \\
\hline \multicolumn{13}{|c|}{ Smoke Results } \\
\hline Steady State $\quad 30 \%$ & 3.6 & 2.73 & 15.94 & 9.61 & 10.45 & 14.13 & 16.52 & 23.66 & 22.63 & 11.38 & 7.75 & 8.34 \\
\hline 30 Second Peak 40\% & 0.32 & 11.37 & 8.5 & 5.26 & 5.91 & 7.99 & 7.15 & 10.92 & 10.16 & 7.69 & 4.72 & 3.4 \\
\hline \multirow[t]{3}{*}{3 Second Peak $50 \%$} & 1.42 & 12.63 & 11.17 & 5.72 & 10.08 & 12.08 & 12.25 & 25.53 & 15.2 & 15.3 & 7.15 & 6.38 \\
\hline & \multicolumn{6}{|c|}{ Line Haul } & \multicolumn{6}{|c|}{ Switch } \\
\hline & \multicolumn{3}{|c|}{ Official Test Results } & \multicolumn{3}{|c|}{ Certification Level } & \multicolumn{3}{|c|}{ Official Test Results } & \multicolumn{3}{|c|}{ Certification Level } \\
\hline THC $\quad$ (g/bhp-hr) & \multicolumn{3}{|c|}{0.25} & \multicolumn{3}{|c|}{1.0} & \multicolumn{3}{|c|}{0.37} & \multicolumn{3}{|c|}{2.10} \\
\hline NO $_{x} \quad(g / b h p-h r)$ & \multicolumn{3}{|c|}{7.05} & \multicolumn{3}{|c|}{9.5} & \multicolumn{3}{|c|}{9.95} & \multicolumn{3}{|c|}{14.00} \\
\hline (g/bhp-hr) & \multicolumn{3}{|c|}{0.87} & \multicolumn{3}{|c|}{5.0} & \multicolumn{3}{|c|}{1.03} & \multicolumn{3}{|c|}{9.00} \\
\hline (g/bhp-hr) & \multicolumn{3}{|c|}{0.19} & \multicolumn{3}{|c|}{0.6} & \multicolumn{3}{|c|}{0.27} & \multicolumn{3}{|c|}{0.72} \\
\hline $\mathrm{CO}_{2} \quad$ (g/bhp-hr) & \multicolumn{3}{|c|}{511} & \multicolumn{3}{|c|}{-} & \multicolumn{3}{|c|}{557} & \multicolumn{3}{|c|}{-} \\
\hline
\end{tabular}


Table B.2: Test 3962-Locomotive 8867 GE Tier Zero EFI with GE 1883 turbo and new cylinder liners.

\begin{tabular}{|c|c|c|c|c|c|c|c|c|c|c|c|c|}
\hline Notch Emissions & $\begin{array}{l}\text { Low } \\
\text { Idle }\end{array}$ & $\begin{array}{l}\text { Normal } \\
\text { Idle }\end{array}$ & $\begin{array}{l}\text { Dynamic } \\
\text { Brake }\end{array}$ & $\begin{array}{c}\text { Notch } \\
1\end{array}$ & $\begin{array}{l}\text { Notch } \\
2\end{array}$ & $\begin{array}{c}\text { Notch } \\
3\end{array}$ & $\begin{array}{c}\text { Notch } \\
4\end{array}$ & $\begin{array}{l}\text { Notch } \\
5\end{array}$ & $\begin{array}{l}\text { Notch } \\
6\end{array}$ & $\begin{array}{c}\text { Notch } \\
7\end{array}$ & $\begin{array}{c}\text { Notch } \\
8 / 7^{\star}\end{array}$ & Notch 8 \\
\hline (g/bhp-hr) & 1.22 & 2.40 & 1.80 & 0.56 & 0.35 & 0.40 & 0.30 & 0.25 & 0.21 & 0.17 & 0.13 & 0.14 \\
\hline NO $_{x} \quad(g / b h p-h r)$ & 21.99 & 41.05 & 16.04 & 11.63 & 9.67 & 12.61 & 12.82 & 6.50 & 5.01 & 6.04 & 6.00 & 5.80 \\
\hline CO (g/bhp-hr) & 1.23 & 3.40 & 4.23 & 0.75 & 0.80 & 1.03 & 1.18 & 1.03 & 1.05 & 0.63 & 0.68 & 0.61 \\
\hline PM $\quad$ (g/bhp-hr) & 0.59 & 2.13 & 1.13 & 0.31 & 0.27 & 0.33 & 0.17 & 0.21 & 0.22 & 0.13 & 0.12 & 0.08 \\
\hline $\mathrm{CO}_{2} \quad$ (g/bhp-hr) & 1232 & 2009 & 853 & 592 & 526 & 513 & 495 & 516 & 506 & 475 & 478 & 487 \\
\hline Power $\quad$ (hp) & 21 & 20 & 202 & 187 & 421 & 950 & 1404 & 2055 & 2734 & 3441 & 4100 & 4100 \\
\hline Speed $\quad$ (rpm) & & & & & & & & & & & & \\
\hline Fuel Rate $(\mathrm{Ib} / \mathrm{hr})$ & 18 & 28 & 121 & 77 & 154 & 339 & 484 & 738 & 962 & 1134 & 1362 & 1386 \\
\hline \multicolumn{13}{|c|}{ Smoke Results } \\
\hline Steady State $\quad 30 \%$ & 2.73 & 3.25 & 15.37 & 12.13 & 10.88 & 9.69 & 8.08 & 17.17 & 20.48 & 11.21 & 7.65 & 8.08 \\
\hline 30 Second Peak $40 \%$ & 0.2 & 10.77 & 8.67 & 5.99 & 6.56 & 6.42 & 5.72 & 9.69 & 10.01 & 7.7 & 4.32 & 3.59 \\
\hline \multirow[t]{3}{*}{3 Second Peak $50 \%$} & 1.43 & 12 & 9.17 & 6.42 & 13.15 & 1.25 & 9.3 & 24.25 & 13.5 & 12.95 & 7.72 & 8.08 \\
\hline & \multicolumn{6}{|c|}{ Line Haul } & \multicolumn{6}{|c|}{ Switch } \\
\hline & \multicolumn{3}{|c|}{ Official Test Results } & \multicolumn{3}{|c|}{ Certification Level } & \multicolumn{3}{|c|}{ Official Test Results } & \multicolumn{3}{|c|}{ Certification Level } \\
\hline THC $\quad$ (g/bhp-hr) & \multicolumn{3}{|c|}{0.24} & \multicolumn{3}{|c|}{1.0} & \multicolumn{3}{|c|}{0.36} & \multicolumn{3}{|c|}{2.10} \\
\hline NO $_{x} \quad(g / b h p-h r)$ & \multicolumn{3}{|c|}{7.03} & \multicolumn{3}{|c|}{9.5} & \multicolumn{3}{|c|}{9.83} & \multicolumn{3}{|c|}{14.00} \\
\hline CO (g/bhp-hr) & \multicolumn{3}{|c|}{0.83} & \multicolumn{3}{|c|}{5.0} & \multicolumn{3}{|c|}{1.00} & \multicolumn{3}{|c|}{9.00} \\
\hline (g/bhp-hr) & \multicolumn{3}{|c|}{0.16} & \multicolumn{3}{|c|}{0.6} & \multicolumn{3}{|c|}{0.27} & \multicolumn{3}{|c|}{0.72} \\
\hline $\mathrm{CO}_{2} \quad$ (g/bhp-hr) & \multicolumn{3}{|c|}{509} & \multicolumn{3}{|c|}{-} & \multicolumn{3}{|c|}{553} & \multicolumn{3}{|c|}{-} \\
\hline
\end{tabular}




\begin{tabular}{|c|c|c|c|c|c|c|c|c|c|c|c|c|}
\hline & & & Dvnamic & Notch & Notch & Notch & Notch & & & Notch & & \\
\hline Notch Emissions & Idle & Idle & Brake & 1 & 2 & 3 & 4 & 5 & 6 & 7 & $8 / 7^{*}$ & Notch 8 \\
\hline (g/bhp-hr) & 1.04 & 2.43 & 1.69 & 0.57 & 0.35 & 0.41 & 0.31 & 0.28 & 0.25 & 0.21 & & 0.17 \\
\hline (g/bhp-hr) & 19.40 & 41.46 & 18.43 & 12.41 & 10.33 & 13.24 & 14.05 & 6.81 & 5.74 & 7.03 & & 6.00 \\
\hline (g/bhp-hr) & 1.36 & 2.91 & 3.91 & 0.75 & 0.69 & 0.80 & 0.77 & 0.64 & 0.69 & 0.38 & & 0.41 \\
\hline (g/bhp-hr) & 1.81 & 1.79 & 1.24 & 0.37 & 0.40 & 1.28 & 0.57 & 0.82 & 0.29 & 0.22 & & 0.17 \\
\hline (g/bhp-hr) & 1062 & 2023 & 890 & 592 & 519 & 503 & 487 & 507 & 496 & 469 & & 482 \\
\hline Power & 23 & 22 & 205 & 187 & 421 & 951 & 1399 & 2048 & 2734 & 3440 & & 4102 \\
\hline Speed & & & & & & & & & & & & \\
\hline Fuel Rate $\quad(\mathrm{lb} / \mathrm{hr})$ & 17 & 31 & 128 & 77 & 152 & 333 & 474 & 721 & 943 & 1120 & & 1372 \\
\hline \multicolumn{13}{|c|}{ Smoke Results } \\
\hline Steady State $\quad 30 \%$ & 2.03 & 1.85 & 13.22 & 8.25 & 7.39 & 5.76 & 5.16 & 12.8 & 14.55 & 7.23 & & 5.07 \\
\hline 30 Second Peak $40 \%$ & -0.47 & 10.125 & 4.45 & 4.45 & 3.88 & 3.89 & 2.73 & 5.97 & 7.25 & 5.12 & & 3.13 \\
\hline \multirow[t]{3}{*}{3 Second Peak $50 \%$} & 0.48 & 12 & 7.98 & 5.62 & 7.98 & 3.87 & 4.2 & 13.3 & 9.38 & 7.58 & & 3.72 \\
\hline & \multicolumn{6}{|c|}{ Line Haul } & \multicolumn{6}{|c|}{ Switch } \\
\hline & \multicolumn{3}{|c|}{ Official Test Results } & \multicolumn{3}{|c|}{ Certification Level } & \multicolumn{3}{|c|}{ Official Test Results } & \multicolumn{3}{|c|}{ Certification Level } \\
\hline (g/bhp-hr) & \multicolumn{3}{|c|}{0.26} & \multicolumn{3}{|c|}{1.0} & \multicolumn{3}{|c|}{0.38} & \multicolumn{3}{|c|}{2.10} \\
\hline (g/bhp-hr) & \multicolumn{3}{|c|}{7.51} & \multicolumn{3}{|c|}{9.5} & \multicolumn{3}{|c|}{10.48} & \multicolumn{3}{|c|}{14.00} \\
\hline (g/bhp-hr) & \multicolumn{3}{|c|}{0.59} & \multicolumn{3}{|c|}{5.0} & \multicolumn{3}{|c|}{0.73} & \multicolumn{3}{|c|}{9.00} \\
\hline (g/bhp-hr) & \multicolumn{3}{|c|}{0.34} & \multicolumn{3}{|c|}{0.6} & \multicolumn{3}{|c|}{0.67} & \multicolumn{3}{|c|}{0.72} \\
\hline (g/bhp-hr) & \multicolumn{3}{|c|}{504} & \multicolumn{3}{|c|}{-} & \multicolumn{3}{|c|}{546} & \multicolumn{3}{|c|}{-} \\
\hline
\end{tabular}




\begin{tabular}{|c|c|c|c|c|c|c|c|c|c|c|c|c|}
\hline $\begin{array}{l}\text { Table } \\
\text { Notch Emissions }\end{array}$ & \multirow{2}{*}{$\begin{array}{l}\text { Test } 5 \\
\text { Low } \\
\text { Idle } \\
1.28\end{array}$} & \multirow{2}{*}{\begin{tabular}{|c|}
66 -Loco \\
$\begin{array}{c}\text { Normal } \\
\text { Idle }\end{array}$ \\
2.53 \\
\end{tabular}} & \multirow{2}{*}{$\begin{array}{c}\begin{array}{c}\text { Dynamic } \\
\text { Brake }\end{array} \\
1.92 \\
\end{array}$} & \multirow{2}{*}{$\begin{array}{c}\text { Notch } \\
\mathbf{1} \\
0.54\end{array}$} & \multirow{2}{*}{$\begin{array}{c}\text { Notch } \\
\mathbf{2} \\
0.34\end{array}$} & \multirow{2}{*}{$\begin{array}{c}\text { Notch } \\
\mathbf{3} \\
0.40\end{array}$} & \multirow{2}{*}{$\begin{array}{c}\text { Notch } \\
\mathbf{4} \\
0.32\end{array}$} & \multirow{2}{*}{$\begin{array}{c}\text { Notch } \\
\mathbf{5} \\
0.29\end{array}$} & \multirow{2}{*}{$\begin{array}{c}\begin{array}{c}\text { Notch } \\
6\end{array} \\
0.23 \\
\end{array}$} & \multirow{2}{*}{$\begin{array}{c}\text { Notch } \\
7 \\
0.21\end{array}$} & \multirow[t]{2}{*}{$\begin{array}{c}\text { Notch } \\
8 / 7^{\star}\end{array}$} & \multirow{2}{*}{$\begin{array}{c}\text { Notch } 8 \\
0.18\end{array}$} \\
\hline (g/bhp-hr) & & & & & & & & & & & & \\
\hline (g/bhp-hr) & 30.08 & 45.76 & 18.24 & 12.15 & 10.60 & 13.45 & 14.20 & 6.96 & 5.69 & 7.28 & & 6.16 \\
\hline (g/bhp-hr) & 2.43 & 4.33 & 4.02 & 0.74 & 0.80 & 0.80 & 0.82 & 0.66 & 0.71 & 0.43 & & 0.26 \\
\hline (g/bhp-hr) & 1.28 & 2.49 & 1.50 & 0.42 & 0.35 & 0.39 & 0.25 & 0.31 & 0.30 & 0.18 & & 0.16 \\
\hline (g/bhp-hr) & 1368 & 2186 & 894 & 578 & 532 & 514 & 487 & 511 & 494 & 469 & & 482 \\
\hline Power (hp) & 21 & 21 & 204 & 189 & 419 & 951 & 1401 & 2052 & 2734 & 3441 & & 4101 \\
\hline \multicolumn{13}{|l|}{ Speed (rpm) } \\
\hline Fuel Rate $\quad(\mathrm{lb} / \mathrm{hr})$ & 20 & 32 & 128 & 76 & 155 & 340 & 475 & 729 & 938 & 1121 & & 1370 \\
\hline \multicolumn{13}{|c|}{ Smoke Results } \\
\hline Steady State $\quad 30 \%$ & 3.34 & 4.12 & 12.72 & 10.29 & 8.17 & 8.42 & 7.91 & 15.5 & 17.82 & 9.19 & & 7.14 \\
\hline 30 Second Peak $40 \%$ & 0.52 & 9.91 & 6.44 & 4.81 & 4.92 & 5.73 & 4.41 & 8.44 & 8.99 & 6.23 & & 5.21 \\
\hline \multirow[t]{3}{*}{3 Second Peak $50 \%$} & 3.97 & 10.78 & 7.03 & 6 & 8.93 & 8.7 & 6.18 & 19.2 & 14.83 & 8.92 & & 10.92 \\
\hline & \multicolumn{6}{|c|}{ Line Haul } & \multicolumn{6}{|c|}{ Switch } \\
\hline & \multicolumn{3}{|c|}{ Official Test Results } & \multicolumn{3}{|c|}{ Certification Level } & \multicolumn{3}{|c|}{ Official Test Results } & \multicolumn{3}{|c|}{ Certification Level } \\
\hline (g/bhp-hr) & \multicolumn{3}{|c|}{0.27} & \multicolumn{3}{|c|}{1.0} & \multicolumn{3}{|c|}{0.37} & \multicolumn{3}{|c|}{2.10} \\
\hline (g/bhp-hr) & \multicolumn{3}{|c|}{7.69} & \multicolumn{3}{|c|}{9.5} & \multicolumn{3}{|c|}{10.83} & \multicolumn{3}{|c|}{14.00} \\
\hline (g/bhp-hr) & \multicolumn{3}{|c|}{0.52} & \multicolumn{3}{|c|}{5.0} & \multicolumn{3}{|c|}{0.79} & & 9.00 & \\
\hline (g/bhp-hr) & & 0.25 & & & 0.6 & & & 0.37 & & & 0.72 & \\
\hline (g/bhp-hr) & & 506 & & & - & & & 556 & & & 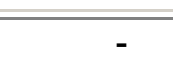 & \\
\hline
\end{tabular}




\begin{tabular}{|c|c|c|c|c|c|c|c|c|c|c|c|c|}
\hline Notch Emissions & $\begin{array}{l}\text { Low } \\
\text { Idle }\end{array}$ & $\begin{array}{l}\text { Normal } \\
\text { Idle }\end{array}$ & $\begin{array}{c}\text { Dynamic } \\
\text { Brake }\end{array}$ & $\begin{array}{c}\text { Notch } \\
1\end{array}$ & $\begin{array}{l}\text { Notch } \\
2\end{array}$ & $\begin{array}{c}\text { Notch } \\
3\end{array}$ & $\begin{array}{c}\text { Notch } \\
4\end{array}$ & $\begin{array}{c}\text { Notch } \\
5\end{array}$ & $\begin{array}{c}\text { Notch } \\
6\end{array}$ & $\begin{array}{c}\text { Notch } \\
7\end{array}$ & $\begin{array}{c}\text { Notch } \\
8 / 7^{\star}\end{array}$ & Notch 8 \\
\hline THC $\quad$ (g/bhp-hr) & 0.87 & 2.48 & 1.76 & 0.55 & 0.33 & 0.41 & 0.30 & 0.22 & 0.17 & 0.15 & & 0.14 \\
\hline (g/bhp-hr) & 19.63 & 43.64 & 17.04 & 12.00 & 9.91 & 12.81 & 12.91 & 6.91 & 5.19 & 6.33 & & 5.52 \\
\hline (g/bhp-hr) & 1.29 & 3.91 & 4.25 & 0.87 & 0.75 & 1.29 & 1.95 & 1.86 & 1.78 & 1.03 & & 0.88 \\
\hline (g/bhp-hr) & 0.28 & 1.18 & 1.52 & 0.31 & 0.29 & 0.30 & 0.20 & 0.30 & 0.31 & 0.12 & & 0.12 \\
\hline (g/bhp-hr) & 1018 & 2059 & 894 & 605 & 533 & 518 & 501 & 529 & 515 & 484 & & 495 \\
\hline Power $\quad$ (hp) & 24 & 23 & 204 & 190 & 421 & 950 & 1401 & 2053 & 2733 & 3441 & & 4099 \\
\hline (rpm) & & & & & & & & & & & & \\
\hline Fuel Rate (lb/hr) & 17 & 33 & 128 & 80 & 156 & 343 & 490 & 757 & 980 & 1159 & & 1409 \\
\hline \multicolumn{13}{|c|}{ Smoke Results } \\
\hline Steady State $\quad 30 \%$ & 2.29 & 2.81 & 15.29 & 16.2 & 9.53 & 11.04 & 14.55 & 31.87 & 30.52 & 15.94 & & 14.05 \\
\hline 30 Second Peak $40 \%$ & -0.12 & 11.17 & 8.85 & 5.53 & 5.8 & 6.82 & 7.08 & 16.42 & 16.53 & 11.88 & & 7.06 \\
\hline \multirow[t]{3}{*}{3 Second Peak $50 \%$} & 0.78 & 12.48 & 8.26 & 6.38 & 9.68 & 12.85 & 11.28 & 36.15 & 24.83 & 15.94 & & 10.27 \\
\hline & \multicolumn{6}{|c|}{ Line Haul } & \multicolumn{6}{|c|}{ Switch } \\
\hline & \multicolumn{3}{|c|}{ Official Test Results } & \multicolumn{3}{|c|}{ Certification Level } & \multicolumn{3}{|c|}{ Official Test Results } & \multicolumn{3}{|c|}{ Certification Level } \\
\hline (g/bhp-hr) & \multicolumn{3}{|c|}{0.23} & \multicolumn{3}{|c|}{1.0} & \multicolumn{3}{|c|}{0.34} & \multicolumn{3}{|c|}{2.10} \\
\hline (g/bhp-hr) & \multicolumn{3}{|c|}{7.02} & \multicolumn{3}{|c|}{9.5} & \multicolumn{3}{|c|}{10.14} & \multicolumn{3}{|c|}{14.00} \\
\hline (g/bhp-hr) & \multicolumn{3}{|c|}{1.20} & \multicolumn{3}{|c|}{5.0} & \multicolumn{3}{|c|}{1.46} & \multicolumn{3}{|c|}{9.00} \\
\hline (g/bhp-hr) & \multicolumn{3}{|c|}{0.20} & \multicolumn{3}{|c|}{0.6} & \multicolumn{3}{|c|}{0.28} & \multicolumn{3}{|c|}{0.72} \\
\hline (g/bhp-hr) & \multicolumn{3}{|c|}{519} & \multicolumn{3}{|c|}{-} & \multicolumn{3}{|c|}{563} & \multicolumn{3}{|c|}{-} \\
\hline
\end{tabular}




\begin{tabular}{|c|c|c|c|c|c|c|c|c|c|c|c|c|}
\hline Notch Emissions & $\begin{array}{l}\text { Low } \\
\text { Idle }\end{array}$ & $\begin{array}{l}\text { Normal } \\
\text { Idle }\end{array}$ & $\begin{array}{c}\text { Dynamic } \\
\text { Brake }\end{array}$ & $\begin{array}{c}\text { Notch } \\
1\end{array}$ & $\begin{array}{c}\text { Notch } \\
2\end{array}$ & $\begin{array}{c}\text { Notch } \\
3\end{array}$ & $\begin{array}{c}\text { Notch } \\
4\end{array}$ & $\begin{array}{l}\text { Notch } \\
5\end{array}$ & $\begin{array}{c}\text { Notch } \\
6\end{array}$ & $\begin{array}{c}\text { Notch } \\
7\end{array}$ & $\begin{array}{c}\text { Notch } \\
8 / 7^{*}\end{array}$ & $\begin{array}{c}\text { Notch } \\
8\end{array}$ \\
\hline (g/bhp-hr) & 1.31 & 2.33 & 1.70 & 0.53 & 0.32 & 0.38 & 0.29 & 0.22 & 0.18 & 0.16 & & 0.14 \\
\hline (g/bhp-hr) & 33.28 & 45.43 & 17.14 & 11.61 & 9.61 & 12.78 & 12.81 & 6.79 & 5.83 & 6.25 & & 5.58 \\
\hline (g/bhp-hr) & 1.51 & 3.69 & 4.34 & 0.83 & 0.81 & 1.27 & 1.93 & 1.70 & 1.72 & 0.93 & & 0.76 \\
\hline (g/bhp-hr) & 0.32 & 1.16 & 1.22 & 0.30 & 0.26 & 0.33 & 0.20 & 0.30 & 0.33 & 0.16 & & 0.13 \\
\hline (g/bhp-hr) & 1507 & 2119 & 906 & 589 & 520 & 513 & 500 & 527 & 517 & 483 & & 492 \\
\hline Power & 21 & 21 & 203 & 188 & 418 & 949 & 1403 & 2049 & 2732 & 3441 & & 4103 \\
\hline \multicolumn{13}{|l|}{ Speed $\quad$ (rpm) } \\
\hline Fuel Rate $\quad(\mathrm{lb} / \mathrm{hr})$ & 22 & 31 & 129 & 77 & 151 & 339 & 489 & 752 & 984 & 1156 & & 1403 \\
\hline \multicolumn{13}{|c|}{ Smoke Results } \\
\hline Steady State $\quad 30 \%$ & 13.4 & 2.9 & 11.5 & 10.8 & 10.11 & 11.8 & 21.4 & 25.5 & 11.8 & 17.58 & & 19.4 \\
\hline 30 Second Peak $40 \%$ & 0.29 & 10.63 & 8.25 & 5.76 & 5.33 & 6.34 & 7.52 & 16.31 & 14.98 & 11.79 & & 6.73 \\
\hline \multirow[t]{3}{*}{3 Second Peak $50 \%$} & 1.47 & 12.17 & 8.72 & 6.67 & 9.25 & 12.6 & 13.47 & 39.75 & 21.28 & 19.48 & & 9.52 \\
\hline & \multicolumn{6}{|c|}{ Line Haul } & \multicolumn{6}{|c|}{ Switch } \\
\hline & \multicolumn{3}{|c|}{ Official Test Results } & \multicolumn{3}{|c|}{ Certification Level } & \multicolumn{3}{|c|}{ Official Test Results } & \multicolumn{3}{|c|}{ Certification Level } \\
\hline (g/bhp-hr) & \multicolumn{3}{|c|}{0.22} & \multicolumn{3}{|c|}{1.0} & \multicolumn{3}{|c|}{0.33} & \multicolumn{3}{|c|}{2.10} \\
\hline (g/bhp-hr) & \multicolumn{3}{|c|}{7.11} & \multicolumn{3}{|c|}{9.5} & \multicolumn{3}{|c|}{10.30} & \multicolumn{3}{|c|}{14.00} \\
\hline (g/bhp-hr) & \multicolumn{3}{|c|}{1.11} & \multicolumn{3}{|c|}{5.0} & \multicolumn{3}{|c|}{1.41} & \multicolumn{3}{|c|}{9.00} \\
\hline (g/bhp-hr) & \multicolumn{3}{|c|}{0.21} & \multicolumn{3}{|c|}{0.6} & \multicolumn{3}{|c|}{0.29} & \multicolumn{3}{|c|}{0.72} \\
\hline (g/bhp-hr) & \multicolumn{3}{|c|}{518} & \multicolumn{3}{|c|}{-} & \multicolumn{3}{|c|}{565} & \multicolumn{3}{|c|}{-} \\
\hline
\end{tabular}




\begin{tabular}{|c|c|c|c|c|c|c|c|c|c|c|c|c|}
\hline \multicolumn{13}{|c|}{ Table B7: Test 3973-Locomotive 8867 GE standard Tier Zero EFI with used cylinder liners } \\
\hline Notch Emissions & $\begin{array}{l}\text { Low } \\
\text { Idle }\end{array}$ & $\begin{array}{l}\text { Normal } \\
\text { Idle }\end{array}$ & $\begin{array}{l}\text { Dynamic } \\
\text { Brake }\end{array}$ & $\begin{array}{c}\text { Notch } \\
1\end{array}$ & $\begin{array}{l}\text { Notch } \\
2\end{array}$ & $\begin{array}{c}\text { Notch } \\
3\end{array}$ & $\begin{array}{c}\text { Notch } \\
4\end{array}$ & $\begin{array}{l}\text { Notch } \\
5\end{array}$ & $\begin{array}{c}\text { Notch } \\
6\end{array}$ & $\begin{array}{c}\text { Notch } \\
7\end{array}$ & $\begin{array}{l}\text { Notch } \\
8 / 7^{*}\end{array}$ & Notch 8 \\
\hline (g/bhp-hr) & 0.99 & 2.72 & 2.50 & 0.55 & 0.36 & 0.49 & 0.29 & 0.26 & 0.22 & 0.18 & & 0.17 \\
\hline (g/bhp-hr) & 15.00 & 41.53 & 15.61 & 11.78 & 9.54 & 12.10 & 12.24 & 6.36 & 4.96 & 6.28 & & 5.73 \\
\hline (g/bhp-hr) & 1.27 & 4.09 & 5.33 & 0.82 & 1.01 & 1.42 & 1.54 & 1.06 & 0.99 & 0.50 & & 0.66 \\
\hline (g/bhp-hr) & 0.53 & 1.74 & 1.88 & 0.37 & 0.37 & 0.41 & 0.25 & 0.27 & 0.26 & 0.15 & & 0.15 \\
\hline (g/bhp-hr) & 848 & 2117 & 880 & 600 & 525 & 513 & 497 & 523 & 507 & 477 & & 488 \\
\hline Power (hp) & 22 & 21 & 203 & 187 & 419 & 950 & 1399 & 2050 & 2733 & 3440 & & 4102 \\
\hline \multicolumn{13}{|l|}{ Speed (rpm) } \\
\hline Fuel Rate $\quad(\mathrm{lb} / \mathrm{hr})$ & 13 & 31 & 126 & 78 & 153 & 340 & 485 & 745 & 963 & 1139 & & 1391 \\
\hline \multicolumn{13}{|c|}{ Smoke Results } \\
\hline Steady State $\quad 30 \%$ & 6.88 & 6.97 & 20.16 & 11.21 & 15.21 & 16.76 & 18.4 & 23.5 & 29.34 & 17.25 & & 19.4 \\
\hline 30 Second Peak $40 \%$ & 2.37 & 12.22 & 11.74 & 6.38 & 8.02 & 9.47 & 9.6 & 11.87 & 12.85 & 10.76 & & 7.8 \\
\hline \multirow[t]{3}{*}{3 Second Peak $50 \%$} & 3.18 & 13.32 & 13.27 & 6.88 & 16.07 & 13 & 15.48 & 26.92 & 18.57 & 17.88 & & 9.18 \\
\hline & \multicolumn{6}{|c|}{ Line Haul } & \multicolumn{6}{|c|}{ Switch } \\
\hline & \multicolumn{3}{|c|}{ Official Test Results } & \multicolumn{3}{|c|}{ Certification Level } & \multicolumn{3}{|c|}{ Official Test Results } & \multicolumn{3}{|c|}{ Certification Level } \\
\hline (g/bhp-hr) & \multicolumn{3}{|c|}{0.27} & \multicolumn{3}{|c|}{1.0} & \multicolumn{3}{|c|}{0.38} & \multicolumn{3}{|c|}{2.10} \\
\hline (g/bhp-hr) & \multicolumn{3}{|c|}{6.92} & \multicolumn{3}{|c|}{9.5} & \multicolumn{3}{|c|}{9.53} & \multicolumn{3}{|c|}{14.00} \\
\hline (g/bhp-hr) & \multicolumn{3}{|c|}{0.92} & \multicolumn{3}{|c|}{5.0} & \multicolumn{3}{|c|}{1.16} & \multicolumn{3}{|c|}{9.00} \\
\hline (g/bhp-hr) & \multicolumn{3}{|c|}{0.24} & \multicolumn{3}{|c|}{0.6} & \multicolumn{3}{|c|}{0.33} & \multicolumn{3}{|c|}{0.72} \\
\hline (g/bhp-hr) & \multicolumn{3}{|c|}{511} & \multicolumn{3}{|c|}{-} & \multicolumn{3}{|c|}{552} & \multicolumn{3}{|c|}{-} \\
\hline
\end{tabular}




\begin{tabular}{|c|c|c|c|c|c|c|c|c|c|c|c|c|}
\hline \multicolumn{13}{|c|}{ Table B8: Test 3974-Locomotive 8867 GE standard Tier Zero EFI with used Cylinder Liners } \\
\hline Notch Emissions & \multirow{2}{*}{$\begin{array}{l}\begin{array}{l}\text { Low } \\
\text { Idle }\end{array} \\
1.65 \\
\end{array}$} & \multirow{2}{*}{$\begin{array}{c}\begin{array}{c}\text { Normal } \\
\text { Idle }\end{array} \\
3.40 \\
\end{array}$} & \multirow{2}{*}{$\begin{array}{c}\begin{array}{c}\text { Dynamic } \\
\text { Brake }\end{array} \\
2.24\end{array}$} & \multirow{2}{*}{$\begin{array}{c}\begin{array}{c}\text { Notch } \\
\mathbf{1}\end{array} \\
0.43\end{array}$} & \multirow{2}{*}{$\begin{array}{c}\text { Notch } \\
\mathbf{2} \\
0.36\end{array}$} & \multirow{2}{*}{$\begin{array}{c}\begin{array}{c}\text { Notch } \\
\mathbf{3}\end{array} \\
0.43\end{array}$} & \multirow{2}{*}{$\begin{array}{c}\text { Notch } \\
\mathbf{4} \\
0.26 \\
\end{array}$} & \multirow{2}{*}{$\begin{array}{c}\text { Notch } \\
\mathbf{5} \\
0.25\end{array}$} & \multirow{2}{*}{$\begin{array}{c}\begin{array}{c}\text { Notch } \\
6\end{array} \\
0.21 \\
\end{array}$} & \multirow{2}{*}{$\begin{array}{c}\begin{array}{c}\text { Notch } \\
7\end{array} \\
0.17\end{array}$} & \multirow[t]{2}{*}{$\begin{array}{c}\text { Notch } \\
8 / 7^{\star}\end{array}$} & \multirow{2}{*}{$\begin{array}{r}\text { Notch \& } \\
0.16\end{array}$} \\
\hline THC $\quad$ (g/bhp-hr) & & & & & & & & & & & & \\
\hline (g/bhp-hr) & 29.09 & 44.14 & 15.75 & 11.33 & 9.79 & 12.28 & 12.12 & 6.28 & 4.94 & 6.25 & & 5.83 \\
\hline (g/bhp-hr) & 2.60 & 5.29 & 4.91 & 0.71 & 1.05 & 1.32 & 1.46 & 0.99 & 0.93 & 0.47 & & 0.67 \\
\hline (g/bhp-hr) & 1.56 & 2.49 & 1.61 & 0.19 & 0.47 & 0.41 & 0.23 & 0.66 & 0.25 & 0.14 & & 0.13 \\
\hline (g/bhp-hr) & 1504 & 2292 & 884 & 569 & 530 & 518 & 490 & 517 & 507 & 475 & & 493 \\
\hline Power & 21 & 20 & 203 & 187 & 420 & 947 & 1400 & 2050 & 2732 & 3437 & & 4101 \\
\hline Speed & & & & & & & & & & & & \\
\hline Fuel Rate $\quad(\mathrm{lb} / \mathrm{hr})$ & 22 & 32 & 126 & 74 & 155 & 342 & 478 & 737 & 962 & 1133 & & 1403 \\
\hline \multicolumn{13}{|c|}{ Smoke Results } \\
\hline Steady State $\quad 30 \%$ & 8.59 & 7.31 & 11.5 & 16.2 & 15.62 & 16.27 & 16.35 & 20.72 & 24.6 & 13.72 & & 19.4 \\
\hline 30 Second Peak $40 \%$ & 3.4 & 13.76 & 10.4 & 5.31 & 7.98 & 9.75 & 9.09 & 12.05 & 12.24 & 9.92 & & 7.85 \\
\hline \multirow[t]{3}{*}{3 Second Peak $50 \%$} & 4.48 & 14.58 & 11.03 & 5.75 & 17 & 14.25 & 13.03 & 25.43 & 16.98 & 16.57 & & 9.13 \\
\hline & \multicolumn{6}{|c|}{ Line Haul } & \multicolumn{6}{|c|}{ Switch } \\
\hline & \multicolumn{3}{|c|}{ Official Test Results } & \multicolumn{3}{|c|}{ Certification Level } & \multicolumn{3}{|c|}{ Official Test Results } & \multicolumn{3}{|c|}{ Certification Level } \\
\hline (g/bhp-hr) & \multicolumn{3}{|c|}{0.26} & \multicolumn{3}{|c|}{1.0} & \multicolumn{3}{|c|}{0.37} & \multicolumn{3}{|c|}{2.10} \\
\hline (g/bhp-hr) & \multicolumn{3}{|c|}{7.02} & \multicolumn{3}{|c|}{9.5} & \multicolumn{3}{|c|}{9.80} & \multicolumn{3}{|c|}{14.00} \\
\hline (g/bhp-hr) & \multicolumn{3}{|c|}{0.89} & \multicolumn{3}{|c|}{5.0} & & 1.16 & & & 9.00 & \\
\hline (g/bhp-hr) & & 0.25 & & & 0.6 & & & 0.44 & & & 0.72 & \\
\hline $\mathrm{CO}_{2} \quad$ (g/bhp-hr) & & 515 & & & - & & & 563 & & & - & \\
\hline
\end{tabular}


Tests Results for Locomotive 8695

\begin{tabular}{|c|c|c|c|c|c|c|c|c|c|c|c|c|}
\hline Notch Emissions & \multirow{2}{*}{$\begin{array}{l}\text { Low } \\
\text { Idle } \\
4.33\end{array}$} & \multirow{2}{*}{$\begin{array}{c}\text { Normal } \\
\text { Idle }\end{array}$} & \multirow{2}{*}{$\begin{array}{c}\begin{array}{c}\text { Dynamic } \\
\text { Brake }\end{array} \\
1.86\end{array}$} & \multirow{2}{*}{$\begin{array}{c}\text { Notch } \\
1 \\
1.28\end{array}$} & \multirow{2}{*}{$\begin{array}{c}\begin{array}{c}\text { Notch } \\
\mathbf{2}\end{array} \\
0.75\end{array}$} & \multirow{2}{*}{$\begin{array}{c}\text { Notch } \\
3 \\
0.48 \\
\end{array}$} & \multirow{2}{*}{$\begin{array}{c}\text { Notch } \\
\mathbf{4} \\
0.37\end{array}$} & \multirow{2}{*}{$\begin{array}{c}\text { Notch } \\
\mathbf{5} \\
0.35\end{array}$} & \multirow{2}{*}{$\begin{array}{c}\begin{array}{c}\text { Notch } \\
6\end{array} \\
0.30\end{array}$} & \multirow{2}{*}{$\begin{array}{c}\text { Notch } \\
7 \\
0.34\end{array}$} & \multirow[t]{2}{*}{$\begin{array}{c}\text { Notch } \\
8 / 7^{\star}\end{array}$} & \multirow{2}{*}{$\begin{array}{c}\text { Notch } 8 \\
0.39\end{array}$} \\
\hline (g/bhp-hr) & & & & & & & & & & & & \\
\hline (g/bhp-hr) & 18.21 & 40.10 & 19.26 & 17.70 & 13.12 & 8.94 & 9.08 & 8.88 & 8.49 & 8.30 & & 7.94 \\
\hline (g/bhp-hr) & 5.58 & 11.39 & 4.42 & 2.91 & 1.93 & 2.05 & 2.04 & 1.32 & 1.14 & 1.17 & & 1.39 \\
\hline (g/bhp-hr) & 0.68 & 3.09 & 1.27 & 0.88 & 0.88 & 0.70 & 0.48 & 0.36 & 0.29 & 0.46 & & 1.34 \\
\hline (g/bhp-hr) & 922 & 1732 & 955 & 779 & 652 & 569 & 533 & 509 & 494 & 487 & & 493 \\
\hline Power & 26 & 22 & 182 & 187 & 422 & 951 & 1401 & 2054 & 2732 & 3442 & & 4107 \\
\hline \multicolumn{13}{|l|}{ Speed $\quad$ (rpm) } \\
\hline Fuel Rate & 17 & 27 & 122 & 102 & 192 & 378 & 521 & 728 & 940 & 1167 & & 1411 \\
\hline \multicolumn{13}{|c|}{ Smoke Results } \\
\hline Steady State $\quad 30 \%$ & 8.85 & 14.3 & 10.2 & 12.03 & 10.45 & 17.74 & 21.4 & 14.05 & 13.22 & 13.63 & & $\begin{array}{l}\text { Bad } \\
\text { Data }\end{array}$ \\
\hline 30 Second Peak 40\% & 3.76 & 6.83 & 8.8 & 7.56 & 5.98 & 10.04 & 21.4 & 7.89 & 6.59 & 7.23 & & $\begin{array}{l}\text { Bad } \\
\text { Data }\end{array}$ \\
\hline \multirow[t]{3}{*}{3 Second Peak $50 \%$} & 4.5 & 13.03 & 12.62 & 11.58 & 8.73 & 12.34 & 33.1 & 12.98 & 13.22 & 11.4 & & $\begin{array}{l}\text { Bad } \\
\text { Data }\end{array}$ \\
\hline & \multicolumn{6}{|c|}{ Line Haul } & \multicolumn{6}{|c|}{ Switch } \\
\hline & \multicolumn{3}{|c|}{ Official Test Results } & \multicolumn{3}{|c|}{ Certification Level } & \multicolumn{3}{|c|}{ Official Test Results } & \multicolumn{3}{|c|}{ Certification Level } \\
\hline (g/bhp-hr) & \multicolumn{3}{|c|}{0.47} & \multicolumn{3}{|c|}{1.0} & \multicolumn{3}{|c|}{0.71} & \multicolumn{3}{|c|}{2.10} \\
\hline (g/bhp-hr) & \multicolumn{3}{|c|}{8.81} & \multicolumn{3}{|c|}{9.5} & \multicolumn{3}{|c|}{10.78} & \multicolumn{3}{|c|}{14.00} \\
\hline (g/bhp-hr) & \multicolumn{3}{|c|}{1.55} & \multicolumn{3}{|c|}{5.0} & \multicolumn{3}{|c|}{2.00} & & 9.00 & \\
\hline (g/bhp-hr) & & 1.00 & & & 0.6 & & & 0.69 & & & 0.72 & \\
\hline (g/bhp-hr) & & 522 & & & - & & & 590 & & & - & \\
\hline
\end{tabular}




\begin{tabular}{|c|c|c|c|c|c|c|c|c|c|c|c|c|}
\hline Notch Emissions & $\begin{array}{l}\text { Low } \\
\text { Idle }\end{array}$ & $\begin{array}{l}\text { Normal } \\
\text { Idle }\end{array}$ & $\begin{array}{c}\text { Dynamic } \\
\text { Brake }\end{array}$ & $\begin{array}{c}\text { Notch } \\
1\end{array}$ & $\begin{array}{l}\text { Notch } \\
2\end{array}$ & $\begin{array}{c}\text { Notch } \\
3\end{array}$ & $\begin{array}{c}\text { Notch } \\
4\end{array}$ & $\begin{array}{l}\text { Notch } \\
5\end{array}$ & $\begin{array}{c}\text { Notch } \\
6\end{array}$ & $\begin{array}{c}\text { Notch } \\
7\end{array}$ & $\begin{array}{c}\text { Notch } \\
8 / 7^{\star}\end{array}$ & Notch 8 \\
\hline (g/bhp-hr) & 4.99 & 7.47 & 1.81 & 1.32 & 0.71 & 0.50 & 0.39 & 0.36 & 0.30 & 0.32 & & 0.35 \\
\hline (g/bhp-hr) & 20.77 & 40.43 & 18.28 & 16.62 & 12.57 & 8.63 & 8.98 & 8.72 & 8.32 & 8.28 & & 7.94 \\
\hline (g/bhp-hr) & 6.95 & 11.32 & 3.93 & 2.82 & 1.90 & 1.96 & 2.09 & 1.34 & 1.12 & 1.19 & & 1.40 \\
\hline (g/bhp-hr) & 1.90 & 3.45 & 1.39 & 0.86 & 0.80 & 0.69 & 0.29 & 0.35 & 0.90 & 0.40 & & 1.11 \\
\hline (g/bhp-hr) & 1089 & 1731 & 941 & 767 & 651 & 560 & 536 & 512 & 496 & 489 & & 493 \\
\hline Power & 22 & 22 & 182 & 188 & 418 & 962 & 1400 & 2053 & 2731 & 3446 & & 4106 \\
\hline Speed & & & & & & & & & & & & \\
\hline Fuel Rate $\quad(\mathrm{lb} / \mathrm{hr})$ & 17 & 27 & 120 & 101 & 190 & 376 & 524 & 732 & 942 & 1173 & & 1410 \\
\hline \multicolumn{13}{|c|}{ Smoke Results } \\
\hline Steady State $\quad 30 \%$ & 9.69 & 15.37 & 11.8 & 13.47 & 11.54 & 18.47 & 16.93 & 16.44 & 15.45 & 17.66 & & 21.36 \\
\hline 30 Second Peak 40\% & 3.9 & 8.05 & 9.31 & 8.59 & 7.28 & 11.79 & 9.77 & 9.55 & 8.54 & 8.89 & & 9.98 \\
\hline \multirow[t]{3}{*}{3 Second Peak $50 \%$} & 4.58 & 14.52 & 14.45 & 14.37 & 9.97 & 14.95 & 13.02 & 14.03 & 15.92 & 13.23 & & 11.18 \\
\hline & \multicolumn{6}{|c|}{ Line Haul } & \multicolumn{6}{|c|}{ Switch } \\
\hline & \multicolumn{3}{|c|}{ Official Test Results } & \multicolumn{3}{|c|}{ Certification Level } & \multicolumn{3}{|c|}{ Official Test Results } & \multicolumn{3}{|c|}{ Certification Level } \\
\hline (g/bhp-hr) & \multicolumn{3}{|c|}{0.44} & \multicolumn{3}{|c|}{1.0} & \multicolumn{3}{|c|}{0.71} & \multicolumn{3}{|c|}{2.10} \\
\hline (g/bhp-hr) & \multicolumn{3}{|c|}{8.72} & \multicolumn{3}{|c|}{9.5} & \multicolumn{3}{|c|}{10.53} & \multicolumn{3}{|c|}{14.00} \\
\hline (g/bhp-hr) & \multicolumn{3}{|c|}{1.55} & \multicolumn{3}{|c|}{5.0} & \multicolumn{3}{|c|}{2.00} & \multicolumn{3}{|c|}{9.00} \\
\hline (g/bhp-hr) & \multicolumn{3}{|c|}{0.92} & \multicolumn{3}{|c|}{0.6} & \multicolumn{3}{|c|}{0.72} & \multicolumn{3}{|c|}{0.72} \\
\hline (g/bhp-hr) & \multicolumn{3}{|c|}{522} & \multicolumn{3}{|c|}{ 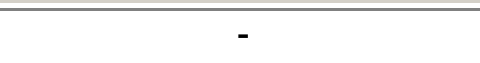 } & \multicolumn{3}{|c|}{590} & \multicolumn{3}{|c|}{-} \\
\hline
\end{tabular}




\begin{tabular}{|c|c|c|c|c|c|c|c|c|c|c|c|c|}
\hline \multicolumn{13}{|c|}{ Table B11: Test 3967-Locomotive 8695 GE Mechanical Tier 0 kit with Globe 1869 Turbo } \\
\hline Notch Emissions & \multirow{2}{*}{$\begin{array}{l}\text { Low } \\
\text { Idle }\end{array}$} & \multirow{2}{*}{$\begin{array}{c}\begin{array}{c}\text { Normal } \\
\text { Idle }\end{array} \\
6.90\end{array}$} & \multirow{2}{*}{$\begin{array}{c}\begin{array}{c}\text { Dynamic } \\
\text { Brake }\end{array} \\
1.79\end{array}$} & \multirow{2}{*}{$\begin{array}{c}\text { Notch } \\
\mathbf{1} \\
1.29\end{array}$} & \multirow{2}{*}{$\begin{array}{c}\begin{array}{c}\text { Notch } \\
\mathbf{2}\end{array} \\
0.66\end{array}$} & \multirow{2}{*}{$\begin{array}{c}\begin{array}{c}\text { Notch } \\
\mathbf{3}\end{array} \\
0.45\end{array}$} & \multirow{2}{*}{$\begin{array}{c}\begin{array}{c}\text { Notch } \\
\mathbf{4}\end{array} \\
0.35\end{array}$} & \multirow{2}{*}{$\begin{array}{c}\text { Notch } \\
\mathbf{5} \\
0.33\end{array}$} & \multirow{2}{*}{$\begin{array}{c}\begin{array}{c}\text { Notch } \\
6\end{array} \\
0.27\end{array}$} & \multirow{2}{*}{$\begin{array}{c}\text { Notch } \\
7 \\
0.32 \\
\end{array}$} & \multirow[t]{2}{*}{$\begin{array}{c}\text { Notch } \\
8 / 7^{\star}\end{array}$} & \multirow{2}{*}{$\begin{array}{r}\text { Notch } 8 \\
0.35\end{array}$} \\
\hline (g/bhp-hr) & & & & & & & & & & & & \\
\hline (g/bhp-hr) & 22.65 & 35.85 & 18.14 & 16.44 & 12.34 & 8.45 & 8.48 & 8.06 & 7.96 & 7.95 & & 7.75 \\
\hline (g/bhp-hr) & 8.80 & 11.61 & 4.44 & 3.03 & 2.00 & 2.27 & 3.29 & 2.43 & 1.69 & 1.41 & & 1.62 \\
\hline (g/bhp-hr) & 2.33 & 2.75 & 1.27 & 0.79 & 0.71 & 0.58 & 0.44 & 0.38 & 0.26 & 0.32 & & 1.00 \\
\hline (g/bhp-hr) & 1284 & 1718 & 942 & 759 & 653 & 570 & 541 & 519 & 497 & 488 & & 491 \\
\hline Power & 23 & 23 & 183 & 190 & 419 & 949 & 1405 & 2056 & 2732 & 3441 & & 4103 \\
\hline \multicolumn{13}{|l|}{ Speed $\quad$ (rpm) } \\
\hline Fuel Rate $\quad(\mathrm{lb} / \mathrm{hr})$ & 21 & 28 & 121 & 101 & 191 & 378 & 532 & 745 & 946 & 1171 & & 1406 \\
\hline \multicolumn{13}{|c|}{ Smoke Results } \\
\hline Steady State $\quad 30 \%$ & 9.87 & 11.8 & 11.21 & 16.2 & 10.62 & 19.2 & 24.13 & 21.4 & 18.47 & 13.1 & & 17.42 \\
\hline 30 Second Peak $40 \%$ & 4.77 & 5.66 & 9.92 & 8.45 & 6.58 & 11.89 & 12.28 & 13.01 & 10.01 & 17.56 & & 7.66 \\
\hline \multirow[t]{3}{*}{3 Second Peak $50 \%$} & 5.32 & 13.93 & 13.77 & 14.03 & 9.55 & 14.72 & 19.7 & 21.7 & 17.98 & 12.77 & & 10.17 \\
\hline & \multicolumn{6}{|c|}{ Line Haul } & \multicolumn{6}{|c|}{ Switch } \\
\hline & \multicolumn{3}{|c|}{ Official Test Results } & \multicolumn{3}{|c|}{ Certification Level } & \multicolumn{3}{|c|}{ Official Test Results } & \multicolumn{3}{|c|}{ Certification Level } \\
\hline (g/bhp-hr) & \multicolumn{3}{|c|}{0.44} & \multicolumn{3}{|c|}{1.0} & \multicolumn{3}{|c|}{0.72} & \multicolumn{3}{|c|}{2.10} \\
\hline (g/bhp-hr) & \multicolumn{3}{|c|}{8.46} & \multicolumn{3}{|c|}{9.5} & \multicolumn{3}{|c|}{10.17} & \multicolumn{3}{|c|}{14.00} \\
\hline (g/bhp-hr) & \multicolumn{3}{|c|}{1.93} & & 5.0 & & & 2.63 & & & 9.00 & \\
\hline (g/bhp-hr) & & 0.79 & & & 0.6 & & & 0.62 & & & 0.72 & \\
\hline (g/bhp-hr) & & 523 & & & - & & & 599 & & & - & \\
\hline
\end{tabular}




\begin{tabular}{|c|c|c|c|c|c|c|c|c|c|c|c|c|}
\hline \multicolumn{13}{|c|}{ Table B12: Test 3968-Locomotive 8695 GE Mechanical Tier 0 kit with Globe 1869 Turbo } \\
\hline Notch Emissions & $\begin{array}{l}\text { Low } \\
\text { Idle }\end{array}$ & $\begin{array}{l}\text { Normal } \\
\text { Idle }\end{array}$ & $\begin{array}{l}\text { Dynamic } \\
\text { Brake }\end{array}$ & $\begin{array}{c}\text { Notch } \\
1\end{array}$ & $\begin{array}{l}\text { Notch } \\
2\end{array}$ & $\begin{array}{c}\text { Notch } \\
3\end{array}$ & $\begin{array}{l}\text { Notch } \\
\quad 4\end{array}$ & $\begin{array}{c}\text { Notch } \\
5\end{array}$ & $\begin{array}{c}\text { Notch } \\
6\end{array}$ & $\begin{array}{c}\text { Notch } \\
7\end{array}$ & $\begin{array}{c}\text { Notch } \\
8 / 7^{*}\end{array}$ & Notch 8 \\
\hline THC $\quad$ (g/bhp-hr) & 5.12 & 6.66 & 1.79 & 1.26 & 0.68 & 0.41 & 0.33 & 0.31 & 0.25 & 0.29 & & 0.33 \\
\hline (g/bhp-hr) & 21.55 & 37.20 & 17.54 & 16.72 & 12.44 & 8.43 & 8.46 & 8.08 & 7.91 & 7.95 & & 7.66 \\
\hline (g/bhp-hr) & 7.75 & 10.75 & 4.15 & 2.79 & 1.97 & 2.37 & 3.46 & 2.56 & 1.72 & 1.46 & & 1.63 \\
\hline (g/bhp-hr) & 1.53 & 2.59 & 1.09 & 0.96 & 0.72 & 0.56 & 0.39 & 0.34 & 0.28 & 0.28 & & 0.88 \\
\hline (g/bhp-hr) & 1165 & 1721 & 924 & 760 & 645 & 572 & 540 & 520 & 499 & 491 & & 492 \\
\hline Power & 23 & 23 & 182 & 188 & 420 & 949 & 1403 & 2056 & 2731 & 3445 & & 4106 \\
\hline (rpm) & & & & & & & & & & & & \\
\hline Fuel Rate $\quad$ (lb/hr) & 19 & 28 & 118 & 100 & 189 & 379 & 531 & 747 & 950 & 1178 & & 1409 \\
\hline \multicolumn{13}{|c|}{ Smoke Results } \\
\hline Steady State $\quad 30 \%$ & 5.94 & 11.8 & 9.19 & 8.76 & 9.69 & 16.68 & 23.19 & 20.56 & 19.2 & 16.27 & & 17.25 \\
\hline 30 Second Peak $40 \%$ & 2.3 & 5.66 & 7.25 & 4.27 & 5.44 & 10 & 11.8 & 12.86 & 9.59 & 7.29 & & 7.62 \\
\hline \multirow[t]{3}{*}{3 Second Peak $50 \%$} & 2.85 & 13.3 & 12.7 & 5.05 & 9.58 & 12.52 & 19.38 & 20.07 & 17.9 & 11.33 & & 9.42 \\
\hline & \multicolumn{6}{|c|}{ Line Haul } & \multicolumn{6}{|c|}{ Switch } \\
\hline & \multicolumn{3}{|c|}{ Official Test Results } & \multicolumn{3}{|c|}{ Certification Level } & \multicolumn{3}{|c|}{ Official Test Results } & \multicolumn{3}{|c|}{ Certification Level } \\
\hline (g/bhp-hr) & \multicolumn{3}{|c|}{0.42} & \multicolumn{3}{|c|}{1.0} & \multicolumn{3}{|c|}{0.66} & \multicolumn{3}{|c|}{2.10} \\
\hline (g/bhp-hr) & \multicolumn{3}{|c|}{8.39} & \multicolumn{3}{|c|}{9.5} & \multicolumn{3}{|c|}{10.19} & \multicolumn{3}{|c|}{14.00} \\
\hline (g/bhp-hr) & \multicolumn{3}{|c|}{1.95} & \multicolumn{3}{|c|}{5.0} & \multicolumn{3}{|c|}{2.64} & \multicolumn{3}{|c|}{9.00} \\
\hline (g/bhp-hr) & \multicolumn{3}{|c|}{0.70} & \multicolumn{3}{|c|}{0.6} & \multicolumn{3}{|c|}{0.59} & \multicolumn{3}{|c|}{0.72} \\
\hline (g/bhp-hr) & \multicolumn{3}{|c|}{523} & \multicolumn{3}{|c|}{-} & \multicolumn{3}{|c|}{596} & \multicolumn{3}{|c|}{-} \\
\hline
\end{tabular}




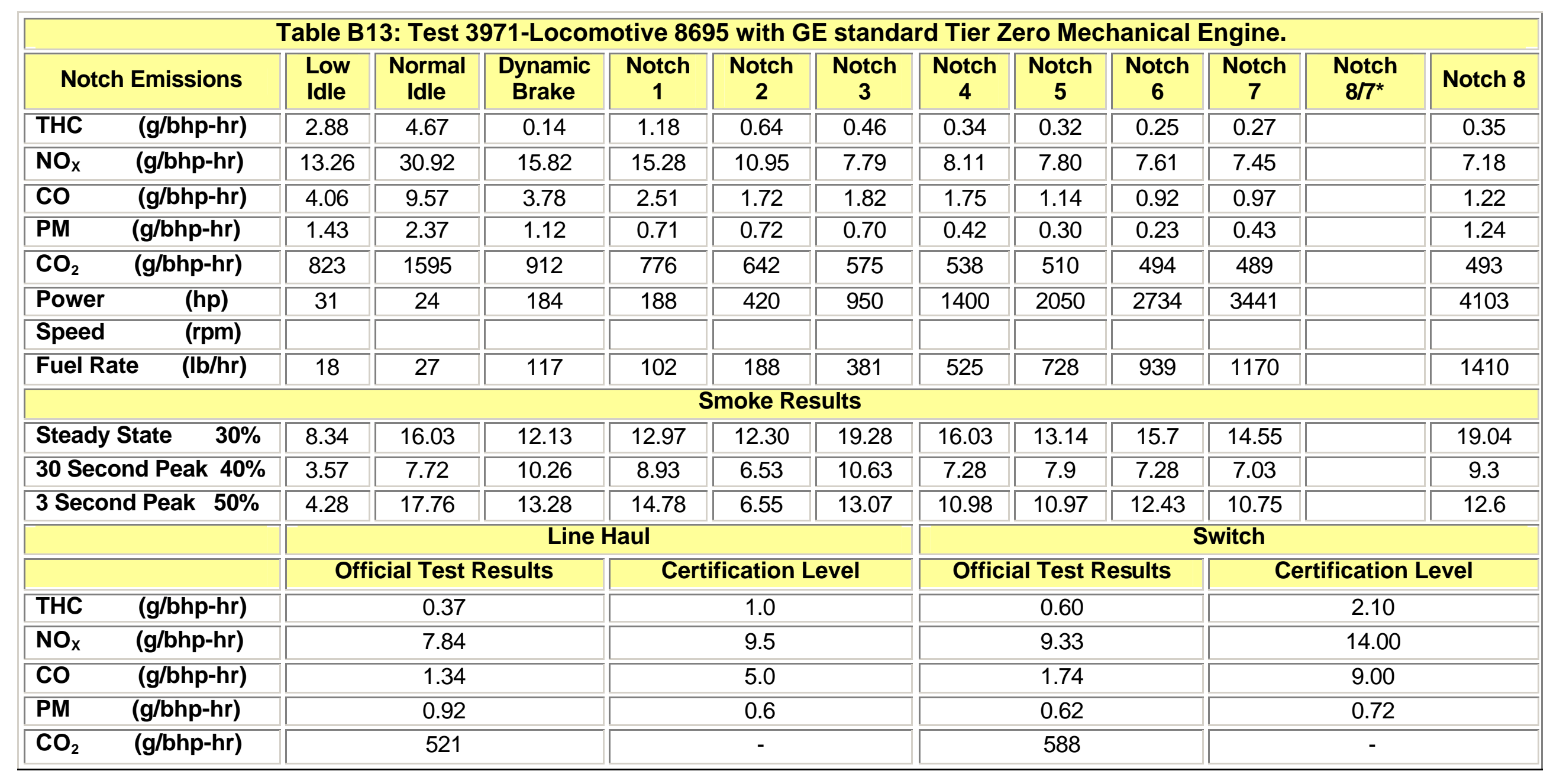




\begin{tabular}{|c|c|c|c|c|c|c|c|c|c|c|c|c|}
\hline Notch Emissions & $\begin{array}{l}\text { Low } \\
\text { Idle }\end{array}$ & $\begin{array}{l}\text { Normal } \\
\text { Idle }\end{array}$ & $\begin{array}{l}\text { Dynamic } \\
\text { Brake }\end{array}$ & $\begin{array}{c}\text { Notch } \\
1\end{array}$ & $\begin{array}{c}\text { Notch } \\
2\end{array}$ & $\begin{array}{c}\text { Notch } \\
3\end{array}$ & $\begin{array}{c}\text { Notch } \\
4\end{array}$ & $\begin{array}{c}\text { Notch } \\
5\end{array}$ & $\begin{array}{c}\text { Notch } \\
6\end{array}$ & $\begin{array}{c}\text { Notch } \\
7\end{array}$ & $\begin{array}{c}\text { Notch } \\
8 / 7^{\star}\end{array}$ & Notch 8 \\
\hline THC $\quad$ (g/bhp-hr) & 4.30 & 5.63 & 1.57 & 1.10 & 0.60 & 0.42 & 0.33 & 0.30 & 0.22 & 0.27 & & 0.30 \\
\hline (g/bhp-hr) & 16.33 & 29.87 & 15.38 & 14.53 & 11.16 & 7.72 & 7.96 & 7.88 & 7.49 & 7.26 & & 6.94 \\
\hline (g/bhp-hr) & 6.19 & 9.46 & 3.53 & 2.44 & 1.70 & 1.85 & 1.81 & 1.08 & 0.96 & 0.98 & & 1.20 \\
\hline (g/bhp-hr) & 1.25 & 2.15 & 1.10 & 0.40 & 0.74 & 0.60 & 0.34 & 0.31 & 0.25 & 0.43 & & 1.21 \\
\hline $\mathrm{CO}_{2} \quad$ (g/bhp-hr) & 1044 & 1663 & 911 & 776 & 647 & 569 & 528 & 507 & 491 & 489 & & 494 \\
\hline Power $\quad$ (hp) & 23 & 23 & 185 & 188 & 419 & 948 & 1399 & 2053 & 2731 & 3446 & & 4104 \\
\hline Speed $\quad$ (rpm) & & & & & & & & & & & & \\
\hline Fuel Rate (lb/hr) & 17 & 27 & 118 & 102 & 189 & 376 & 515 & 725 & 933 & 1171 & & 1411 \\
\hline \multicolumn{13}{|c|}{ Smoke Results } \\
\hline Steady State $\quad 30 \%$ & 12.55 & 16.44 & 11.88 & 15.2 & 12.05 & 19.34 & 17.25 & 14.9 & 15.78 & 15.7 & & 19.76 \\
\hline 30 Second Peak $40 \%$ & 5.32 & 8.23 & 10.18 & 8.89 & 7.17 & 10.74 & 9.78 & 8.37 & 6.88 & 6.9 & & 11.05 \\
\hline \multirow[t]{3}{*}{3 Second Peak $50 \%$} & 6.37 & 6.37 & 14.03 & 13.42 & 10.52 & 12.84 & 11.65 & 13.2 & 11.48 & 10.13 & & 10.22 \\
\hline & \multicolumn{6}{|c|}{ Line Haul } & \multicolumn{6}{|c|}{ Switch } \\
\hline & \multicolumn{3}{|c|}{ Official Test Results } & \multicolumn{3}{|c|}{\begin{tabular}{|l} 
Certification Level \\
\end{tabular}} & \multicolumn{3}{|c|}{ Official Test Results } & \multicolumn{3}{|c|}{ Certification Level } \\
\hline (g/bhp-hr) & \multicolumn{3}{|c|}{0.37} & \multicolumn{3}{|c|}{1.0} & \multicolumn{3}{|c|}{0.60} & \multicolumn{3}{|c|}{2.10} \\
\hline (g/bhp-hr) & \multicolumn{3}{|c|}{7.65} & \multicolumn{3}{|c|}{9.5} & \multicolumn{3}{|c|}{9.25} & \multicolumn{3}{|c|}{14.00} \\
\hline (g/bhp-hr) & \multicolumn{3}{|c|}{1.33} & \multicolumn{3}{|c|}{5.0} & \multicolumn{3}{|c|}{1.75} & \multicolumn{3}{|c|}{9.00} \\
\hline (g/bhp-hr) & \multicolumn{3}{|c|}{0.90} & \multicolumn{3}{|c|}{0.6} & \multicolumn{3}{|c|}{0.56} & \multicolumn{3}{|c|}{0.72} \\
\hline $\mathrm{CO}_{2} \quad$ (g/bhp-hr) & \multicolumn{3}{|c|}{521} & \multicolumn{3}{|c|}{-} & \multicolumn{3}{|c|}{589} & \multicolumn{3}{|c|}{-} \\
\hline
\end{tabular}




\begin{tabular}{|c|c|c|c|c|c|c|c|c|c|c|c|c|}
\hline Notch Emissions & $\begin{array}{l}\text { Low } \\
\text { Idle }\end{array}$ & $\begin{array}{l}\text { Normal } \\
\text { Idle }\end{array}$ & $\begin{array}{c}\text { Dynamic } \\
\text { Brake }\end{array}$ & $\begin{array}{c}\text { Notch } \\
1\end{array}$ & $\begin{array}{c}\text { Notch } \\
2\end{array}$ & $\begin{array}{c}\text { Notch } \\
3\end{array}$ & $\begin{array}{c}\text { Notch } \\
4\end{array}$ & $\begin{array}{c}\text { Notch } \\
5\end{array}$ & $\begin{array}{c}\text { Notch } \\
6\end{array}$ & $\begin{array}{c}\text { Notch } \\
7\end{array}$ & $\begin{array}{c}\text { Notch } \\
8 / 7^{\star}\end{array}$ & $\begin{array}{c}\text { Notch } \\
8\end{array}$ \\
\hline THC $\quad$ (g/bhp-hr) & 1.04 & 2.06 & 2.24 & 0.53 & 0.36 & 0.47 & 0.25 & 0.21 & 0.19 & 0.17 & & 0.14 \\
\hline (g/bhp-hr) & 21.07 & 36.64 & 16.18 & 11.80 & 9.57 & 11.90 & 12.12 & 6.51 & 5.25 & 6.46 & & 5.43 \\
\hline (g/bhp-hr) & 1.67 & 4.07 & 5.35 & 0.87 & 0.97 & 1.68 & 2.14 & 1.37 & 1.35 & 0.71 & & 0.75 \\
\hline (g/bhp-hr) & 1.05 & 2.24 & 1.81 & 0.49 & 0.44 & 0.44 & 0.29 & 0.30 & 0.32 & 0.16 & & 0.16 \\
\hline $\mathrm{CO}_{2} \quad$ (g/bhp-hr) & 1208 & 1836.00 & 886.00 & 593.00 & 538.00 & 515.00 & 502.00 & 532.00 & 514.00 & 485.00 & & 503.00 \\
\hline Power (hp) & 25 & 25 & 205.00 & 189.00 & 422.00 & 952.00 & 1402.00 & 2054.00 & 2735.00 & 3439.00 & & 4104.00 \\
\hline \multicolumn{13}{|l|}{ Speed (rpm) } \\
\hline Fuel Rate $\quad(\mathrm{lb} / \mathrm{hr})$ & 21 & 32 & 128 & 78 & 158 & 342 & 491 & 761 & 979 & 1159 & & 1433 \\
\hline \multicolumn{13}{|c|}{ Smoke Results } \\
\hline Steady State $\quad 30 \%$ & 4.21 & 3.1 & 16.76 & 8.42 & 11.63 & 14.96 & 17.42 & 21.92 & 27.1 & 13.72 & & 19.4 \\
\hline 30 Second Peak $40 \%$ & 0.89 & 12.05 & 9.17 & 4.54 & 6.87 & 9.15 & 9.59 & 12.71 & 12.36 & 9.64 & & 6.54 \\
\hline \multirow[t]{3}{*}{3 Second Peak $50 \%$} & 1.83 & 12.98 & 10.18 & 4.98 & 10.38 & 16.98 & 16.97 & 30.45 & 17.72 & 18.4 & & 9.32 \\
\hline & \multicolumn{6}{|c|}{ Line Haul } & \multicolumn{6}{|c|}{ Switch } \\
\hline & \multicolumn{3}{|c|}{ Official Test Results } & \multicolumn{3}{|c|}{ Certification Level } & \multicolumn{3}{|c|}{ Official Test Results } & \multicolumn{3}{|c|}{ Certification Level } \\
\hline (g/bhp-hr) & \multicolumn{3}{|c|}{0.24} & \multicolumn{3}{|c|}{1.0} & \multicolumn{3}{|c|}{0.35} & \multicolumn{3}{|c|}{2.10} \\
\hline (g/bhp-hr) & \multicolumn{3}{|c|}{6.83} & \multicolumn{3}{|c|}{9.5} & \multicolumn{3}{|c|}{9.68} & \multicolumn{3}{|c|}{14.00} \\
\hline (g/bhp-hr) & \multicolumn{3}{|c|}{1.09} & \multicolumn{3}{|c|}{5.0} & \multicolumn{3}{|c|}{1.43} & \multicolumn{3}{|c|}{9.00} \\
\hline (g/bhp-hr) & \multicolumn{3}{|c|}{0.27} & \multicolumn{3}{|c|}{0.6} & \multicolumn{3}{|c|}{0.40} & \multicolumn{3}{|c|}{0.72} \\
\hline (g/bhp-hr) & \multicolumn{3}{|c|}{523.74} & \multicolumn{3}{|c|}{-} & \multicolumn{3}{|c|}{566.51} & \multicolumn{3}{|c|}{-} \\
\hline
\end{tabular}




\begin{tabular}{|c|c|c|c|c|c|c|c|c|c|c|c|c|}
\hline \multicolumn{13}{|c|}{ Table B16: Test 3977-Locomotive 8867 with GLOBE 1883 rebuilt turbo with used liners. } \\
\hline Notch Emissions & $\begin{array}{l}\text { Low } \\
\text { Idle }\end{array}$ & $\begin{array}{l}\text { Normal } \\
\text { Idle }\end{array}$ & $\begin{array}{c}\text { Dynamic } \\
\text { Brake }\end{array}$ & $\begin{array}{c}\text { Notch } \\
1\end{array}$ & $\begin{array}{l}\text { Notch } \\
2\end{array}$ & $\begin{array}{c}\text { Notch } \\
3\end{array}$ & $\begin{array}{l}\text { Notch } \\
4\end{array}$ & $\begin{array}{l}\text { Notch } \\
5\end{array}$ & $\begin{array}{l}\text { Notch } \\
6\end{array}$ & $\begin{array}{l}\text { Notch } \\
7\end{array}$ & $\begin{array}{c}\text { Notch } \\
8 / 7^{\star}\end{array}$ & $\begin{array}{l}\text { Notch } \\
8\end{array}$ \\
\hline (g/bhp-hr) & 1.15 & 2.09 & 2.32 & 0.51 & 0.34 & 0.50 & 0.26 & 0.20 & 0.17 & 0.12 & & 0.12 \\
\hline (g/bhp-hr) & 19.68 & 35.21 & 14.62 & 11.47 & 9.88 & 11.76 & 12.08 & 6.43 & 5.15 & 6.43 & & 5.22 \\
\hline (g/bhp-hr) & 1.67 & 3.59 & 5.23 & 0.80 & 0.99 & 1.99 & 2.50 & 1.67 & 1.63 & 0.85 & & 0.88 \\
\hline (g/bhp-hr) & 1.61 & 1.89 & 1.74 & 0.36 & 0.40 & 0.43 & 0.29 & 0.35 & 0.15 & 0.18 & & 0.13 \\
\hline (g/bhp-hr) & 1301 & 1983.00 & 880.00 & 586.00 & 539.00 & 523.00 & 507.00 & 537.00 & 521.00 & 491.00 & & 506.00 \\
\hline Power & 21 & 21.00 & 200.00 & 189.00 & 419.00 & 950.00 & 1401.00 & 2053.00 & 2731.00 & 3440.00 & & 4105.00 \\
\hline (rpm) & & & & & & & & & & & & \\
\hline Fuel Rate $\quad(\mathrm{lb} / \mathrm{hr})$ & 19 & 29.00 & 124.00 & 77.00 & 157.00 & 347.00 & 496.00 & 768.00 & 991.00 & 1173.00 & & 1444.00 \\
\hline \multicolumn{13}{|c|}{ Smoke Results } \\
\hline $\begin{array}{l}\text { Steady State } \\
30 \%\end{array}$ & 4.12 & 3.67 & 11.5 & 8.59 & 12.22 & 20.16 & 25 & 32.47 & 39.61 & 13.72 & & 21.36 \\
\hline $\begin{array}{l}30 \text { Second Peak } \\
40 \%\end{array}$ & 0.89 & 11.58 & 10.09 & 4.86 & 7.35 & 10.01 & 11.95 & 15.52 & 14.42 & 11.86 & & 7.625 \\
\hline \multirow[t]{3}{*}{$\begin{array}{l}3 \text { Second Peak } \\
50 \%\end{array}$} & 1.73 & 12.75 & 12.35 & 5.12 & 20.68 & 16.2 & 19.37 & 36.43 & 20.53 & 20.17 & & 10.78 \\
\hline & \multicolumn{6}{|c|}{ Line Haul } & \multicolumn{6}{|c|}{ Switch } \\
\hline & \multicolumn{3}{|c|}{ Official Test Results } & \multicolumn{3}{|c|}{ Certification Level } & \multicolumn{3}{|c|}{ Official Test Results } & \multicolumn{3}{|c|}{ Certification Level } \\
\hline (g/bhp-hr) & \multicolumn{3}{|c|}{0.22} & \multicolumn{3}{|c|}{1.0} & \multicolumn{3}{|c|}{0.34} & \multicolumn{3}{|c|}{2.10} \\
\hline (g/bhp-hr) & \multicolumn{3}{|c|}{6.60} & \multicolumn{3}{|c|}{9.5} & \multicolumn{3}{|c|}{9.44} & \multicolumn{3}{|c|}{14.00} \\
\hline (g/bhp-hr) & \multicolumn{3}{|c|}{1.24} & \multicolumn{3}{|c|}{5.0} & \multicolumn{3}{|c|}{1.62} & \multicolumn{3}{|c|}{9.00} \\
\hline (g/bhp-hr) & \multicolumn{3}{|c|}{0.23} & \multicolumn{3}{|c|}{0.6} & \multicolumn{3}{|c|}{0.37} & \multicolumn{3}{|c|}{0.72} \\
\hline (g/bhp-hr) & \multicolumn{3}{|c|}{527.03} & \multicolumn{3}{|c|}{-} & \multicolumn{3}{|c|}{568.16} & \multicolumn{3}{|c|}{-} \\
\hline
\end{tabular}


Weighted Emissions for Locomotive 8867:

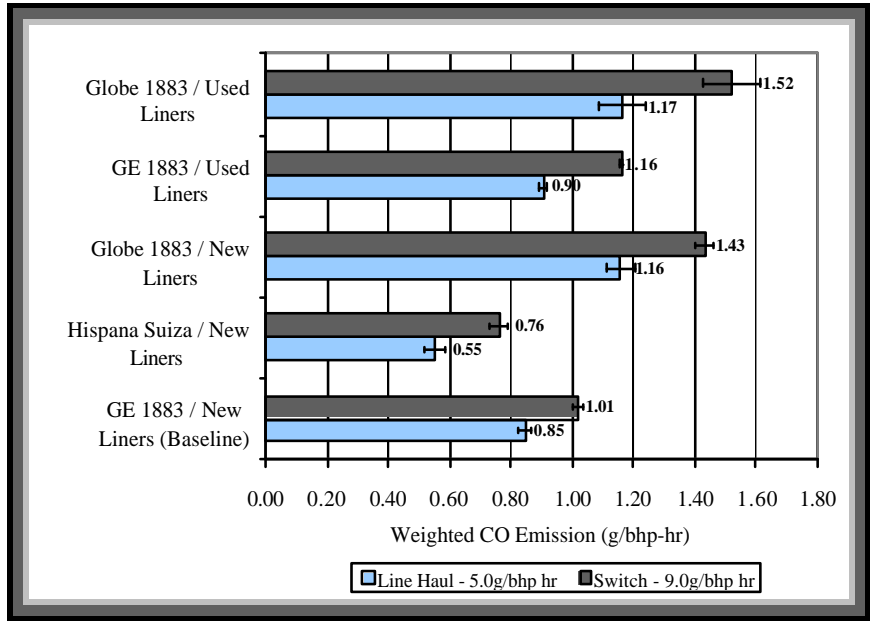

Figure B1: Weighted CO Emissions

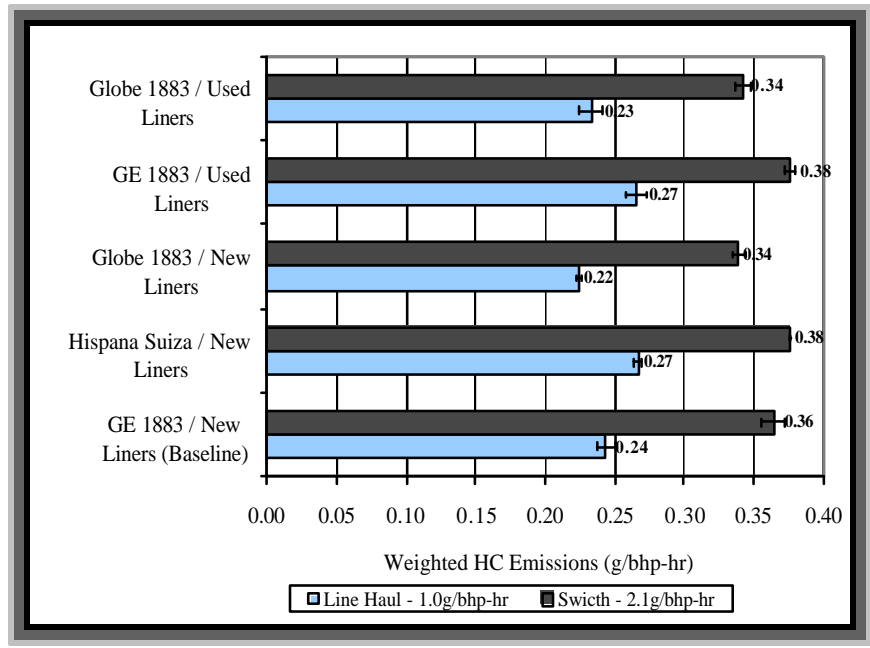

Figure B3: Weighted HC Emissions

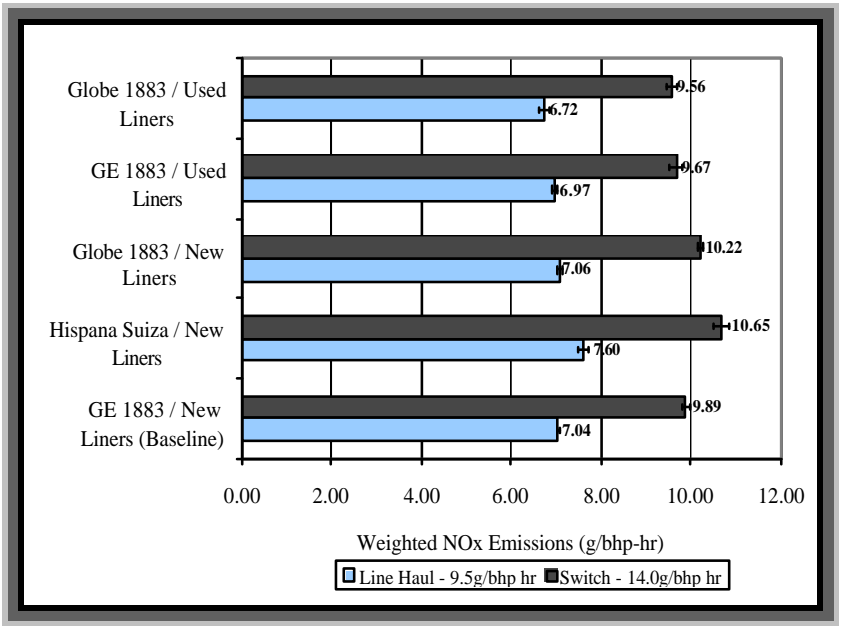

Figure B2: Weighted NOx Emissions

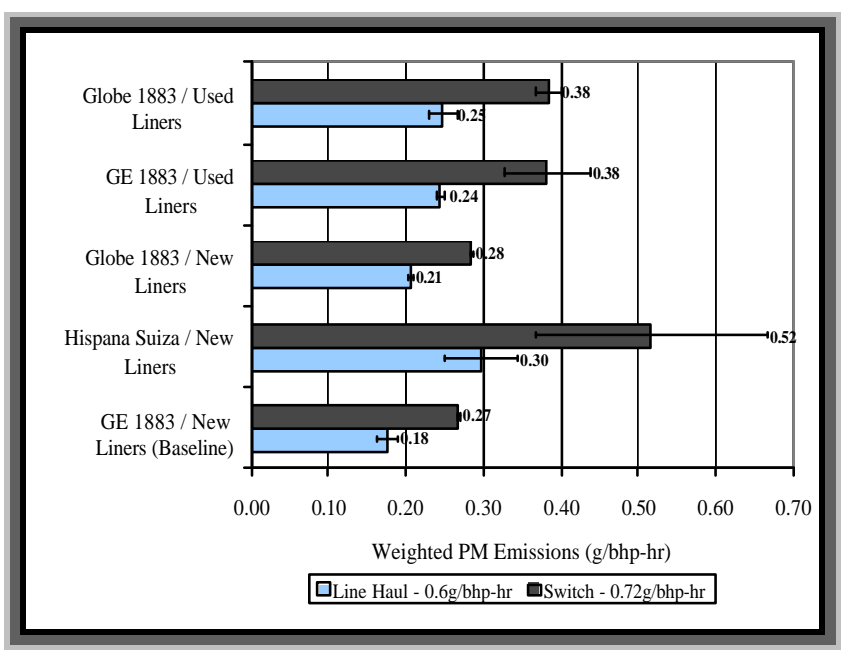

Figure B4: Weighted PM Emissions 
Weighted Emissions for Locomotive 8695:

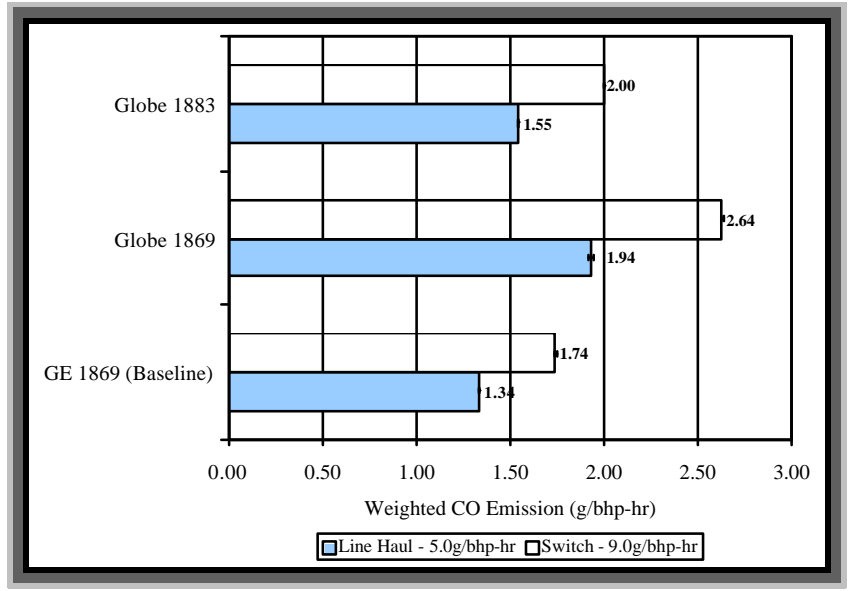

Figure B5: Weighted CO Emissions

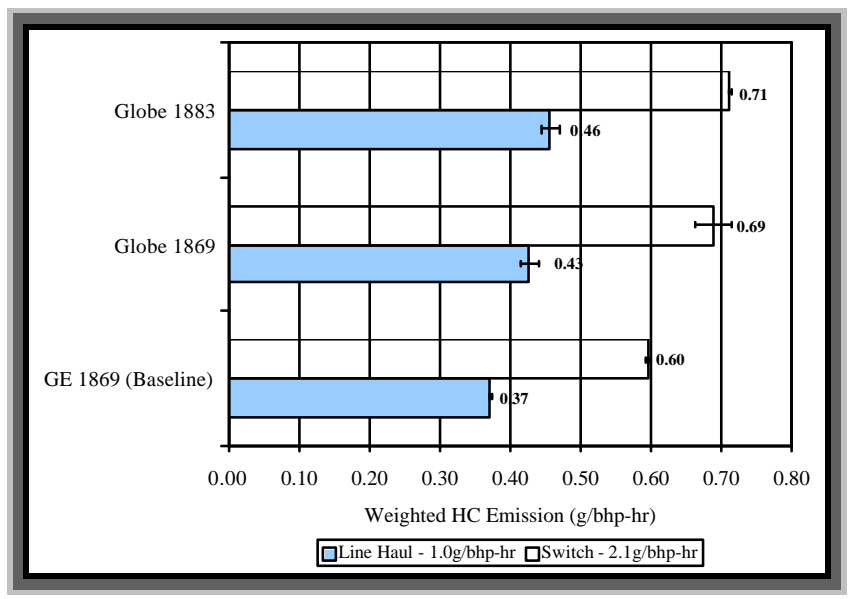

Figure B7: Weighted HC Emissions

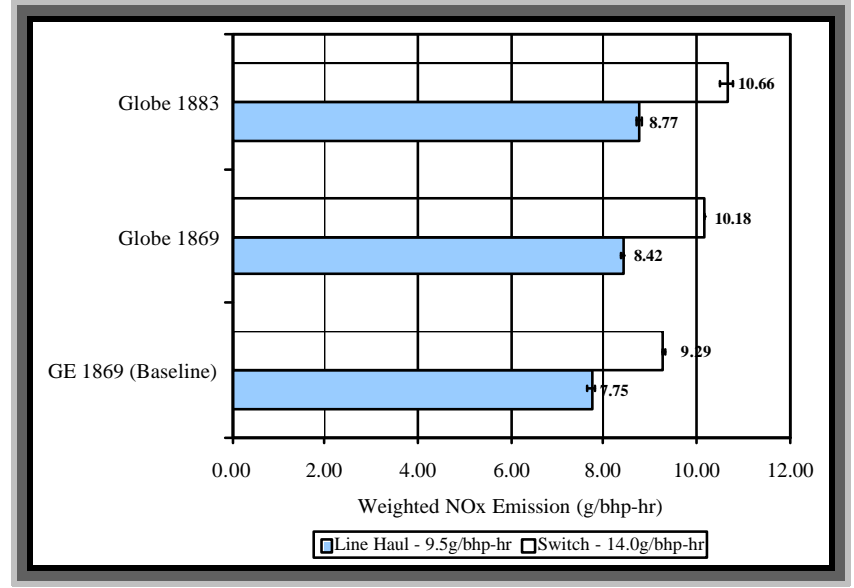

Figure B6: Weighted NOx Emissions

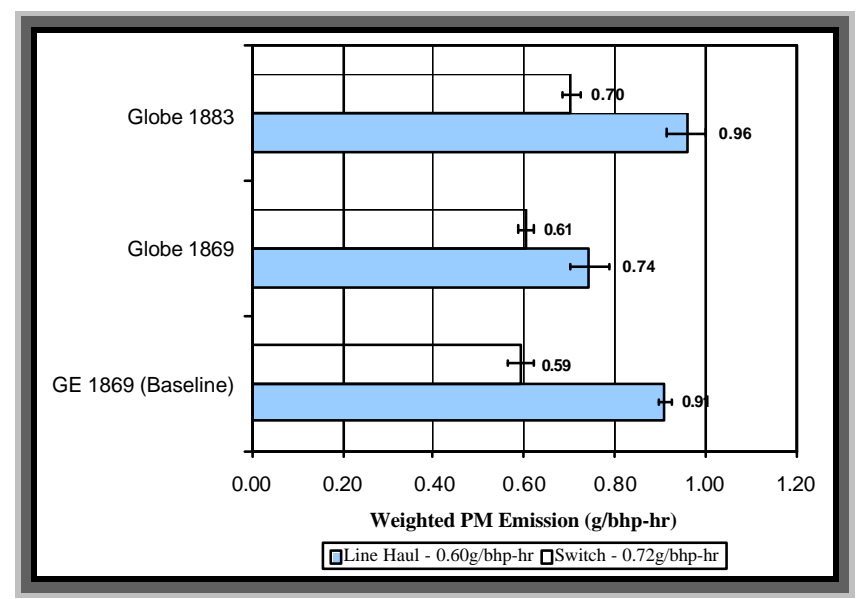

Figure B8: Weighted PM Emissions 
Notch Emissions for Locomotive 8867:

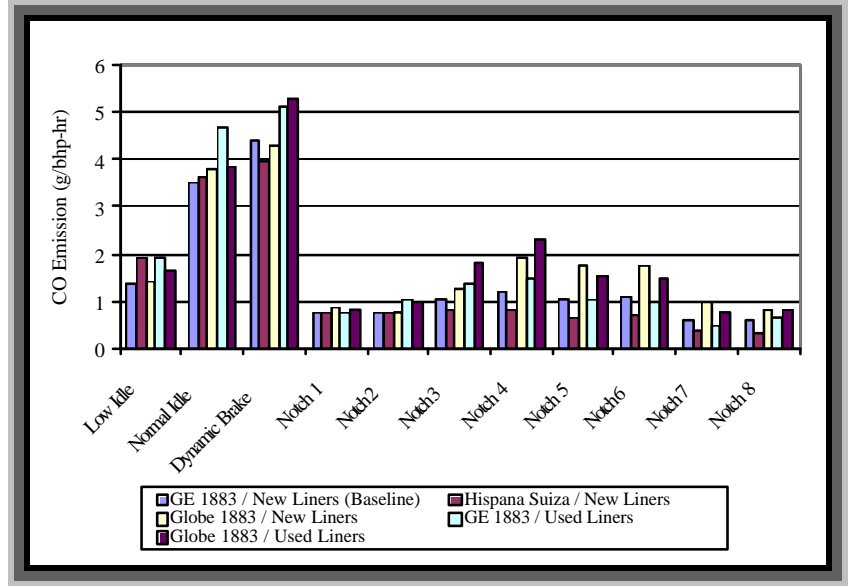

Figure B9: CO Emissions

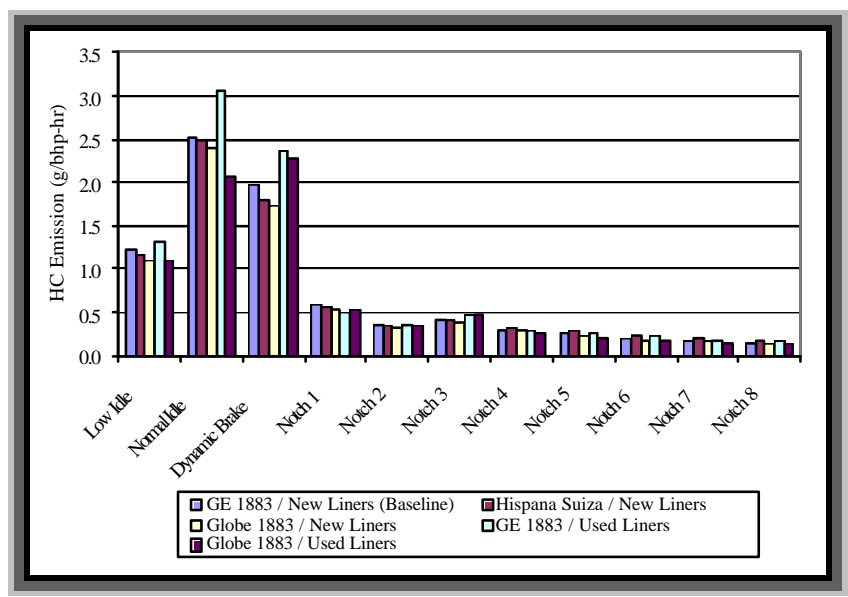

Figure B11: HC Emissions

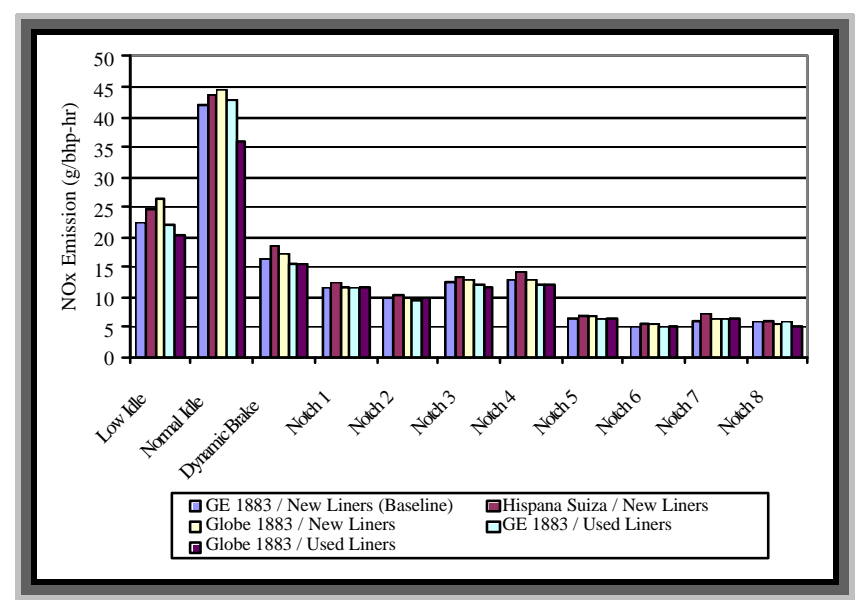

Figure B10: NOx Emissions

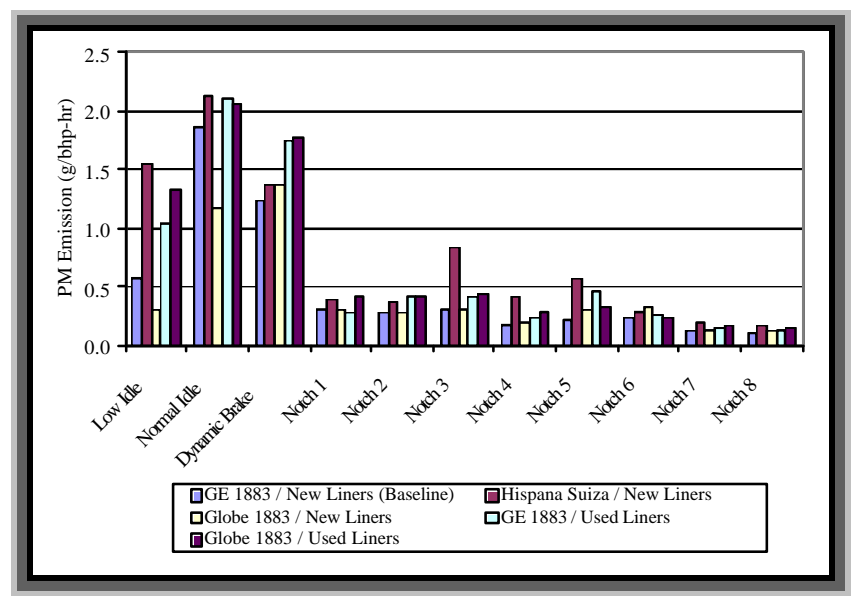

Figure B12: PM Emissions 
Notch Emissions for Locomotive 8695:

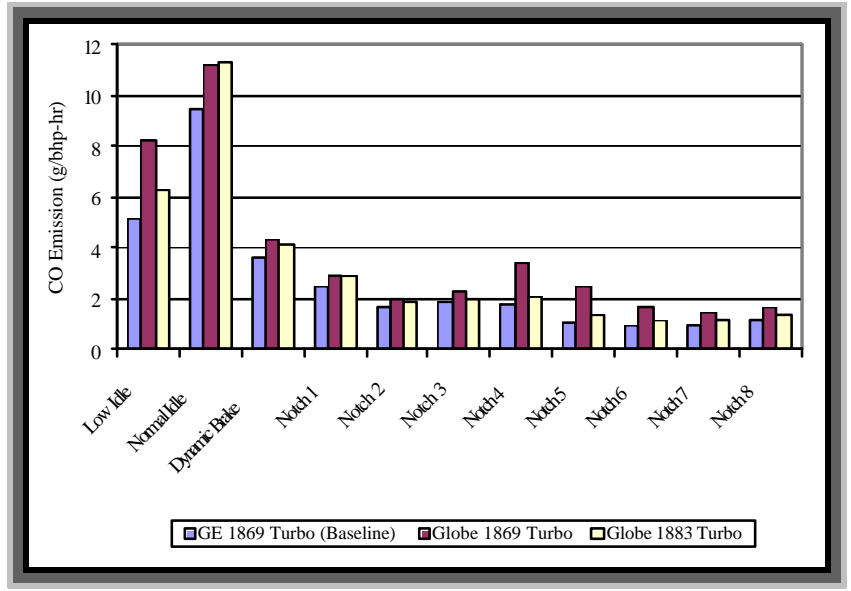

Figure B13: CO Emissions

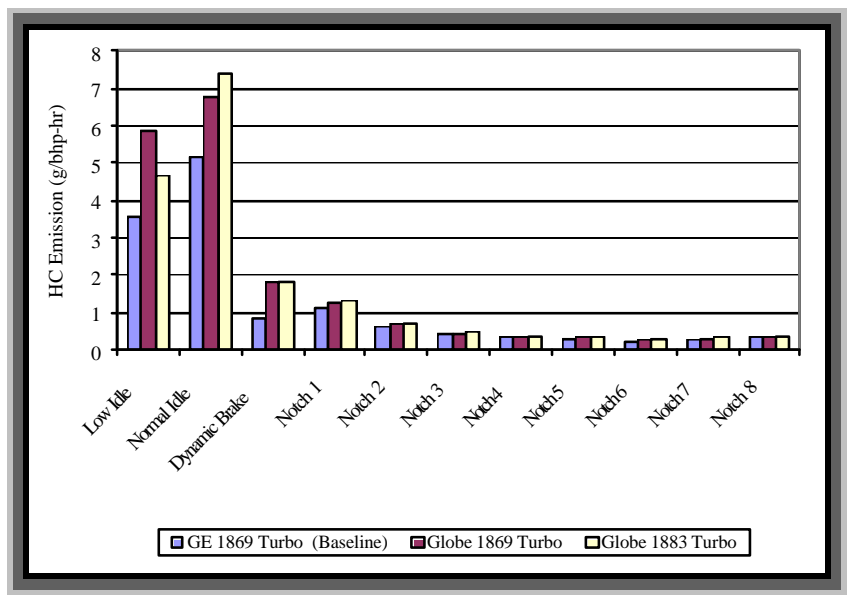

Figure B15: HC Emissions

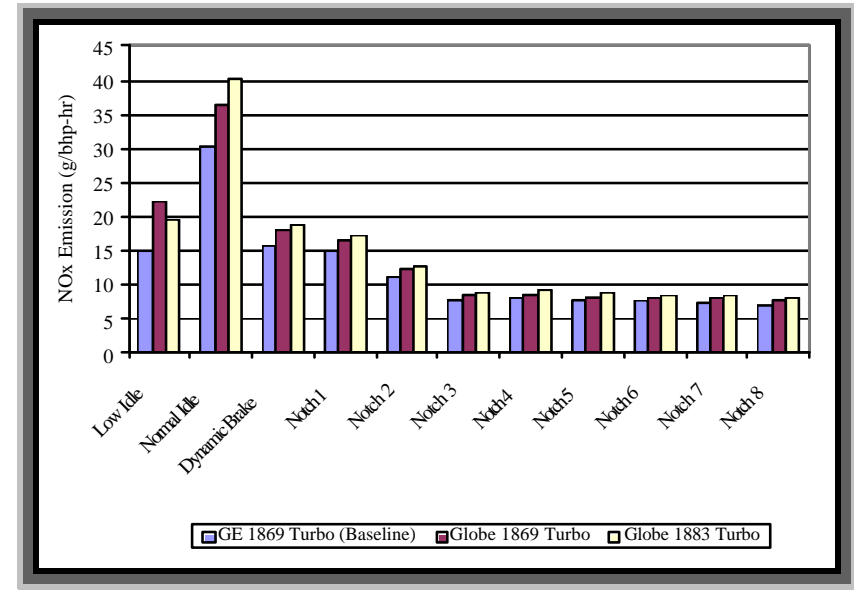

Figure B14: NOx Emissions

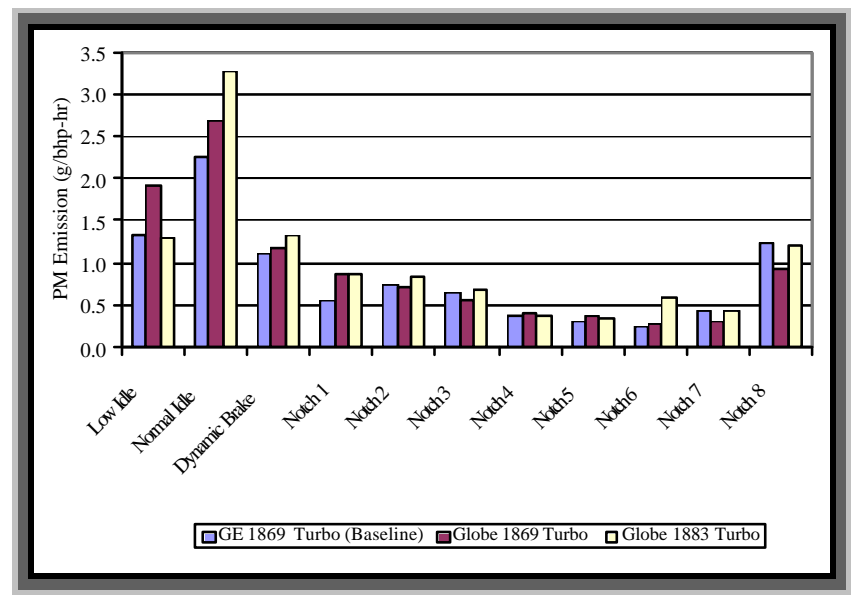

Figure B16: PM Emissions 


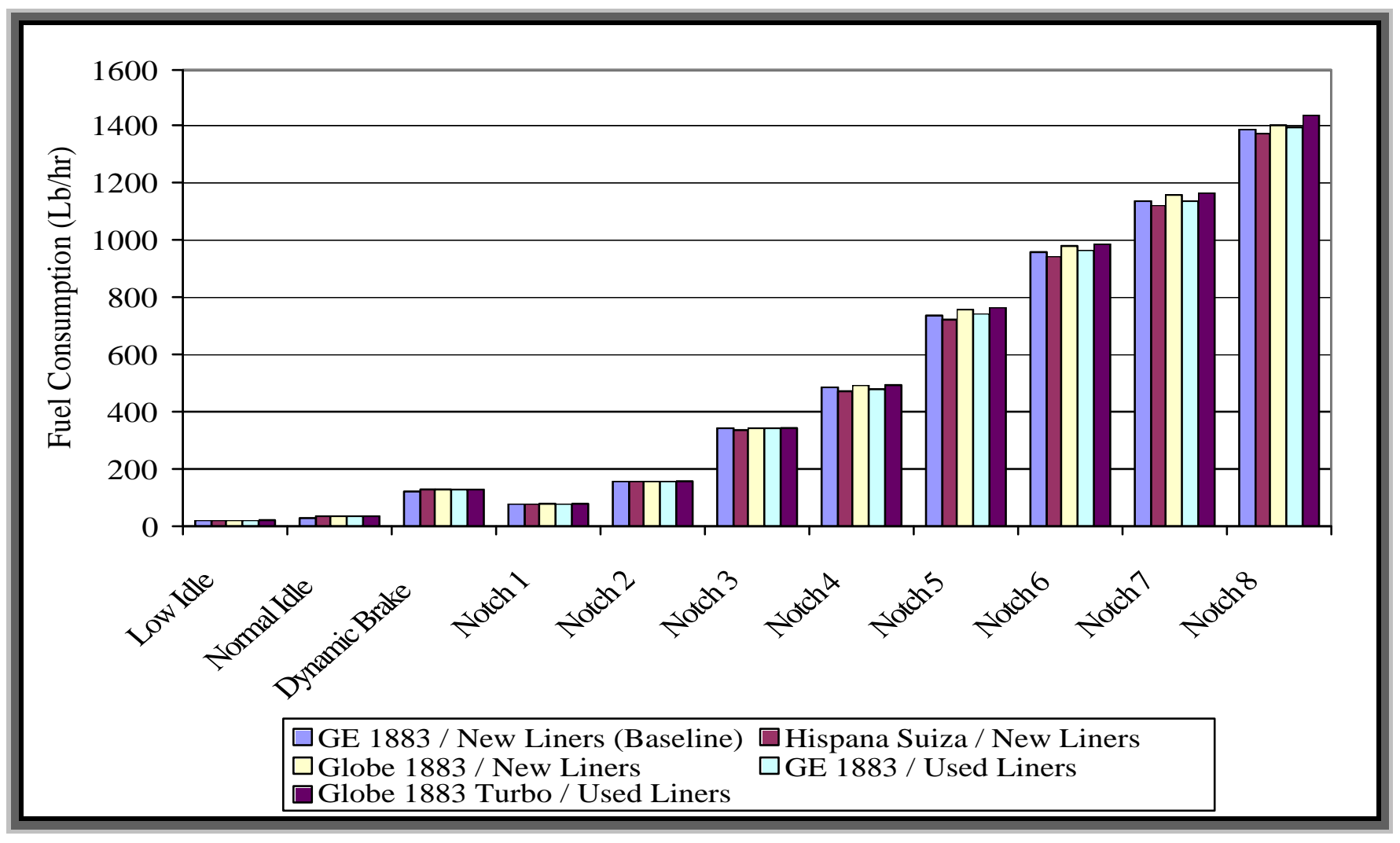

Figure B17: Fuel Consumption for Locomotive 8867

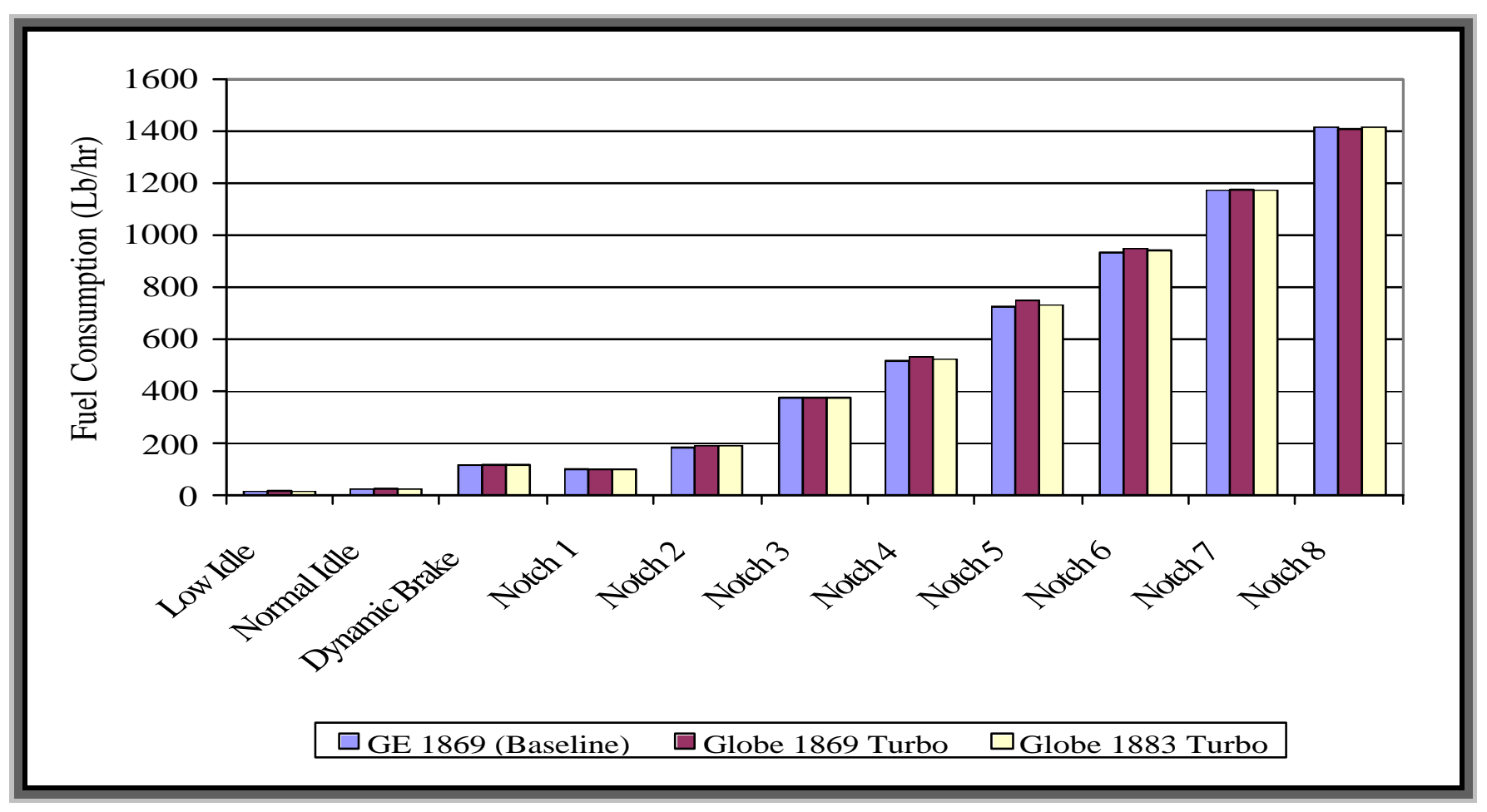

Figure B18: Fuel Consumption for Locomotive 8695 


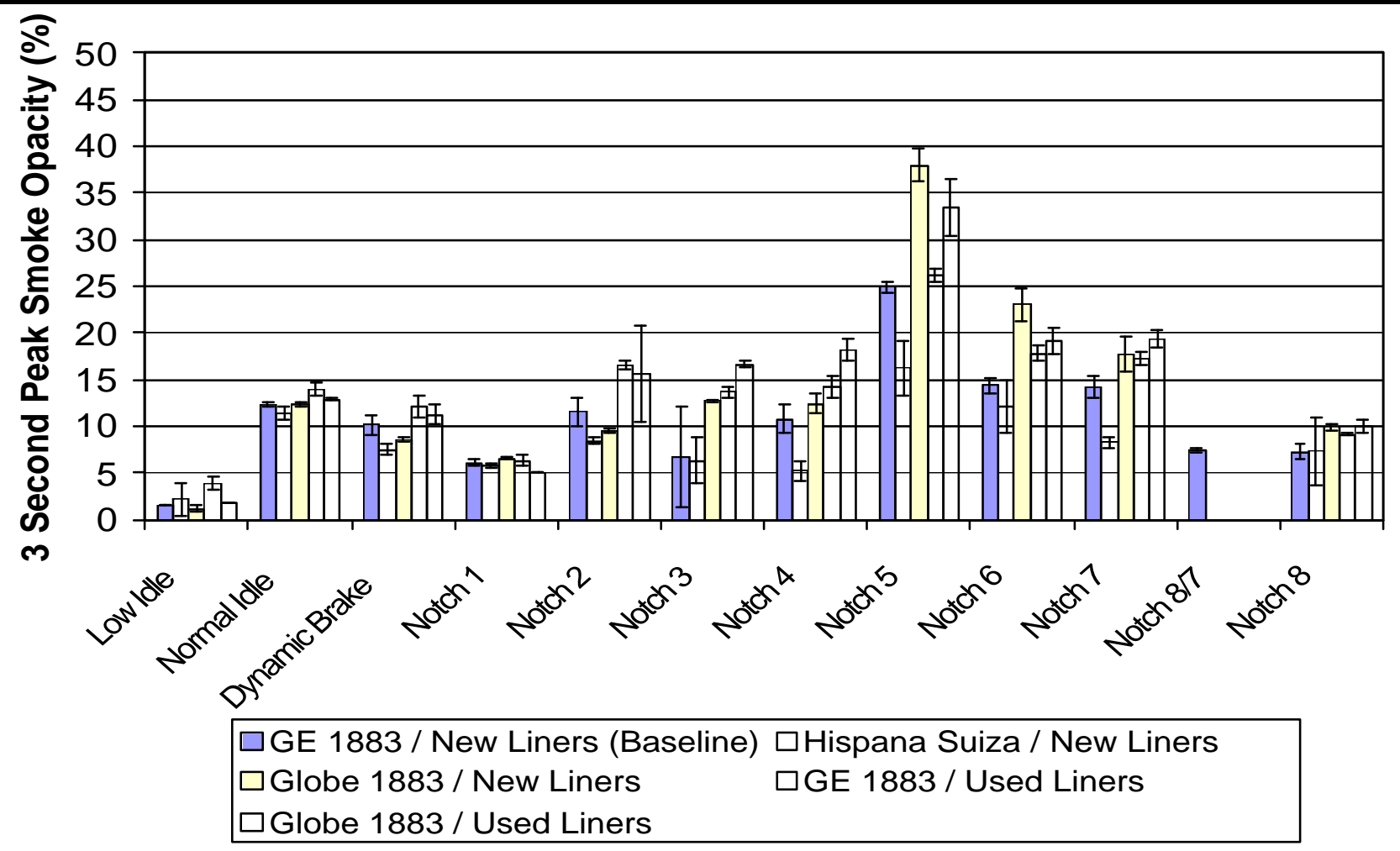

Figure B19: 3 Second Peak Smoke Opacity for Locomotive 8867

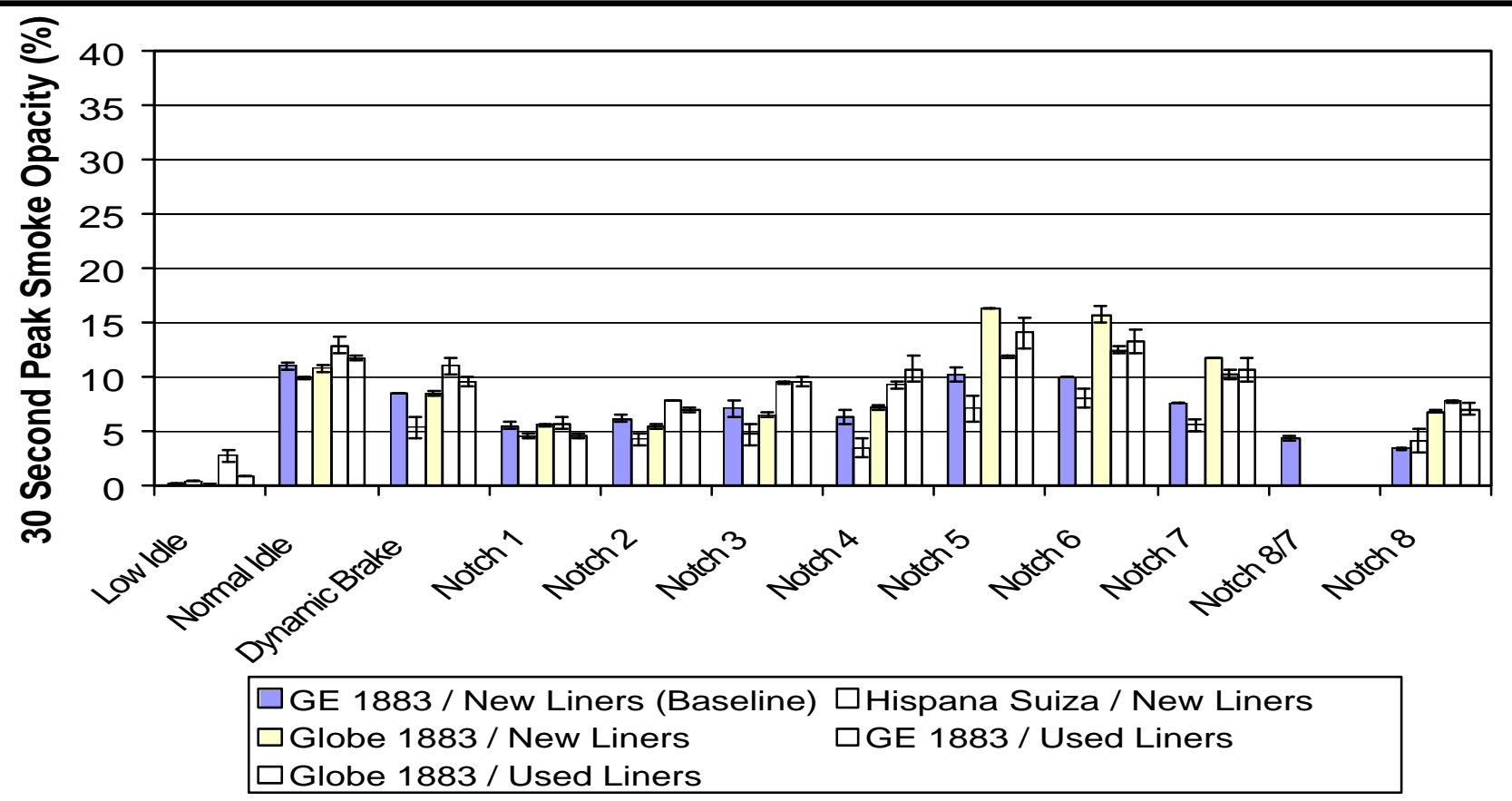

Figure B20: 30 Second Peak Smoke Opacity for Locomotive 8867 


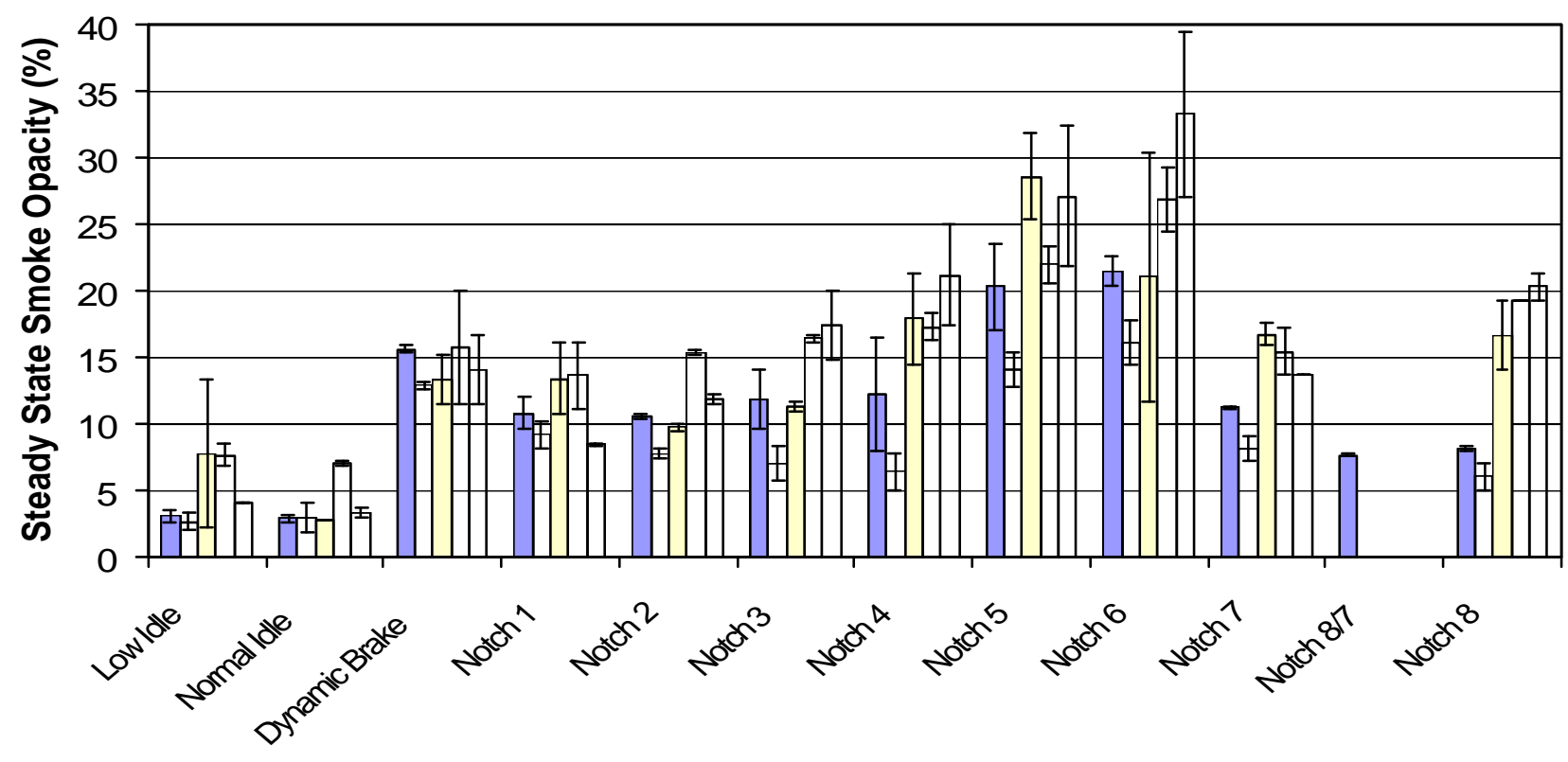

$\square$ GE 1883 / New Liners (Baseline) $\square$ Hispana Suiza / New Liners

$\square$ Globe 1883 / New Liners $\square \mathrm{GE} 1883$ / Used Liners

$\square$ Globe 1883 / Used Liners

Figure B21: Steady State Smoke Opacity for Locomotive 8867

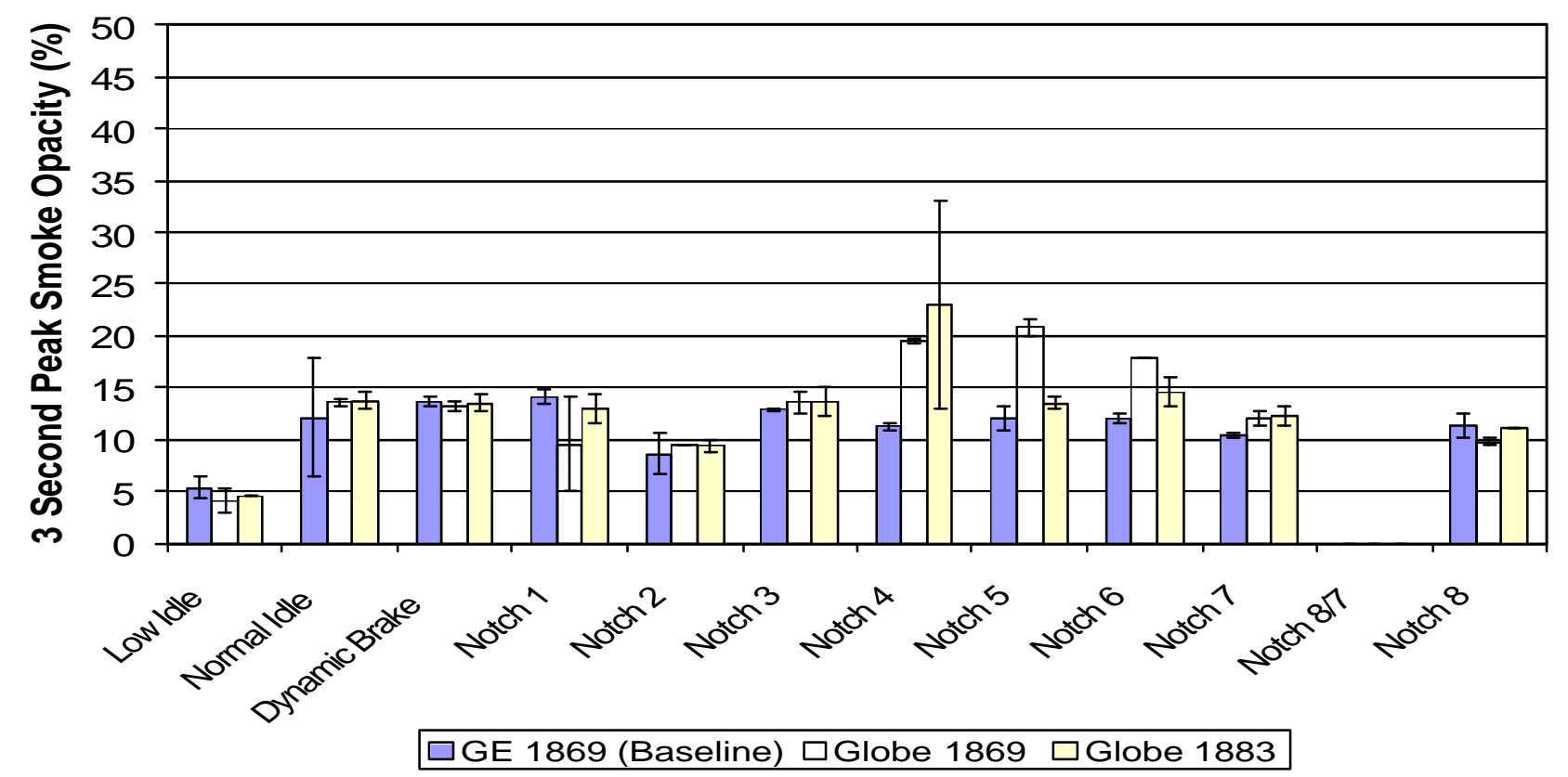

Figure B22: 3 Second Peak Smoke Opacity for Locomotive 8695 


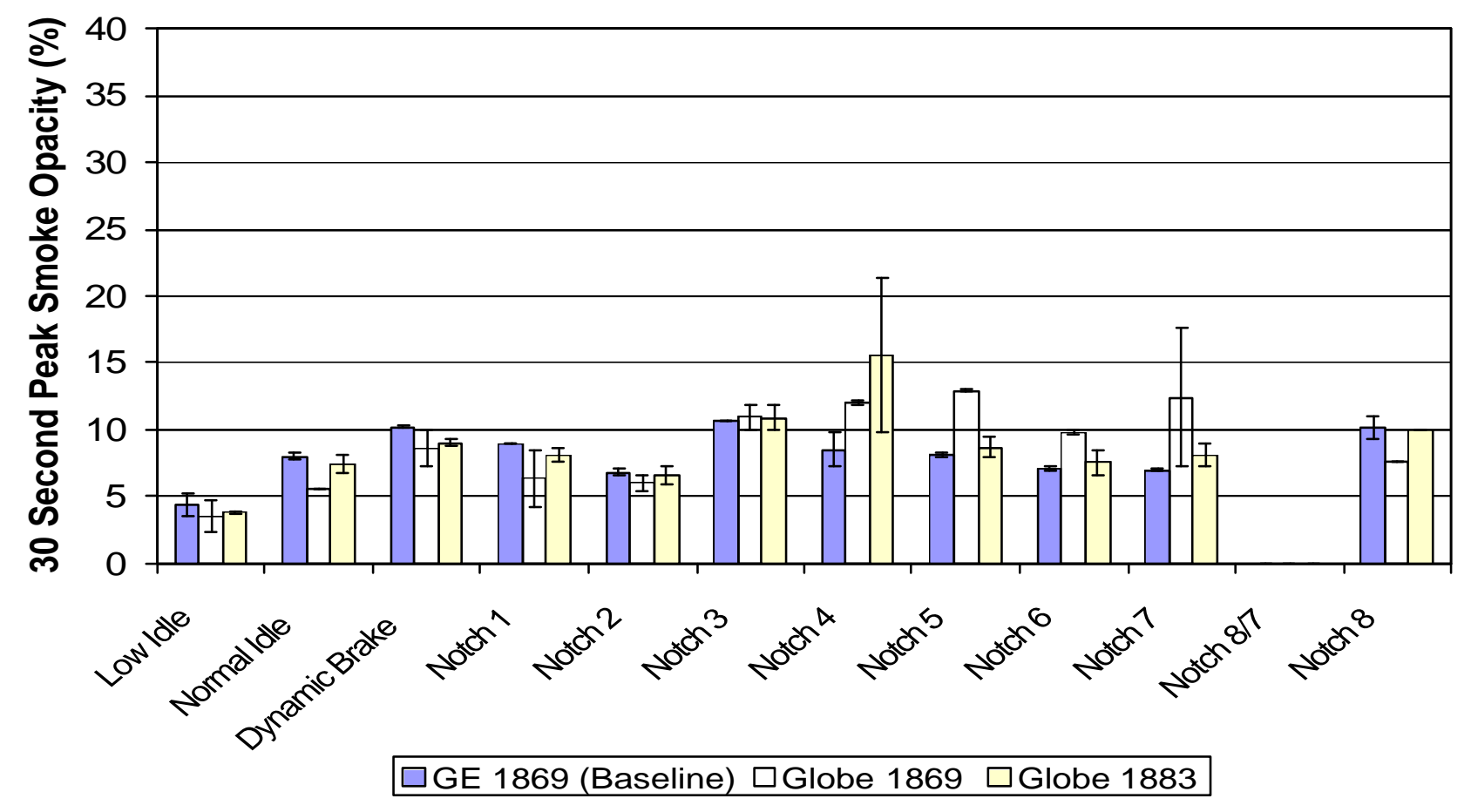

Figure B23: 30 Second Peak Smoke Opacity for Locomotive 8695

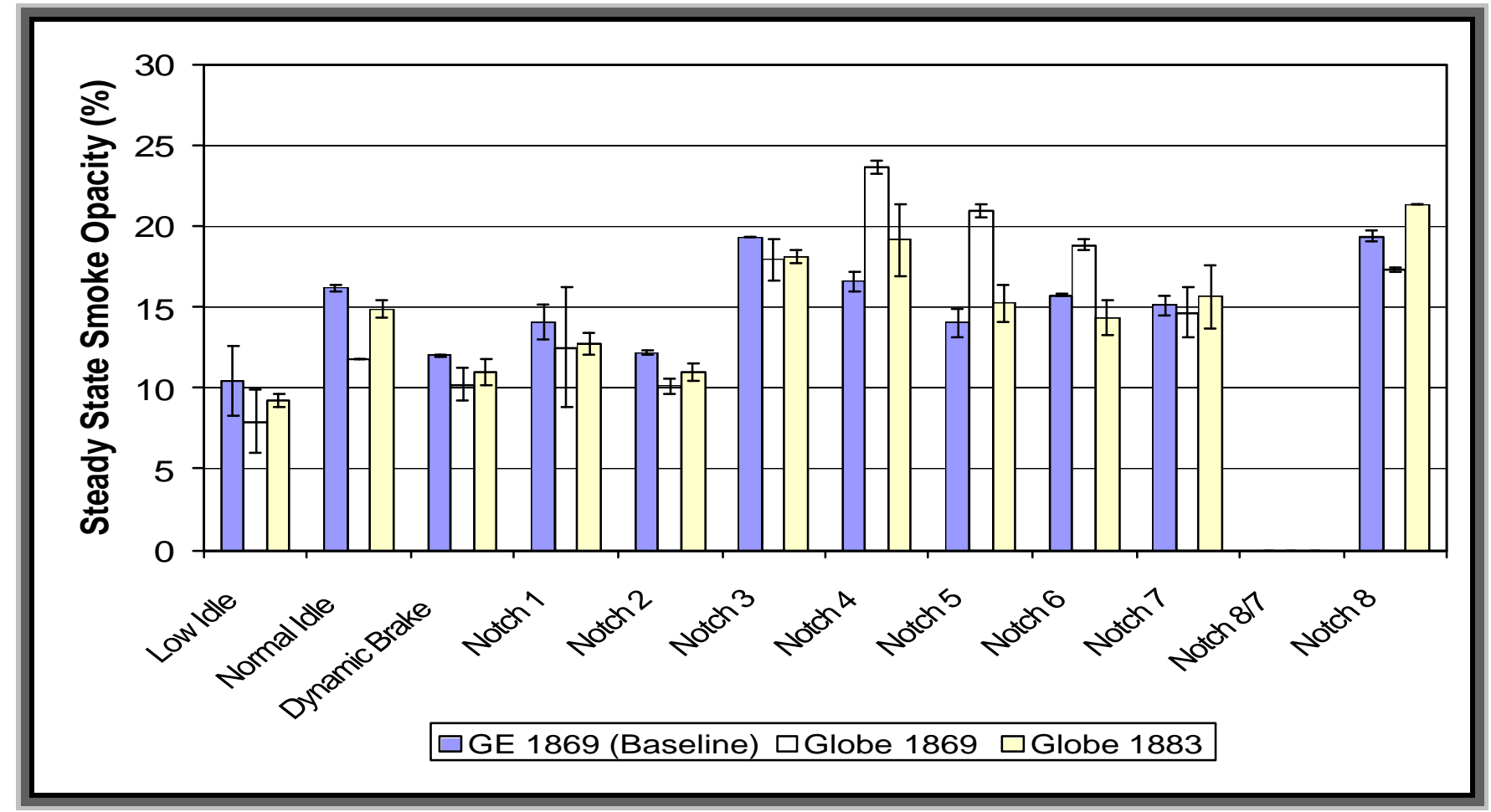

Figure B24: Steady State Smoke Opacity for Locomotive 8695 


\section{Appendix C Continuous Smoke Data for Locomotive 8678}

In this study, the smoke meter data was calculated at a frequency of $10 \mathrm{~Hz}$. The data from runs 3690,3691 , and 3692 was then taken and corrected to a $1 \mathrm{~Hz}$ frequency. The continuous traces of these runs are given in this Appendix.
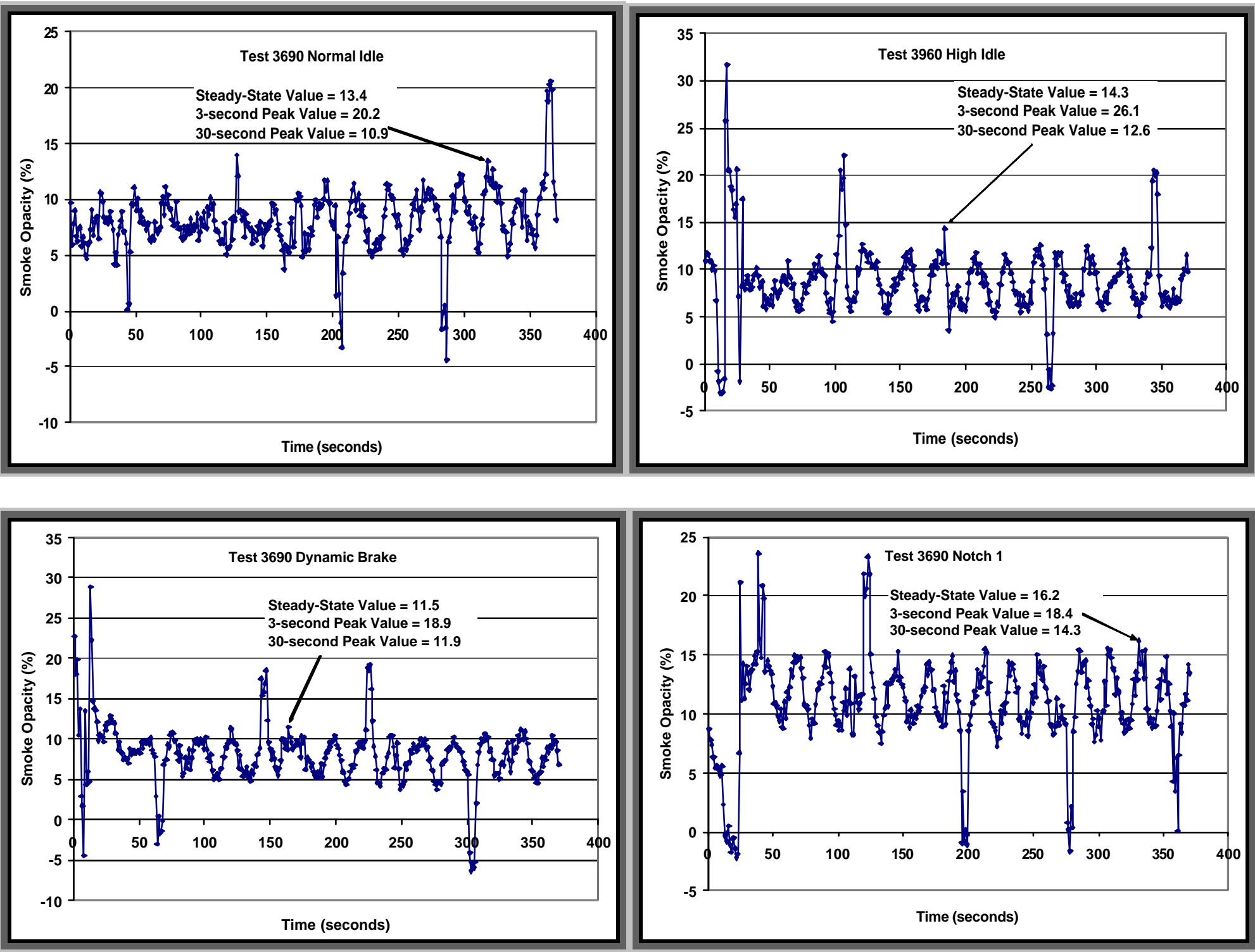

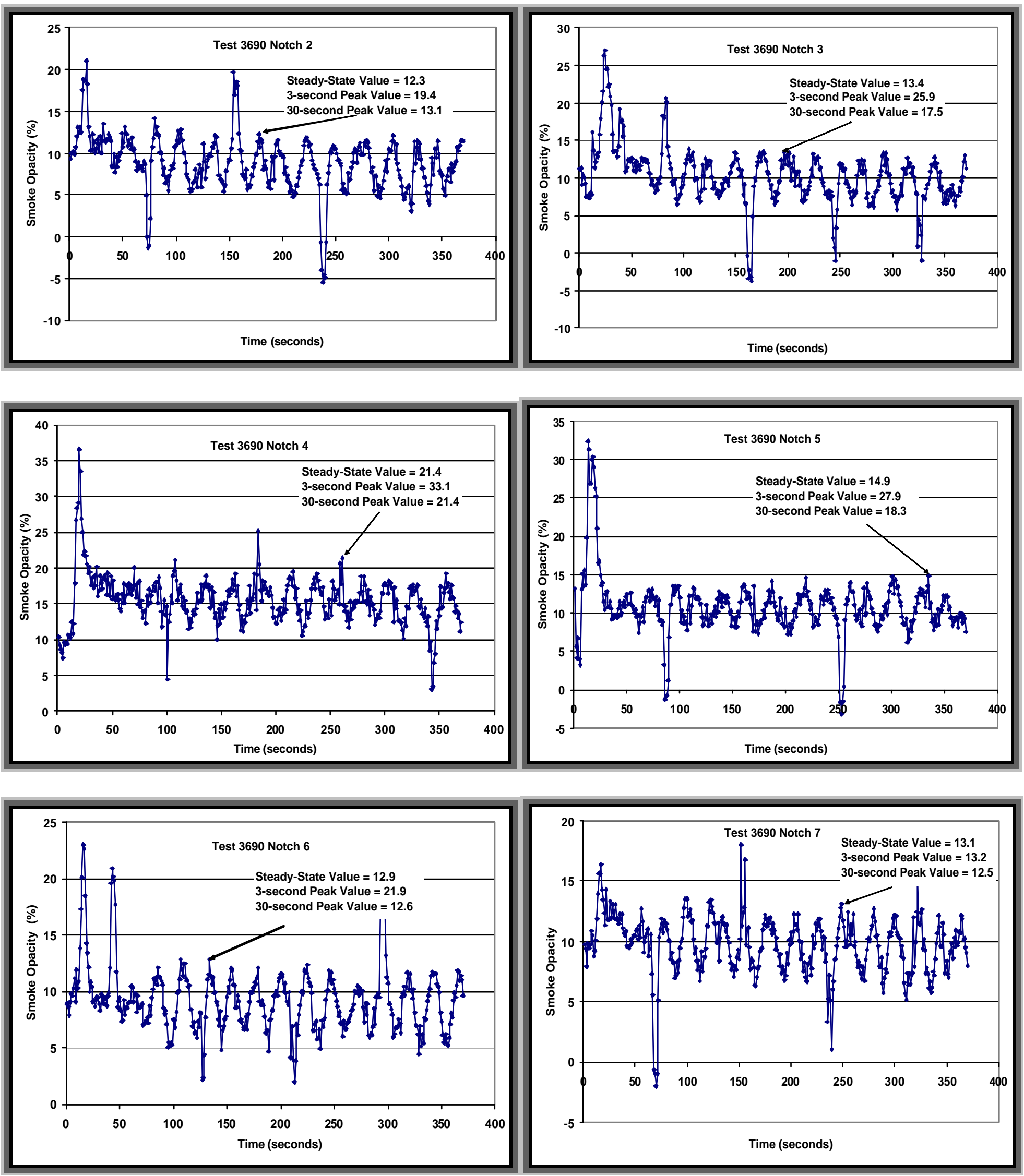

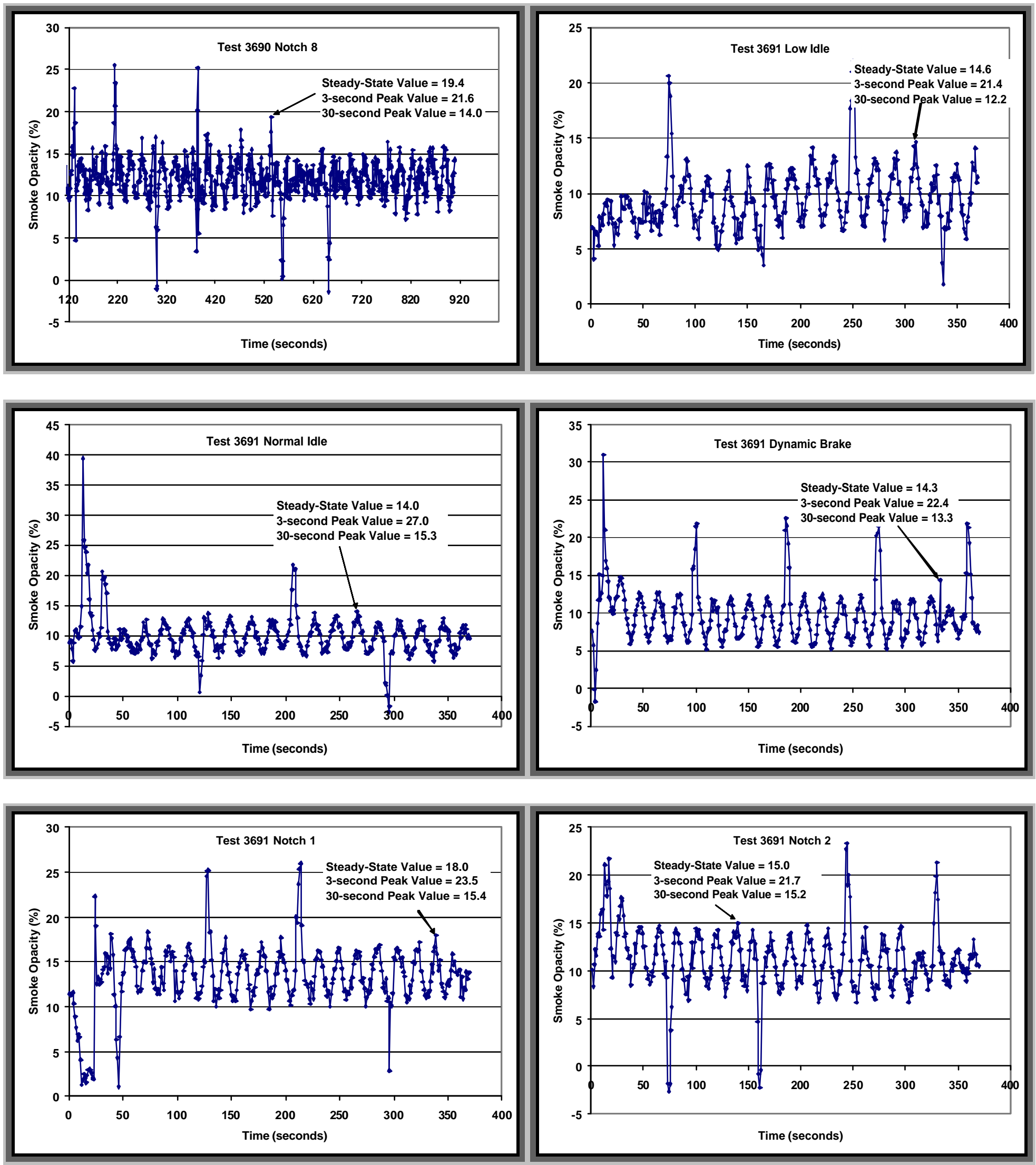

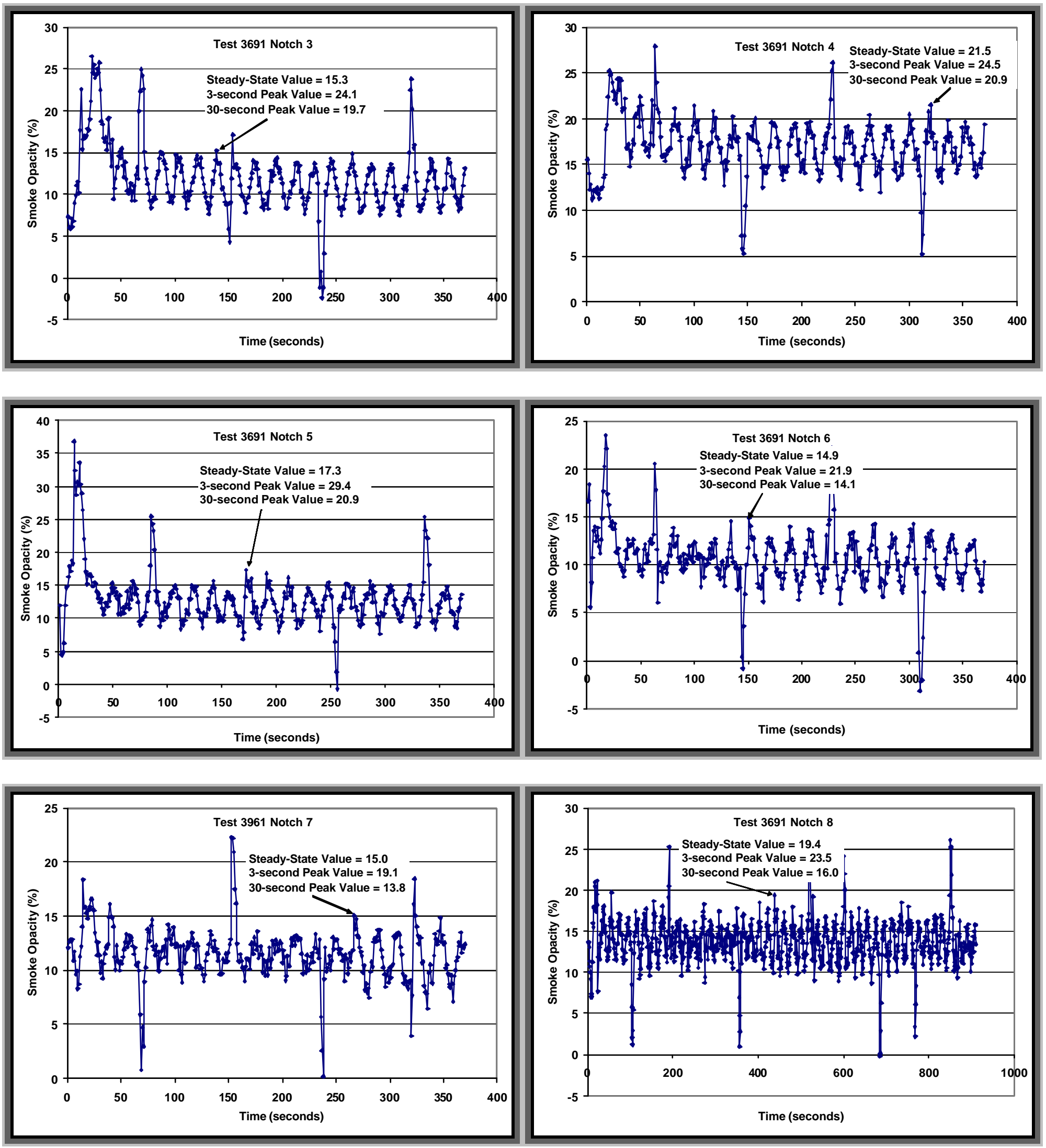

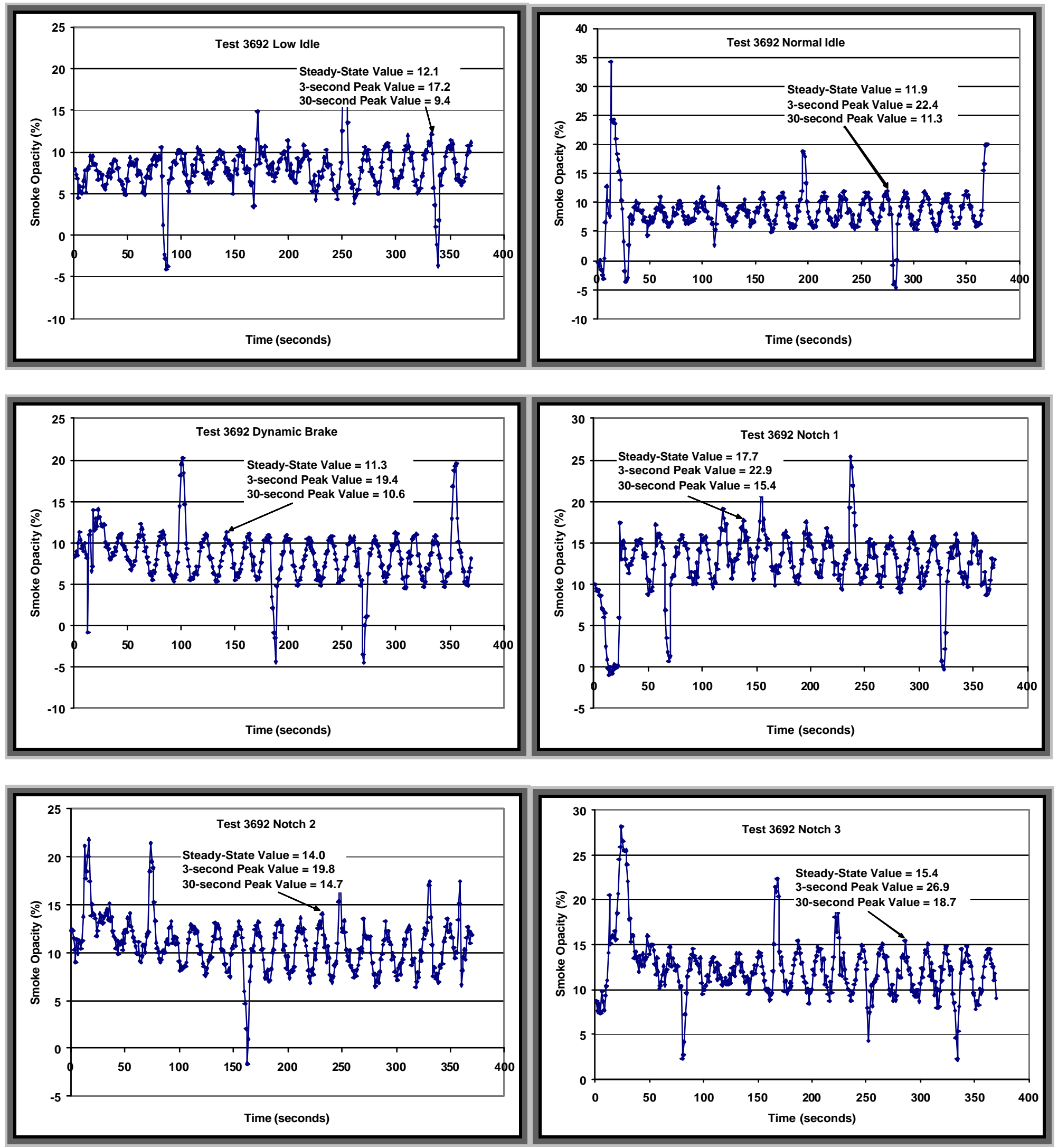

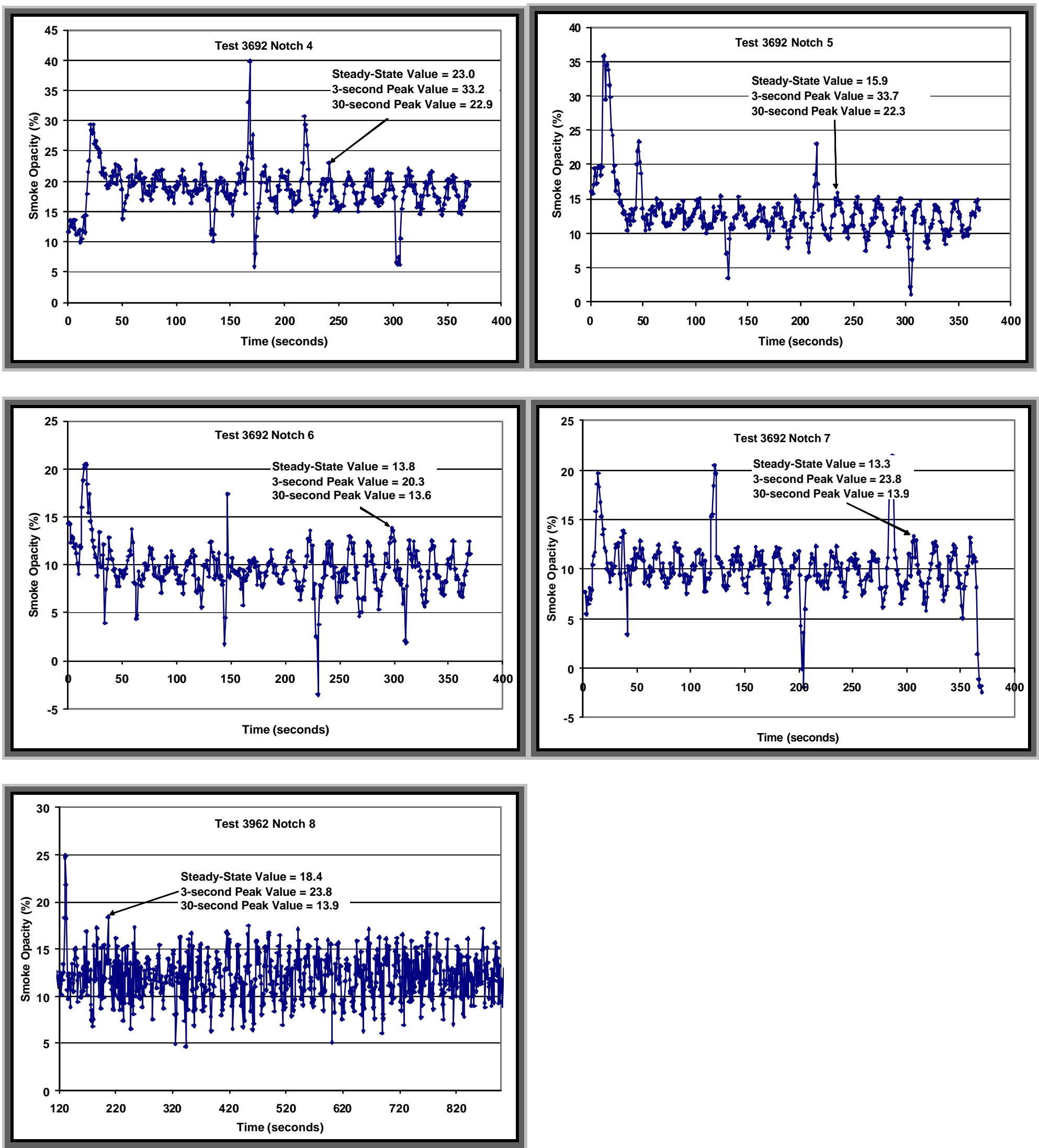


\section{Appendix D Continuous Smoke Data for Locomotives 8867 and 8695}

In this study, the smoke meter data was calculated at a frequency of $10 \mathrm{~Hz}$. The continuous traces of these locomotives are given in this Appendix.
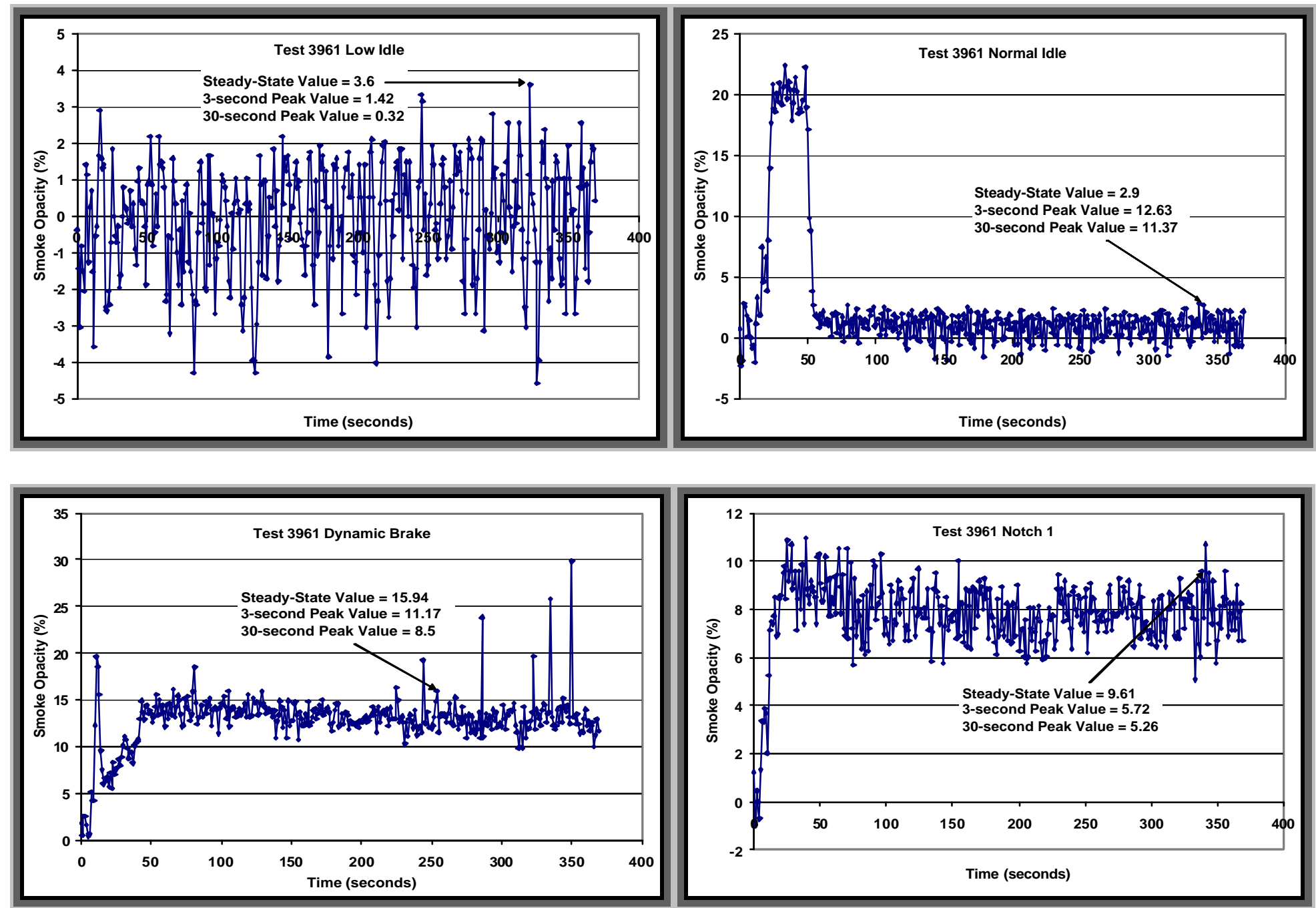

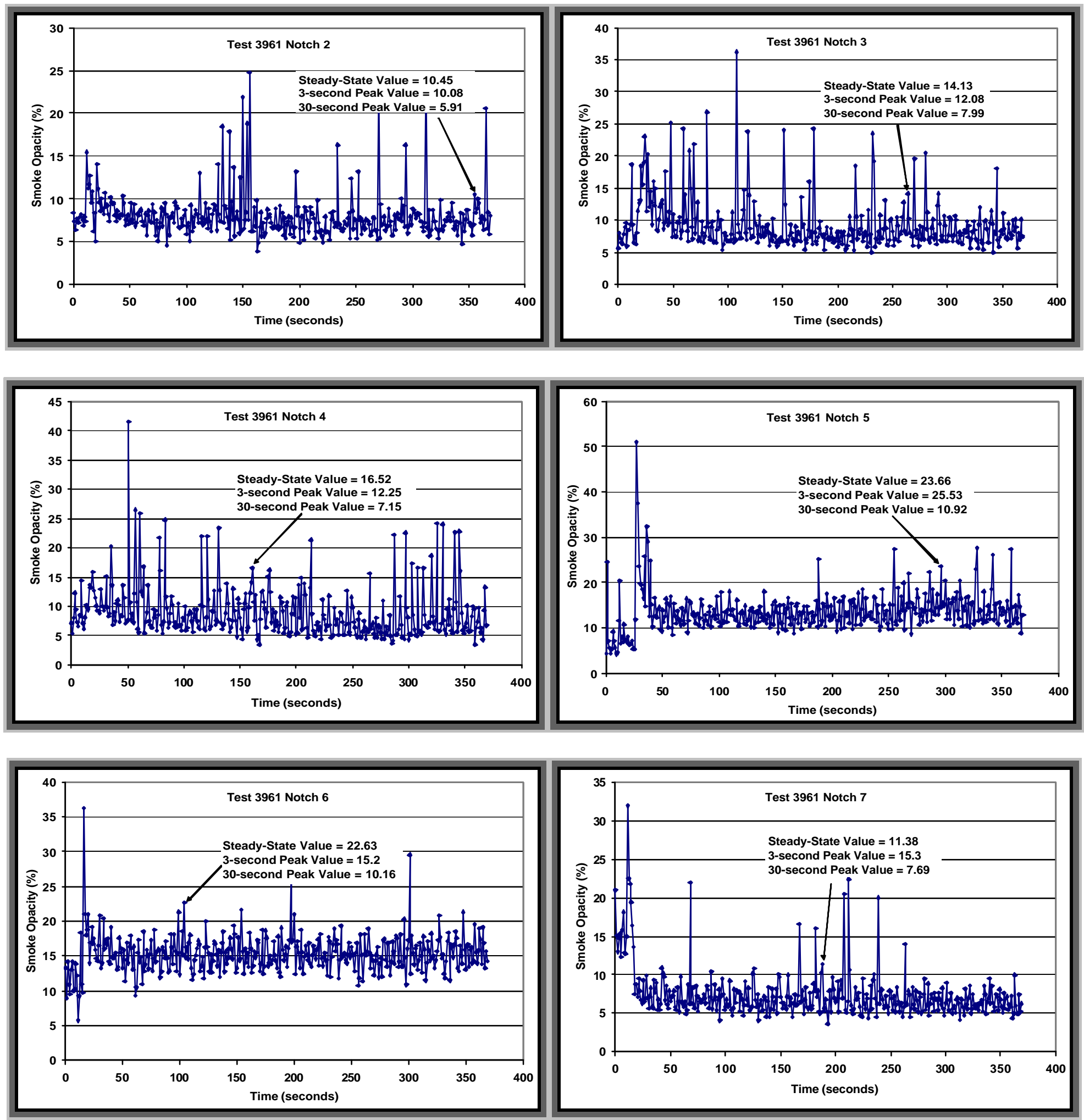

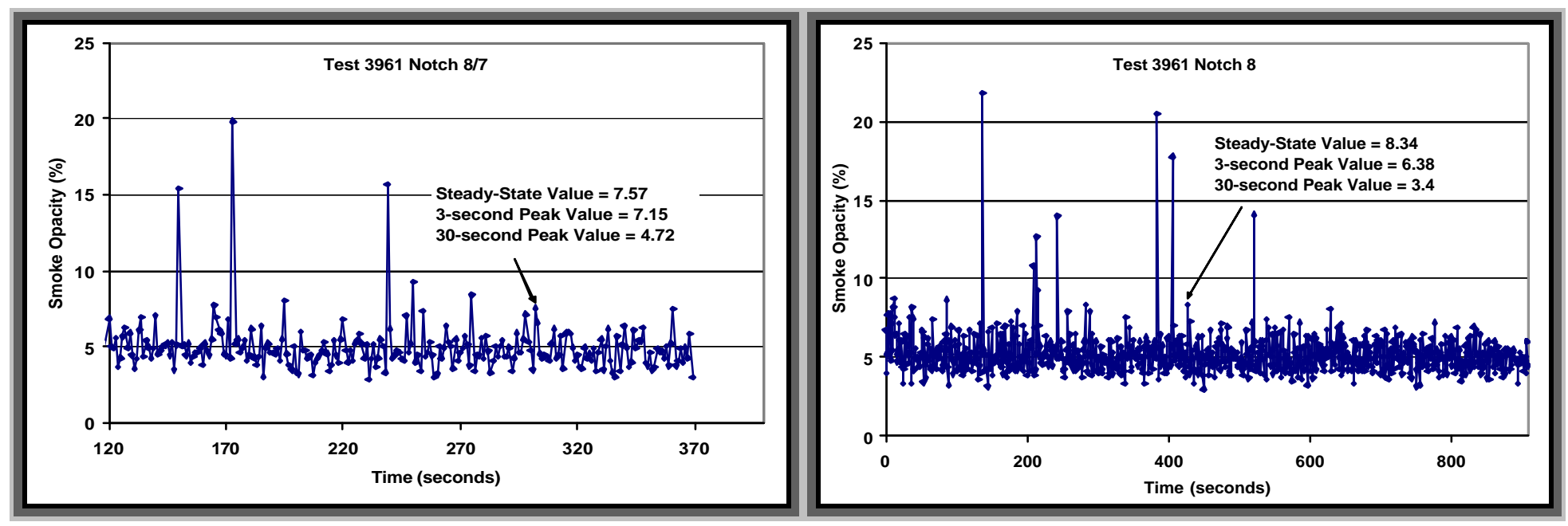

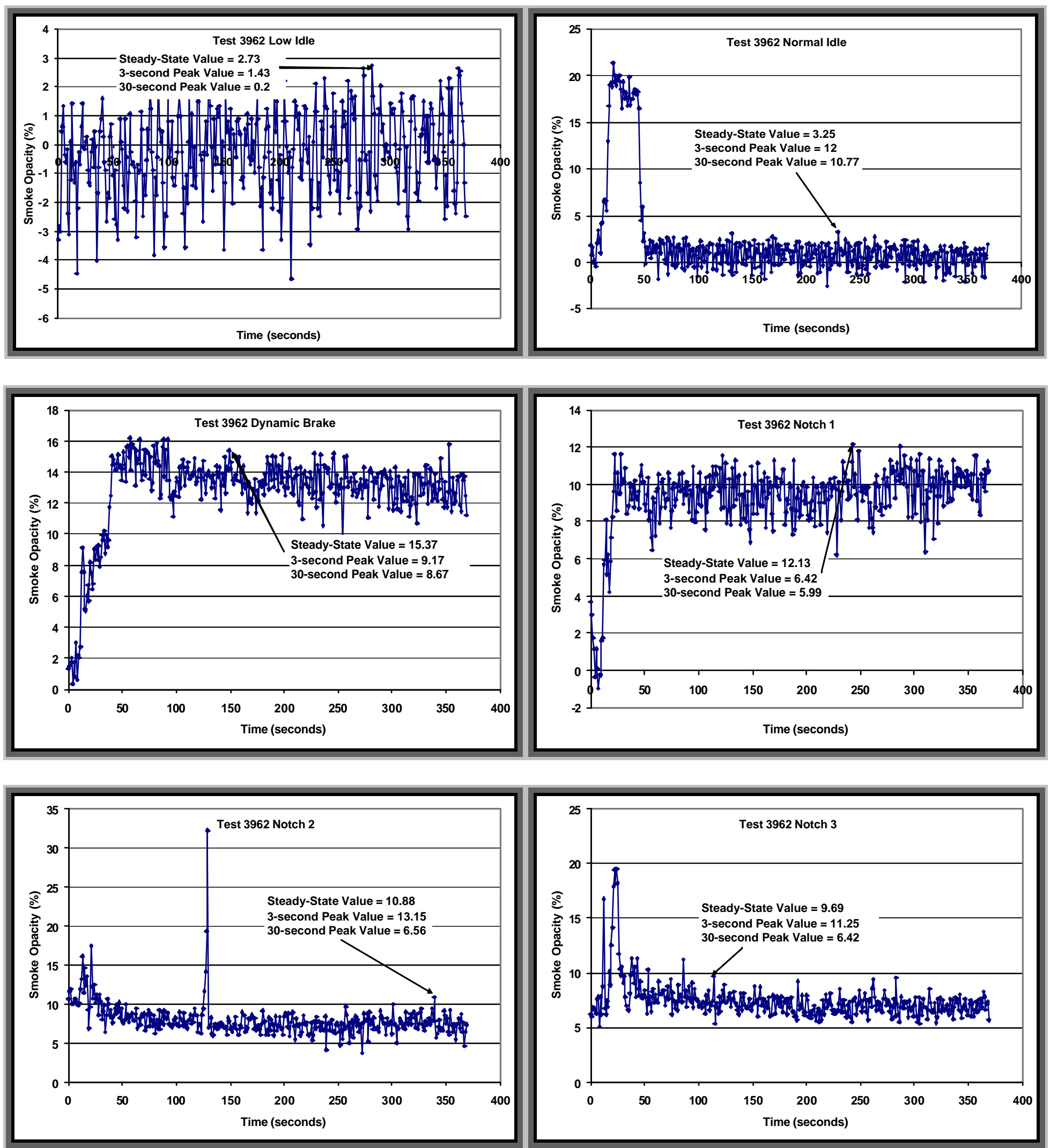

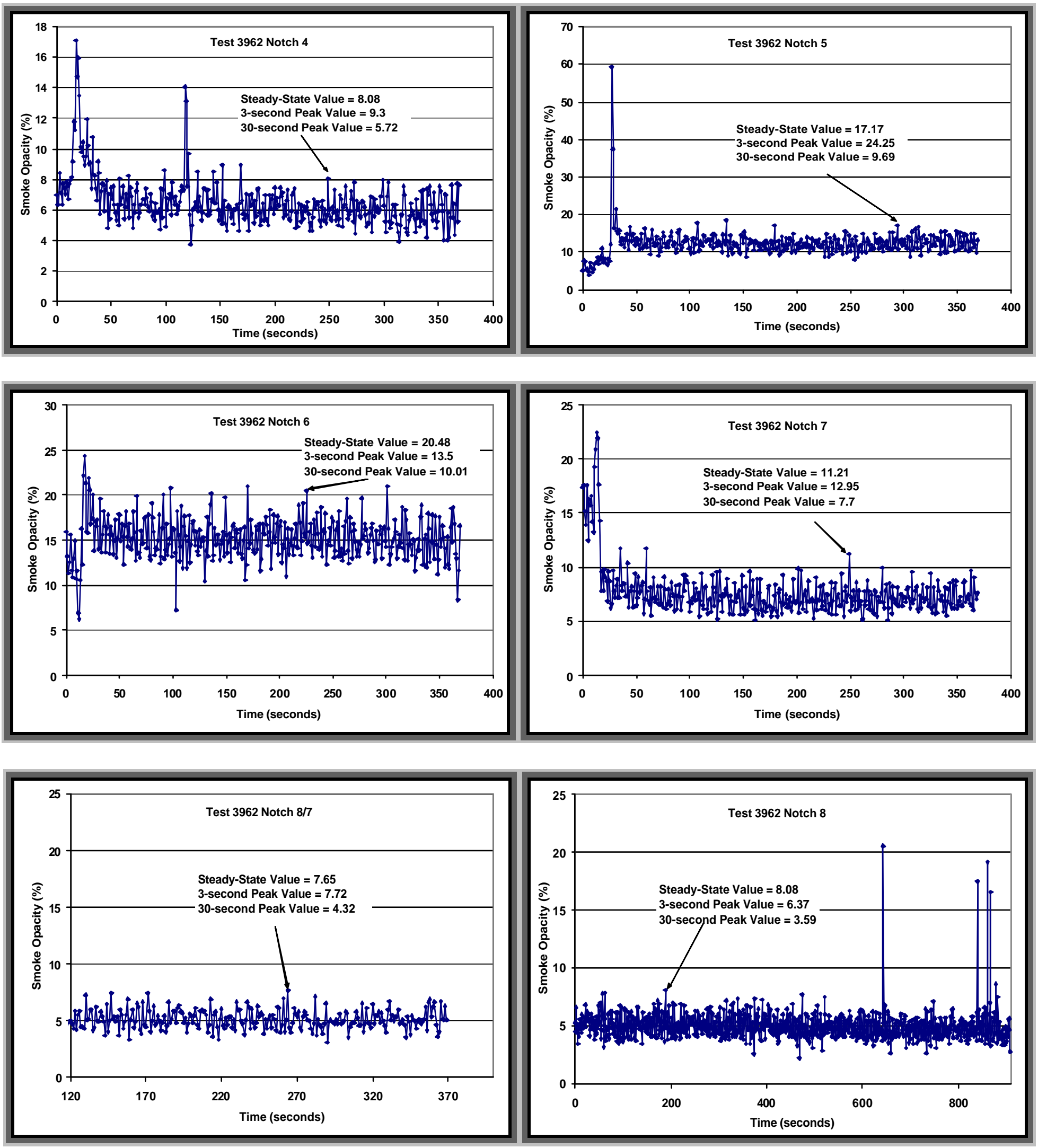

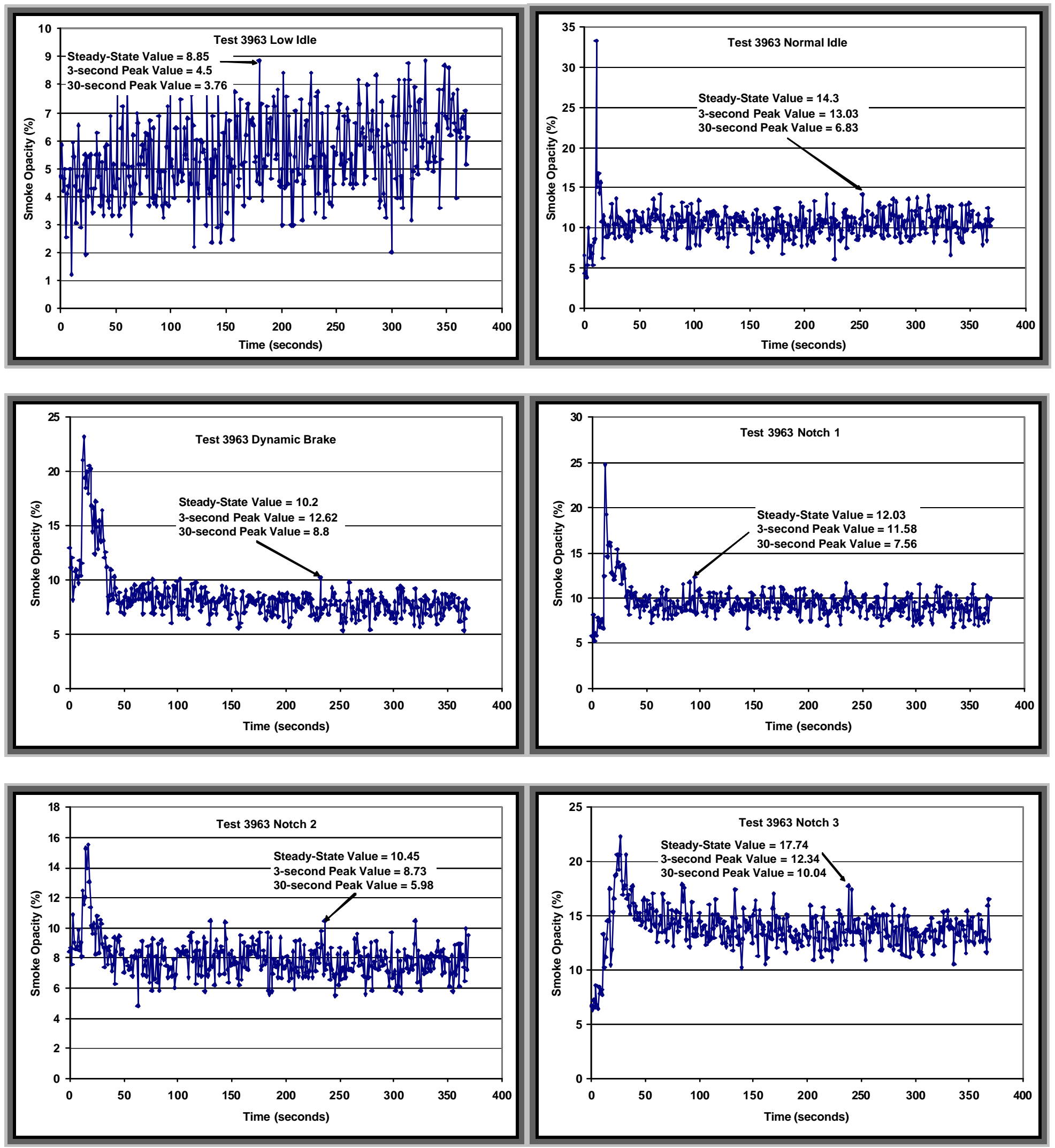

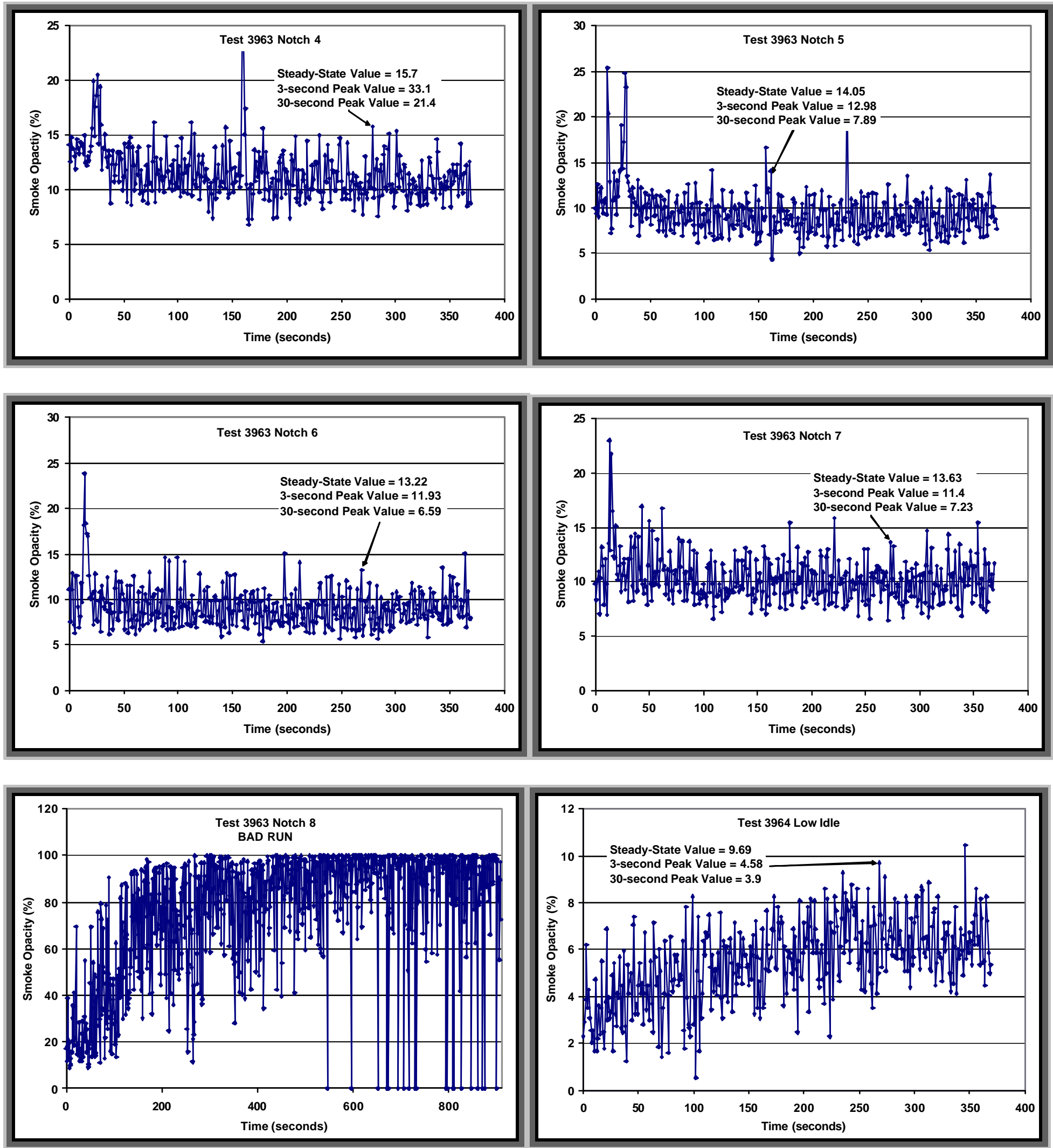

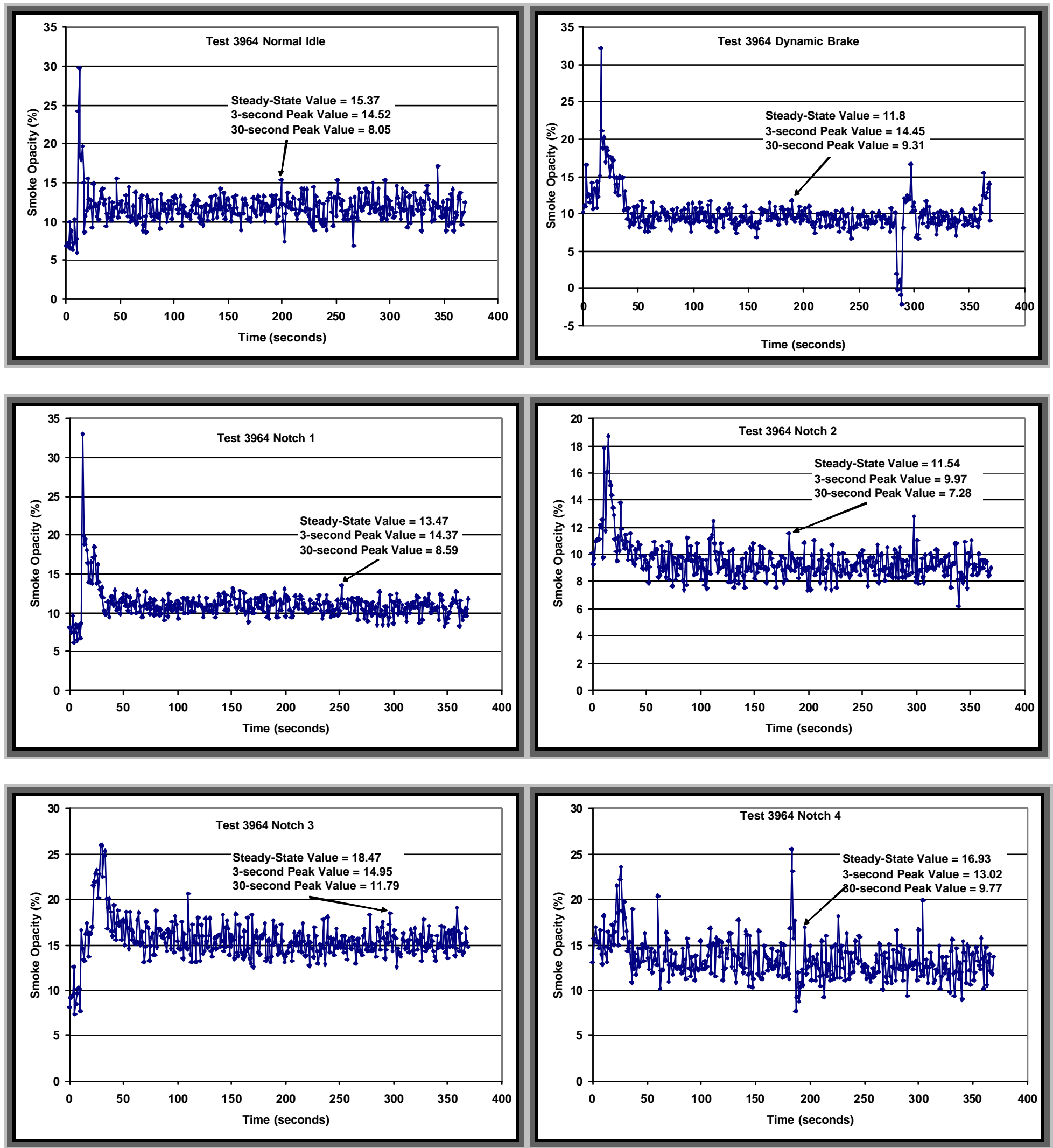

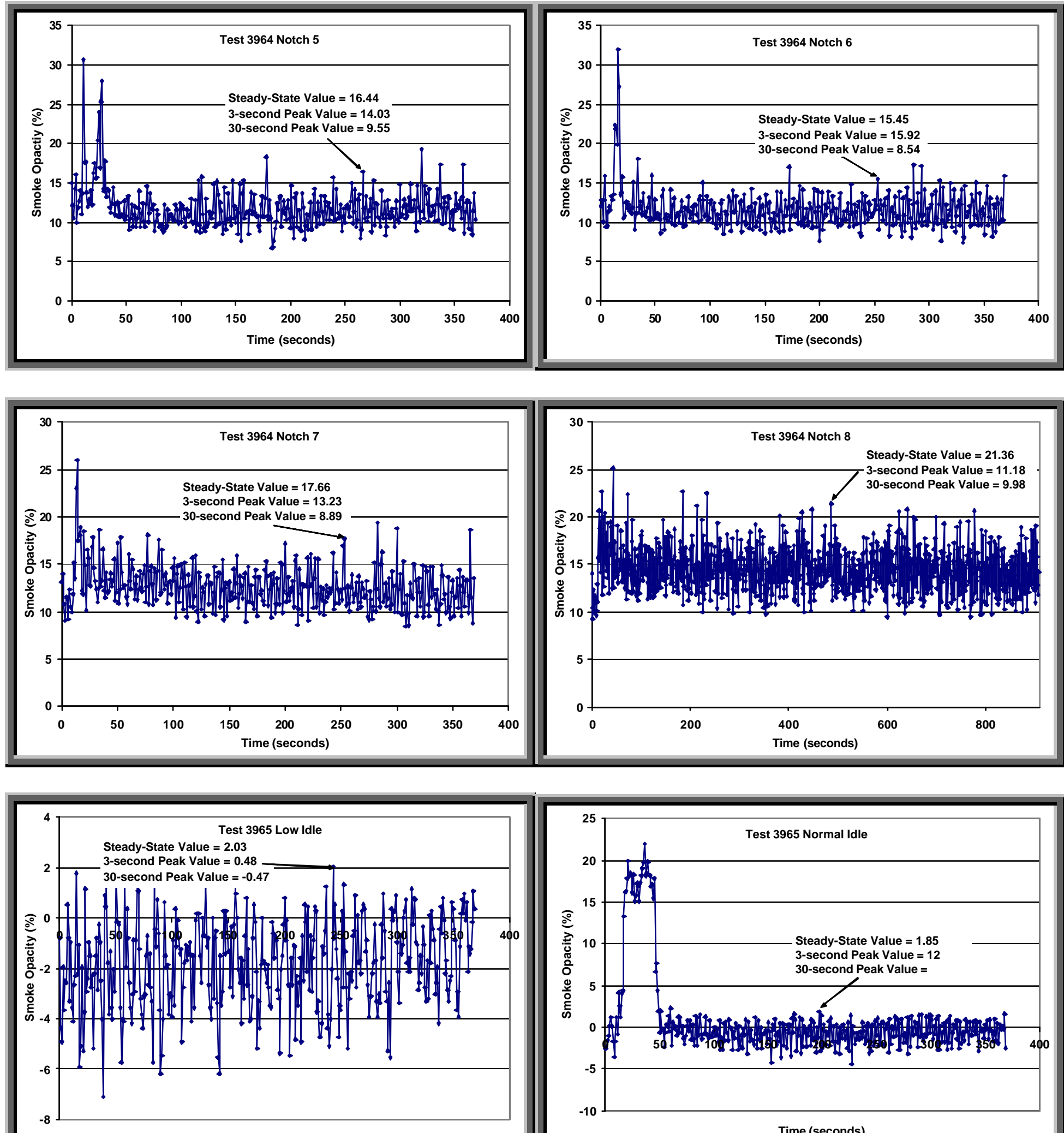

Time (seconds)

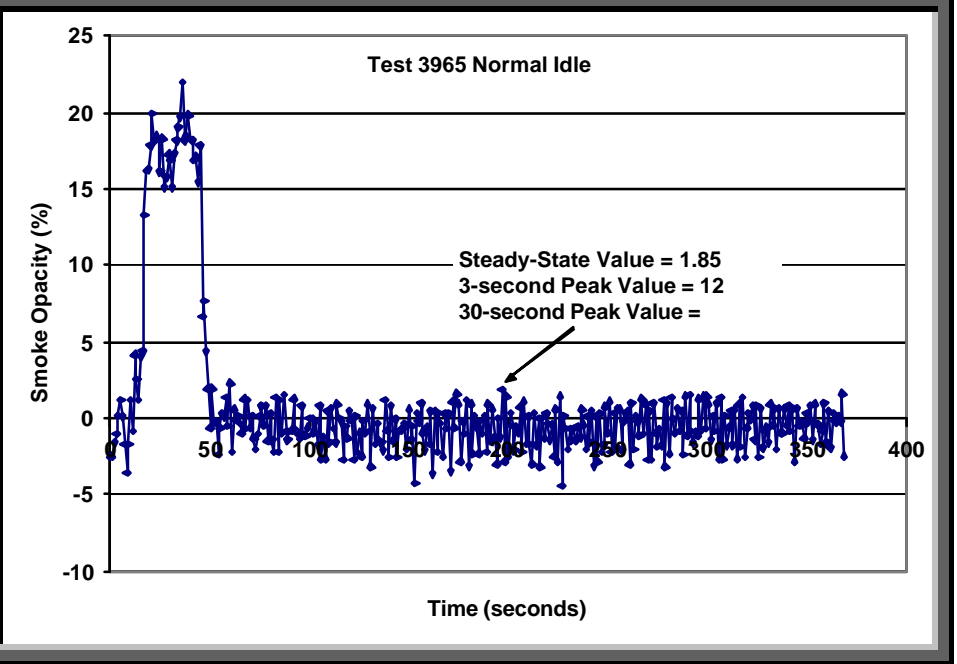



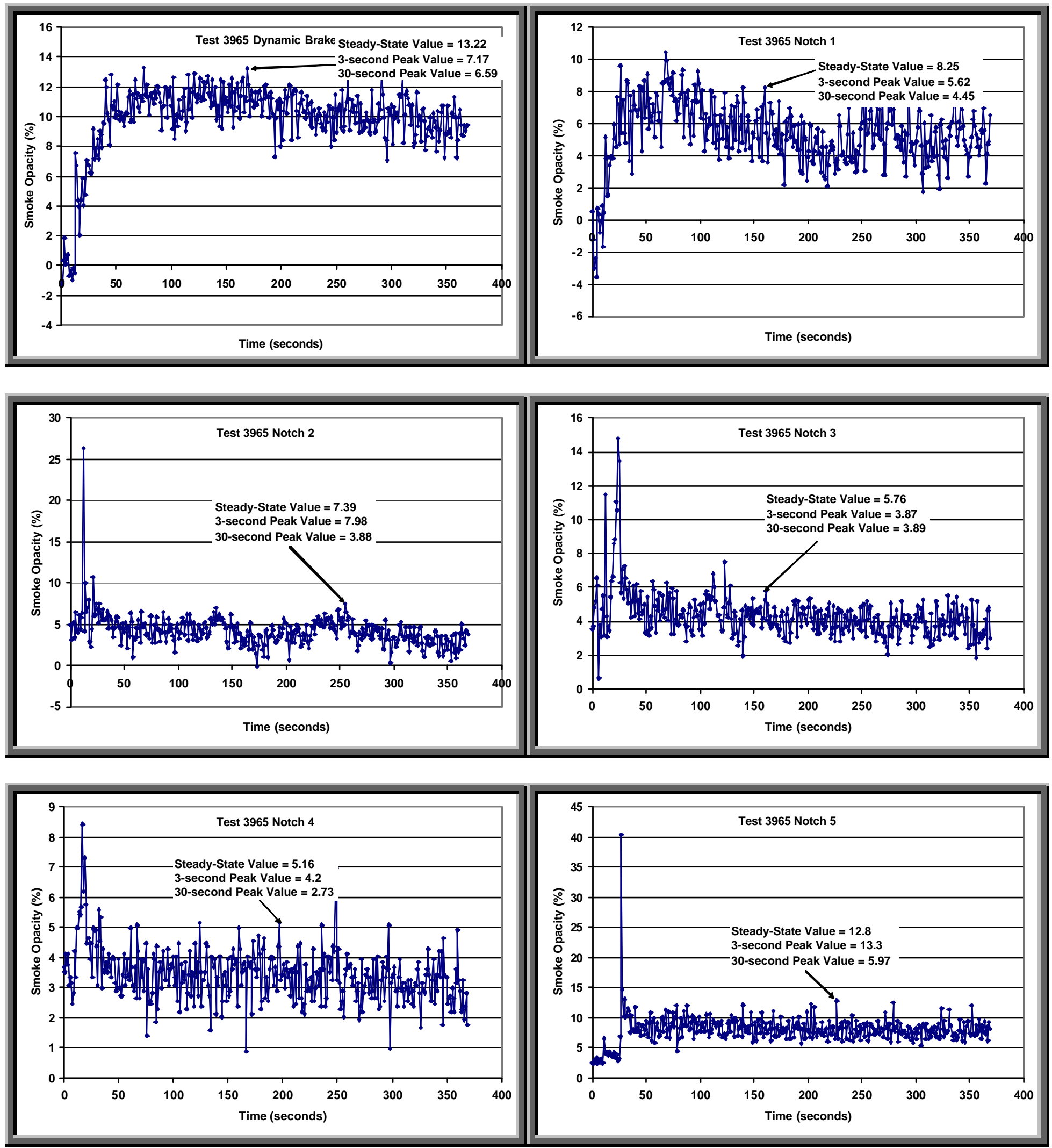

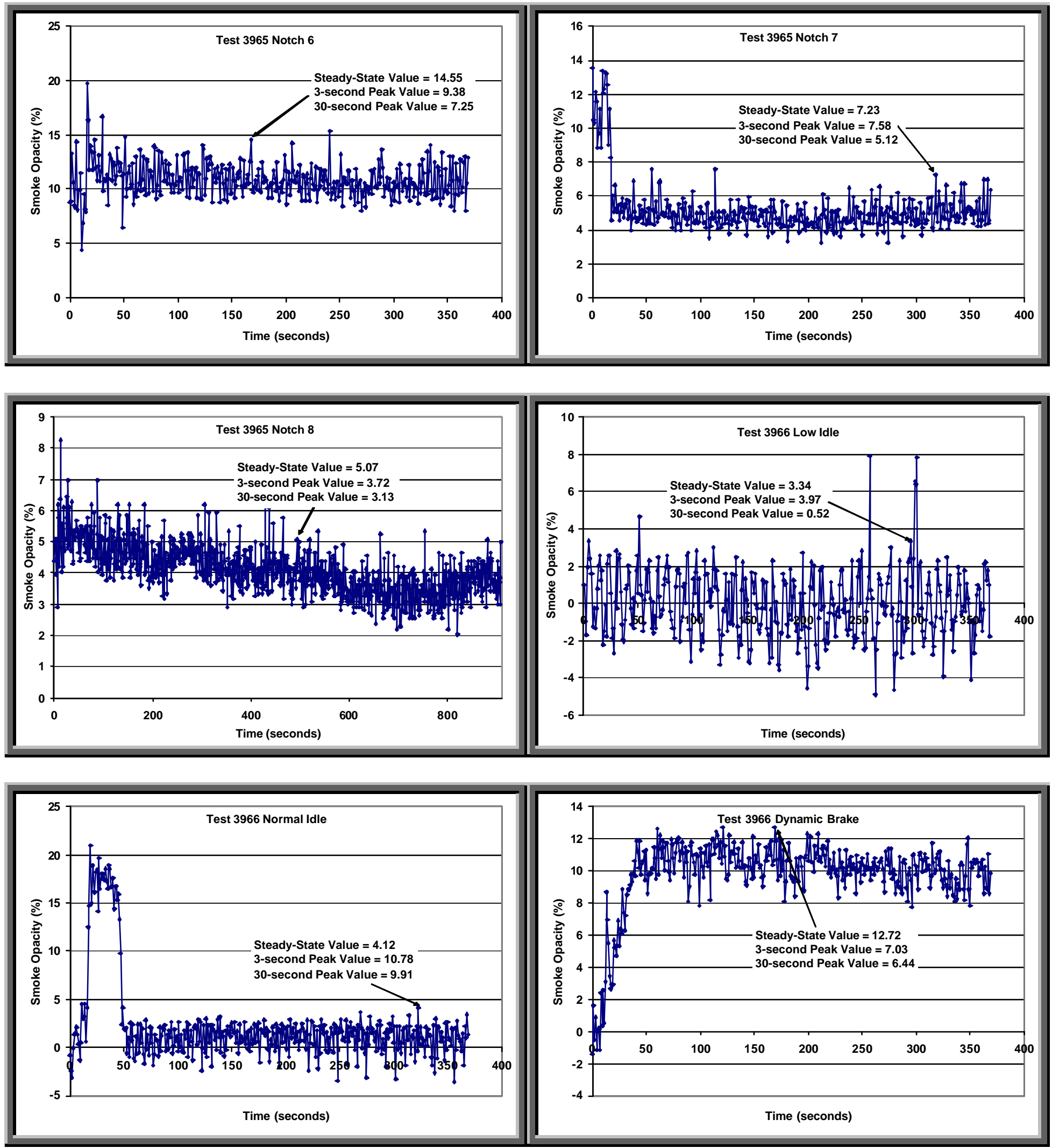

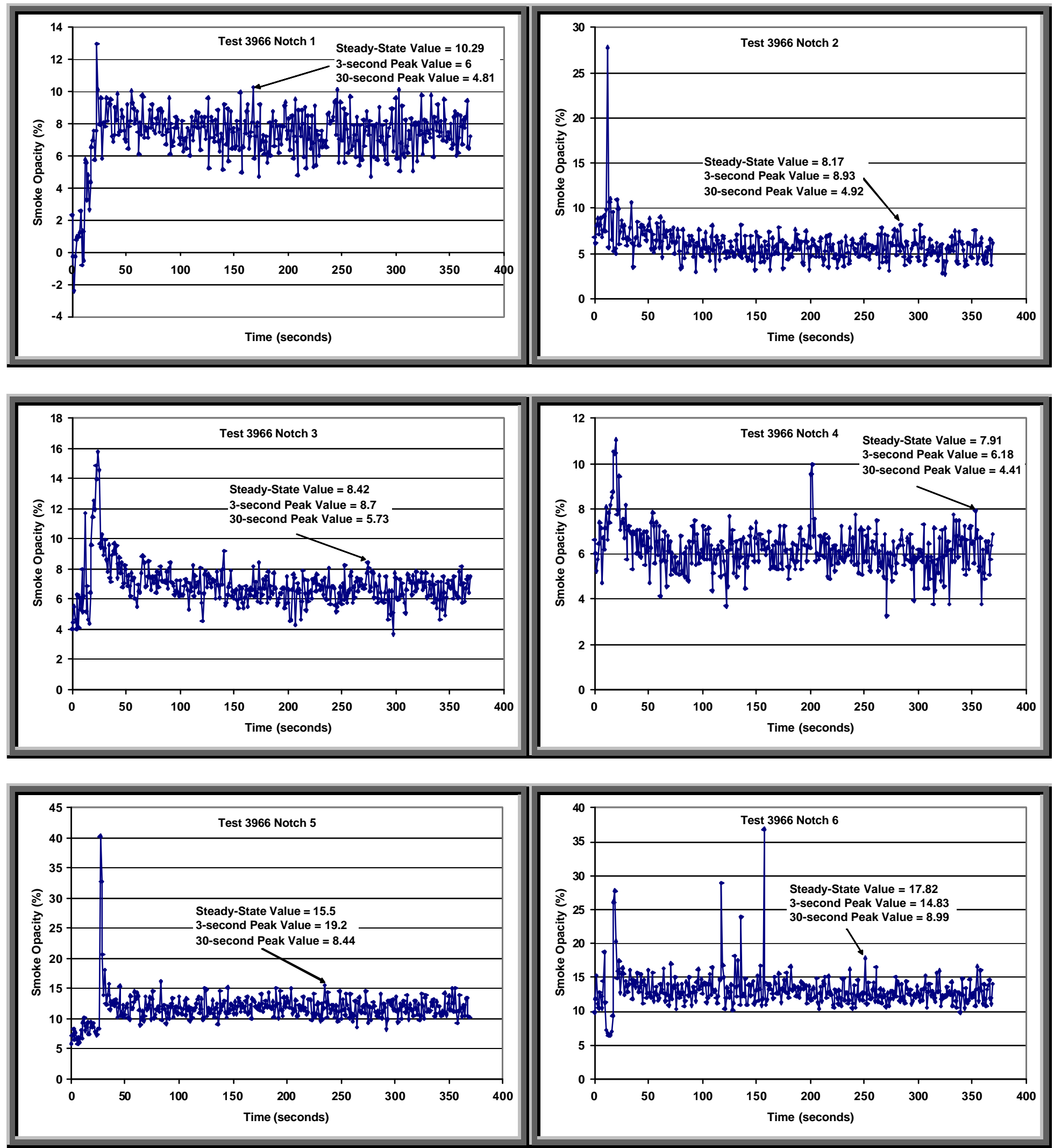

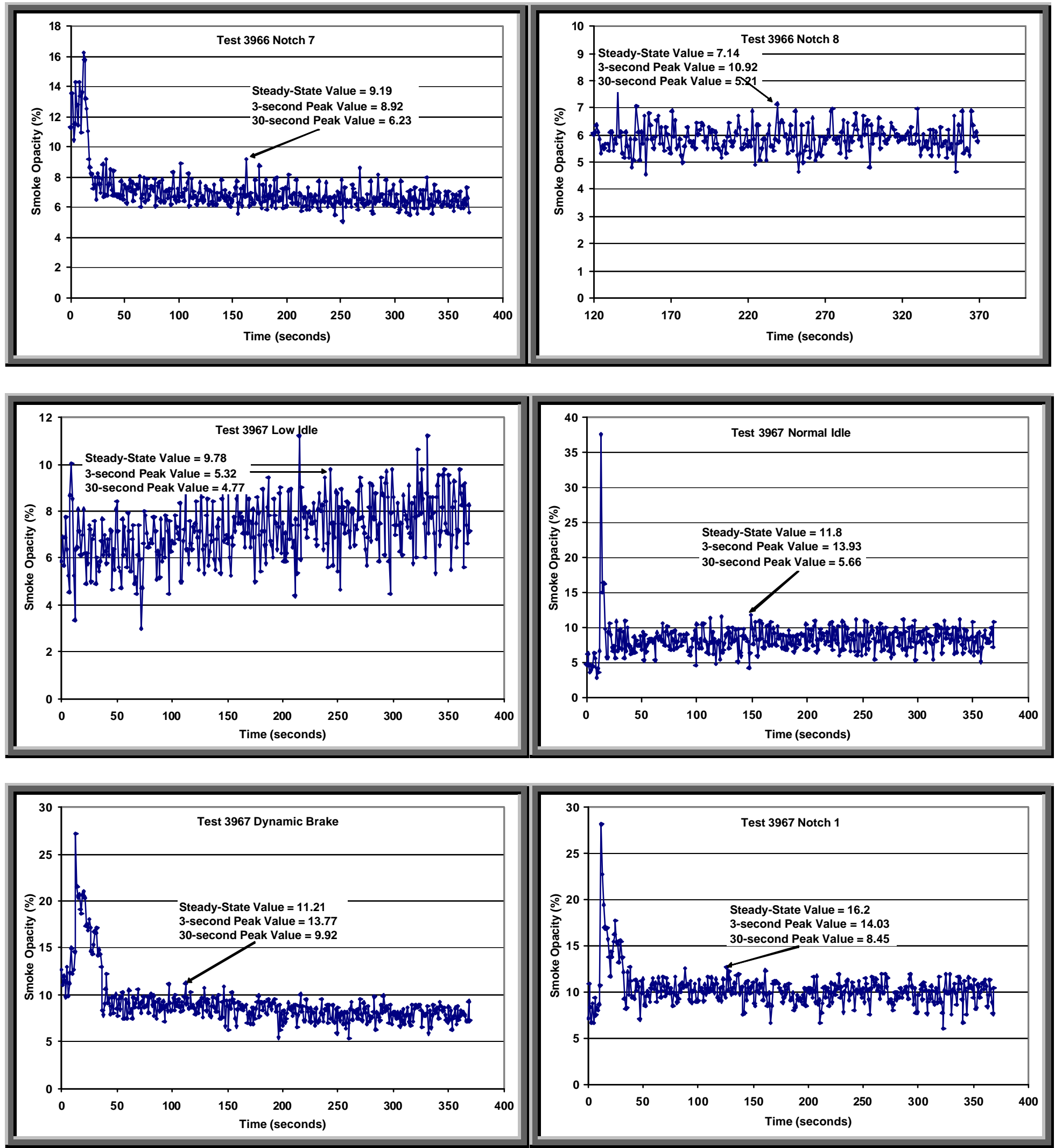

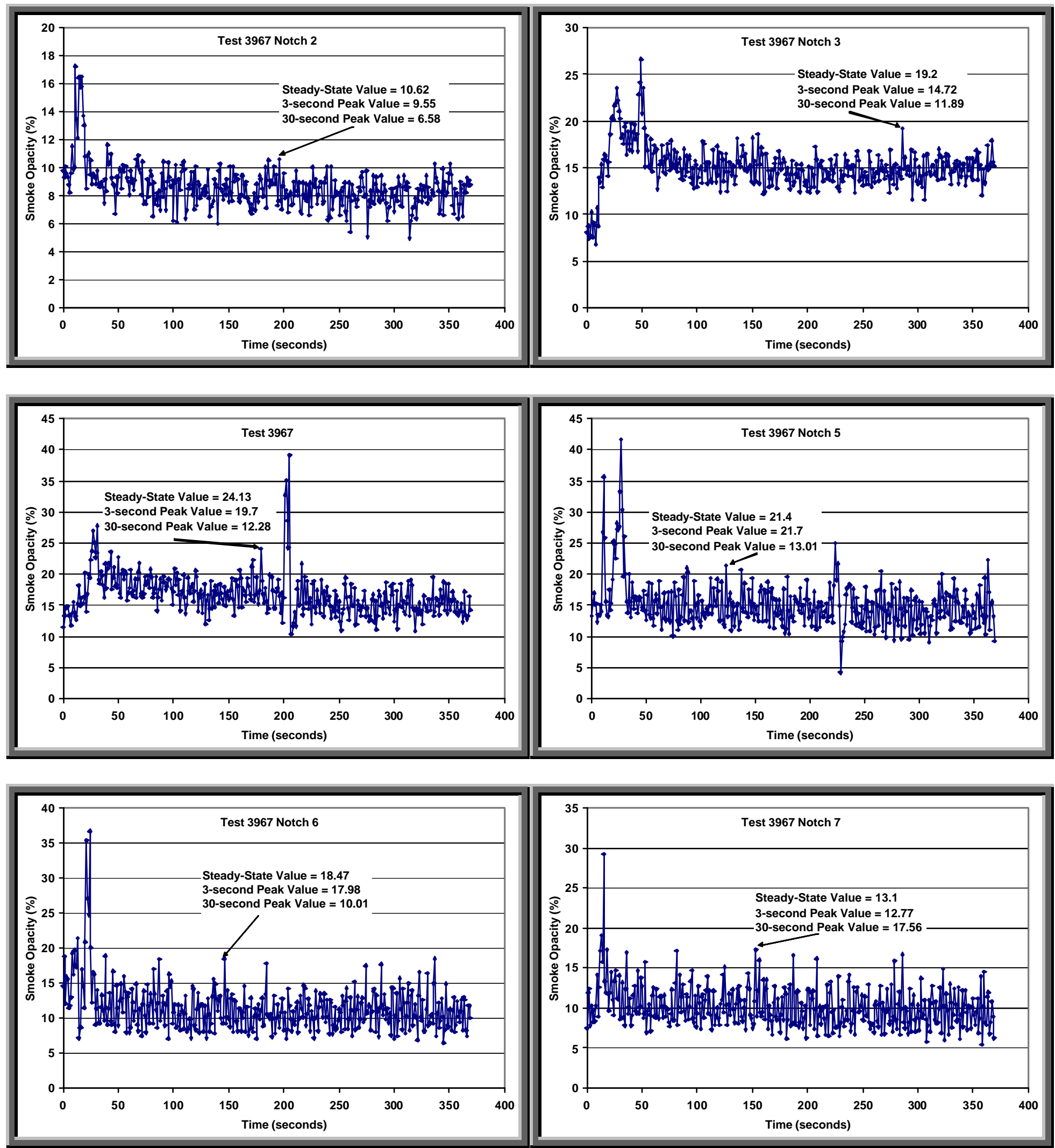

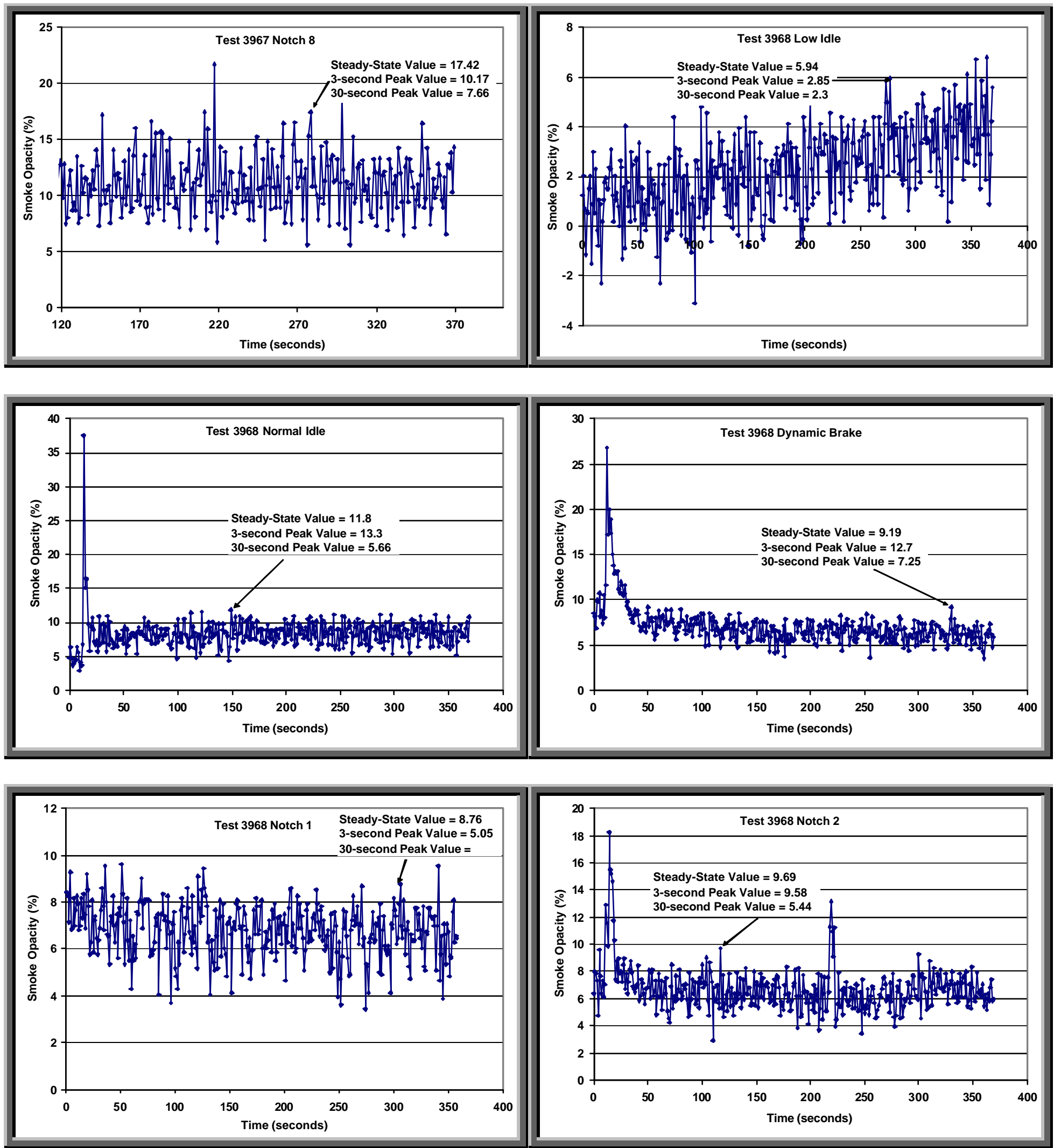

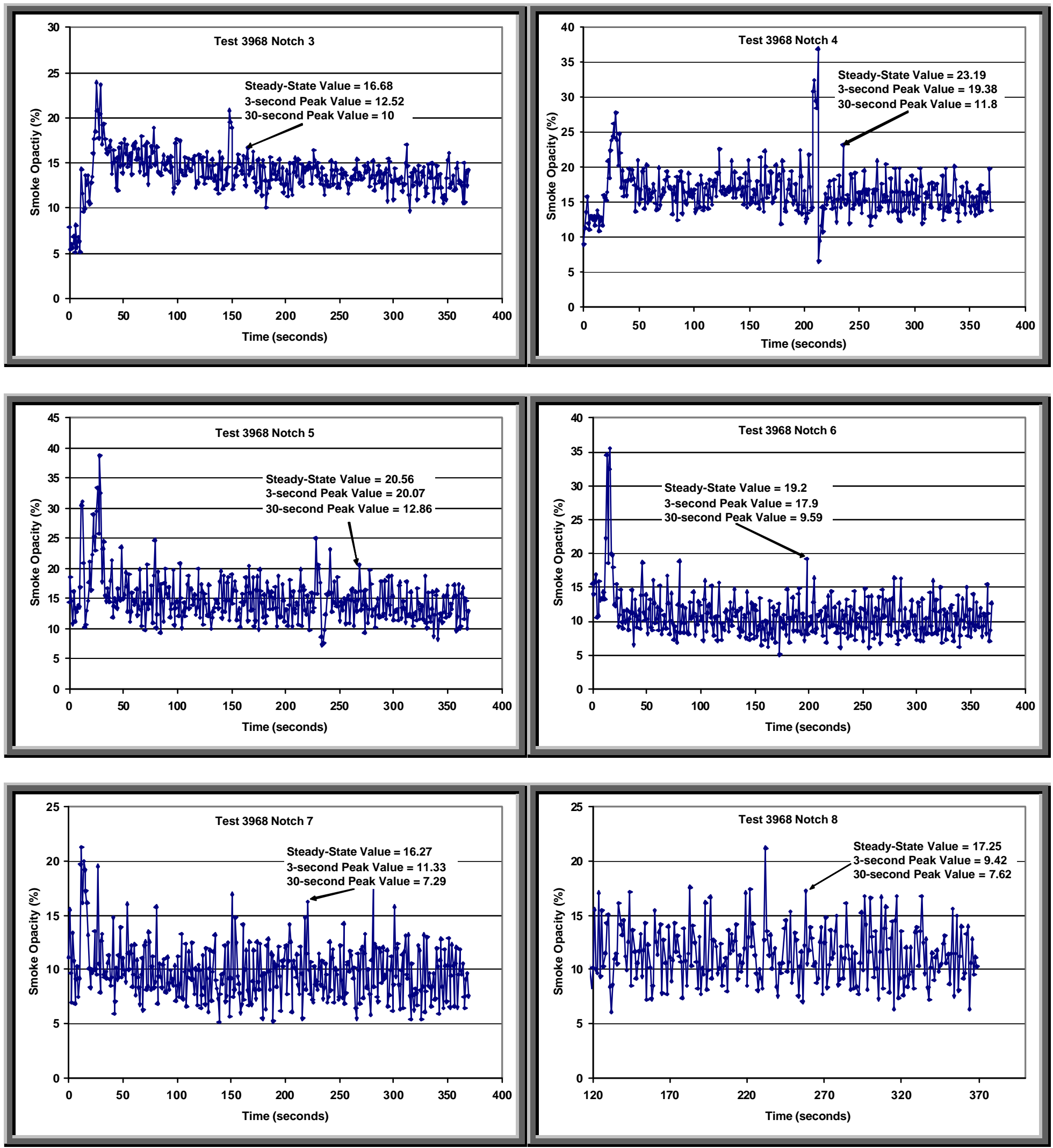


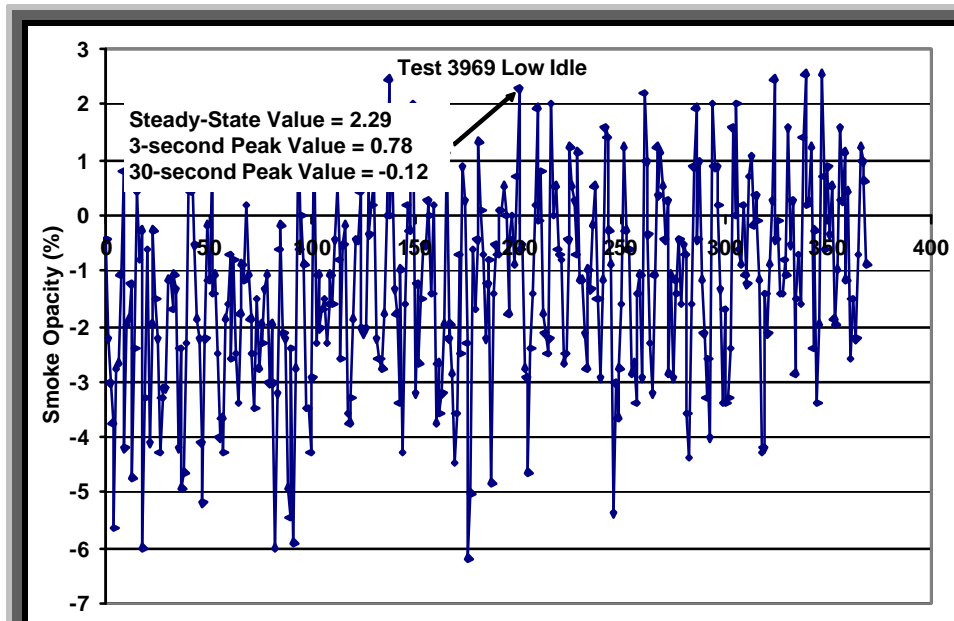

Time (seconds)

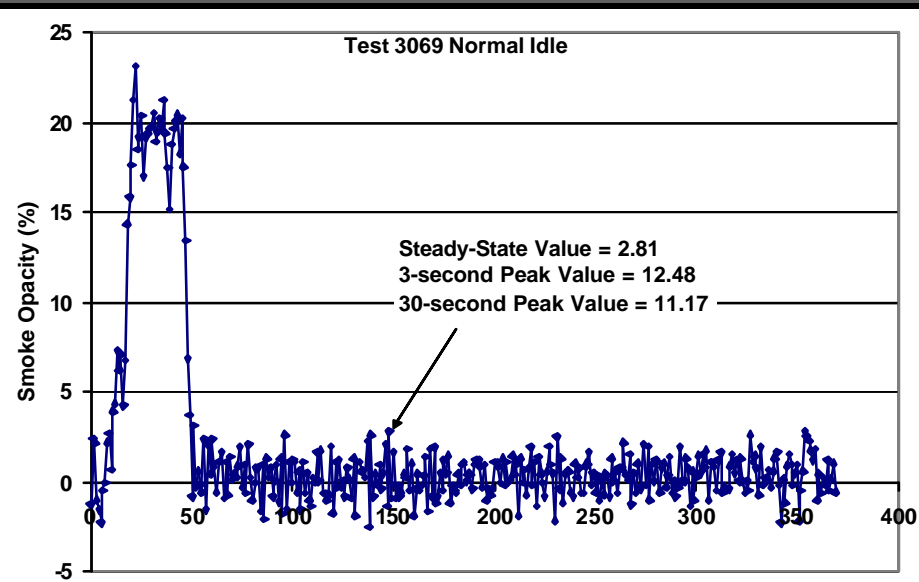

Time (seconds)

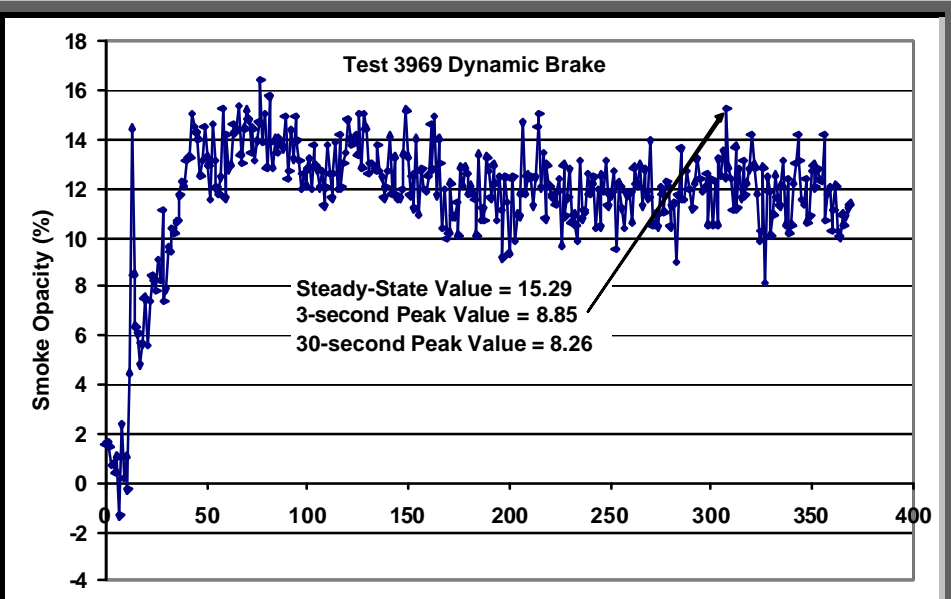

Time (seconds)

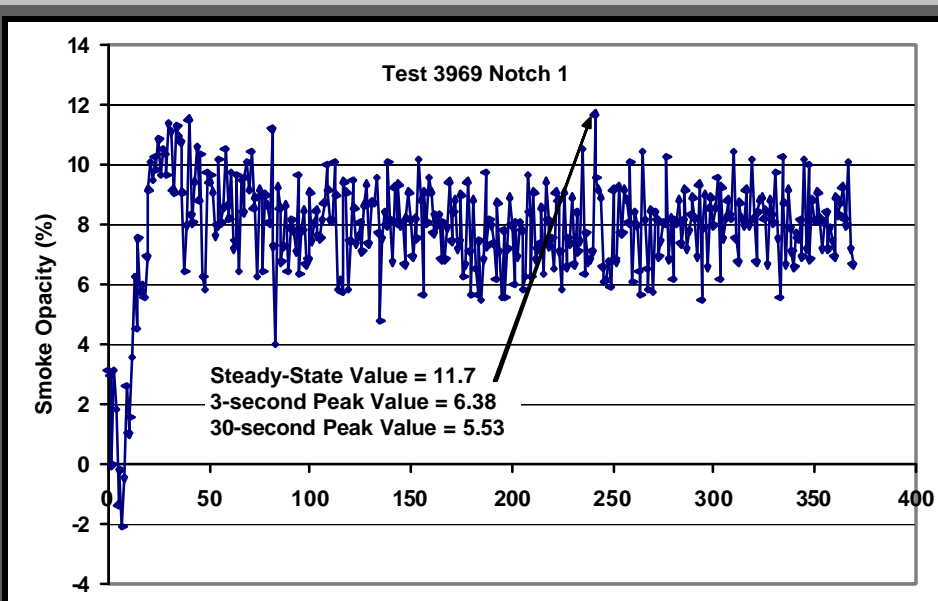

Time (seconds)
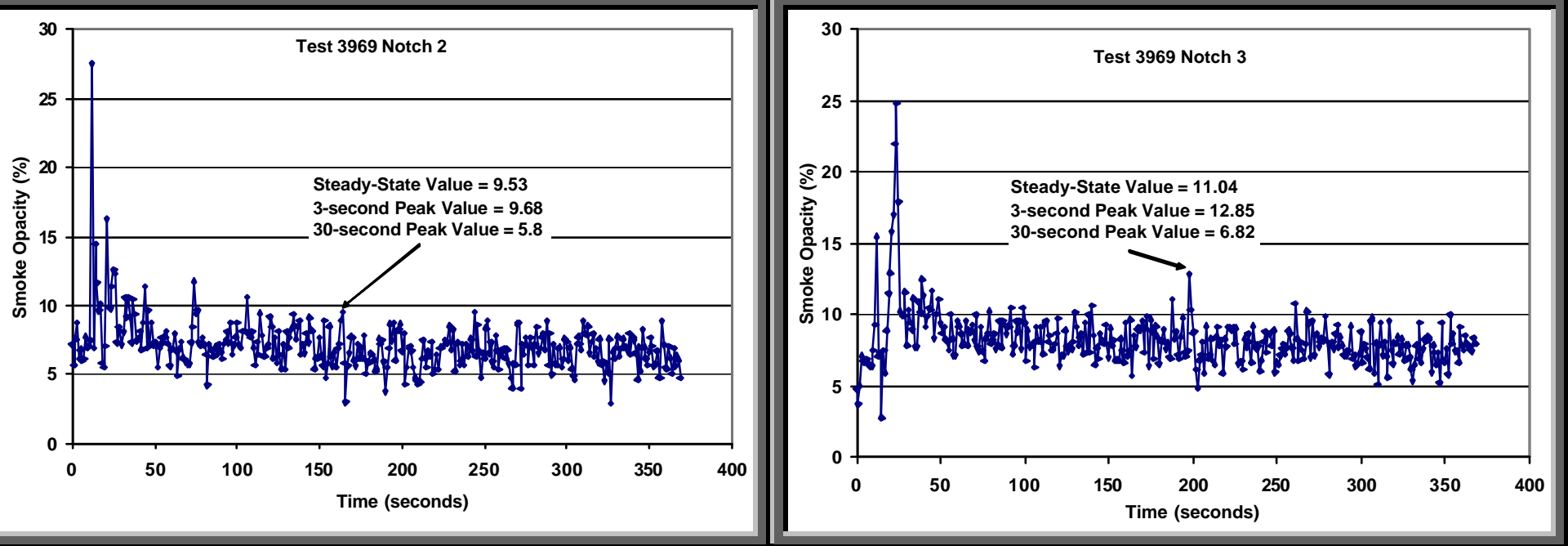

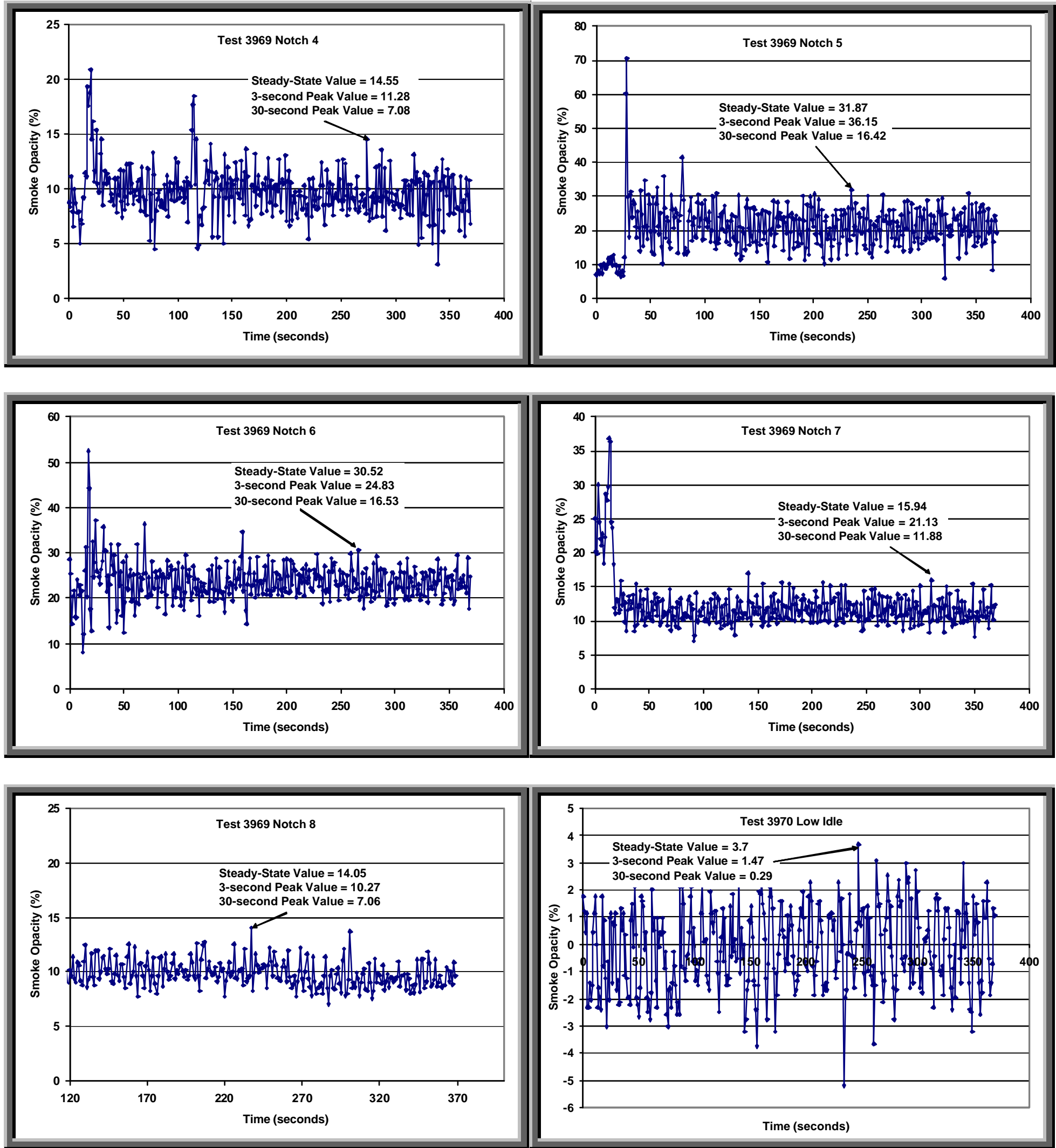

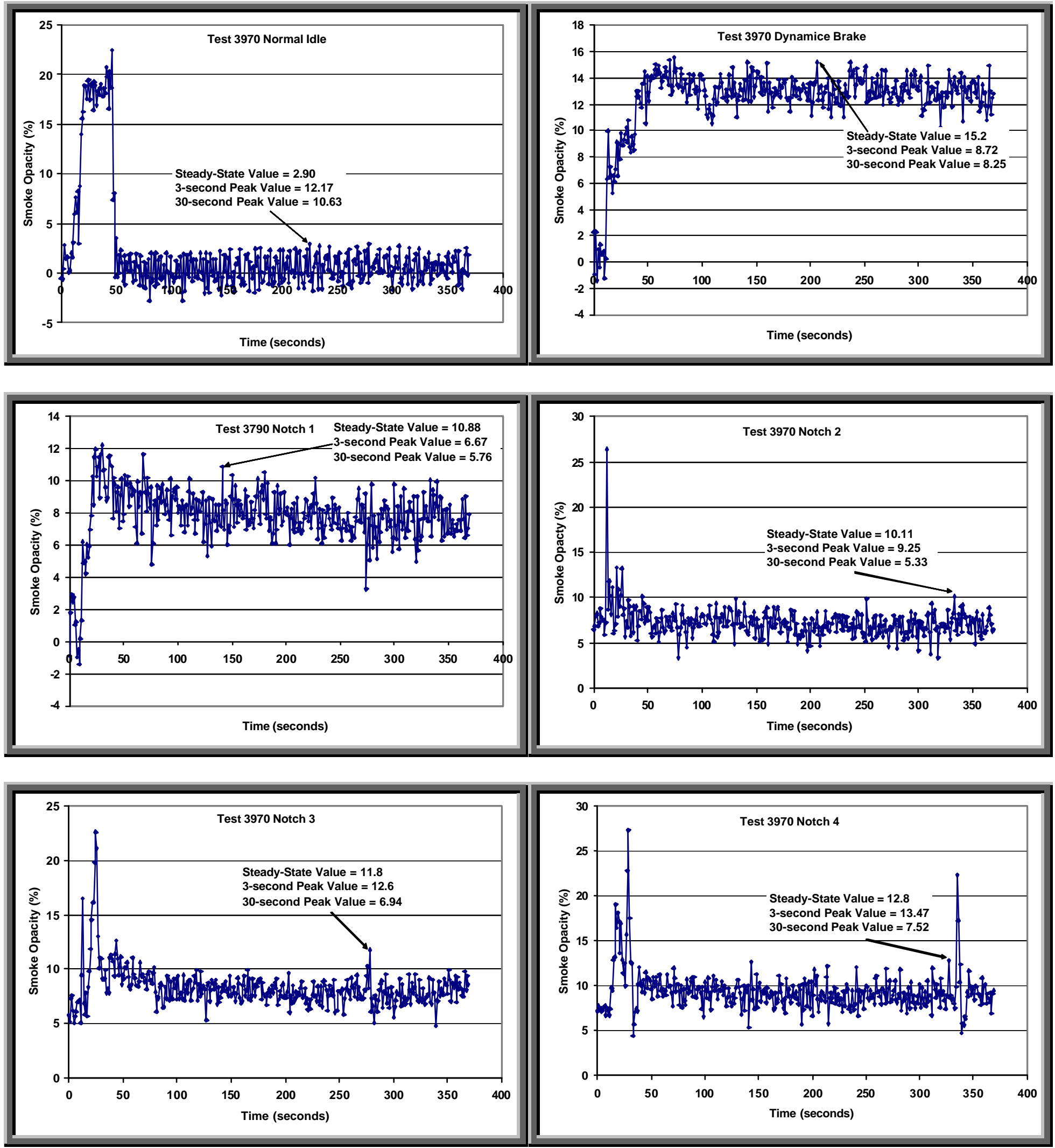

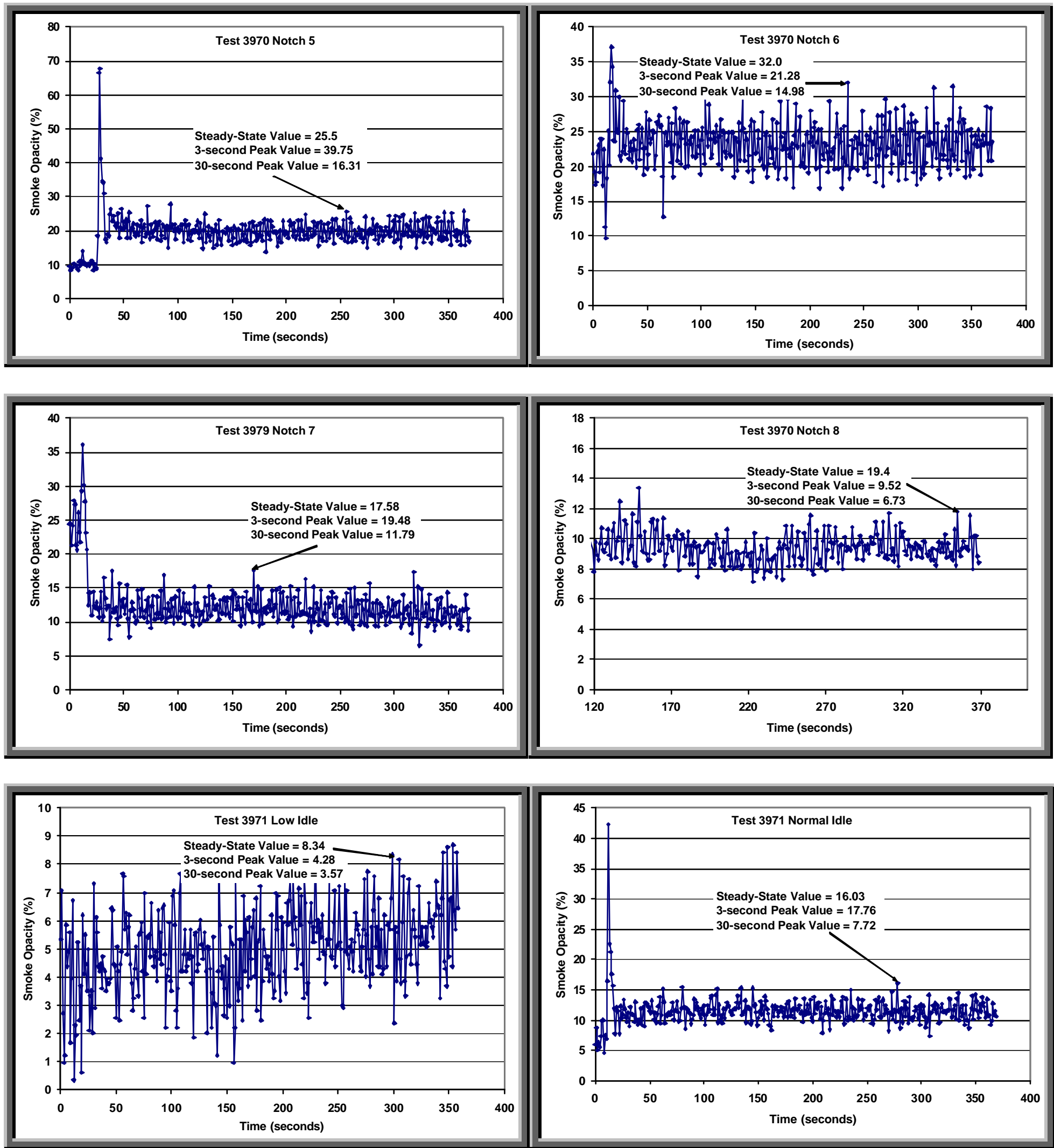

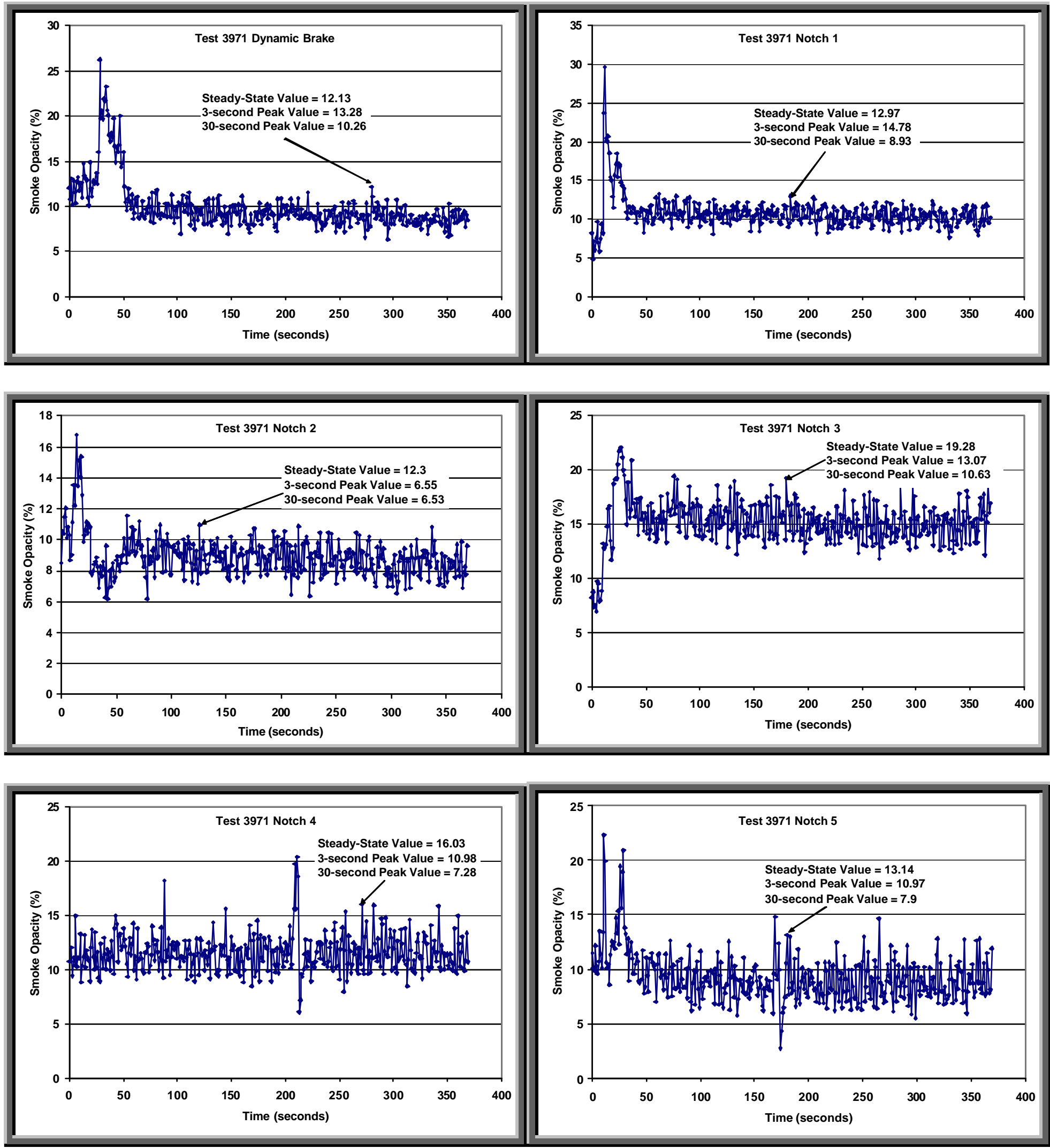

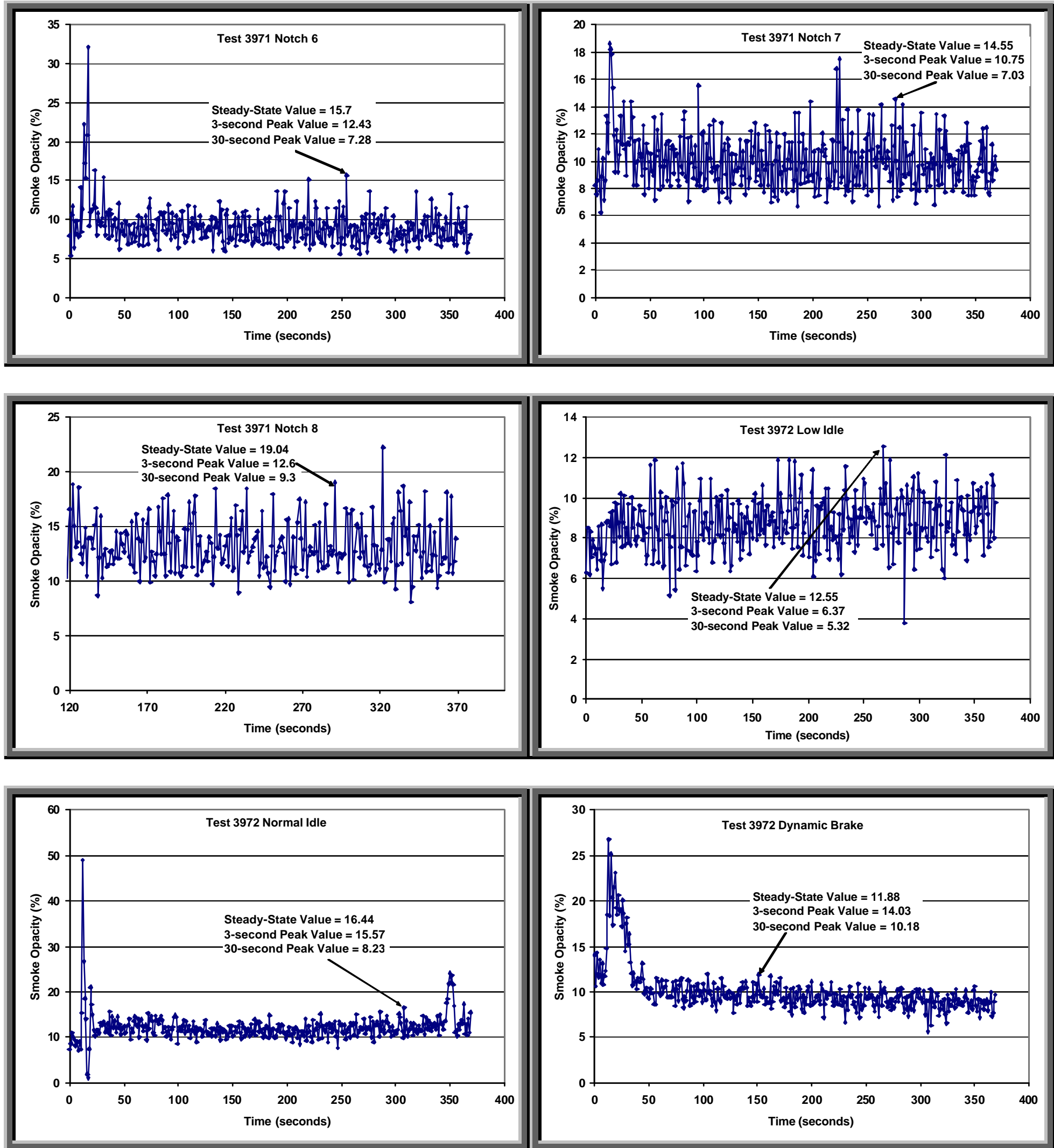

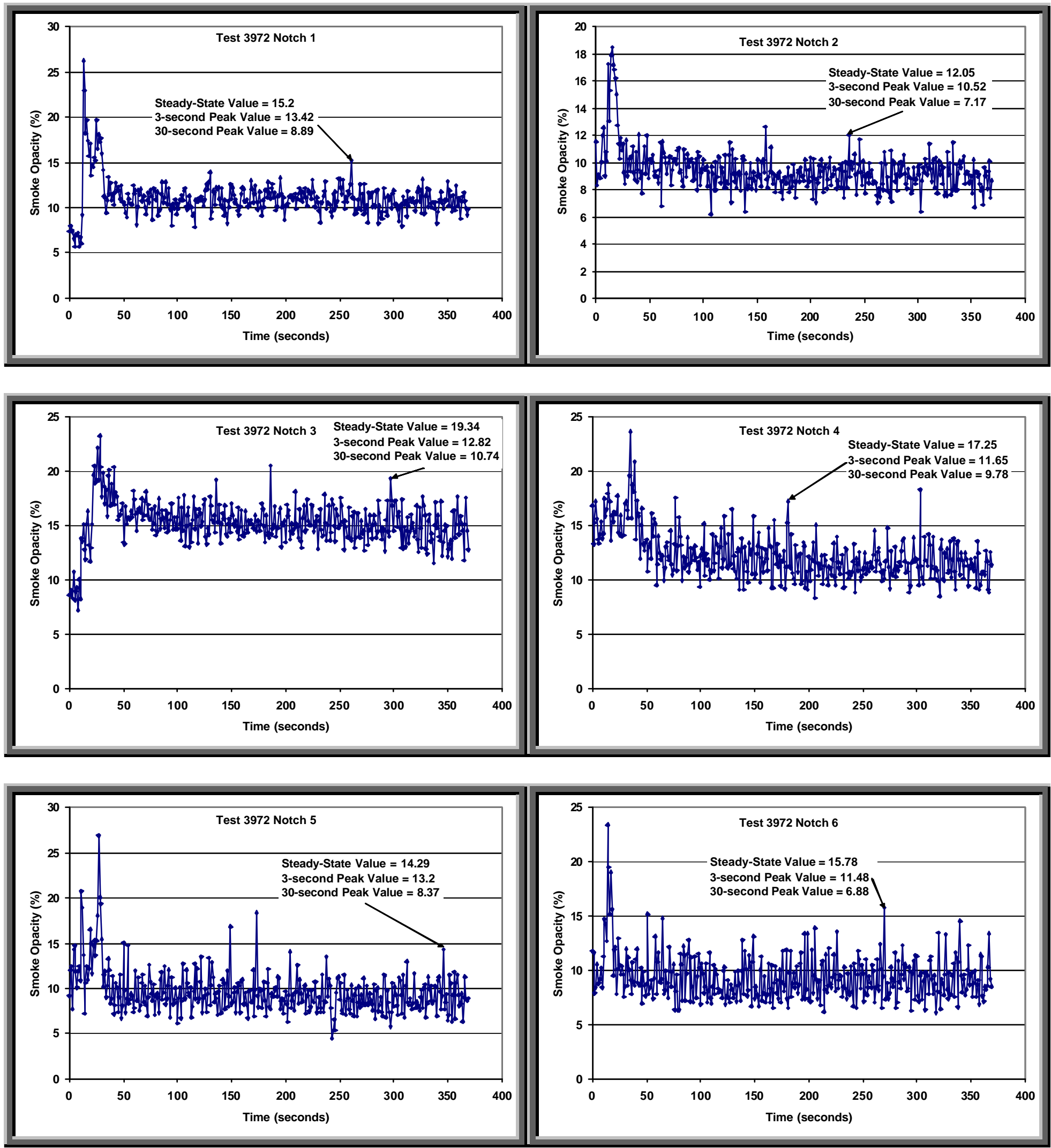

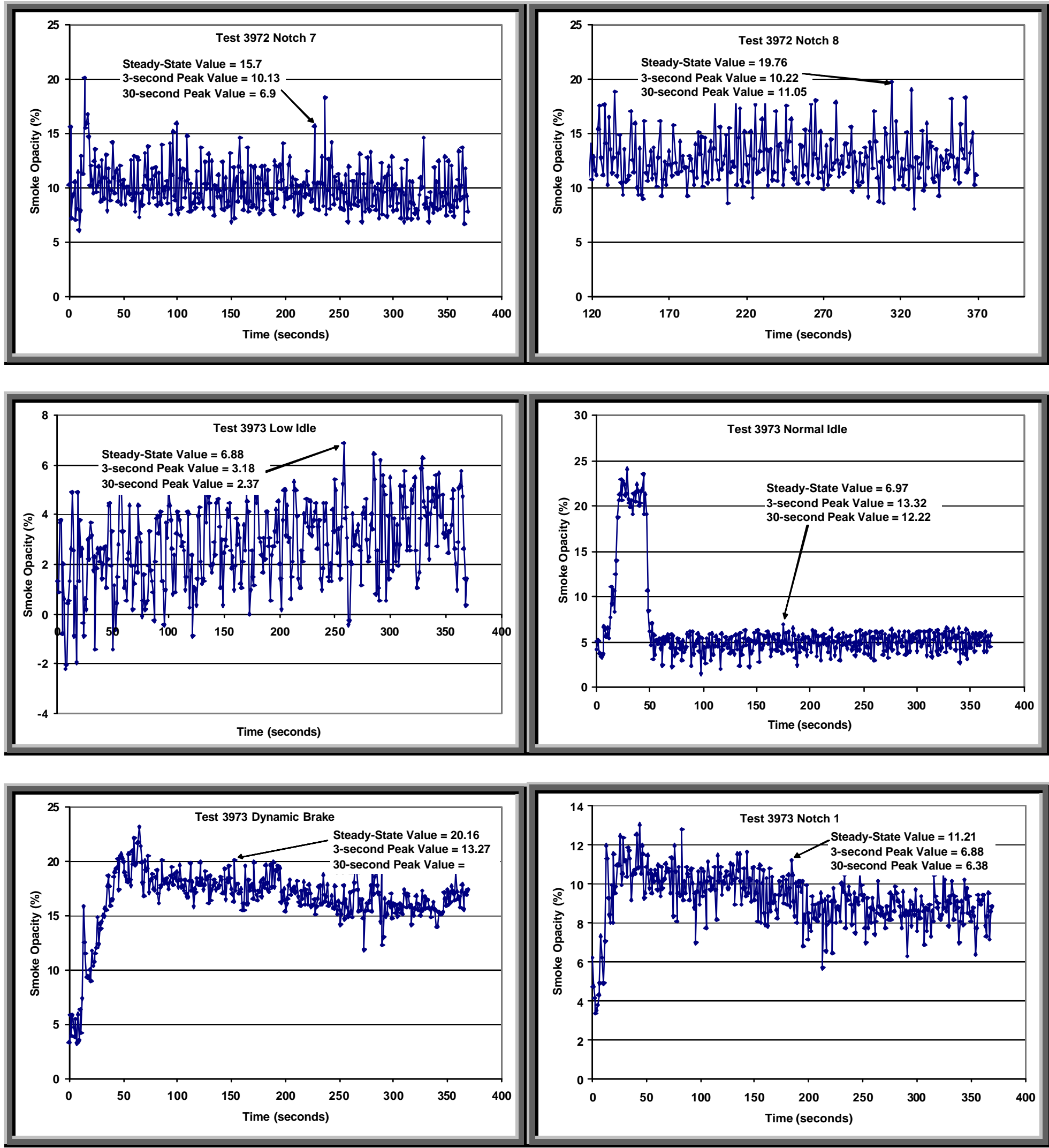

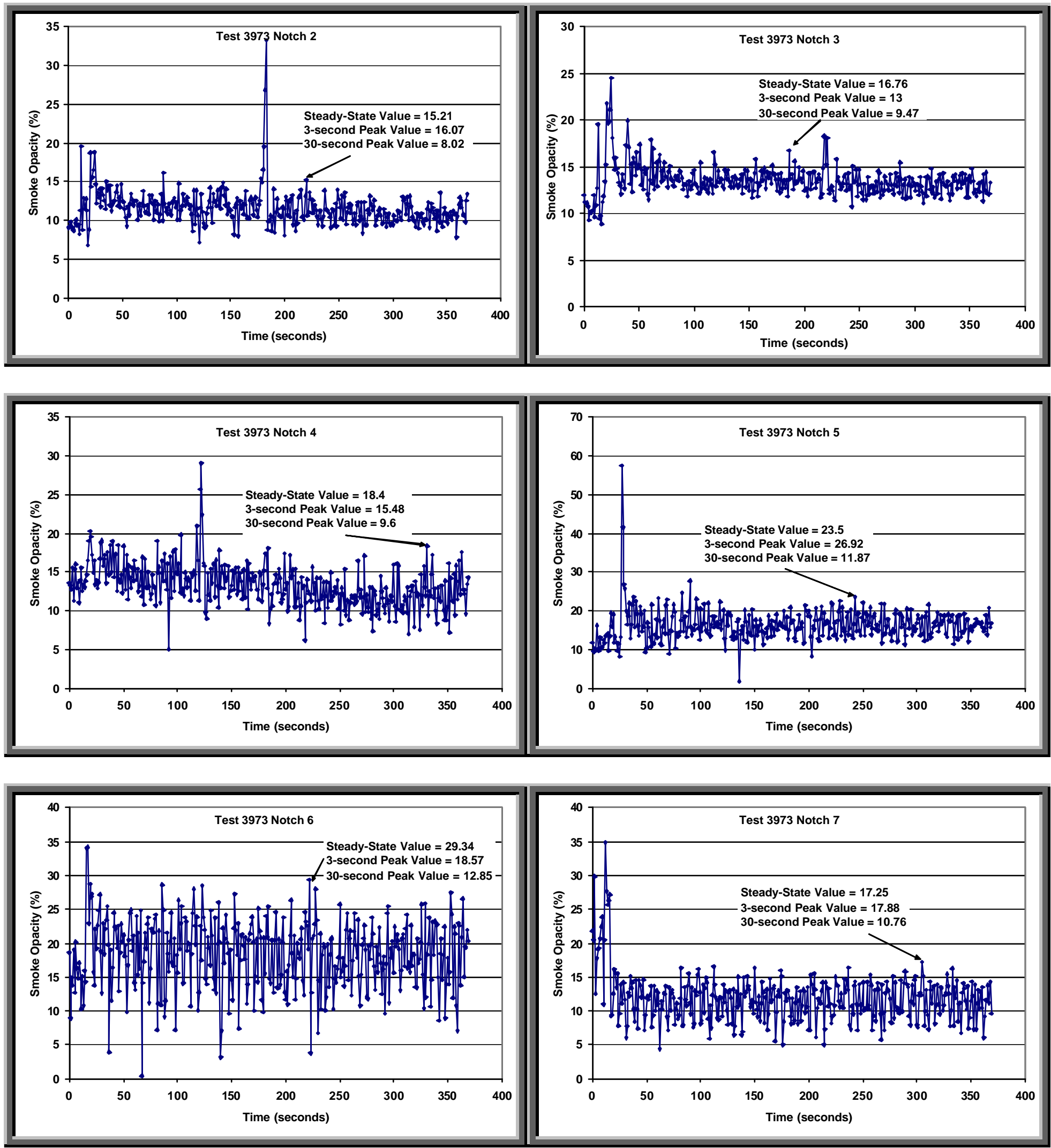

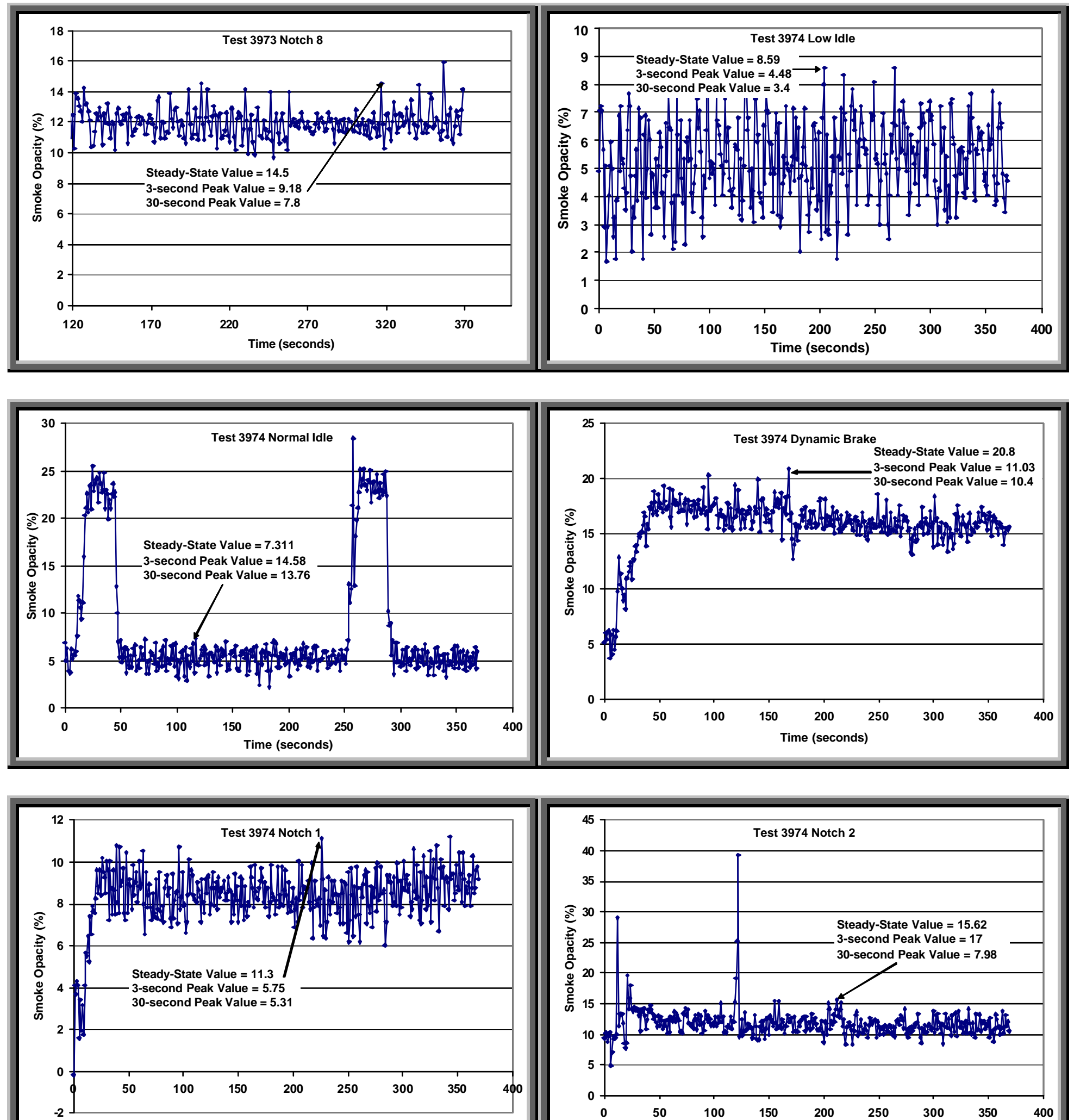

Time (seconds)

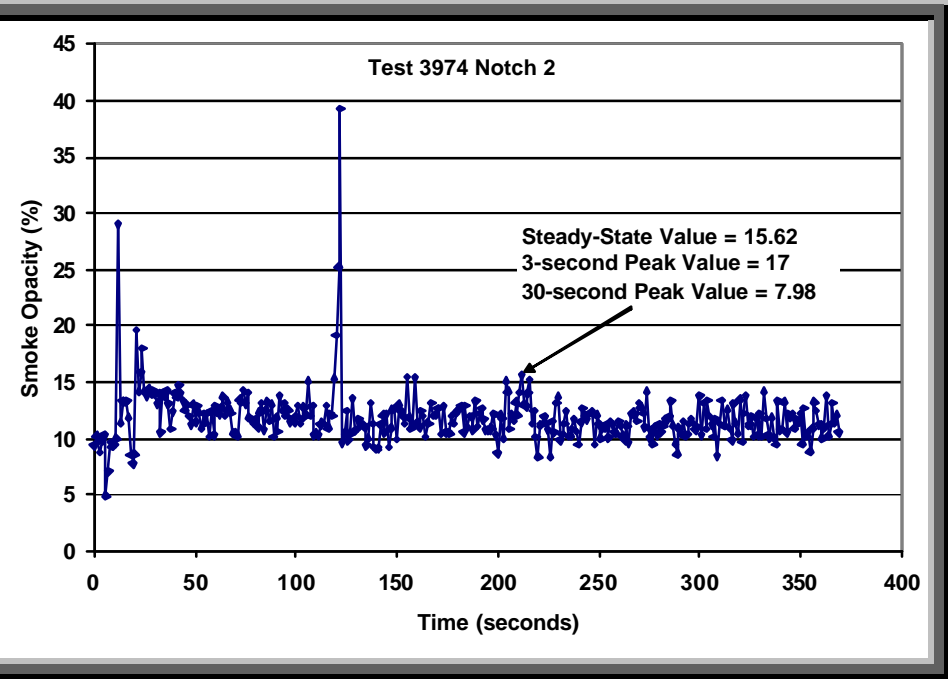



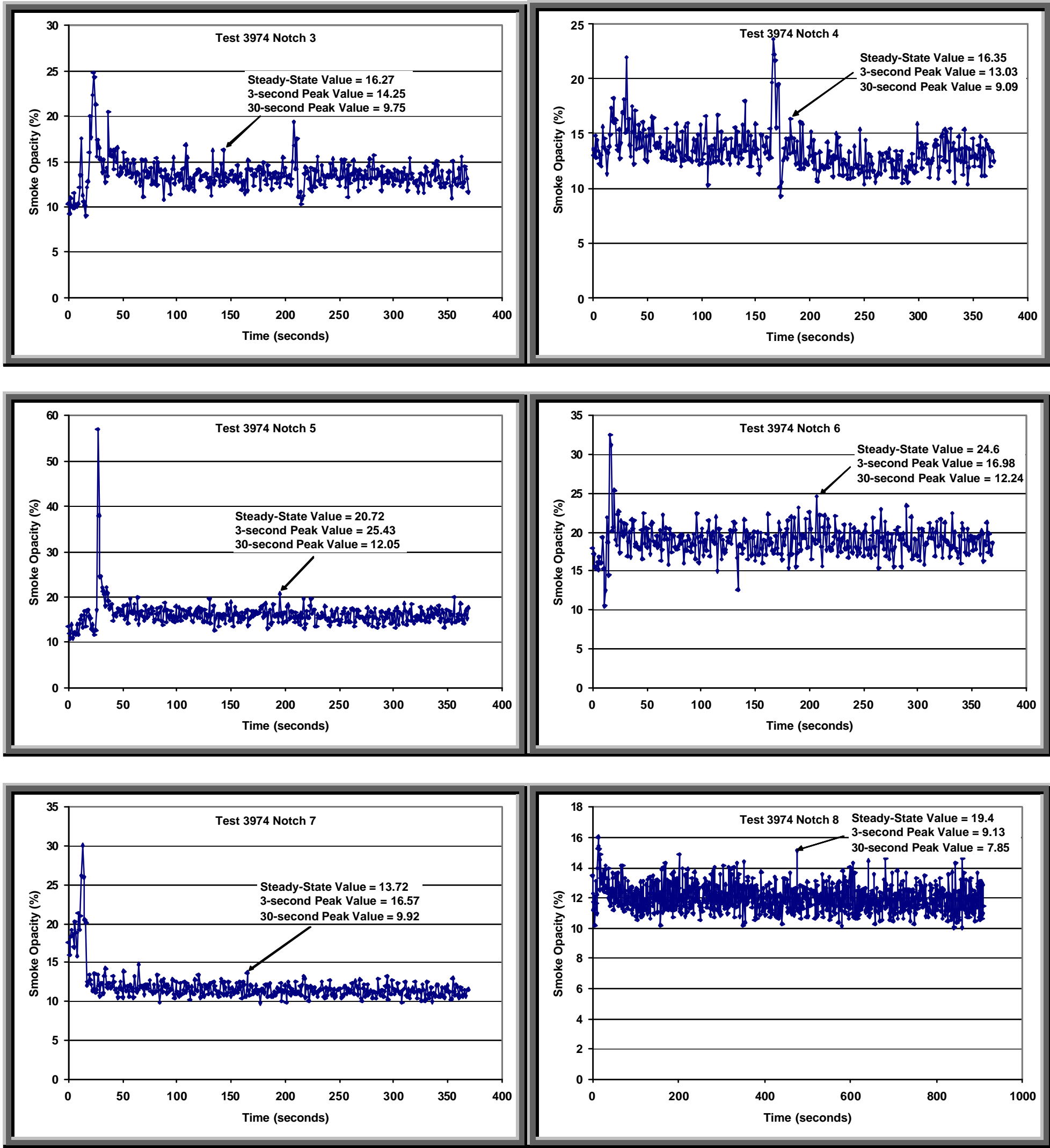


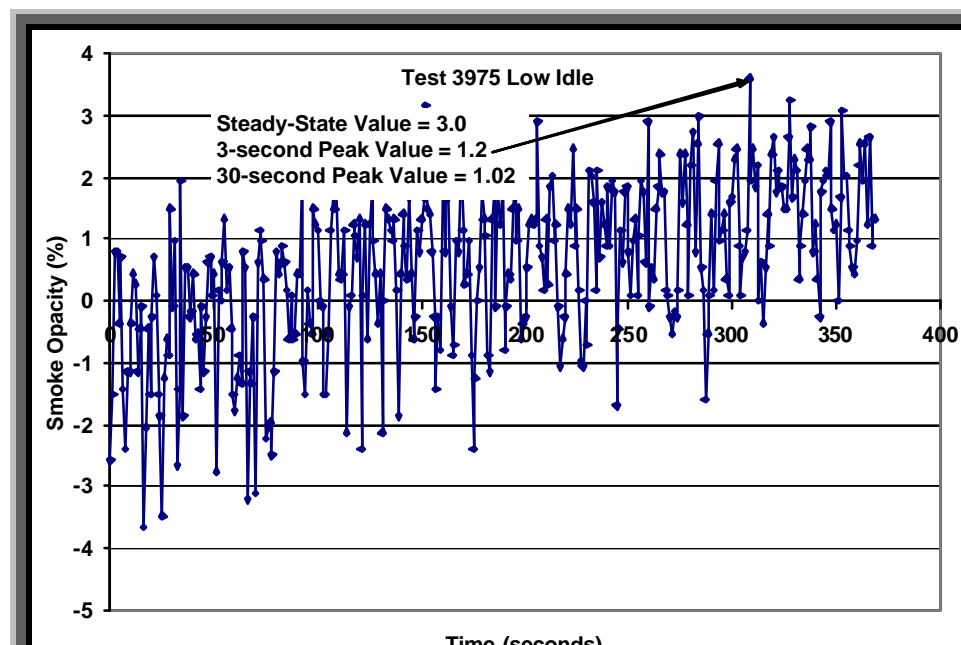

Time (seconds)

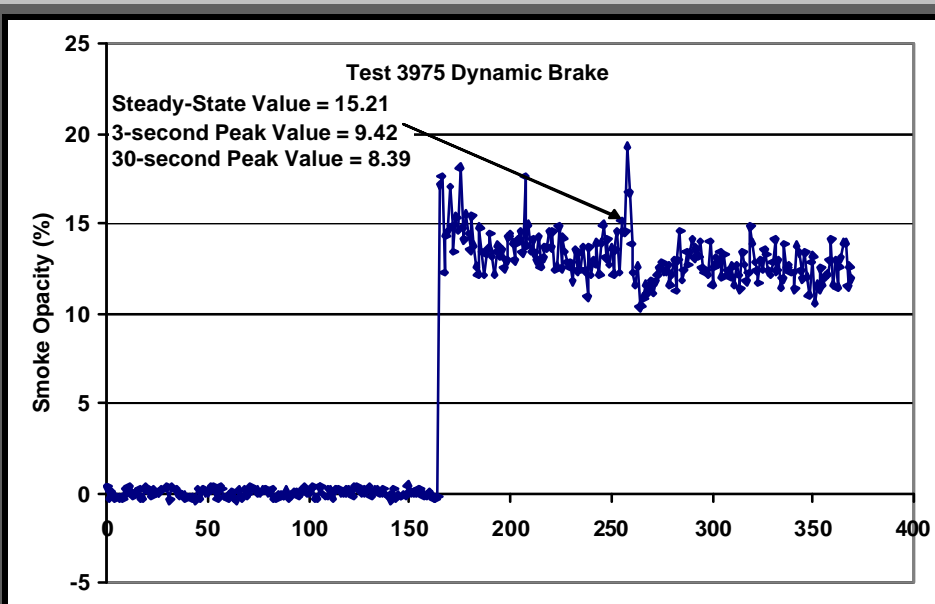

Time (seconds)

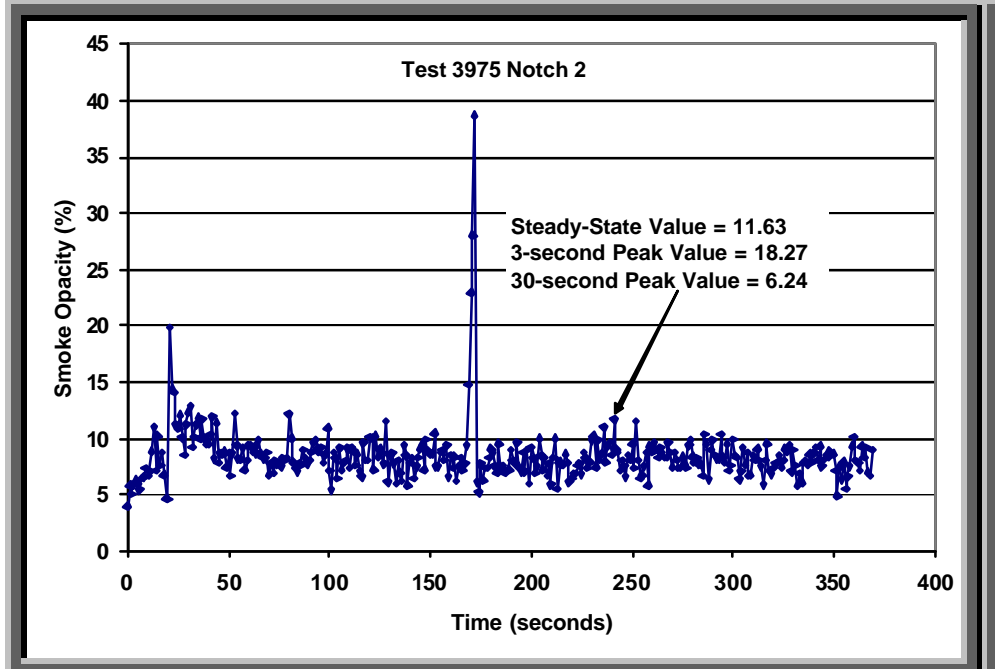

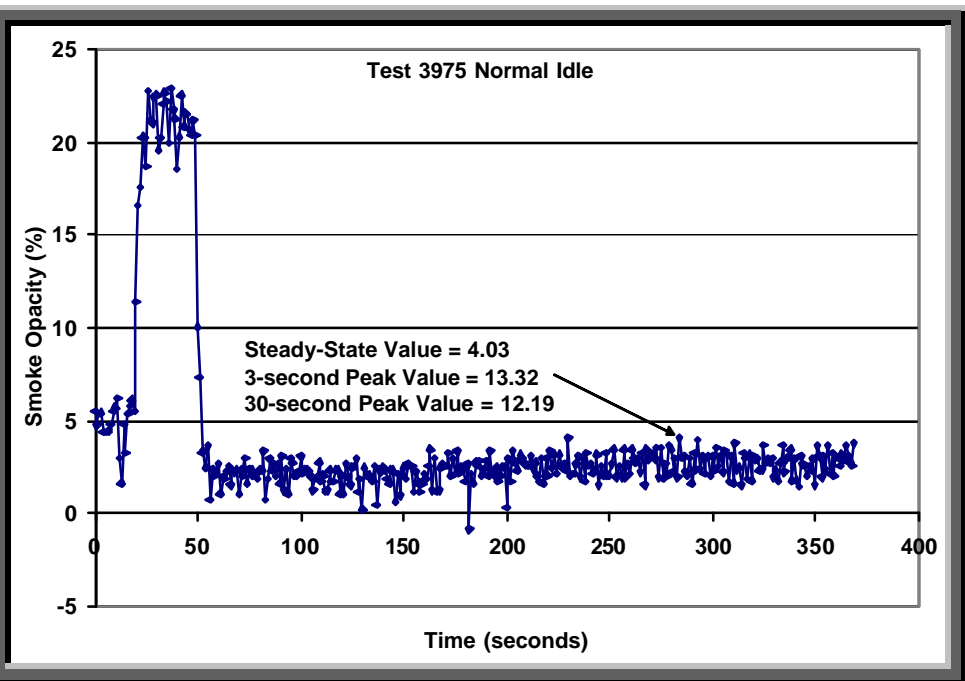
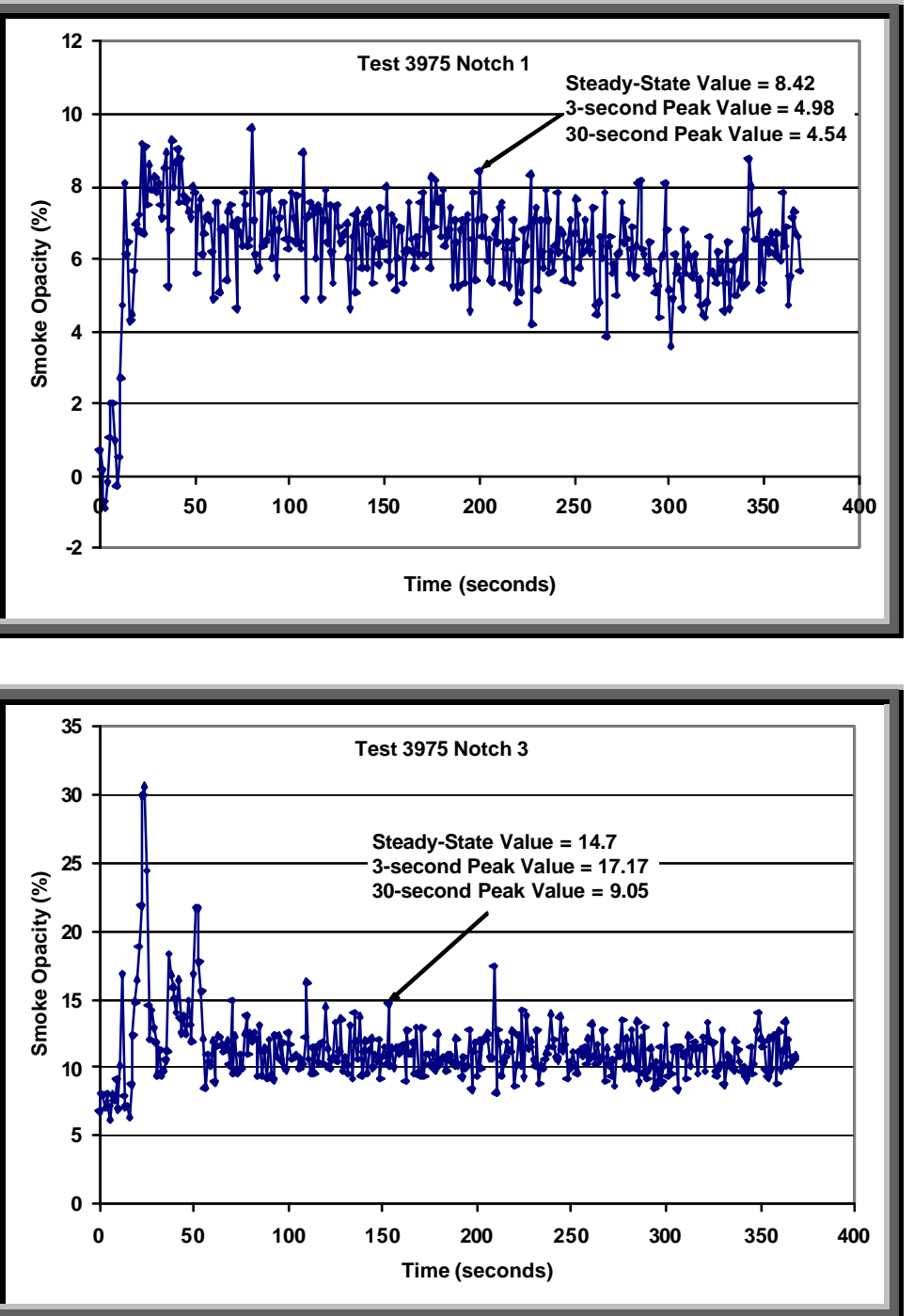

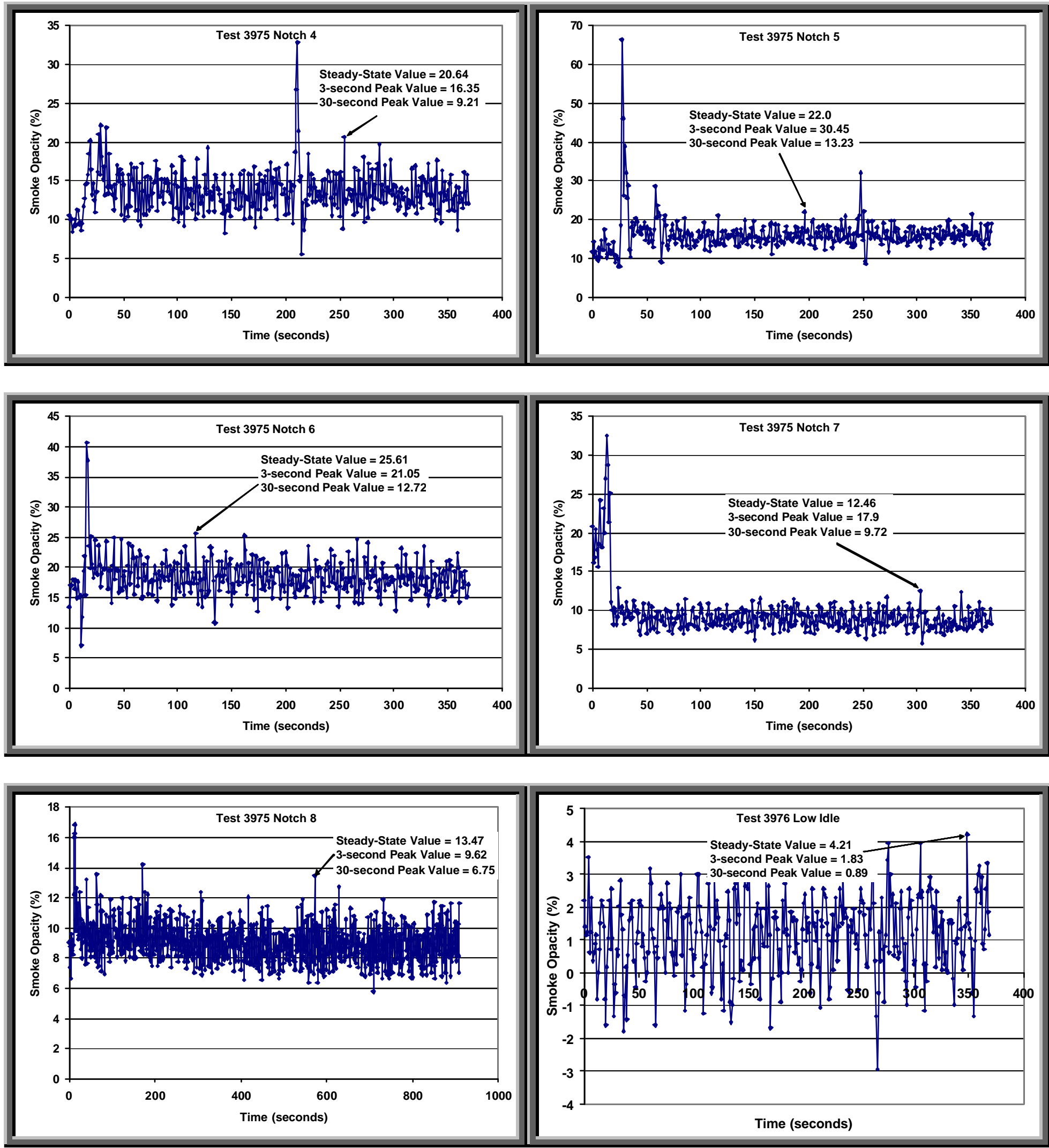


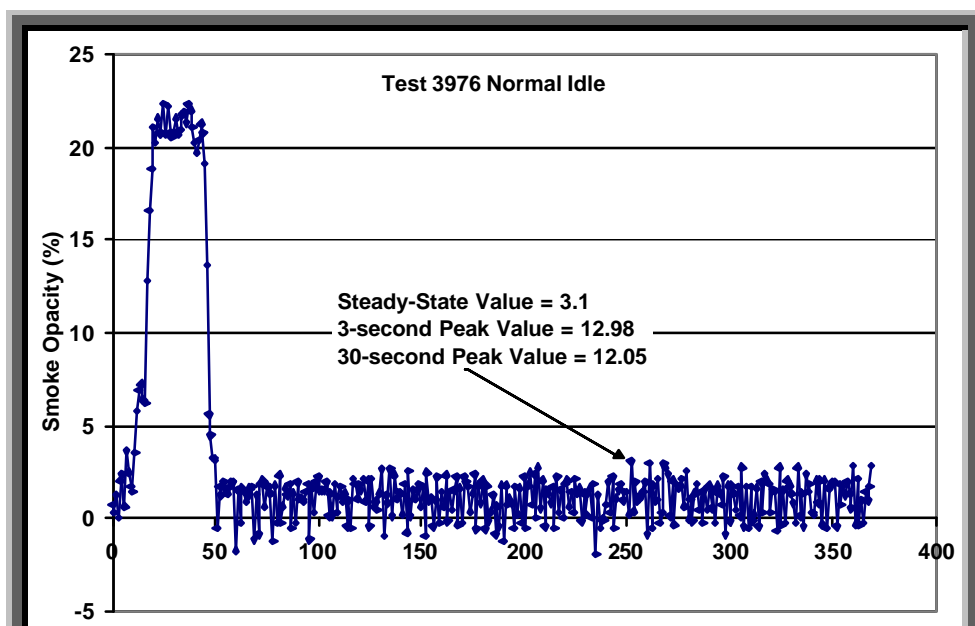

Time (seconds)

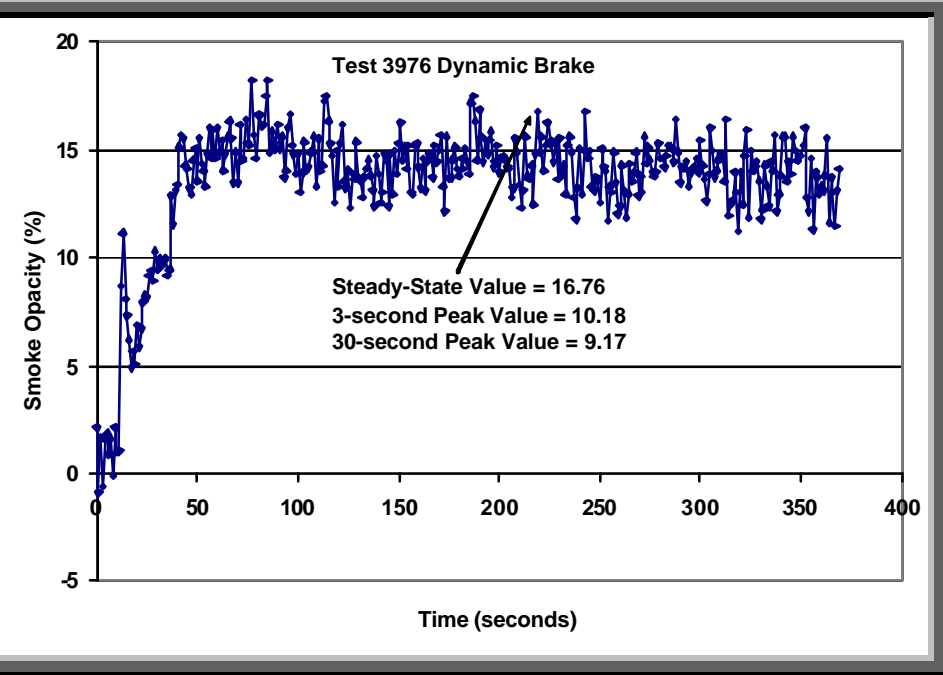

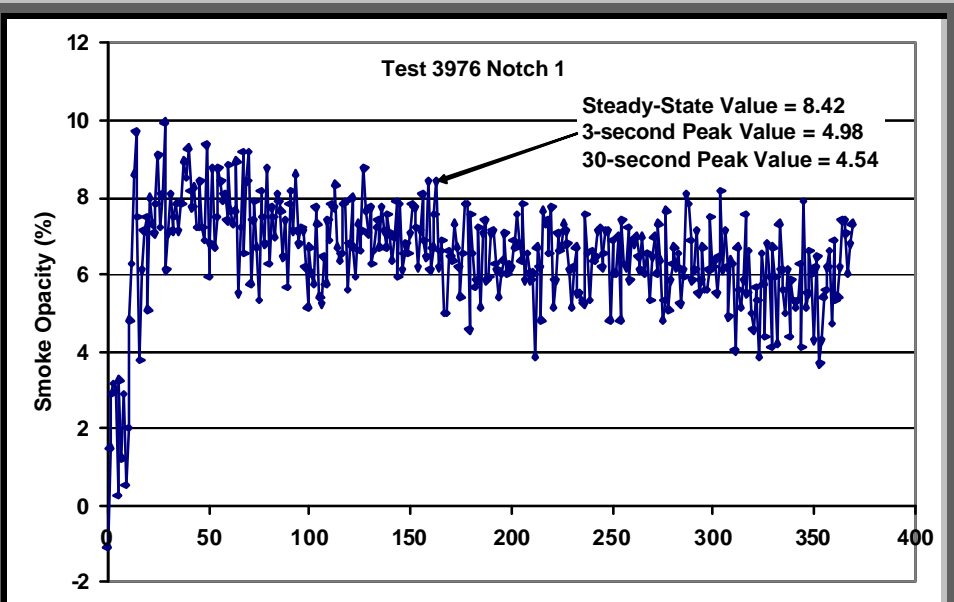

Time (seconds)
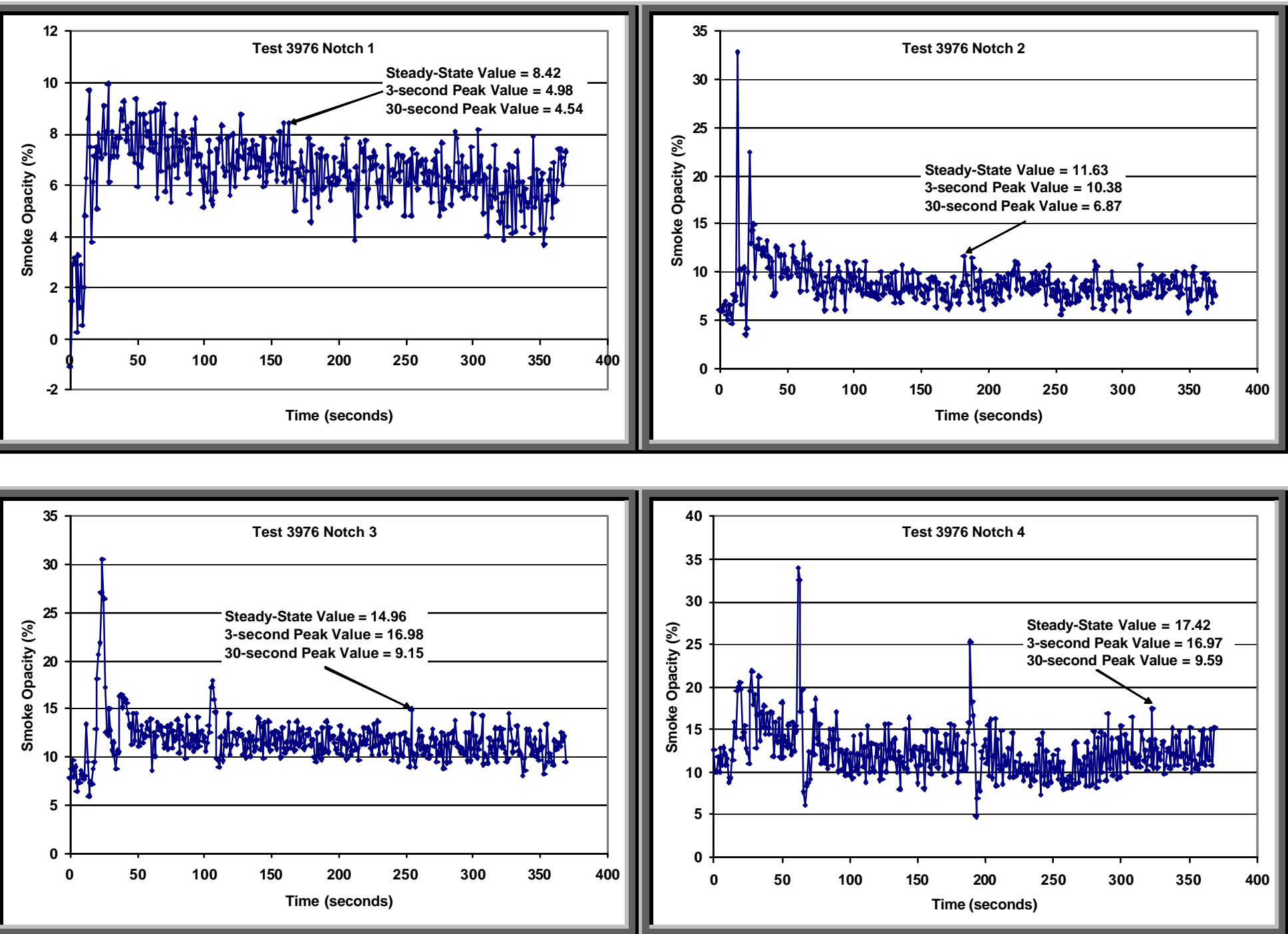

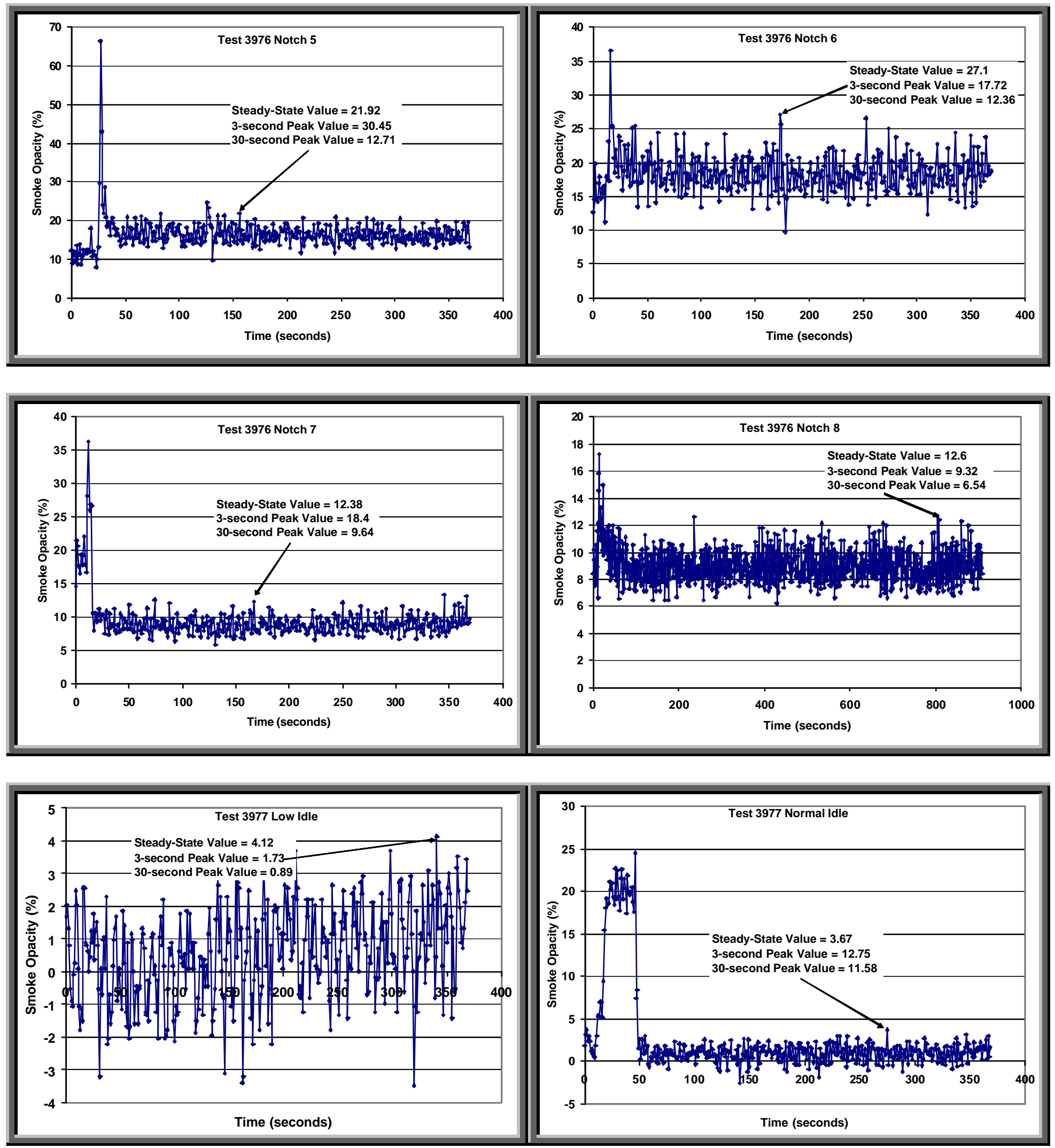

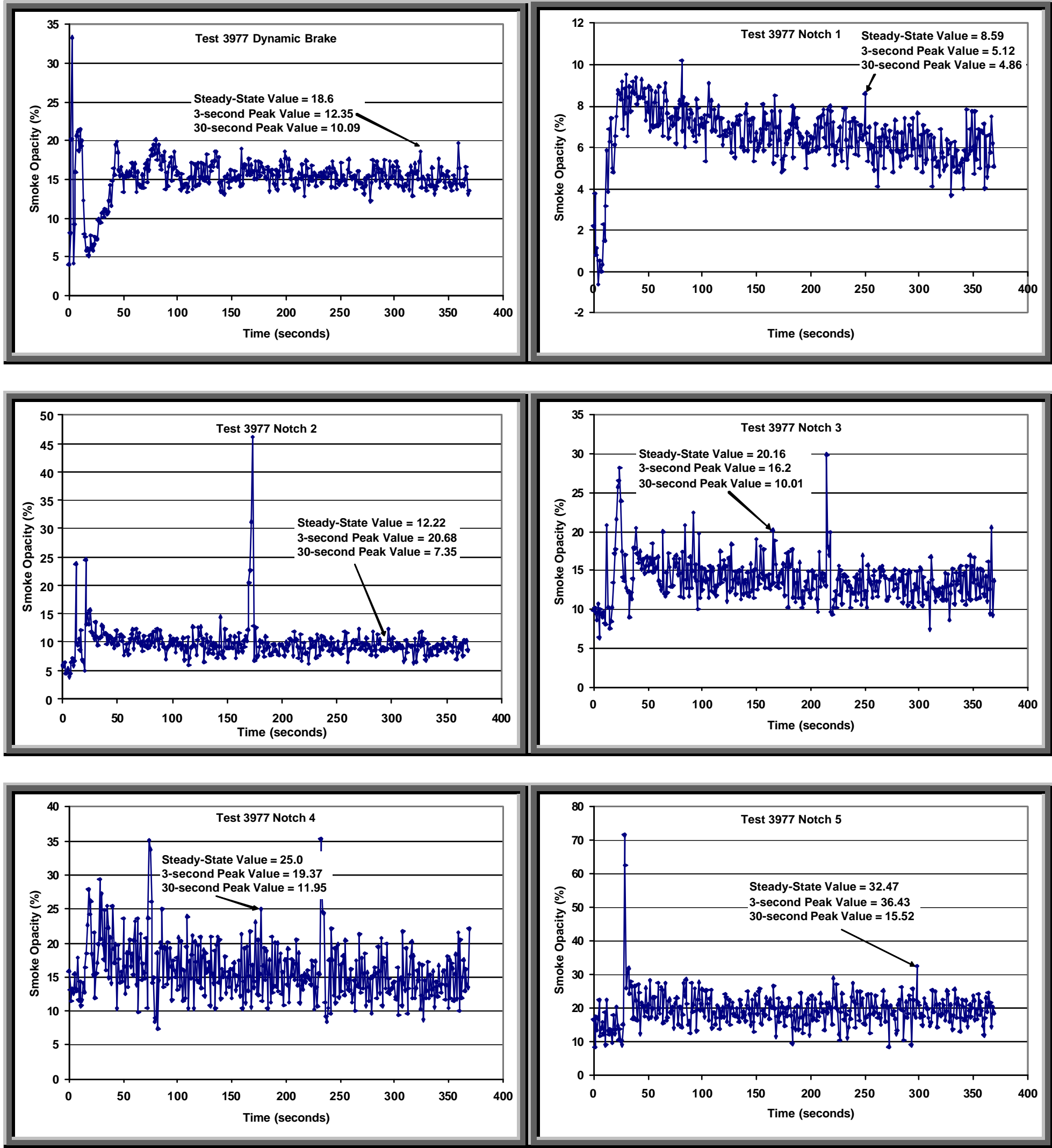

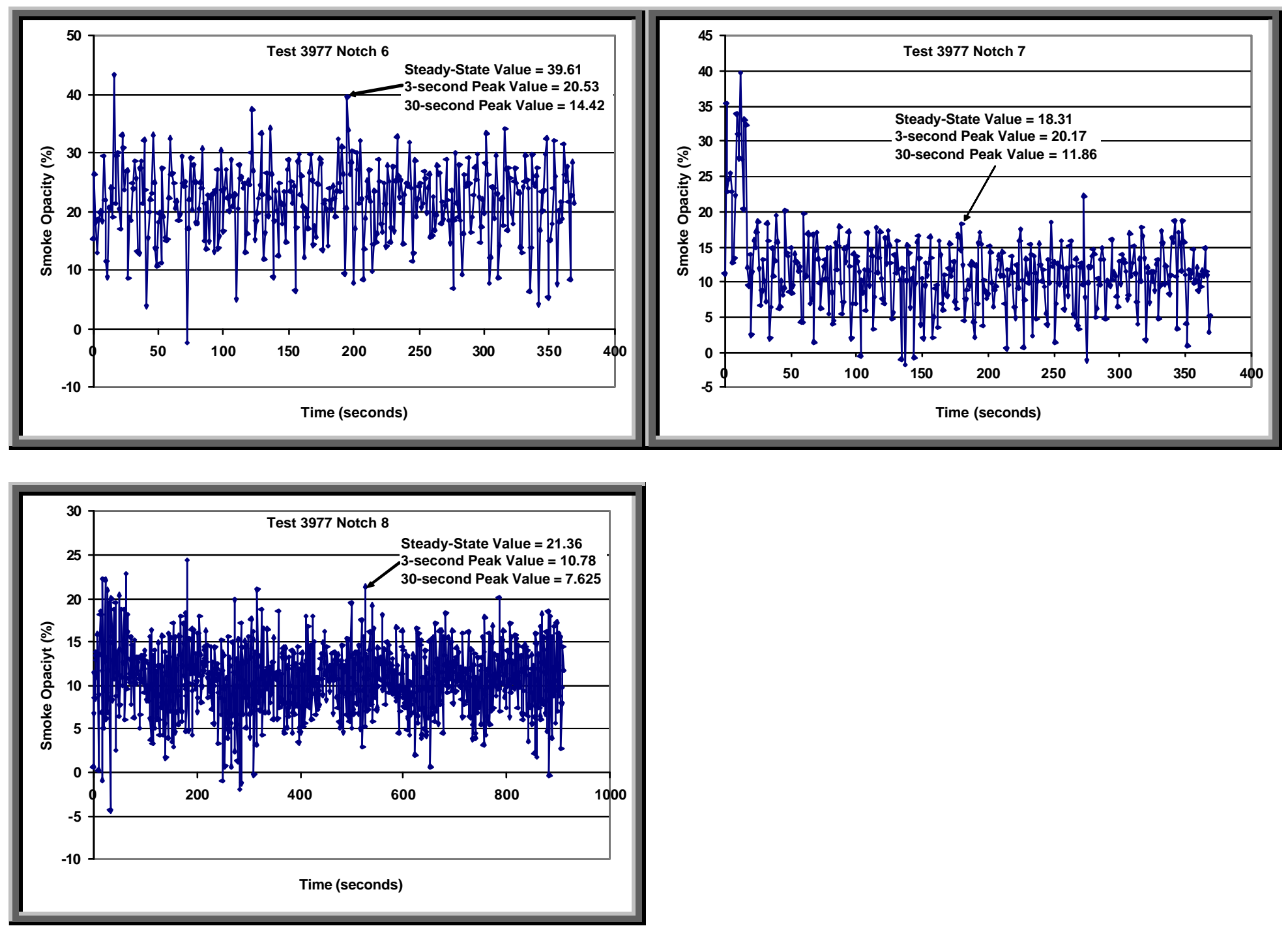